PASSIVE VOLATLIZATION BEHAVIOUR OF GASOLINE

IN UNSATURATED SOILS

\author{
A Thesis \\ Presented to \\ The Faculty of Graduate Studies \\ of \\ The University of Guelph \\ by \\ TEJWANT SINGH GIDDA \\ In partial fulfilment of requirements \\ for the degree of \\ Master of Science \\ July, 1997
}

(O) Tejwant Singh Gidda, 1997 
National Library

of Canada

Acquisitions and Bibliographic Services

395 Wellington Street Ottawa ON K1A ONA Canada
Bibliothèque nationale du Canada

Acquisitions et services bibliographiques

395. ne Wellington Ottawa ON K1A ON4 Canada
The author has granted a nonexclusive licence allowing the National Library of Canada to reproduce, loan, distribute or sell copies of this thesis in microform, paper or electronic formats.
L'auteur a accordé une licence non exclusive permettant à la Bibliothèque nationale du Canada de reproduire, prêter, distribuer ou vendre des copies de cette thèse sous la forme de microfiche/film, de reproduction sur papier ou sur format électronique.

L'auteur conserve la propriété du droit d'auteur qui protège cette thèse. $\mathrm{Ni}$ la thèse ni des extraits substantiels de celle-ci ne doivent être imprimés ou autrement reproduits sans son autorisation. 


\section{ABSTRACT \\ PASSIVE VOLATILIZATION BEHAVIOUR OF GASOLINE IN UNSATURATED SOILS}

Tejwant Singh Gidda

University of Guelph, 1997
Advisors:

Professor W.H. Stiver Professor R.G. Zytner

Gasoline contamination of soil can present a health and explosion risk. This risk will be determined by the gasoline's ability to migrate in the soil; one important mechanism in soil is volatilization. To describe passive volatilization behaviour of gasoline in unsaturated soils, laboratory experiments using synthetic gasoline and acrylic columns were conducted. Objectives were to monitor gasoline component behaviour as a function of depth and time at different water contents and temperatures.

Gasoline volatilization behaviour was heavily influenced by immiscible phase capillary rise (wicking). Wicking was sufficiently important that surface gasoline concentrations could be higher than average column concentrations. Solidification of low molecular weight components at the soil surface was responsible for this accumulation. Water content had a non-linear effect on wicking, but the initial gasoline content was the most important wicking factor. Subzero temperatures slowed wicking, and allowed immiscible phase movement to continue for longer periods of time. 


\section{Acknowledgements}

First and foremost, I have to thank Dr. Richard Zytner and Dr. Warren Stiver for the opportunity to do this research, for all their help concerning the various aspects of the research, for sending me to conferences and treating me well, and for giving me the opportunity to continue on with yet another degree (thereby keeping me in Guelph for another three years). There are also a number of other people who helped with the research, including Bill Verspaagen and Paul Found (for quick fixes to the apparatus), Al Miller and Ross Cochrane (for computer help), Dave Teichroeb (for help with instrumentation), Mary Leunissen (for the extra hands and eyes in the lab), and Diane Duncan (for helping me create a snazzy poster).

Beyond that, there are a number of people who made life a lot easier (and sometimes harder, if they felt like it) during the course of the Masters. These include Peggy Coghlan, Judy "Freak" Campbell, Sue Lewis, and Merie Hiskett. They always made trips to the second floor worth the while, despite all the verbal abuse.

To my family in Ottawa: thanks for the support and all the generous food offerings, not to mention the new Pathfinder which I have yet to receive.

The second side of doing my Masters should also be acknowledged; this is the side less concerned with academics and more with other things. There are a number of grad students I'd like to acknowledge: Chris Kresin, John Burnside, Aaron Law (SRG), Selma Guigard (SRG), Bruce Harper (SRG), Troy Laplante (SRG), Craig Kipkie, Wayne Speller,

Tracy Thompson, Mahmoud Hosseini, Nabi Kohlachi, Dale Scott and Keith Driver (coming 
soon); this for equal parts socializing, helping, and inspiration.

For the last two years or so, there are also a number of undergraduates who have permeated Guelph and made this place a better one. These include Mike Wrigglesworth, Eric Monteith, Matt Ritchie, Scott Robertson, Karen Taylor, Mina McCluskey, Seton Stiebert, and Laureen Chung. There are also some younger folk worth thanking, particularly certain Cluster members (and some of the best pranksters around): Wayne Sorensen, Wayne Jenken, Jeff Whitty, Angela Mason, Dave Hough, Tom Aaltomaa, Chad Stephen, Adam Lacombe, Sameer Dhalla and Mike Petepiece. Despite all their troublemaking, I made it to grad school. I also want to acknowledge the Class of 99, who I got to know (better than anyone should really want to) during this last year; in particular, I'd like to acknowledge TA.

I'm just going to keep listing names, I'm already on page two. There are a number of other people I'd like to thank: Becky Thatcher, Anne Atkinson and Wendy Crummy, the Rowe family (for trips to Elora), Kit Chan, and everyone back in Ottawa (too many people to name).

On a final note, I have to thank, without trying to fill up another couple of pages, Kristi Rowe. As essentially good a person as I've met, everything would have been more difficult without you. 


\section{Table of Contents}

CHAPTER 1 INTRODUCTION $\ldots \ldots \ldots \ldots \ldots \ldots \ldots \ldots \ldots \ldots \ldots$

CHAPTER 2 LITERATURE REVIEW $\ldots \ldots \ldots \ldots \ldots \ldots \ldots \ldots \ldots \ldots \ldots \ldots$

2.1 Soil Properties ...............................

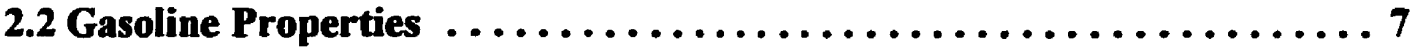

2.3 Behaviour of Gasoline in Soil $\ldots \ldots \ldots \ldots \ldots \ldots \ldots \ldots \ldots \ldots$.

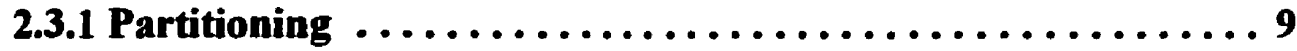

2.3.1.1 Dissolution .........................11

2.3.1.2 Adsorption ........................ 12

2.3.1.3 Volatilization ........................ 12

2.3.2 Vapour-Phase Diffusion in Soil $\ldots \ldots \ldots \ldots \ldots \ldots \ldots \ldots \ldots$

2.3.3 Experimental Work on Volatilization $\ldots \ldots \ldots \ldots \ldots \ldots \ldots 14$

2.3.3.1 Soil Water Content ................... 15

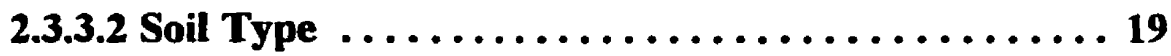

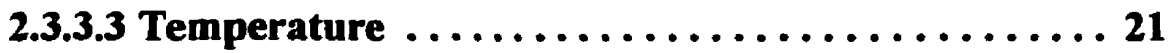

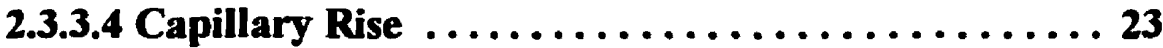

2.4 Literature Defíciencies.$\ldots \ldots \ldots \ldots \ldots \ldots \ldots \ldots \ldots \ldots \ldots \ldots$

3.0 MATERIALS AND METHODS $\ldots \ldots \ldots \ldots \ldots \ldots \ldots \ldots \ldots \ldots \ldots \ldots \ldots \ldots \ldots$

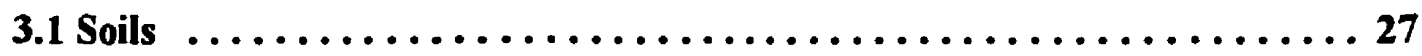

3.1.1 Soil Preparation and Storage $\ldots \ldots \ldots \ldots \ldots \ldots \ldots \ldots \ldots \ldots \ldots \ldots \ldots \ldots$

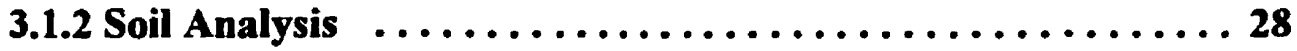

3.1.3 Soil Analysis of Windsor Clay Loam ............. 29

3.1.4 Additional Soil Properties .................... 30

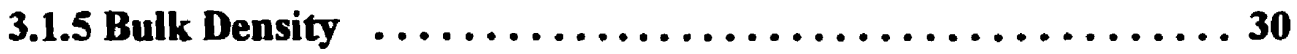

3.1.6 Air-Dry Soil Water Content $\ldots \ldots \ldots \ldots \ldots \ldots \ldots \ldots \ldots \ldots \ldots$

3.2 Chemicals ................................... 31

3.3 Volatilization Experiments $\ldots \ldots \ldots \ldots \ldots \ldots \ldots \ldots \ldots \ldots \ldots \ldots \ldots$

3.4 Columns for Gasoline Volatilization Experiments ............. 34

3.5 Cold Temperature Sand and Silt Volatilization Experiments ........ 37

3.5.1 Column Preparation ....................... 37

3.5.2 Cold Weather Environment .................. 38

3.5.3 Analytical Procedures . ..................... 41

3.6 Room Temperature Clay Loam Experiments $\ldots \ldots \ldots \ldots \ldots \ldots \ldots 42$

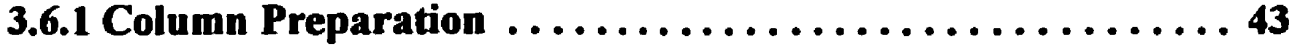

3.6.2 Zero-Hour Columns ...................... 45

3.7 Frozen Clay Loam Experiments ................... 46

3.7.1 Frozen Weather Environment $\ldots \ldots \ldots \ldots \ldots \ldots \ldots \ldots \ldots 47$

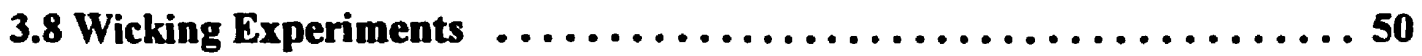

3.9 Gasoline Freezing Experiments $. \ldots \ldots \ldots \ldots \ldots \ldots \ldots \ldots \ldots, \ldots \ldots$ 
CHAPTER 4 RESULTS $\ldots \ldots \ldots \ldots \ldots \ldots \ldots \ldots \ldots \ldots \ldots \ldots \ldots \ldots \ldots \ldots \ldots$

4.1 Zero Hour Columns ............................ 53

4.2 Extraction Efficiencies .......................... 54

4.3 Comparison-Gravimetric Measurements \& Gas Chromatograph Data 55

4.4 Cold and Frozen Weather Temperature Results ............. 56

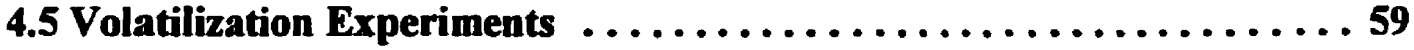

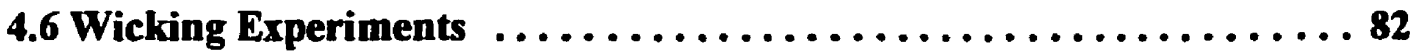

4.7 Windsor Clay Loam Air Permeability Experiments $\ldots \ldots \ldots \ldots \ldots 82$

4.8 Frozen Gasoline Experiments $. . \ldots \ldots \ldots \ldots \ldots \ldots \ldots \ldots \ldots . \ldots . \ldots 3$

CHAPTER 5 DISCUSSION $\quad$......................... 84

5.1 Experimental Procedures $\ldots \ldots \ldots \ldots \ldots \ldots \ldots \ldots \ldots \ldots \ldots \ldots \ldots \ldots$

5.1.1 Effect of Column Packing Procedures ........... 84

5.1.2 Effect of Extraction Methods .................88

5.1.3 Overall Losses ......................... 90

5.1.4 Checks on Analytical Methods ................ 92

5.1.5 Cold and Frozen Weather Environment ............ 93

5.2 Volatilization Experiments $\ldots \ldots \ldots \ldots \ldots \ldots \ldots \ldots \ldots \ldots . \ldots 94$

5.2.1 Effect of Water Content .................... 95

5.2.1.1 Room Temperature Air-Dry Experiments ......995

5.2.1.2 Room Temperature Wet Experiments ........ 106

5.2.1.3 Cold and Frozen Air-Dry Experiments ........ 117

5.2.1.4 Cold and Frozen Wet Experiments. ......... 119

5.2.2 Effect of Temperature .................... 121

5.2.2.1 Air-Dry Cold or Frozen Versus Room

Temperature Experiments ............... 121

5.2.2.2 Wet Cold or Frozen and Room Temperature

Experiments ...................... 124

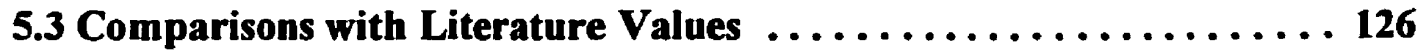

5.4 Engineering Significance.$\ldots \ldots \ldots \ldots \ldots \ldots \ldots \ldots \ldots \ldots \ldots \ldots$

Chapter 6 Conclusions $\ldots \ldots \ldots \ldots \ldots \ldots \ldots \ldots \ldots \ldots \ldots \ldots \ldots \ldots \ldots \ldots \ldots \ldots \ldots$

Chapter 7 Recommendations $\ldots \ldots \ldots \ldots \ldots \ldots \ldots \ldots \ldots \ldots \ldots \ldots \ldots \ldots$

Chapter 8 References $\ldots \ldots \ldots \ldots \ldots \ldots \ldots \ldots \ldots \ldots \ldots \ldots \ldots \ldots \ldots \ldots \ldots \ldots$ 


\section{List of Tables}

Table 2.1 Gasoline Composition $\ldots \ldots \ldots \ldots \ldots \ldots \ldots \ldots \ldots \ldots \ldots \ldots \ldots \ldots$

Table 2.2 Gasoline Properties . . . . . . . . . . . . . . . . . . . . . 9

Table 3.1 Analytical Soil Services $\ldots \ldots \ldots \ldots \ldots \ldots \ldots \ldots \ldots \ldots \ldots \ldots$

Table 3.2 Soil Analysis of WCL-School of Engineering $\ldots \ldots \ldots \ldots \ldots \ldots$

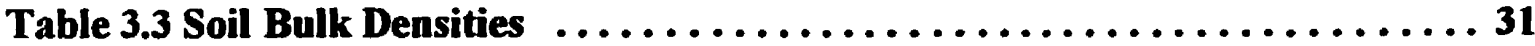

Table 3.4 Soil Air-Dry Water Contents $\ldots \ldots \ldots \ldots \ldots \ldots \ldots \ldots \ldots \ldots \ldots$

Table 3.5 Synthetic Gasoline Composition ... . . . . . . . . . . . . . 32

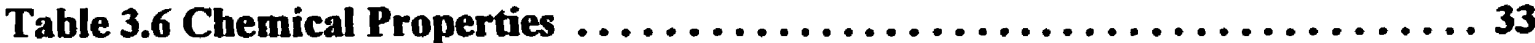

Table 3.7 Volatilization Experiments . . . . . . . . . . . . . . . . . . 34

Table 4.1 Percent Recovery in Zero Hour Columns . . . . . . . . . . . . . 54

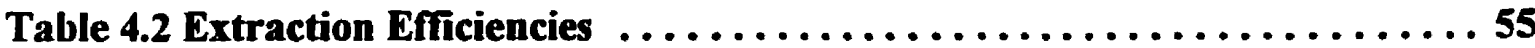

Table 4.3 Comparison-Gravimetric Measurements vs GC DATA (WCL) . . . . . 56

Table 4.4 Temperature Conditions . . . . . . . . . . . . . . . . . . 58

Table 4.5 Notation for Volatilization Experiments $\ldots \ldots \ldots \ldots \ldots \ldots$

Table 4.6 10-Day C16 Ratio for Windsor Clay Loam . . . . . . . . . . . . 82

Table 4.7 Air Permeability of Windsor Clay Loam . . . . . . . . . . . . 83

Table 4.8 Petroleum Mixture Solidification . . . . . . . . . . . . . . . . 83

Table 5.1 Liquid-FilledPorosities for Air-Dry and Wet Soils $\ldots \ldots \ldots$. . . . . 105 


\section{List of Figures}

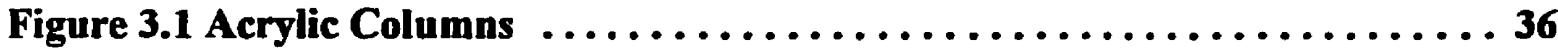

Figure 3.2 Schematic of Cold Temperature Setup $\ldots \ldots \ldots \ldots \ldots \ldots \ldots \ldots \ldots$

Figure 3.3 Schematic of Column Packing Apparatus $\ldots \ldots \ldots \ldots \ldots \ldots \ldots \ldots 4$

Figure 3.4 Modified Ventilated Box $\ldots \ldots \ldots \ldots \ldots \ldots \ldots \ldots \ldots \ldots \ldots \ldots$. 4 .

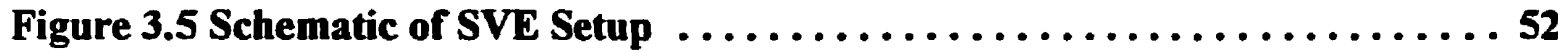

Figure 4.1 Typical Temperature Response Curve of Columns in Cold Conditions 57

Figure 4.2 Total Gasoline C/Co in Air-Dry 5\% Gasoline WCL (Room) .......64

Figure 4.3 Total Gasoline C/Co in Air-Dry 14\% Gasoline WCL (Room) ...... 64

Figure 4.4 Isopentane C/Co in Air-Dry 5\% Gasoline WCL (Room) ........ 65

Figure 4.5 Isopentane C/Co in Air-Dry 14\% Gasoline WCL (Room) $\ldots \ldots \ldots \ldots 6$

Figure 4.6 C16 Ratio for Air-Dry WCL (Room) ................. 66

Figure 4.7 1,3,5-Trimethylbenzene and Naphthalene Ratios in WCL-14G-AD-R . 66

Figure 4.8 Normalized Fraction of Gasoline Lost for Air-Dry Soils (Room) . . . . 67

Figure 4.9a Isopentane $C / C o$ for Air-Dry Soils (Room) $\ldots \ldots \ldots \ldots \ldots \ldots 66$

Figure 4.9b Normalized Isopentane C/Co for Air-Dry Soils (Room) $\ldots \ldots \ldots \ldots 68$

Figure 4.10 C16 Ratio for Air-Dry Soils (Room) ................. 69

Figure 4.11a Normalized Fraction of Gasoline Lost for Air-Dry

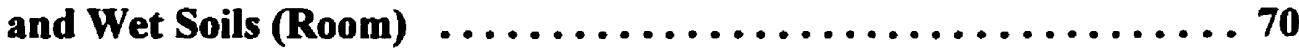

Figure 4.11b Normalized Fraction of Gasoline Lost for Wet Soils (Room) . . . . 70

Figure 4.12a Isopentane C/Co for Air-Dry and Wet Soils (Room) ......... 71

Figure 4.12b Normalized Isopentane $C /$ Co for Wet Soils (Room) $\ldots \ldots \ldots \ldots 71$

Figure 4.13a C16 Ratio for Air-Dry and Wet Soils (Room) $\ldots \ldots \ldots \ldots \ldots \ldots 72$

Figure 4.13b Normalized C16 Ratio for Wet Soils (Room) . . . . . . . . . 72

Figure 4.14a Isopentane $C / C o$ for Air-Dry and Wet Soils (Cold) . . . . . . . 73

Figure 4.14b Normalized Isopentane $C /$ Co for Wet Soils (Cold) $\ldots \ldots \ldots \ldots \ldots 73$

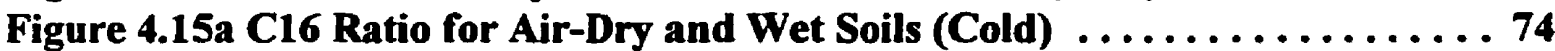

Figure 4.15b Normalized C16 Ratio for Wet Soils (Cold) .............. 74

Figure 4.16 Normalized Fraction of Gasoline Lost for Air-Dry

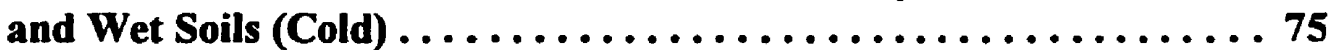

Figure 4.17 Normalized Fraction of Gasoline Lost for Cold Soils (Air-Dry) . . . . 76

Figure 4.18 Normalized Isopentane C/Co for Cold Soils (Air-Dry) ......... 77

Figure 4.19 Normalized C16 Ratio for Cold Soils (Air-Dry) . . . . . . . . . 78

Figure 4.20 Normalized Fraction of Gasoline Lost for Cold Soils (Wet) ...... 79

Figure 4.21 Normalized Isopentane $\mathbf{C} / \mathbf{C o}$ for Cold Soils (Wet) $\ldots \ldots \ldots \ldots \ldots 80$

Figure 4.22 Normalized C16 Ratio for Cold Soils (Wet) ..............81

Figure 5.1 Liquid\& Gasoline-Filled Porosity Vs C16 Ratio for WCL ....... 111

Figure 5.2 Liquid \& Gasoline-Filled Porosity Vs C16 Ratio for DLS \& ESL ... 112 


\section{List of Appendices}

Appendix A Temperature Program for Datalogger

Appendix B Extraction Efficiency Data and Sample Calculations

Appendix C Soil Gasoline Concentration Sample Calculations

Appendix D Graph Sample Calculations

Appendix E Cold Temperature Delhi Loamy Sand and Elora Silt Loam Volatilization Data

Appendix F Room Temperature Windsor Clay Loam Volatilization Data Appendix G Frozen Temperature Windsor Clay Loam Volatilization Data Appendix H Windsor Clay Loam Air Permeability Data and Sample Calculations Appendix I Gasoline Freezing Data and Sample Calculations 


\section{CHAPTER 1 INTRODUCTION}

The predominance of gasoline in society is unquestionable. With approximately fifty million cars being produced annually in the world (Hamilton, 1996), the quantity of fuel required to run them is huge. One estimate for the United States alone has gasoline usage at approximately $400000 \mathrm{ML} /$ year in the late 1980's (Kirk-Othmer, 1990).

Inevitably, gasoline is spilled. Sudden or accidental spills during handling are common at service stations. Additional spills occur during the transportation of gasoline. Gradual leaks may also occur during storage, particularly from underground storage tanks (UST's). It has been estimated that $10-25 \%$ of all UST's containing gasoline in North America are leaking to some extent (USEPA, 1996). Spills and leaks, unfortunately, make gasoline a prime candidate for contamination of soil. Of particular interest is the unsaturated zone, the region that connects the surface of the soil and the groundwater. Gasoline contamination of soil will occur primarily in the unsaturated zone.

Some gasoline components are known to be toxic. For example, benzene is a known carcinogen, and MTBE (tert-methylbutyl ether) and benzo-a-pyrene are suspected carcinogens. Other components have been shown to cause liver, kidney and nerve damage (Marine Environmental Priorities Report, 1995). Because contamination of soil can lead to pollution of surface and ground water, the toxicity of gasoline presents a serious health hazard. Migration of gasoline vapours through soil and into buildings can also result in a reduction in air quality. High concentrations of gasoline vapour in indoor air can present an explosion hazard sufficiently serious that buildings can be destroyed (Environment Canada Atlantic Region, 1997). As an example, it has been estimated that a single cup of 
gasoline, vaporized and ignited, has the explosive potential of five sticks of dynamite (Shell Canada, 1996).

Gasoline-soil interactions are complex, and are determined by the characteristics of both materials and the prevailing environmental conditions. In general, gasoline will partition into separate phases in a soil system: soil-air, soil-water, and soil-solids. If all these phases are at saturated concentrations, then an immiscible phase will also develop. The characteristics of the soil will play a large part in determining the fate of gasoline spills or leaks. Parameters such as permeability, porosity, pore size distribution, and organic matter content will affect the migrative ability of gasoline. Additional environmental factors such as temperature and soil moisture content further complicate the process. Various properties of gasoline, such as vapour pressure, viscosity, wettability and density, will also determine the fate of a spill. Yet more complexity is introduced into the system because of the varying composition of the gasoline mixture. Aged spills, for example, will demonstrate different chemical characteristics than fresh spills.

Once gasoline has entered the unsaturated soil system, it will move as a result of diffusive and convective processes. Diffusive transport will occur in the aqueous, vapour or immiscible phase. Convective transport will occur as a result of bulk movement of soilair or soil-water, or of the immiscible phase itself. Soil characteristics, gasoline properties and environmental conditions will all affect the movement of gasoline in the soil system by these mechanisms.

One important mechanism of gasoline movement in soil is volatilization. In particular, passive volatilization refers to the natural evaporative behaviour of a chemical. 
For high-vapour pressure mixtures such as gasoline, passive volatilization will be a dominant mechanism in its migration in a soil system. Additionally, passive volatilization has demonstrated use as an inexpensive means of soil remediation when compared to processes such as soil vapour extraction (Vreeken et al., 1990).

To date, information on passive volatilization rates of gasoline in soil is limited. Several areas of importance have not been fully addressed, including the effects of water content, temperature, soil type and immiscible phase movement. In particular, the effects of subzero temperatures on volatilization rates of gasoline need to be understood. This is important with respect to the behaviour of gasoline in a frozen soil typical of a Canadian climate. Further, information is limited on more experimentally-complex soils. Primarily, passive volatilization experiments have been conducted on sands and some silts, with only very limited work having been conducted on clay soils. Though the effect of water content on soil has been examined to some extent, it has not been adequately quantified at the high range that would be associated with a natural clay soil. Finally, very little information on the immiscible phase movement of gasoline and its contributions to volatilization rates is available.

Objectives of this thesis are to describe passive volatilization behaviour in unsaturated soils as a function of:

- $\quad$ soil type

- $\quad$ soil water content

temperature 
To meet these objectives, laboratory scale experiments were conducted using methods developed by Smith et al. (1994) and Rogaz and Hussain (1994). A number of acrylic columns were used to hold various soils spiked with combinations of water and gasoline. A synthetic gasoline was used in order to ease analytical procedures while still covering the range of vapour pressures seen in gasoline. An additional non-volatile component was added in order to study immiscible phase movement of the mixture. Destructive sampling of the soil columns allowed for quantification of the volatilization of ten different chemicals at various locations in a column after a minimum of seven different time periods.

This thesis will present literature relevant to the topic of passive volatilization of gasoline from unsaturated soil. All methods and materials used in the experiments are outlined and explained. Results of the experimental work are presented, and the observed trends are explained. Finally, conclusions are made and recommendations for further work and improvements to the existing experiments are proposed. 


\section{CHAPTER 2 LITERATURE REVIEW}

The passive volatilization process is distinctly different from active volatilization processes such as soil vapour extraction. In the latter, air is forced through the soil to volatilize the organic chemical; in the former, no energy is added to promote volatilization. Emphasis in this literature review will be placed on the passive process.

In this chapter, the physical properties of soil will be discussed, as will the physical and chemical properties of gasoline. The partitioning behaviour of gasoline into distinct phases within the soil environment will be presented, followed by an examination of vapour- phase diffusion. The literature review continues with an examination of experimental and modelling studies that have been conducted on passive volatilization of gasoline, with emphasis on the effects of soil water content, soil type, temperature and capillary rise effects. Finally, deficiencies in the literature related to the understanding of passive volatilization of gasoline from soil will be highlighted.

\subsection{Soil Properties}

Soil is a complex mixture whose characteristics can vary with small changes in location and depth. The non-homogeneity of soils makes their classification and an understanding of their properties difficult. A number of soil properties have been defined, however, and are important to an understanding of the passive volatilization process in unsaturated soils.

The particle size distribution of a soil is typically used in soil classification, but it will also determine the distribution of pores ie., smaller particles will result in smaller pores. Sands have the largest soil particles, followed by silt and clay. Soils with high clay contents 
will thus have smaller pores and present the greatest resistance to the movement of chemicals through them. A related parameter is porosity, defined as the ratio of the volume of voids in the soil to the total volume of the soil (Craig, 1992). In general, porosity increases with increasing clay content. As a result, clay soils will have the largest porosity, but the smallest overall pore sizes.

Clay soils also exhibit shrinking and swelling behaviour which will affect the movement of chemicals through them. Shrinking soils will tend to aggregate and restrict pathways of chemical migration. Swelling soils will tend to open up additional pathways for chemical movement (Goss, 1993).

Permeability refers to the ability of a fluid to move through the soil matrix, and is closely related to the pore size distribution. For example, sandy soils with larger average pore sizes will have higher permeabilities (Craig, 1992).

The organic matter content of a soil generally decreases with increasing sand content. Organic matter in soil will determine the degree to which organic chemicals such as gasoline will adsorb to the soil matrix. Sorption can also occur on mineral sites. Soils with larger total particle surface areas, such as clays, will have a greater number of mineral sites; however, these sites can become inaccessible because of the smaller pore sizes in a clay soil.

Soil will also exert capillary forces on liquids within them. Capillary forces occur because of differences in surface tension between two substances in contact, and can result in the capillary rise of the liquid into dryer regions of the soil. A parameter called field capacity is defined as the water content that the capillary forces will hold against the force of gravity. Field capacity will always be reached before saturation of the soil occurs. A 
corresponding parameter called retention capacity is defined as the contaminant content which a soil can hold against the force of gravity.

\subsection{Gasoline Properties}

Gasoline is formed through the fractional distillation of crude oil, using processes such as evaporation and condensation. Given its significant volatility, gasoline is one of the higher distillates of crude oil (Peterson, 1996). On the subject of gasoline properties and components, discussion will be limited to unleaded blends.

The approximately 200 chemicals composing gasoline include aliphatics (primarily alkanes and alkenes), aromatics and oxygenates (Hamilton, 1996). Alkanes (or paraffins) are saturated hyrdocarbons ie., all carbon atoms are joined by single bonds (Morrison and Boyd, 1983). They form the largest fraction of the mixture, and range from pentane (five carbon chain) to nonane (nine carbon chain) (Hamilton, 1996). Alkenes (or olefins) are unsaturated hydrocarbons characterized by one or more double bonds between carbon atoms, and are present in lesser amounts. Aromatics (or arenes) are identified by a benzene ring, and are generally the most toxic components of gasoline. It is for this reason that the aromatics benzene, toluene, ethylbenzenes and xylenes (BTEX) are commonly of interest when examining gasoline contamination. The BTEX compounds exhibit the greatest solubility, volatility and toxicity of all the aromatics (Donaldson et al., 1992). A further subset of aromatics is the polynuclear aromatics, which are characterized by fused benzene rings, and do not constitute a large fraction of gasoline. These include chemicals such as naphthalene. Oxygenates are those hydrocarbon compounds which contain at least one oxygen atom in their structure, and tend to be present in gasoline in extremely small amounts (Hamilton, 
1996). Oxygenates such as MTBE are used as blending agents to improve the octane rating of gasoline, and vary sharply in their use between different gasoline blends.

Table 2.1 illustrates a typical gasoline composition. Compositions can vary, depending on the quality of the distillate and the inclusion of oxygenates as octane enhancers (Hamilton, 1996). Table 2.1 describes a gasoline without oxygenates.

Table 2.1 Gasoline Composition

\begin{tabular}{lc}
\hline Chemical Group & \% By Mass in Gasoline \\
\hline n-paraffins & 15 \\
iso-paraffins & 30 \\
cycloparaffins & 12 \\
aromatics & 35 \\
olefins & 8 \\
\hline \hline
\end{tabular}

Other gasoline additives include corrosion inhibitors, antioxidants, dyes, and antiicing agents. All are present in trace amounts (Hamilton, 1996).

Table 2.2 gives some of the physical properties of a gasoline. Again, properties will vary with the gasoline composition. 
Table 2.2 Gasoline Properties

\begin{tabular}{lcc}
\hline \multicolumn{1}{c}{ Property } & Value & Reference \\
\hline Density & $0.72 \mathrm{~g} / \mathrm{cm}^{3}$ & Hayden et al. (1994) \\
Viscosity & $3.5 \times 10^{-5} \mathrm{~Pa} . \mathrm{s}\left(\right.$ at $\left.20^{\circ} \mathrm{C}\right)$ & Hayden et al. (1994) \\
Vapour Pressure & $30 \mathrm{kPa}\left(\right.$ at $\left.20^{\circ} \mathrm{C}\right)$ & Kirk-Othmer $(1980)$ \\
Initial Boiling Point $\left({ }^{\circ} \mathrm{C}\right)$ & $32^{\circ} \mathrm{C}$ & Kirk-Othmer (1980) \\
\hline \hline
\end{tabular}

\subsection{Behaviour of Gasoline in Soil}

After a spill or leak, gasoline will move in the unsaturated soil environment through diffusive and convective processes. These processes can take place in the aqueous, vapour and immiscible phases. Adsorption of gasoline to the soil will also affect chemical movement.

Equilibrium partitioning can be used to describe the distribution of gasoline between the various phases when the immiscible phase is present. Each of the partitioning relationships will be examined. Emphasis will be placed on volatilization and vapour-phase transport of gasoline. Finally, the effects of soil water content, soil type, temperature and capillary rise on volatilization of gasoline will be described based on previous experimental work and modelling studies.

\subsubsection{Partitioning}

If the concentration of gasoline in the aqueous, vapour and adsorbed phases reach saturation, an immiscible or oil phase will develop. For such a four-phase system, an equilibrium partitioning can be assumed between all phases (Charbeneau and Weaver, 1992). Pore space will be filled by each of the fluids according to: 


$$
n=\theta_{w}+\theta_{a}+\theta_{0}
$$

where $\theta_{w}=$ water content $\left(\mathrm{m}^{3}\right.$ water $/ \mathrm{m}^{3}$ bulk soil)

$\theta_{\mathrm{a}}=$ air content $\left(\mathrm{m}^{3}\right.$ air $/ \mathrm{m}^{3}$ bulk soil)

$\theta_{0}=$ immiscible phase or oil content $\left(\mathrm{m}^{3} \mathrm{immiscible} \mathrm{liquid} / \mathrm{m}^{3}\right.$ bulk soil)

An assumption of local equilibrium is commonly used to simplify relationships

between all phases. The local equilibrium assumption states that mass transfer is sufficiently fast between all phases such that an equilibrium condition exists between them ie., mass transfer is fast between phases as compared to mass transfer within any one phase (Zaidel and Russo, 1994). Charbeneau and Weaver (1992) define a bulk concentration $\mathrm{m}$ as:

$$
m=\theta_{w} c_{w}+\theta_{a} c_{a}+\theta_{o} c_{o}+\rho_{b} c_{s}
$$

A simpler form of this equation is commonly derived by expressing all concentrations in terms of the water concentration. The simplified form is:

$$
m=\left(\theta_{w}+\theta_{a} K_{H}+\theta_{0} K_{0}+\rho_{b} K_{d}\right) c_{w}
$$

where $\mathrm{K}_{\mathrm{H}}=$ Henry's Law Constant

$$
\mathrm{K}_{\mathrm{o}}=\text { oil-water partition coefficient }
$$


$\mathrm{K}_{\mathrm{d}}=$ sorption distribution coefficient $\left(\mathrm{m}^{3} / \mathrm{g}\right)$

$\rho_{\mathrm{b}}=$ soil bulk density $\left(\mathrm{g} / \mathrm{m}^{3}\right)$

$c_{\mathrm{w}}=$ water concentration $\left(\mathrm{g} / \mathrm{m}^{3}\right)$

It should be noted that local equilibrium is a simplifying assumption, and that its validity has been questioned. Hayden et al. (1994) suggest that local equilibrium is valid for such time as the immiscible phase is present. At lower contaminant concentrations, the assumption becomes less valid.

In terms of volatilization, the local equilibrium assumption implies that the organic contaminant would instantly vaporize into the soil-air from the non-aqueous phase liquid and from the aqueous phase (Shonnard and Bell, 1993). A further implication of the local equilibrium assumption is that concentration gradients in the air phase will follow those in other phases (Charbeneau and Weaver, 1992).

The partition coefficients in Equation 2.3 will be examined individually.

\subsubsection{Dissolution}

$K_{0}$ is the equilibrium partition coefficient between the immiscible phase and the aqueous phase (Charbeneau and Weaver, 1992). A non-polar contaminant such as gasoline will have a low but non-zero solubility in water. Gasoline will dissolve in water to a maximum value dictated by this solubility. At equilibrium conditions, the concentration of each contaminant in the aqueous phase will obey Raoult's Law.

Estimates of the aqueous solubility for gasoline place it from between 50 to $150 \mathrm{ppm}$ (Kostecki and Calabrese, 1989). The low value of aqueous solubility implies that saturated concentrations in water will be reached quickly. 


\subsubsection{Adsorption}

$\mathbf{K}_{d}$ is the linear equilibrium partition coefficient between the amount of gasoline adsorbed to soil solids and the amount dissolved in soil water (Charbeneau and Weaver, 1992). Typically, $K_{d}$ is related to the organic carbon content of the soil by the following equation:

$$
\boldsymbol{K}_{d}=\boldsymbol{K}_{o c} f_{o c}
$$

where $K_{o c}=$ organic carbon partition coefficient $\left(\mathrm{m}^{3} / \mathrm{kg}\right)$

$f_{o c}=$ fraction of organic carbon in the soil

Organic carbon partition coefficients are given in the literature for many organic chemicals. $\mathrm{K}_{\mathrm{oc}}$ may also be estimated from the octanol-water partition coefficient $\left(\mathrm{K}_{\mathrm{ow}}\right)$ or from aqueous solubility (Charbeneau and Weaver, 1992).

\subsubsection{Volatilization}

The volatilization process occurs in three distinct stages. First, the contaminant is vaporized into the soil-air, this will occur from the dissolved and immiscible phases. These vapours will then migrate through the soil environment and be affected by soil parameters such as permeability and organic carbon content. Finally, the contaminant will be emitted to the atmosphere.

The Henry's Law Constant, or $K_{\mathfrak{b}}$ is the partition coefficient between gasoline in the vapour and aqueous phases at equilibrium conditions. Higher values of the Henry's Law Constant indicate a preference for the vapour phase. Tabulated values of $\mathrm{K}_{\mathrm{H}}$ are given in the literature for numerous organic chemicals including gasoline. 
Equilibrium conditions between the immiscible phase and the soil-air can be described by Raoult's Law, which states that the partial pressure of any component in the air is simply the product of the mole fraction present in the liquid phase and the saturated vapour pressure of the component (Mercer and Cohen, 1990):

$$
p_{i}=m P_{\text {sat }}
$$

\subsubsection{Vapour-Phase Diffusion in Soil}

Once gasoline has vaporized, diffusion of the organic vapours will dominate the removal process from soil. A model for the mass flux of contaminant as a result of vapour diffusion in unsaturated soil was proposed by Jury et al. (1983):

$$
J_{v}=-D_{a}\left(\delta C_{G} / \delta Z\right)
$$

where $D_{G}=$ soil gas diffusion coefficient $\left(\mathrm{m}^{2} / \mathrm{d}\right)$

$$
\begin{gathered}
C_{G}=\text { gas concentration }\left(\mathrm{g} / \mathrm{m}^{3}\right) \\
Z=\text { distance of transport }(\mathrm{m})
\end{gathered}
$$

One relationship for deriving the soil gas diffusion coefficient is given by the Millington-Quirk tortuosity formula (Jury et al., 1983):

$$
D_{G}=\left(a^{10 / 3} / \phi^{2}\right) D_{G}^{a t r}
$$


where $\mathrm{a}=$ volumetric air content

$\phi=$ soil porosity

$D_{G}{ }^{\text {is }}=$ air gas diffusion coefficient $\left(\mathrm{m}^{2} / \mathrm{d}\right)$

The air gas diffusion coefficient for gasoline can be measured or found in the literature. A similar relationship can be written for soil liquid diffusion. $D_{G}$ is usually several orders of magnitude larger than $D_{L}$ which, coupled with the relatively high Henry's Law Constant for gasoline, means that the diffusive transport of gasoline in soil will occur primarily in the vapour phase (Charbeneau and Weaver, 1992).

Once gasoline vapours have reached the soil surface, a second relationship can be used to define a flux into the atmosphere. Though air movement above the soil's surface is generally turbulent in nature, a stagnant layer close to the soil's surface is assumed. The movement of gaseous vapour through this stagnant layer can best be approximated by molecular diffusion (Jury, 1986). Jury et al. (1983) represented this flux using Fick's Law of diffusion as follows:

$$
J=D_{G}^{a t r}\left[C_{G}(0)-C_{G}(d)\right] / d
$$

where $\operatorname{Cg}(0)=$ gas concentration at the soil surface $\left(g / \mathrm{m}^{3}\right)$

$\mathrm{Cg}(\mathrm{d})=\mathrm{gas}$ concentration in the air above the stagnant layer $\left(\mathrm{g} / \mathrm{m}^{3}\right)$

$d=$ thickness of the stagnant air layer (m)

\subsubsection{Experimental Work on Volatilization}

As previously mentioned, there are a number of soil, chemical and environmental 
parameters which will affect the volatilization of an organic chemical. As the focus of this research is on the effects of soil water content, soil type, temperature and capillary rise, emphasis will be placed in these areas. Literature consulted included experimental and modelling studies relating to volatilization behaviour of organic chemicals in the unsaturated zone.

Advective flow of organic vapours as a result of vapour density differences has been suggested as a potential mechanism for their migration. Density-driven vapour advective flow is defined as flow created by the change in vapour densities resulting from evaporation of contaminant into pore space (Falta et al., 1989). Primarily, the role of advective vapour transport has been determined using modelling studies such as those conducted by Falta $e t$ $a l$. (1989), Frind (1982) and Sleep and Sykes (1989). Other authors have pointed to the dominance of vapour-phase diffusion as the primary migrative pathway of organic vapours (Jury et al., 1983; Swallow and Gschwend, 1983; Abriola and Pinder, 1985; Baehr and Corapcioglu, 1987; and Silka, 1988). As experimental quantification of advective vapour flow resulting from density differences is limited, and the diffusive process is commonly assumed to dominate, emphasis will be placed on vapour-phase diffusion.

\subsubsection{Soil Water Content}

The water content of a soil will be one of the most important determining parameters in diffusive transport of gasoline vapours in the unsaturated zone. Water will offer resistance to a contaminant entering the soil-air. Additionally, pore water will have an effect on two primary factors that control vapour-phase diffusion: adsorption of organic vapours onto organic carbon and mineral sites, and impedance of vapour flow because of a reduced 
effective porosity. Adsorption will be important at low water contents, and impedance of flow will control at higher water contents.

Ideally, increases in soil water content will effectively reduce the gas-phase diffusion constant, as there is less available volume in the pores through which vapour can migrate (Jury, 1986). Acher et al. (1989) reported that vapour diffusion of kerosene was completely inhibited when approaching the field capacity of the soil. Similar results were found by Barbee and Brown (1986) for xylene applied to a sandy loam soil.

In field studies, Johnson and Perrott (1990) showed that in a fine silty clay contaminated with gasoline, a moisture content approaching $90 \%$ of saturation dramatically reduced vapour-phase diffusion of the contaminant. Further studies indicated that continuous airways still existed in the high water content soil, and that vapour-phase diffusion still dominated over aqueous phase diffusion. The authors postulated that vapour diffusion was occurring in macropores resulting from the soil structure. An implication of reduced vapour diffusion is that gasoline vapours will persist in a high water content soil for extended periods of time.

Karimi et al. (1987) demonstrated that water contents of between 8 and $12 \%$ by mass in a clay exponentially decreased the apparent benzene diffusion coefficient. Again, this was explained by water decreasing the pore space available for diffusion of the benzene vapour.

At lower water contents, adsorption of the organic vapours to organic carbon and mineral sites becomes increasingly important to vapour-phase diffusion (Jury, 1986). Goss (1993) demonstrated that an inverse exponential relationship existed between relative humidity and the sorption coefficient above a relative humidity of $30 \%$ in an air-dried sandy 
soil. The quartz sand used was considered to be organic-carbon free, and thus sorption was attributed to mineral sites. A similar behaviour was encountered for a clay soil of low organic matter. Lower adsorption at higher relative humidities was explained by competitive action for soil sorption sites between water and organic vapour. Batterman et $a l$. (1995) conducted vapour diffusion experiments using toluene on an air-dried sand and a loam. The authors found that soil gas humidities less than $30 \%$ resulted in significant vapour retardation in the sand and the loam. Again, it was proposed that water was acting in competition with organic vapours for sorption sites above the $30 \%$ relative humidity mark. Grass et al. (1994) found that under similar wind speeds, trifluralin was evaporated faster at $78 \%$ relative humidity than at $49 \%$ relative humidity in an air-dried sandy soil.

Ong et al. (1992) formulated a model to characterize organic vapour diffusion at low water contents in soil. The authors found that in air-dry soils, adsorption significantly inhibited vapour-phase diffusion of organic pollutants. Voudrias and $\mathrm{Li}$ (1993) used a different model to show similar behaviour in sand at air-dry ( $0.067 \%$ water content) and wet ( $8.86 \%$ water content) conditions. Retardation factors for the wet soil were almost four times lower than for the dry soil, primarily because of the decrease in adsorption of organic vapours. Again, this can be explained by preferential adsorption of water over organic vapours to the soil mineral sites.

The adsorption of organic vapours also appears to exhibit a hysteretic effect. Shonnard and Bell (1993) demonstrated that in an air-dried silty sand, relative humidity played a large part in adsorption of benzene vapours. They found that for an $18 \%$ decrease in relative humidity (to $0 \%$ ), benzene emission rates decreased by $60 \%$ because of increased 
adsorption of the vapours to mineral sites. Upon returning to $18 \%$ relative humidity, the benzene emission rate did not return to the original level. This hysteretic effect was explained by assuming that benzene sorbed to soil sites during the drying phase were not all desorbed upon raising the relative humidity.

A differentiation also needs to be made between adsorption of organic vapours to soil organic carbon and to mineral sites. Adsorption to organic carbon will be most important at the soil's surface, where for the large part it resides; adsorption to mineral sites will be more important at greater depths. Experiments by Voudrias and Li (1992) showed that at low water contents, adsorption of organic compounds to the mineral sites was negligible; as a result, dissolution into the organic phase predominated. English and Loebr (1991) came to a similar conclusion based on benzene and 0-xylene vapour experiments. Rutherford and Chiou (1992) performed experiments on high and low carbon content soils. They found that at air-dry conditions, mineral sorption dominated over sorption onto organic matter even for high organic content soils. As water content was increased, mineral sorption became less important, and the soil organic matter became the primary medium for sorption of the organic vapours.

Studies by Donaldson et al. (1992) demonstrated that adsorption of organic chemicals to soil particles was reversible. The authors found that infiltration of water into a loamy sand contaminated with gasoline components sponsored increased rates of volatilization. Increased water contents promoted the desorption of the chemical and made it available for vapour-phase diffusion to the soil surface.

Water can also affect volatilization by modifying the structure of the soil. Fine and 
Yaron (1993) conducted volatilization experiments on a number of soils ranging from sands to clays. They found that initial wetting of soil often promoted cracking of soils and thus increased volatilization.

In conclusion, decreased migration of organic vapours by increasing water content can be offset by the decrease in sorption that will occur in wet soils (Spencer et al., 1982), and especially in wet soils of low organic matter. If organic vapours can no longer be adsorbed to available sites, the net vapour pressure increases and volatilization will also increase. An upper limit on this would appear to occur when water in the soil pores presents a barrier to vapour transport.

\subsubsection{Soil Type}

Information on volatilization of organic chemicals from different soil types is generally limited to studies on sand and silt, with only limited studies having been performed on clay soils. The effects of changing soil type lie primarily in resulting changes in porosity and pore size distribution. Adsorption characteristics will also change with soil type.

Fine and Yaron (1993) performed kerosene volatilization studies on soils ranging from sands to clays. They determined that volatilization corresponded to the air permeability of the soil, with higher permeabilities leading to increased volatilization rates.

Galin et al. (1990a) showed that after twenty days of kerosene volatilization from columns, $30 \%$ of the initial amount remained in a dune sand and a loamy sand soil. In a silty loam soil, over $60 \%$ of the kerosene was retained. The authors proposed that if mass transfer of kerosene to the atmosphere was entirely through the vapour phase, then the pore 
structure of the soils was responsible for differences in volatilization. Though the dune sand had a much lower total porosity than the silty loam, the pore sizes in the dune sand were on average much larger. Thus, the authors theorized that the pore size distribution and not the total porosity most strongly affected vapour-phase diffusion.

Similar evaporation studies by Burkhard and Guth (1981) showed that 24-hour volatilization fluxes of pesticides were approximately 3-4 times greater for a Collombey sand than for a less coarse Les Evouettes silt loam. Experiments performed by Jarsjo et al. (1994) on sand, sandy loam and peat showed similar trends. Approximately $40 \%$ of the original kerosene mass had volatilized from the sand after 40 hours, from the sandy loam after 70 hours, and from the peat after 150 hours. Acher et al. (1989) demonstrated that mxylene had been lost to $99 \%$ from a sandy clay after only 2 hours. n-Dodecane, meanwhile, had been lost to only $14.3 \%$ after 2 hours and to $61.3 \%$ after 16 hours. The authors attributed the difference directly to the higher vapour pressure of $\mathrm{m}$-xylene as compared to n-dodecane, and not to a soil property. This implicates the volatility of each component in a mixture as being important to the overall volatilization of the mixture from soil. Galin et al. (1990b) showed that at residual kerosene amounts, it took 15 days to evaporate $85 \%$ of the initial mass from a coarse sand, $83 \%$ from a medium sand, and $80 \%$ from a fine sand.

Modelling studies by Jury et al. (1990) demonstrated that a number of pesticides and organic compounds showed higher cumulative volatilization losses from a sandy soil than from a clay soil. For benzene, the difference was an order of magnitude.

Adsorption of chemical in the immiscible phase and in the vapour phase also changes with soil type, primarily as a result of changes in organic carbon content and soil surface 
area. Zytner (1994) demonstrated that adsorption of BTEX chemicals onto the soil matrix occurred to a higher degree in a clay soil than a sandy soil. As expected, sorption increased for soils high in organic carbon, with a maximum for peat moss and organic top soil. Other studies by Zytner et al. (1990) with perchloroethylene demonstrated similar trends. An implication of greater sorption of liquid contaminant is that less contaminant will be available for volatilization.

Yaron et al. (1989) showed a similar relationship between organic carbon content and retardation of organic vapours. The authors found that a silty loam exhibited greater adsorption capacity than did a soil with higher clay content. One explanation offered was that the higher clay content soil had more available sorption sites, but restricted access to them because of the smaller pore sizes. The authors also demonstrated that adsorption in low organic content soils is primarily on the mineral sites, and is inhibited by the presence of water. For two soils, one with a low organic carbon content and one with a higher organic carbon content, at the same water contents, adsorption was shown to be substantially lower in the low organic carbon content soil.

Goss (1993) found that sorption of organic vapours to air-dried kaolinite and quartz sand were different only in relation to differences in the specific area of the soils. Ong et al. (1992) also suggested that oven-dry soils will exhibit differences in sorption according to the soil surface areas.

\subsubsection{Temperature}

The vapour pressure of an organic chemical is non-linearly dependant on temperature. As temperature increases, the saturated vapour density of an organic chemical 
also increases. Thus, an increase in temperature will enhance the transfer of contaminant into soil-air. Temperature may also affect the physical properties, such as pore size distribution, of the soil matrix, and thus alter the diffusive behaviour of gasoline (Jury, 1986).

Donaldson et al. (1992) conducted gasoline volatilization experiments on a loamy sand during both spring and summer seasons. Overall volatilization losses were consistently higher during the summer experiments, a result of high soil temperature and the resulting increase in vapour pressure of the gasoline components.

Jarsjo et al. (1994) compared volatilization rates of kerosene from various soils at 27 and $5^{\circ} \mathrm{C}$. For all soils used, the higher temperature exhibited the greater overall fraction of kerosene volatilized for any given time period. The fraction of kerosene volatilized was 2 to 3 times higher at 27 than $5^{\circ} \mathrm{C}$.

Temperature gradients in soil can also affect the distribution of organic contaminant. Prunty (1992) showed that thermal gradients on the order of $7^{\circ} \mathrm{C}$ in soil drastically affected the distribution of octane. Using closed soil cells with temperatures at the ends differing by $7^{\circ} \mathrm{C}$, they showed that octane migrated to the cooler end of the cell within 1.5 hours. Water distributed itself towards the cool end of the cell at a slower rate. Movement of the water to the cool end eventually forced the redistribution of octane back to the dryer soil regions after extended periods of time ( $>12.5$ hours). This indicates that temperature gradients can have an effect on organic compound distribution because of water distribution.

One case where increasing temperature may slightly decrease volatilization is in the case of drying. If the soil surface is dried of water by high temperatures, adsorption sites 
may become available that entrap organic vapours (Spencer et al., 1982). This effect may offset the increased vapour pressures.

Little experimental data is available on the effects of subzero (water freezing) temperatures on volatilization. It has been shown that hydraulic conductivity in a soil is constant for temperatures above the freezing point. At a temperature equal to the freezing point, conductivity decreases by orders of magnitude as water freezes and expands. For subsequent decreases in temperature, hydraulic conductivity decreases exponentially with temperature (Van Loon, 1991).

\subsubsection{Capillary Rise}

There is evidence in the literature of two additional mechanisms by which chemicals can be transported to the surface of the soil in the liquid phase, and thus be more readily volatilized. These are capillary rise in the immiscible phase and convective flow in water as a result of water evaporation.

A wicking effect has been shown to move contaminant to the surface of the soil in the dissolved phase. As water evaporates, it creates a suction that pulls water to the surface of the soil. If water contains dissolved contaminant, the chemical will volatilize readily upon reaching the soil surface (Spencer et al, 1982). This phenomenon has been shown to accumulate chemicals, specifically pesticides, at the surface of the soil when water is evaporating (Jury, 1986).

During gasoline volatilization experiments, Donaldson et al. (1992) demonstrated higher volatilization in wet soils. Though convective flow of gasoline was not verified, it was postulated that evaporation of water was promoting convective flow of the gasoline and 
thus providing an alternate pathway for volatilization to occur.

The experiments of Spencer et al. (1988) demonstrated that prometon, a pesticide with a relatively low Henry's Law Constant, was accumulating at the surface of the soil through convective flow. This effect was not observed in the absence of water evaporation. It was postulated that accumulation at the surface would increase the evaporation rate of this compound. Sheppard and Dzik (1987) determined that while contamination of surface water from irrigation water was the greater factor, capillary rise of contaminated groundwater was not an insignificant source of surface water contamination. They attributed contamination from groundwater to a convective flow mechanism. Further experiments by Sheppard et al. (1987) demonstrated the same behaviour in laboratory experiments dealing with a tracer in sandy soil.

Spencer and Cliath (1973) showed that evaporation of water from soil promoted higher volatilization rates of lindane from a Gila silt loam. Fluxes reached approximately $400 \mathrm{ng} / \mathrm{cm}^{2-d}$ for cases of no water evaporation and $900 \mathrm{ng} / \mathrm{cm}^{2}-\mathrm{d}$ for evaporation.

Spencer et al. (1988) demonstrated that water evaporation significantly increased the vapour flux of prometon from San Joaquin sandy loam, but did not affect the vapour flux of lindane. These results were correlated to Henry's Law Constants. At low $K_{H}$ values, volatilization is additionally a function of boundary layer thickness and water evaporation rate. Meanwhile, high $K_{H}$ chemicals such as lindane are most strongly affected by resistances in the soil itself and are not susceptible to convective flow in water as in the case of prometon. Modelling studies by Jury et al. (1984) also showed that water evaporation promoted convective upwards migration of dissolved pesticides. 
In landfill cover experiments, Karimi et al. (1987) demonstrated that for benzene, there was no mass flow due to capillary transport. It was suggested that the Henry's Law Constant of benzene was sufficiently high and its aqueous solubility sufficiently low that diffusion occurred primarily in the vapour phase. This suggests that for volatile non-water soluble chemicals, convective upwards flow in water as a result of drying is essentially negligible. Grifoll and Cohen (1994) came to a similar conclusion.

Capillary rise can also promote upwards movement of the immiscible or oily phase itself; however, information on immiscible phase capillary rise in soils is extremely limited. Acher et al. (1989) compared kerosene movement from two different contaminant sources: infiltration of kerosene from the soil surface and capillary rise of kerosene from a kerosene plume already in the soil. They found that liquid front movement in the latter case was slower, but only by $20 \%$. Capillary rise of kerosene showed steady decline with increasing water content, with almost negligible rise at $4 \%$ water, ostensibly as a result of water occupying the smallest better-conducting soil pores.

Ho and Udell (1992) found that in low permeability sands topped with high permeability sands, toluene was pulled up by capillary action to the edge of the fine sandcoarse sand interface. It was postulated by the authors that evaporation at the interface would subsequently increase this liquid phase movement of toluene. The authors did not quantify the effect.

Arthurs et al. (1994) and Smith et al. (1994) performed synthetic gasoline evaporation experiments on Delhi Loamy Sand and Elora Silt Loam. Both authors demonstrated that immiscible phase convective flow of the bulk mixture was responsible for 
the accumulation of lower volatility components at the evaporative surface. Studies showed that increases in water content gradually reduced the rate of immiscible phase wicking.

\subsection{Literature Deficiencies}

The review as presented above has demonstrated that a number of deficiencies pertaining to gasoline volatilization behaviour in soil exist in the literature. First, the paucity of data relating to volatilization rates and behaviour in clay soils needs to be addressed. The effects of water, especialiy at the high level present in natural clay soils, has not been fully explored. Temperature conditions associated with a typical winter Canadian climate also need to be examined. This requires experimentation on cold and frozen soils. Finally, immiscible phase movement of gasoline in soils has received little attention, both in terms of its effect on volatilization and the conditions under which it will occur. 


\subsection{MATERIALS AND METHODS}

A series of different experiments were run to quantify passive volatilization behaviour of gasoline in unsaturated soil using acrylic columns. Soil type, soil water content and temperature were varied. The following sections outline all experimental procedures and materials used.

Additional experiments were conducted to evaluate freezing behaviour of actual gasoline blends. Air permeability experiments were also run on a clay loam at high water content at both room temperature and sub-zero temperatures.

\subsection{Soils}

Three different soils were used in the experiments: Delhi Loamy Sand (DLS), Elora Silt Loam (ESL) and Windsor Clay (WCL). The soils were chosen to represent a range of sand, silt and clay fractions. Of particular interest was the Windsor Clay Loam, which represented a soil type not commonly used in laboratory experiments.

The Delhi Loamy Sand and Elora Silt Loam were collected from the Agriculture Canada Research Station at Delhi and the Ontario Ministry of Agriculture and Food Research Station at Elora, Ontario, respectively. The Windsor Clay Loam was obtained from a plot of land near Windsor.

All soils were analysed prior to use in order to detect existing contamination. Gas chromatograph analysis demonstrated that the soils contained no detectable hydrocarbon contaminants.

\subsubsection{Soil Preparation and Storage}

In order to ensure consistency of experimental results, all soils were sieved and 
mixed before being stored. This procedure was completed before the beginning of this work by previous graduate students using the same soils. The procedure is outlined below.

All soils were first air-dried for at least three days, with periodic turning. They were then passed individually through a No. 10 sieve ( $2 \mathrm{~mm}$ openings). Gravel retained on the sieve was discarded. Aggregates of soil remaining on the sieve were crushed and then resieved. This process was repeated three times. Any soil still remaining on the No. 10 sieve was discarded.

The sieved soil was then mixed into smaller piles. In turn, these piles were subdivided and mixed again. The soil was then separated into four-kilogram piles and placed into Ziploc ${ }^{\mathrm{TM}}$ freezer bags. All soils were stored in the School of Engineering Research and Development Laboratory, where they would not be disturbed.

\subsubsection{Soil Analysis}

Representative samples of the Delhi Loamy Sand, Elora Silt Loam, and Windsor Clay Loam were sent to Analytical Soil Services at the University of Guelph to determine soil particle size distribution and organic matter content. These are summarized in Table 3.I.

Table 3.1 Analytical Soil Services

\begin{tabular}{lccc}
\hline \hline \multicolumn{1}{c}{ Characteristic } & DLS & ESL & WCL \\
\hline \% Sand (by weight) & 86.5 & 34 & 44.6 \\
\% Silt (by weight) & 9.0 & 50.1 & 32.5 \\
\% Clay (by weight) & 4.5 & 15.9 & 22.9 \\
\%Organic Carbon & 1.2 & 2.5 & 1.7 \\
(by Weight) & & & \\
\hline
\end{tabular}




\subsubsection{Soil Analysis of Windsor Clay Loam}

Independent tests were run in Soils Laboratories of the Thornborough Building, University of Guelph, to verify the percent fines in each of the soils. These tests were conducted by placing a known mass of soil in a No. 200 sieve and washing the sieve through with water. The No. 200 sieve is used to distinguish between fines, comprised of the silt and clay fraction of the soil, and sand and gravel. After drying the sample and sieve for 24 hours at $105^{\circ} \mathrm{C}$, the sample was reweighed.

Calculation of percent fines for the Delhi Loamy Sand and Elora Silt Loam agreed with the figures provided by the soil analysis. For the Windsor Clay, the tests indicated that there were approximately $8 \%$ more fines in the soil than indicated by the soil analysis. For this reason, a particle size analysis of the Windsor soil was performed in the Soils Laboratory at the Thornborough Building, University of Guelph.

A sand size analysis was conducted using Standard Methods (Bowles, 1992). Fines were eliminated from the sample by washing them through a No. 200 sieve $(0.075 \mathrm{~mm}$ openings). The remaining soil was oven dried for 24 hours and then shaken through the following series of sieves: No. 4, No. 10, No. 40, No. 60, No. 100, and No. 200 .

The hydrometer method as outlined in Standard Methods was used to analyse the fine fraction of the soil. Sodium metabisulphate was used as the deflocculating agent, and a control column was employed. Hydrometer bulbs were of model $152 \mathrm{H}$. The hydrometer test was run for $\mathbf{4 8}$ hours.

Table 3.2 presents results of the particle size analysis for Windsor Clay Loam. 
Table 3.2 Soil Analysis of WCL-School of Engineering

\begin{tabular}{lc}
\hline \hline \multicolumn{1}{c}{ Characteristic } & WCL \\
\hline \% Sand (by weight) & 37 \\
\% Silt (by weight) & 37 \\
\% Clay (by weight) & 26 \\
\hline \hline
\end{tabular}

\subsubsection{Additional Soil Properties}

Additional soil properties were required for the experiments, including bulk density and air-dry soil water content. These were determined in the Environmental and Soils Laboratories of the Thornborough Building, University of Guelph.

\subsubsection{Bulk Density}

Bulk density for Elora Silt Loam and Delhi Loamy Sand had previously been determined by graduate students using the same soils. The methodology used was as follows: compaction tests were performed in graduated cylinders with air-dried soil. Bulk densities were calculated from the volume which a known weight of soil occupied. Six replicates were conducted for each soil, yielding an average bulk density. The identical methodology was used for the Windsor Clay Loam.

Table 3.3 shows the bulk densities for all soils used. 
Table 3.3 Soil Bulk Densities

\begin{tabular}{lc}
\hline \multicolumn{1}{c}{ Soil } & Bulk Density $\left(\mathrm{g} / \mathrm{cm}^{3}\right)$ \\
\hline Delhi Loamy Sand & 1.5 \\
Elora Silt Loam & 1.3 \\
Windsor Clay Loam & 1.2 \\
\hline \hline
\end{tabular}

\subsubsection{Air-Dry Soil Water Content}

The air-dry soil water content was required to establish the mass of additional water required for wet column experiments. Water content was determined by gravimetric analysis. A known mass of soil was air-dried for two days, and then weighed. The soil samples were then oven dried at $105^{\circ} \mathrm{C}$ for 24 hours, placed in a dessicator to cool, and reweighed.

Table 3.4 shows the air-dry soil water content for all soils used.

Table 3.4 Soil Air-Dry Water Contents

\begin{tabular}{lc}
\hline \multicolumn{1}{c}{ Soil } & $\begin{array}{c}\text { \% Air-Dry Water Content } \\
\text { (g water/g dry soil) }\end{array}$ \\
\hline Delhi Loamy Sand & 0.5 \\
Elora Silt Loam & 3.5 \\
Windsor Clay Loam & 5.0 \\
\hline \hline
\end{tabular}

\subsection{Chemicals}

Ten chemicals were used to formulate the synthetic gasoline used in the experiments. A synthetic gasoline was chosen in order to simplify analysis of results. The final composition listed in Table 3.5 was chosen through consultation with Imperial Oil (1994) 
based on chemical cost, handling safety, ease of GC identification, boiling point range and total mixture volatility. Hexadecane, though not a normal component of gasoline, was added as a non-volatile tracer to monitor the immiscible phase wicking behaviour of the mixture. The mixture used in the experiments is the same as that developed by Rogaz and Hussain (1994) for similar volatilization experiments. Table 3.6 lists relevant physical and chemical properties of the chemicals used.

Table 3.5 Synthetic Gasoline Composition

\begin{tabular}{lcc}
\hline \multicolumn{1}{c}{ Component } & Mass \% & Volume \% \\
\hline Hexadecane & 1.1 & 1 \\
Naphthalene & 1.6 & 1 \\
1,3,5-Trimethylbenzene & 5.9 & 5 \\
m-Xylene & 11.9 & 10 \\
Toluene & 17.9 & 15 \\
Isooctane & 12.4 & 13 \\
Methylcyclopentane & 5.2 & 5 \\
Hexane & 18.1 & 20 \\
MTBE & 2.0 & 2 \\
Isopentane & 23.9 & 28 \\
\hline \hline
\end{tabular}


Table 3.6 Chemical Properties

\begin{tabular}{|c|c|c|c|c|c|}
\hline Chemical & $\begin{array}{l}\text { Chemical } \\
\text { Formula }\end{array}$ & $\begin{array}{l}\text { Boiling } \\
\text { Point } \\
\left({ }^{\circ} \mathrm{C}\right)\end{array}$ & $\begin{array}{l}\text { Melting } \\
\text { Point } \\
\left.\text { ( }^{\circ} \mathrm{C}\right)\end{array}$ & $\begin{array}{l}\text { Specific } \\
\text { Gravity }\end{array}$ & $\begin{array}{c}\text { Vapour } \\
\text { Pressure } \\
(\mathbf{m m} \text { of } \mathbf{H g})\end{array}$ \\
\hline n-Hexadecane & $\mathrm{C}_{16} \mathrm{H}_{34}$ & 287 & 18 & 0.77 & $1 @ 105^{\circ} \mathrm{C}$ \\
\hline Naphthalene & $\mathrm{C}_{10} \mathrm{H}_{8}$ & 218 & 107 & 1.16 & $0.054 @ 20^{\circ} \mathrm{C}$ \\
\hline $\begin{array}{l}\text { 1,3,5-Trimethyl- } \\
\text { benzene }\end{array}$ & $\mathrm{C}_{9} \mathrm{H}_{12}$ & 163 & -45 & 0.86 & $2.49 @ 25^{\circ} \mathrm{C}$ \\
\hline m-Xylene & $\mathrm{C}_{8} \mathrm{H}_{10}$ & 139 & -48 & 0.9 & $8.3 @ 25^{\circ} \mathrm{C}$ \\
\hline Toluene & $\mathrm{C}_{7} \mathrm{H}_{8}$ & 111 & -95 & 0.87 & $22 @ 20^{\circ} \mathrm{C}$ \\
\hline Isooctane & $\mathrm{C}_{8} \mathrm{H}_{48}$ & 99 & 107 & 0.69 & $41 @ 21^{\circ} \mathrm{C}$ \\
\hline Methylcyclopentane & $\mathrm{C}_{6} \mathrm{H}_{12}$ & 72 & -142 & 0.75 & $232 @ 37^{\circ} \mathrm{C}$ \\
\hline Hexane & $\mathrm{C}_{6} \mathrm{H}_{14}$ & 66 & -69 & 0.68 & $150 @ 20^{\circ} \mathrm{C}$ \\
\hline MTBE & $\mathrm{C}_{5} \mathrm{H}_{12} \mathrm{O}$ & 55 & N/A & 0.74 & $312 @ 20^{\circ} \mathrm{C}$ \\
\hline Isopentane & $\mathrm{C}_{5} \mathrm{H}_{12}$ & 28 & -160 & 0.62 & $762 @ 20^{\circ} \mathrm{C}$ \\
\hline
\end{tabular}

1,3,5-trimethylbenzene ( $98 \%$ pure), m-xylene ( $99 \%$ pure), methylcyclopentane ( $98 \%$ pure) and MTBE ( $99.8 \%$ pure) were all purchased from Aldrich.

Toluene (HPLC grade), isopentane (certified), hexane (HPLC grade), isooctane (HPLC grade), hexadecane (certified) and naphthalene (certified) were all purchased from Fisher Scientific. The solvent used in the experiments, dichloromethane (HPLC grade) was also purchased from Fisher Scientific.

\subsection{Volatilization Experiments}

Table 3.7 shows a summary of the volatilization experiments run. Cold conditions are those performed outdoors but not necessarily characterized by temperatures consistently 
below zero; frozen conditions are those that are consistently below zero. All gasoline and water contents are expressed in terms of dry weight of soil.

Table 3.7 Volatilization Experiments

\begin{tabular}{cccc}
\hline Soil Type & $\begin{array}{c}\text { Gasoline \% } \\
\text { (by weight) }\end{array}$ & $\begin{array}{c}\text { Water \% } \\
\text { (by weight) }\end{array}$ & $\begin{array}{c}\text { Temperature } \\
\text { Conditions }\end{array}$ \\
\hline ESL & 17.5 & 3.5 (air-dry) & Cold \\
ESL & 13 & 8 & Cold \\
DLS & 14.5 & 0.5 (air-dry) & Cold \\
DLS & 10 & 5 & Cold \\
WCL & 14 & 5 (air-dry) & Room \\
WCL & 5 & 5 (air-dry) & Room \\
WCL* & 5 & 20 & Room \\
WCL* & 5 & 30 & Room \\
WCL & 5 & 20 & Room \\
WCL & 5 & 30 & Room \\
WCL & 5 & 5 (air-dry) & Frozen \\
WCL & 5 & 20 & Frozen \\
WCL & 5 & 30 & Frozen \\
\hline \hline
\end{tabular}

* refers to experiments where sodium sulfate was not used to improve the extraction efficiency from the wet clay loam

\subsection{Columns for Gasoline Volatilization Experiments}

Seven acrylic columns were used in the gasoline volatilization experiments. The acrylic tubing was purchased from Johnston Plastics (Toronto, Ontario).

Figure 3.1 illustrates a typical column used in the gasoline volatilization experiments. 
Dimensions of the outside collar were: $63.5 \mathrm{~mm}$ I.D., $73.0 \mathrm{~mm}$ O.D., and a height of 250 $\mathrm{mm}$. There were eleven inner segments in total, designed such that they could be inserted easily into the outer sleeve. Ten had the following dimensions: $49.3 \mathrm{~mm}$ I.D., $63.0 \mathrm{~mm}$ O.D. and a height of $20 \mathrm{~mm}$. A final segment had the same diameter dimensions, but had a height of $50 \mathrm{~mm}$; this was the bottom segment of the columns.

An acrylic top plate for each of the columns was constructed with openings of $49.3 \mathrm{~mm}$ diameter to coincide with the inner dimensions of the segments. The opening provided the evaporative area for the experiments. The top plate was held onto the column using two threaded rods, washers and wing nuts. The bottom plate, also acrylic, had a pinhole opening drilled into it, so as to maintain atmospheric pressure at the bottom of the column. The bottom plate was held onto the column by friction against rubber o-rings. The columns were constructed to the specifications described by Rogaz and Hussain (1994).

Columns were assembled by first placing a teflon gasket into the column, and then inserting the $50 \mathrm{~mm}$ high segment. Each of the other segments were then added, using a Teflon gasket in between each. The top plate was then added and fastened to the column with the washers and wing nuts. 


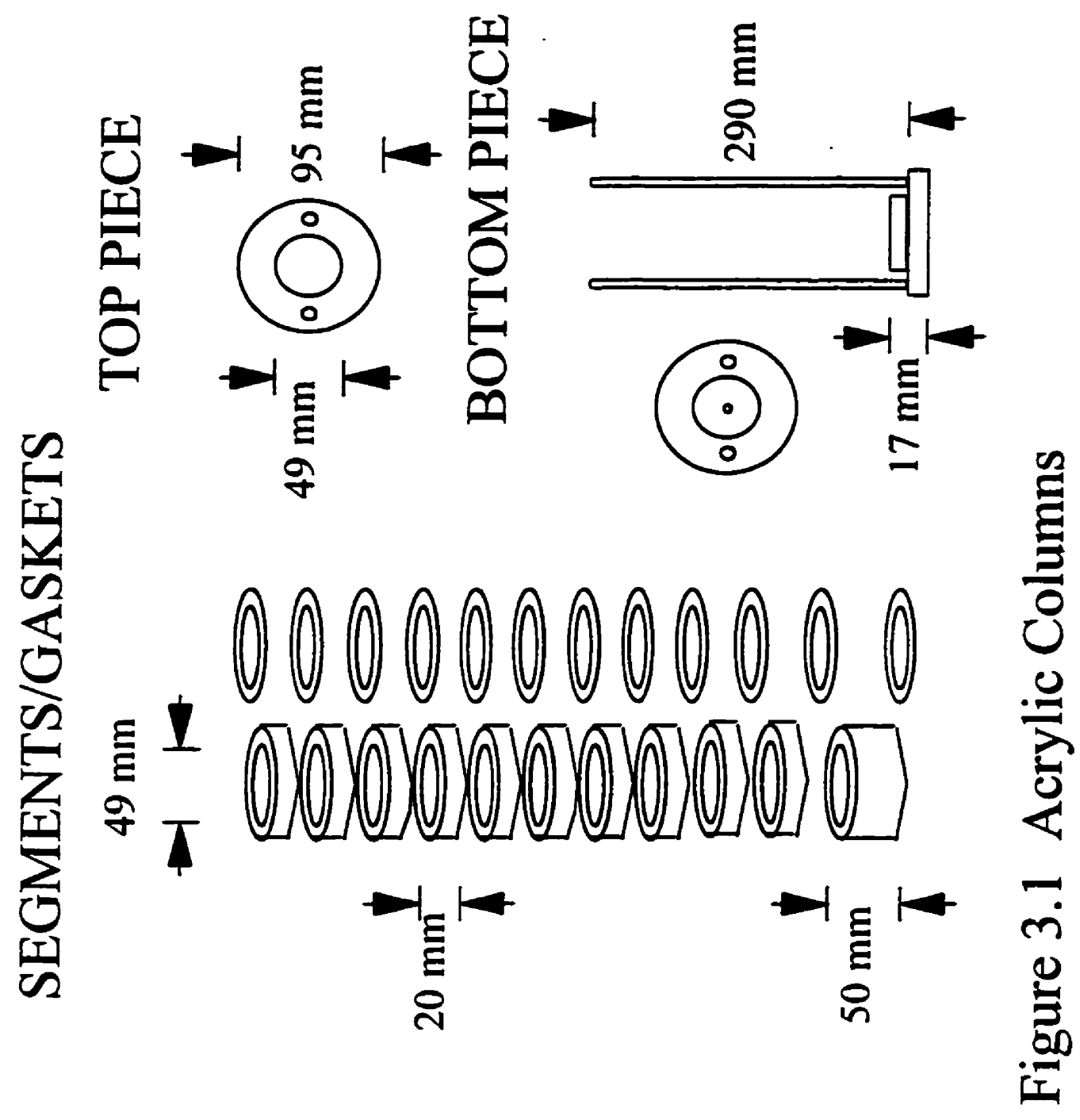

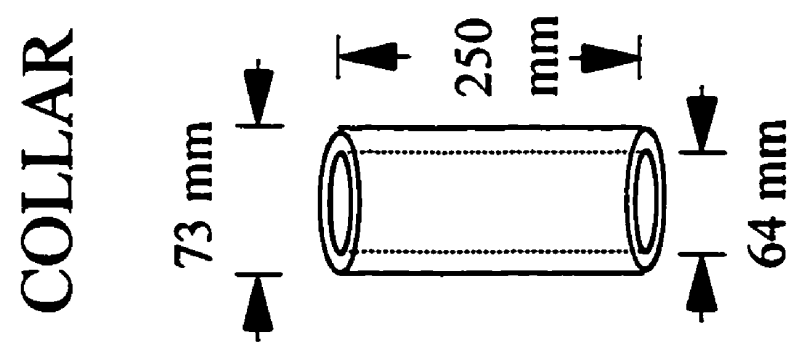




\subsection{Cold Temperature Sand and Silt Volatilization Experiments}

The first set of experiments were conducted on Elora Silt Loam and Delhi Loamy Sand in a cold-weather environment at two different water contents for each soil. The cold weather environment consisted of a ventilated box placed on the roof of the Thornborough Building during the latter portion of February and the early part of March, 1996.

\subsubsection{Column Preparation}

For the cold Delhi Loamy Sand and Elora Silt Loam experiments, soil was packed into the acrylic columns using methods (as outlined below) previously developed by Rogaz and Hussain (1994). Packing was done to achieve the desired bulk air-dry densities for each soil.

For each column, four equal lifts of soil were mixed with a predetermined amount of water in shaking jars. Shaking was done by hand until the water was evenly mixed with the soil. The adequacy of the mixing was determined by visual observation. For the air-dry water contents, no water was added. The shaking jars were then mixed with an amount of synthetic gasoline, and shaking was performed once again as to achieve a relatively uniform mixture of soil, water and gasoline. All four lifts were prepared prior to packing of the columns in order to minimize losses, and were stored in a refrigerator at $4^{\circ} \mathrm{C}$ until ready for use.

Each of the four equal lifts were then added in succession to the inner segments of the acrylic columns. A wooden plunger was employed to compact the soil layer to the desired bulk density shown in Table 3.3. Mixing and packing were accomplished as quickly as possible so that handling losses would be minimized. Average time of construction of 
each column was approximately 10 minutes.

\subsubsection{Cold Weather Environment}

For the Delhi Loamy Sand and Elora Silt Loam experiments, cold conditions were maintained. Cold conditions are defined as typical winter temperatures, and do not represent a case of consistently freezing temperatures.

Upon packing, the columns were placed in a ventilated box on the roof of the Thornborough Building, University of Guelph, during the month of February and early March, 1996. The box was constructed of plywood and drilled with holes to allow for ventilation of the headspace within while protecting the columns from precipitation. The exterior of the box was painted white in order to offer some reflectivity of the sun. The dimensions of the box are presented in Figure 3.2. A hinge was subsequently added to the top of the box in order to make access to its contents easier. The box was placed in a location where access would be fairly easy.

The temperature in the soil columns was monitored using type $T$ thermocouples and a CRIOX Datalogger. The datalogger itself was kept in a box insulated with styrofoam so that its reference temperature was not biased by outside temperature fluctuations. For the same reason, the styrofoam box was kept in a consistently shaded area.

Two thermocouples monitored the box headspace and outside temperature. Thermocouples were also inserted into the surface of longer duration columns, in order to monitor temperature fluctuations of the soil columns themselves. Monitoring of all thermocouples was achieved by connecting a computer to the datalogger and periodically downloading data to a floppy disk. A schematic of the temperature apparatus is presented 
in Figure 3.2.

The temperature program used by the datalogger is presented in Appendix A. 


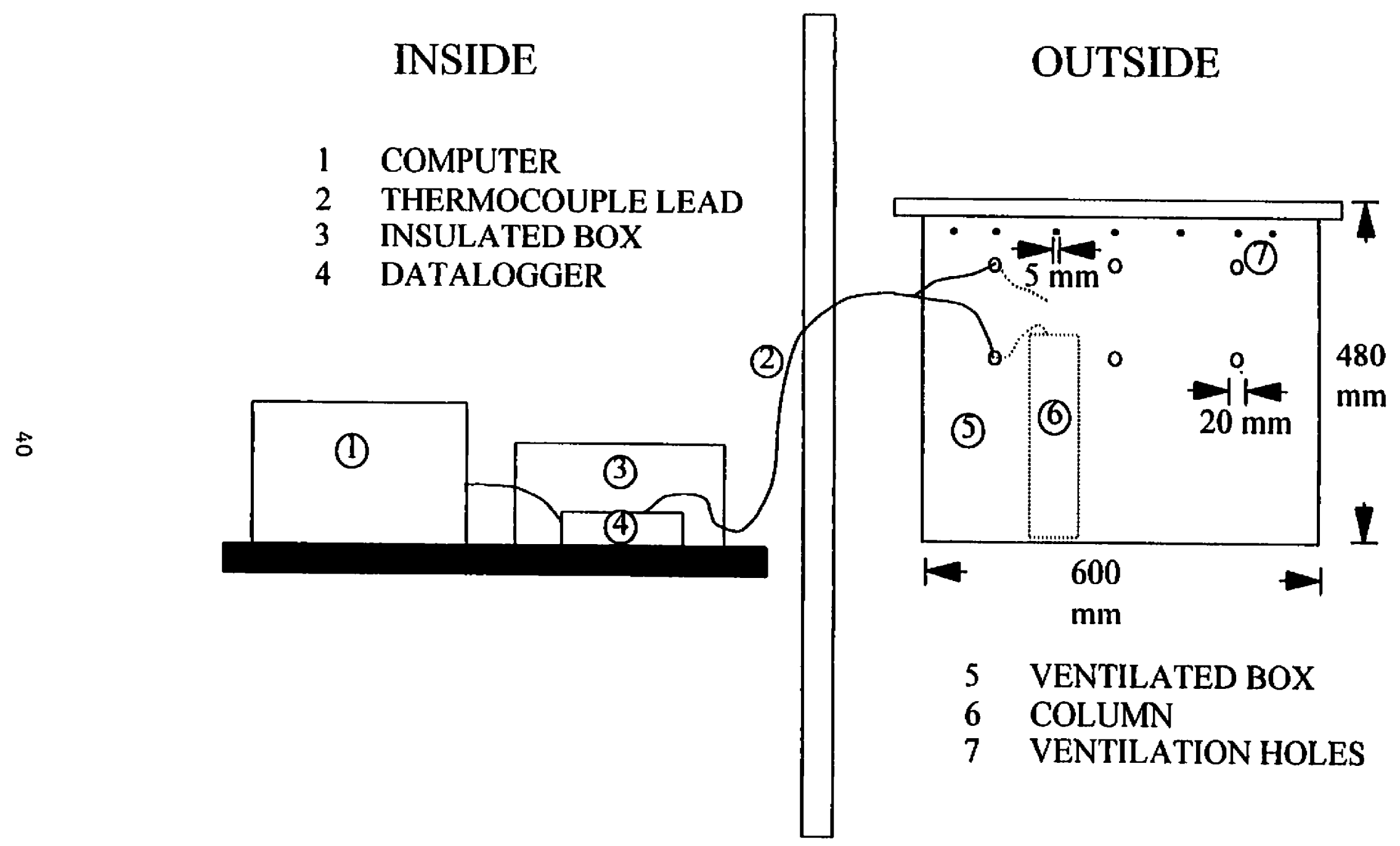

Figure 3.2 Schematic of Cold -Temperature Setup 


\subsubsection{Analytical Procedures}

Sampling of the columns was conducted in a fumehood using proper safety procedures.

Columns were placed in the ventilated box for periods of $1,2,6,24,48,72,120$, 240 , and 336 hours. After these durations, the columns were destructively sampled. The inner segments of the columns were removed from the outer sleeve, and a grab sample of approximately $3-4 \mathrm{~g}$ of soil was taken for analysis from each segment. The soil was placed into $10 \mathrm{~mL}$ of dichloromethane solvent in a $15 \mathrm{~mL}$ borosilicate vial with a teflon-lined silicone septum. All caps were then covered in teflon tape to ensure the integrity of the seal.

The vials were placed on a multi-wrist action shaker (Lab-line \#3589) for 10 minutes at maximum agitation to extract the samples. The samples were subsequently allowed to settle by gravity for approximately one hour in a refrigerator at $4^{\circ} \mathrm{C}$, after which time a fraction of the separated solvent was transferred to a $2 \mathrm{~mL}$ sample vial using a Pasteur pipette. The $2 \mathrm{~mL}$ vials were then placed into the autosampler queue for $\mathrm{GC}$ analysis. If the number of vials exceeded 25 , the remainder were placed in the refrigerator for storage until analysis could proceed the next day. This was done to minimize losses from the vials while waiting for analysis.

Chemical concentrations in the soil were determined using a Hewlett Packard 5890 Series II Gas Chromatograph equipped with a Flame Ionization Detector (GC-FD). The temperature program used was 4 minutes at $40^{\circ} \mathrm{C}$, a ramp of $15^{\circ} \mathrm{C} / \mathrm{min}$ to $140^{\circ} \mathrm{C}$, then $30^{\circ} \mathrm{C} / \mathrm{min}$ to $260^{\circ} \mathrm{C}$, with a final hold time of 2 minutes. Calibration was by means of external standards. The entire temperature program plus cool-down period for the oven took 
approximately 27 minutes to nu for each vial.

Zero-hour columns were also run for each experiment by taking down columns immediately upon finishing their packing. These were used to evaluate handling losses during column packing and take down, and also to evaluate losses due to extraction.

In order to assess losses due entirely to the extraction procedure, vial tests were conducted for each soil used at each gasoline-water content. These were done by placing small amounts ( $<15 \mathrm{~g}$ ) of soil into $40 \mathrm{~mL}$ vials, wetting the soil with water where needed, and then spiking with prechilled synthetic gasoline. The mixture was then immediately sampled. All procedures were completed as quickly as possible in order to minimize evaporative losses. For the wet Clay Loam tests, the extraction was enhanced with the aid of sodium sulfate, as discussed in section 3.6.3. Six vial tests were run for each soil-watergasoline combination.

\subsection{Room Temperature Clay Loam Experiments}

Room temperature Clay Loam experiments were conducted in a fumehood. The average temperature ranged between 19 and $21^{\circ} \mathrm{C}$ for the entire experimental run. Column preparation and analytical techniques were changed for the Clay Loam experiments. The method of column preparation used for the Sand and Silt experiment was found to create an excessive number of large aggregates when the Clay Loam was mixed with water. This reduced the ability to evenly spike the mixture with gasoline, and lead to increased handling losses. Several attempts were made to overcome the problem, and will be discussed later. The final procedure used is provided here. 


\subsubsection{Column Preparation}

The natural air-dried bulk density of the soil was used to pack the column. In total, 48 lifts of $13 \mathrm{~g}$ each were used for every Clay Loam column. The first air-dried lift was deposited to the lowest segment, to which the appropriate amount of water was added using a syringe pump. A small diameter teflon tube was used to direct the water from the syringe pump so that it was dispersed evenly over the soil slice. The water was allowed to evenly infiltrate into the soil slice. A second teflon tube was employed to direct a gasoline stream from a syringe pump onto the wetted soil slice. The water and gasoline bottles were suspended above the column using retort stands. In order to achieve even distribution of water and gasoline, a small mirror was fastened to a third retort stand and angled such that the interior of the column could be viewed from outside the fumehood, and the teflon tubes could be directed accordingly. The mirror allowed for even wetting of the soil slices with water and gasoline without requiring the operator to be exposed to gasoline vapours. Figure 3.3 illustrates the apparatus used to pack the columns using the new method.

Handling losses were moderated by cooling the gasoline mixture to $0^{\circ} \mathrm{C}$ and immediately depositing the next segment of soil after addition of the gasoline. Cooling was achieved by using a bucket of snow or ice to hold the gasoline bottle on the retort stand. The time to prepare each column increased to an average of 35 minutes. 


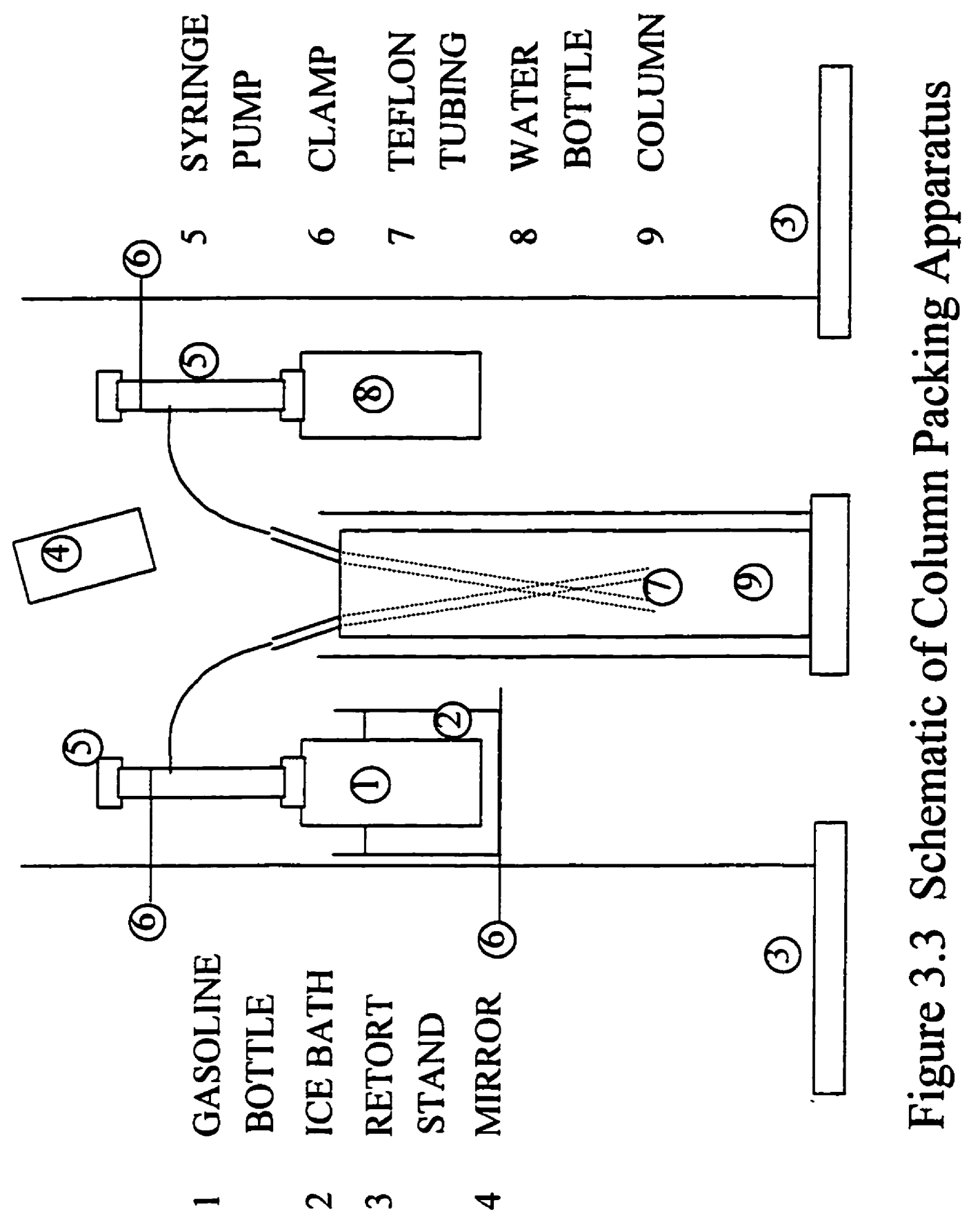


One air-dried clay loam experiment ( $5 \%$ gasoline by dry weight) was conducted using this method of column construction. Another air-dried experiment (14\% gasoline by dry weight) was also conducted using Clay Loam. Because problems with Clay Loam column packing were only encountered when adding water, it was decided to use the column preparation method as outlined in the Section for the Delhi Loamy Sand and Elora Silt Loam experiments. Two modifications were made to the 4-lift method for the $14 \%$ gasoline Windsor Clay Loam experiment. First, the gasoline was prechilled to $-20^{\circ} \mathrm{C}$ in order to reduce evaporative losses. Second, an effort was made to reduce the time to pack the columns. The average time to complete a modified 4-lift column was 5 minutes, compared to 10 minutes using the older experimental method.

In summary, all Delhi Loamy Sand and Elora Silt Loam experiments, plus the 14\% gasoline Windsor Clay experiment, were conducted using the 4-lift method. The 5\% gasoline (air-dry) and both wet Clay Loam experiments were conducted using the 48-lift method.

\subsubsection{Zero-Hour Columns}

Measured values from zero-hour columns showed an excessive amount of noise, and so it was decided that more time should be allowed for proper distribution of water and gasoline in the Clay Loam soil. This was accomplished by allowing the zero-hour columns to sit tightly capped with aluminum in a refrigerator at $4^{\circ} \mathrm{C}$ for approximately 3 hours. After that time, they were analysed with the procedures that follow.

\subsubsection{Modified Analytical Procedures}

Columns were destructively sampled after $2,6,24,72,120,240$ and 336 hours. 
Zero-hour columns were again used to assess extraction efficiencies and handling losses.

It was found that using the same analytical procedure as outlined for the Delhi Loamy Sand and Elora Silt Loam experiments lead to poor extraction efficiencies. In contrast, extraction efficiencies for the air-dried experiment were much higher. Poor extraction efficiencies resulted in a considerable amount of noise in the data, though trends were still discernible.

Efficiencies for the wet Clay soil were increased by adding a drying agent, sodium sulphate, and increasing the mechanical mixing in the extraction process. The 3-4 gram soil sample was added to the borosilicate vial containing sodium sulphate in a mass ratio of $1: 3$ (g dry sample:g sodium sulphate). Mechanical mixing of the sodium sulphate with the sample mass was then undertaken, until the sample was sufficiently discretized. $10 \mathrm{~mL}$ of dichloromethane was then added to the borosilicate vial and shaken for 10 minutes at maximum agitation.

Sodium sulphate was prepared for the experiments by oven drying it at $105^{\circ} \mathrm{C}$ for 48 hours prior to use.

\subsection{Frozen Clay Loam Experiments}

Column packing and analytical procedures were identical for the frozen Clay Loam experiments as for the room temperature Clay Loam experiments. A change in the experimental protocol was made in terms of the cold weather environment, as consistently subzero temperatures were required.

A warmer period of weather in mid-February did not allow for the inclusion of the 336 hour time duration. 


\subsubsection{Frozen Weather Environment}

Upon packing, the Clay Loam columns were placed with tightly fitting aluminum caps into a freezer for two hours to achieve frozen conditions. The aluminum caps ensured that losses would be minimal for the two hour waiting period. Only after the soil was frozen were the experiments initiated.

In order to ensure freezing temperatures at all times during the actual experiment, the ventilated box was modified slightly. First, a gravel base was added beneath it, and typical household insulation was added to the inside walls in a manner designed not to interfere with ventilation. The interior of the box was then packed with ice, and the columns added. Some melting of the ice did occur, and so it was periodically replenished. Runoff of melt water occurred through the gravel. The temperature of the ice, the soil in the columns and the box headspace was monitored using thermocouples. A shield consisting of an office partition covered in plastic coating was used to deflect sunlight from the entire box.

Figure 3.4 illustrates the modifications made to the ventilated box.

Occasionally, outside temperatures were sufficiently above zero that additional cooling was required. Small amounts of dry ice were used once a day to cool the ice packing. This achieved adequate freezing conditions for the frozen clay loam experiments. Additionally, a new CR10 type datalogger was used for the frozen Clay Loam experiments. The shielding box, temperature program and thermocouples used were the same as for the cold Sand and Silt experiments. 
The average temperature of the experimental run was $-3.8^{\circ} \mathrm{C}$, with a maximum temperature of $-0.5^{\circ} \mathrm{C}$. The frozen and cold weather environments will be discussed in greater detail in Chapter 5. 


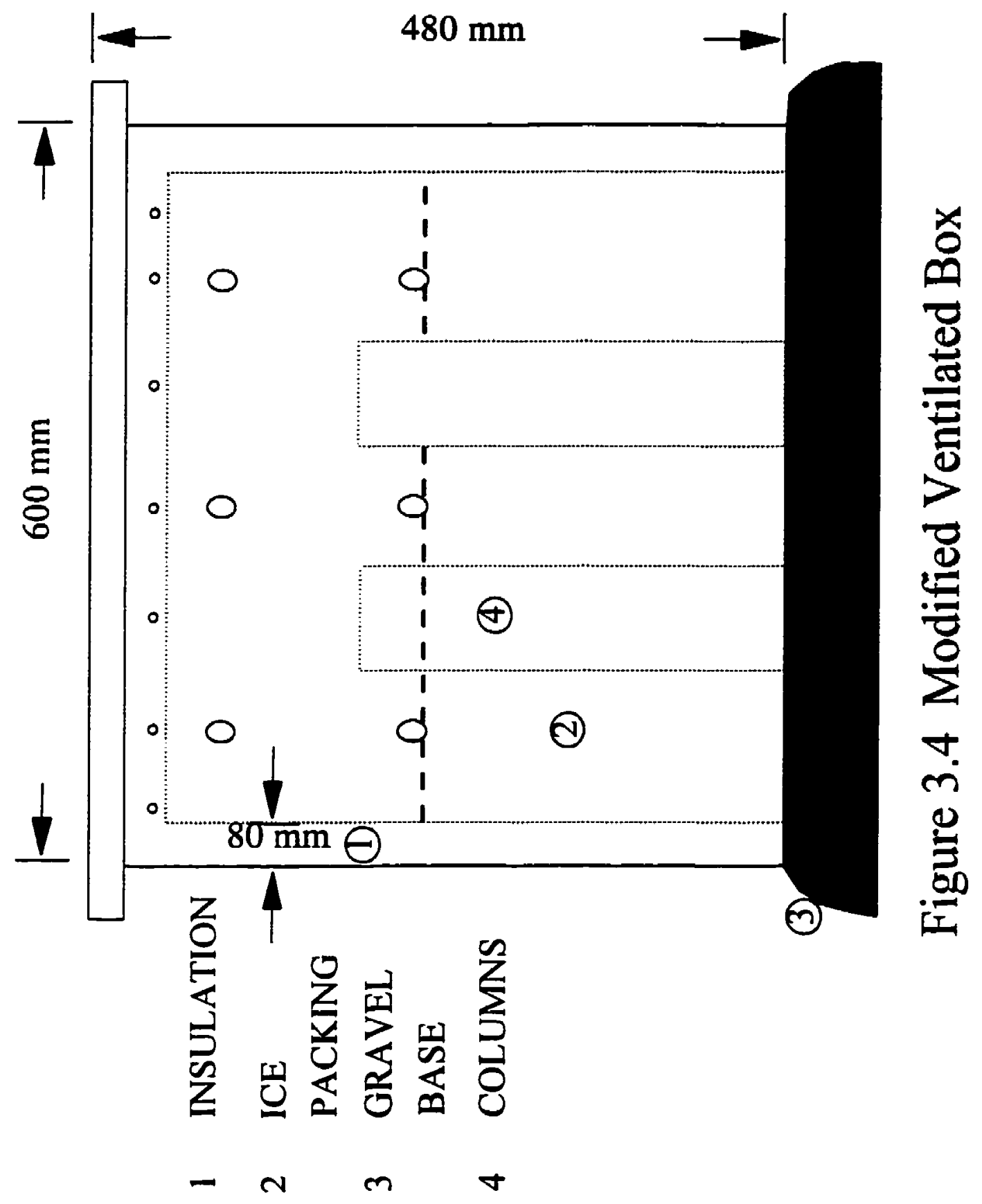




\subsection{Wicking Experiments}

Additional wicking experiments were also performed. These were simply volatilization experiments run at differing gasoline-water contents using Windsor Clay Loam at room temperature. Columns were only up for a ten hour duration, after which analysis using the methods outlined in section 3.6.3 was conducted. All columns and the synthetic gasoline composition used for these experiments were the same as those used in the volatilization experiments.

\subsection{Gasoline Freezing Experiments}

Trends observed for cold weather experiments suggested that freezing of heavier components of gasoline had occurred. To verify this behaviour, freezing experiments were conducted on raw gasoline blends and on samples of the synthetic gasoline used in the experiments.

Small amounts of weighed fuel were added to $500 \mathrm{~mL}$ beakers in a fumehood. The beakers were packed in ice, which was occasionally doused with dry ice in order to maintain freezing conditions (average temperature of $-2^{\circ} \mathrm{C}$ ). The fuel was then allowed to evaporate until the majority of lighter molecular weight components had been evaporated and heavier components had fallen out of solution, a total of 3 hours.

The beakers were subsequently dried and weighed again, so that the remaining gasoline mass could be determined. Control beakers were also placed in the ice in order to assess the contributions of water condensation.

\subsection{Frozen Soil Permeability Experiments}

In order to differentiate volatilization mechanisms in frozen clay loam, air 
permeability experiments were run. These were conducted at $30 \%$ water content at room temperature and subzero (frozen) conditions.

The apparatus used to measure air permeability was a soil vapour extraction experimental setup that had been used in other research. The apparatus had been designed by Harper et al. (1997). Figure 3.5 shows a schematic of the SVE system.

The acrylic columns were incompatible with the permeability measurements, as excessive leaks occurred at the top and bottom plates. The existing glass columns used in the SVE apparatus were employed instead. These columns were approximately $\mathrm{I} \mathrm{cm}$ larger in diameter and $5 \mathrm{~cm}$ shorter in total height than the acrylic columns. Soil was added to the columns using the same procedure as outlined for the clay loam experiments. The larger diameter of the columns necessitated using lifts of $26 \mathrm{~g}$ rather than $13 \mathrm{~g}$. In total, 30 lifts of soil were added. Water was deposited onto the slices using a syringe pump and teflon tubing.

Permeability was determined five times for each temperature condition, and the average permeability was reported. Pressures were measured using a water manometer, while flowrates were measured using a needle-valve flowmeter. 


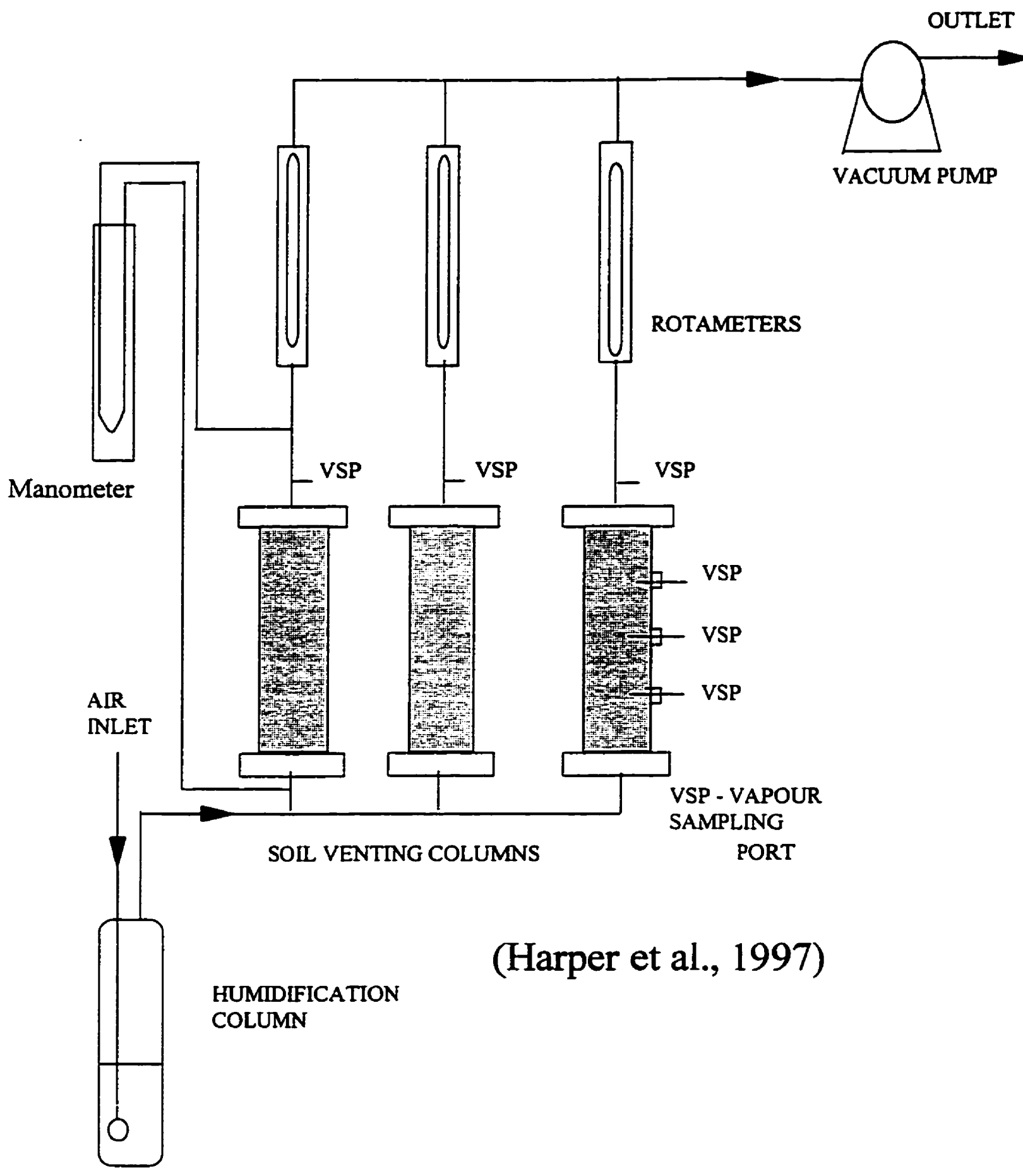

Figure 3.5 Schematic of SVE Setup 


\section{CHAPTER 4 RESULTS}

Results for all volatilization, permeability and wicking experiments are presented in this chapter. Extraction efficiency tests are presented, as well as results from zero-hour columns used to assess the contributions of overall losses Raw data for the extraction efficiency experiments and calculations used are given in Appendix B. Calculations used to determine soil concentrations of gasoline components from Gas Chromatograph data are presented in Appendix C.

Volatilization data is presented graphically for all experiments in this chapter. Sample calculations showing how the graphs were derived from raw concentration data are presented in Appendix D. It should be noted that all data points are not presented graphically in this section, as that would necessitate an impractical number of graphs. Instead, total gasoline and specific component behaviour is examined. Complete concentration data is contained in the Appendices: Cold-weather Delhi Loamy Sand and Elora Silt Loam volatilization data is included in Appendix E; Windsor Clay Loam at room temperature data in Appendix F; and data for Windsor Clay Loam at subzero temperatures in Appendix G. Results from the permeability experiments conducted on Windsor Clay Loam at varying temperatures are presented in this chapter, with sample calculations presented in Appendix H. A section on experiments performed to estimate the freezing behaviour of gasoline components is also included; calculations are presented in Appendix 1 .

\subsection{Zero Hour Columns}

Zero hour columns were used to assess handling losses and losses due to extraction 
efficiencies for each experiment. Table 4.1 presents results of zero hour columns run for all experiments under all conditions. It should be noted that all gasoline and water contents are expressed in terms of dry weight of soil.

Table 4.1 Percent Recovery in Zero Hour Columns

\begin{tabular}{ccccc}
\hline \hline Soil Type & $\begin{array}{c}\text { Initial } \\
\text { Gasoline \% } \\
\text { (by weight) }\end{array}$ & $\begin{array}{c}\text { Water \% } \\
\text { (by weight) }\end{array}$ & $\begin{array}{c}\text { Measured } \\
\text { Gasoline \% } \\
\text { (by weight) }\end{array}$ & \% Recovery \\
\hline DLS & 14.5 & 0.5 & 10.2 & 70 \\
DLS & 10 & 5 & 5.2 & 52 \\
ESL & 17.5 & 3.5 & 12.2 & 70 \\
ESL & 13 & 8 & 8.2 & 63 \\
WCL & 14 & 5 & 12 & 86 \\
WCL & 5 & 5 & 4.3 & 86 \\
WCL & 5 & 20 & 1.5 & 30 \\
WCL & 5 & 30 & 0.8 & 16 \\
WCL* & 5 & 20 & 1.8 & 36 \\
WCL* & 5 & 30 & 3 & 60 \\
WCL** & 5 & 20 & 3 & 60 \\
WCL** & 5 & 30 & 3.6 & 72 \\
\hline \hline
\end{tabular}
using sodium sulfate to improve the extraction

** using sodium sulfate and a three hour distribution period to improve the extraction

\subsection{Extraction Efficiencies}

Extraction efficiencies using the methods given in Section 3.5 varied with soil type and water content. Table 4.2 presents average results from vial extractions conducted in such a manner as to minimize handling losses. Six tests were conducted for each condition. All extraction efficiency data and sample calculations are shown in Appendix B. 
Table 4.2 Extraction Efficiencies

\begin{tabular}{ccccc}
\hline \hline $\begin{array}{c}\text { Soil Type/ } \\
\text { Conditions }\end{array}$ & $\begin{array}{c}\text { Gasoline \% } \\
\text { (by weight) }\end{array}$ & $\begin{array}{c}\text { Water \% } \\
\text { (by weight) }\end{array}$ & $\begin{array}{c}\% \\
\text { Extracted }\end{array}$ & Range (\%) \\
\hline DLS (DRY) & 14.5 & 0.5 & 99 & none \\
DLS (Wet) & 10 & 5 & 86 & $86-87$ \\
ESL (Dry) & 17.5 & 3.5 & 99 & $99-100$ \\
ESL (Wet) & 13 & 8 & 81 & $80-82$ \\
WCL (Dry) & 5 & 5 & 98 & $98-99$ \\
WCL (Wet) & 5 & 30 & 68 & none \\
$\begin{array}{c}\text { WCL (Wet) using } \\
\text { sodium sulfate }\end{array}$ & 5 & 30 & 84 & $84-85$ \\
\hline \hline
\end{tabular}

\subsection{Comparison-Gravimetric Measurements \& Gas Chromatograph Data}

For the air-dry experiments conducted on Windsor Clay Loam at room temperature and frozen conditions, gravimetric measurements of the columns were conducted. The results of these measurements and the corresponding fractions of gasoline lost from Gas Chromatograph data are presented in Table 4.3. Similar gravimetric data was collected for wet experiments; however, the effect of water evaporation could not be distinguished from gasoline volatilization using these methods. As a result, gravimetric measurements of wet soil columns were not presented. 
Table 4.3 Comparison-Gravimetric Measurements \& GC Data (WCL)

\begin{tabular}{ccc}
\hline Experiment & $\begin{array}{c}\text { \% Gasoline Volatilized } \\
\text { Based on Gravimetric } \\
\text { Measurements }\end{array}$ & $\begin{array}{c}\text { \% Gasoline Volatilized } \\
\text { Based on Gas } \\
\text { Chromatograph Data }\end{array}$ \\
\hline $\begin{array}{c}5 \% \text { Gasoline (Room } \\
\text { Temperature) }\end{array}$ & 67 & 66 \\
$\begin{array}{c}14 \% \text { Gasoline (Room } \\
\text { Temperature) } \\
\begin{array}{c}5 \% \text { Gasoline (Frozen } \\
\text { Temperature) }\end{array}\end{array}$ & 82 & 88 \\
\hline \hline
\end{tabular}

* these values were determined after 336 hours of volatilization

\subsection{Cold and Frozen Weather Temperature Results}

For the cold weather experiments, different temperature conditions were defined. Temperatures were typically subzero for the Delhi Loamy Sand and Elora Silt Loam experiments; these are defined as cold conditions. Temperatures were consistently subzero for the frozen Windsor Clay Loam experiments, with a maximum hourly average of $-0.5^{\circ} \mathrm{C}$; these are defined as frozen conditions. Table 4.4 presents the average temperatures during each of the experimental runs. For cold-weather conditions, a total of 102 out of 120 hours showed hourly average temperatures below $0^{\circ} \mathrm{C}$. Figure 4.1 illustrates a typical temperature response curve with time for a soil column placed in these cold weather conditions. The ambient temperature for this curve is approximately $-10^{\circ} \mathrm{C}$. 


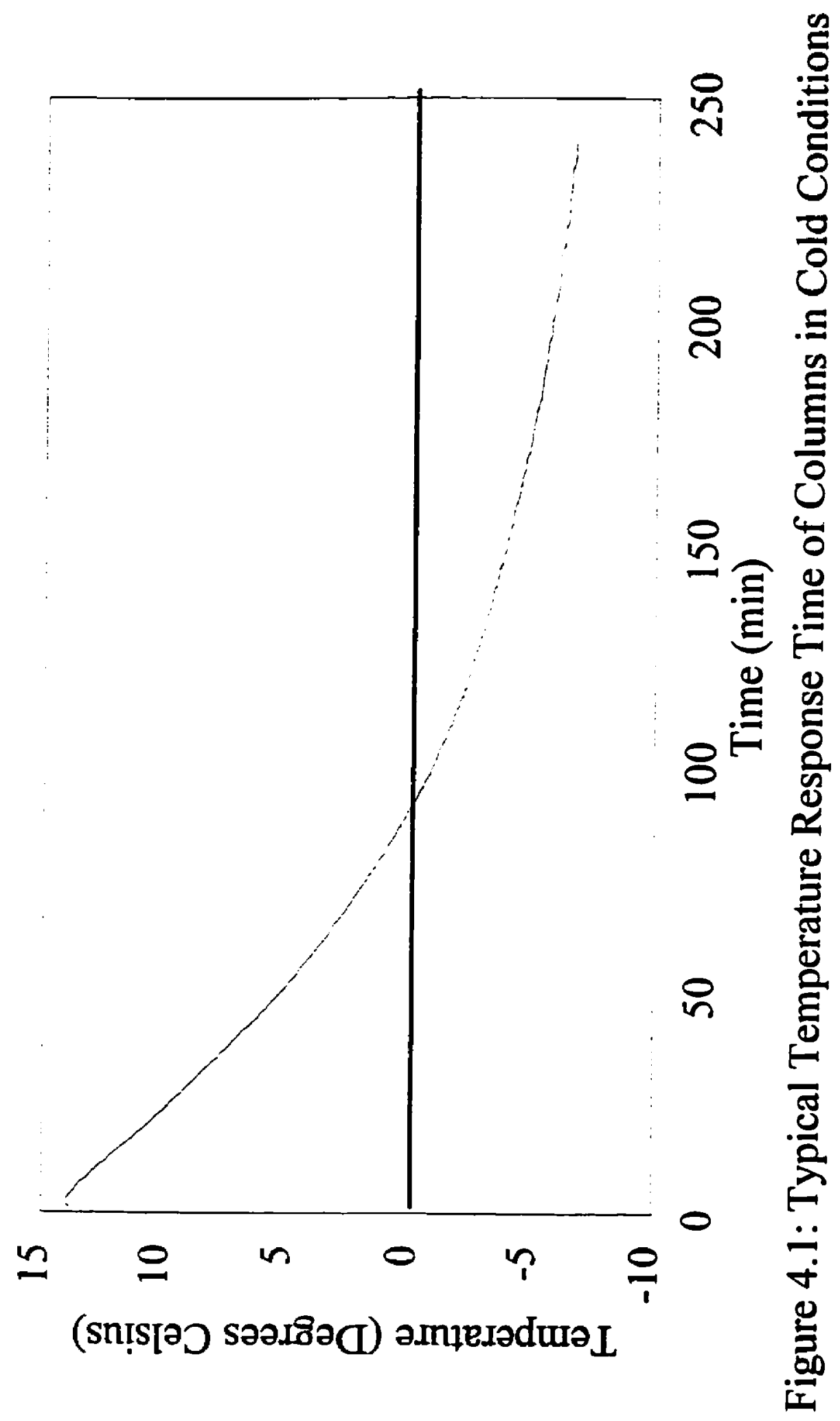


Table 4.4 Temperature Conditions

\begin{tabular}{cccc}
\hline \hline & $\begin{array}{c}\text { Cold } \\
\text { Conditions }\end{array}$ & $\begin{array}{c}\text { Frozen } \\
\text { Conditions }\end{array}$ & $\begin{array}{c}\text { Room } \\
\text { Temperature }\end{array}$ \\
\hline $\begin{array}{c}\text { Average } \\
\text { Temperature }\left({ }^{\circ} \mathrm{C}\right)\end{array}$ & -3.5 & -3.8 & 19 \\
$\begin{array}{c}\text { Marimum } \\
\text { Temperature }\left({ }^{\circ} \mathrm{C}\right)\end{array}$ & 4 & -0.5 & 21 \\
$\begin{array}{c}\text { Minimum } \\
\text { Temperature }\left({ }^{\circ} \mathrm{C}\right)\end{array}$ & -11 & -12.3 & 18 \\
\hline \hline
\end{tabular}




\subsection{Volatilization Experiments}

Again, complete component concentration data is not shown; rather, total gasoline and select component behaviour is illustrated. Full data sets are included in the Appendices, as described at the beginning of this chapter.

In order to simplify presentation of results, raw concentration data is not presented in this chapter; rather calculations have been performed on the raw concentration data in order to help explain the observed trends. As an example, total gasoline concentration data for a number of graphs has been normalized against the initial gasoline concentrations (C/Co). The rest of this Section describes the calculations used to create the graphs. For sample calculations relating to these graphs, see Appendix D.

Total gasoline and isopentane $\mathrm{C} / \mathrm{Co}$ versus time and depth of soil (Figures 4.2-4.5) trends were calculated by taking individual data points and dividing them by the component concentrations observed in the zero-hour columns at the same depth of soil. The zero-hour columns were used in these calculations because they were a more accurate reflection of the initial conditions, and considered such factors as handling losses and losses due to extraction efficiencies.

Hexadecane (Cl6), naphthalene and 1,3,5-trimethylbenzene ratios were obtained by taking the component concentration at the topmost slice of the column and dividing by the average concentration of the component in the column. Results were then plotted against time. For hexadecane, this parameter was called the $\mathrm{C} 16$ ratio. A naphthalene and 1,3,5trimethylbenzene plot is given in Figure 4.7. Hexadecane ratio plots are shown in Figures $4.6,4.10 \mathrm{a}, 4.13 \mathrm{a}, 4.16 \mathrm{a}, 4.19 \mathrm{a}$, and 4.22a. 
In order to better compare the effects of, for instance, water content and temperature on bulk gasoline movement, a second set of $\mathrm{Cl} 6$ graphs was created. These involved normalizing the $\mathrm{C} 16$ ratio for an experiment against the $\mathrm{Cl}$ ratio for a corresponding experiment that would isolate a parameter of interest. For example, to compare the effects of water content, $\mathrm{Cl} 6$ ratios for the $20 \%$ and $30 \%$ water content Windsor Clay Loam experiments were normalized against the air-dry experiment for the same soil at the same gasoline content. This was simply done by dividing the $\mathrm{Cl} 6$ ratios of the first two experiments against the $\mathrm{C} 16$ ratio of the air-dry experiment at every time point. The same normalizing experiment was used where the soil type was the same ie., wet Delhi Loamy Sand experiments were normalized against air-dry Delhi Loamy Sand experiments and cold Elora Silt Loam air-dry experiments were normalized against room temperature air-dry experiments. Figure $4.10 \mathrm{~b}$ normalizes room temperature air-dry experiments against Windsor Clay Loam (air-dry) at $14 \%$ gasoline; Figure 4.13b normalizes room temperature wet soils against the corresponding room temperature air-dry soils; Figure $4.16 \mathrm{~b}$ normalizes cold temperature wet soils against the corresponding cold temperature air-dry soils; Figure 4.19b normalizes cold temperature air-dry soils against the corresponding room temperature air-dry soils; and Figure $4.22 \mathrm{~b}$ normalizes cold temperature wet soils against the corresponding room temperature wet soils.

For total gasoline trends other than those presented in Figures 4.2-4.5, a similar normalization process to that used for hexadecane was used in order to isolate parameters of interest. Fractions of gasoline lost were determined by calculating 1-C/Co for any data point, with Co referring to the concentrations in the zero-hour columns. These values were 
then divided by the fractions of gasoline lost for the corresponding normalizing experiment. Figure 4.8 normalizes room temperature air-dry experiments against $14 \%$ gasoline Windsor Clay Loam (air-dry); Figure 4.11 normalizes room temperature wet soils against the corresponding room temperature air-dry soils; Figure 4.14 normalizes cold temperature wet soils against the corresponding cold temperature air-dry soils; Figure 4.17 normalizes cold temperature air-dry soils against the corresponding room temperature air-dry soils; and Figure 4.20 normalizes cold temperature wet soils against the corresponding room temperature wet soils.

Isopentane $\mathrm{C} / \mathrm{Co}$ graphs were created by dividing the average column isopentane concentration by the average isopentane concentration in the corresponding zero-hour columns. Results were plotted against time, and are shown in Figures 4.9a, 4.12a, 4.15a, 4.18a, and 4.21a. A normalized set of isopentane graphs was also created, in order to better isolate important parameters. Figure $4.9 \mathrm{~b}$ normalizes room temperature air-dry experiments against $14 \%$ gasoline Windsor Clay Loam (air-dry); Figure $4.12 \mathrm{~b}$ normalizes room temperature wet soils against the corresponding room temperature air-dry soils; Figure 4.15b normalizes cold temperature wet soils against the corresponding cold temperature air-dry soils; Figure 4.18b normalizes cold temperature air-dry soils against the corresponding room temperature air-dry soils; and Figure $4.21 \mathrm{~b}$ normalizes cold temperature wet soils against the corresponding room temperature wet soils.

A further set of data, obtained by Rogaz and Hussain (1994), was used in comparison with the results of this thesis. This data was obtained using the same acrylic columns and synthetic gasoline blend, and the 4-lift method of column construction. In total, four room 
temperature experiments were used. These included Elora Silt Loam at 19\% gasoline (airdry) and Delhi Loamy Sand at $14 \%$ gasoline (air-dry). Two wet experiments were also used, including Elora Silt Loam at 13\% gasoline-8\% water and Delhi Loamy Sand at 10\% gasoline-5\% water. This data is included in Figures 4.8-4.13 and Figures 4.18-4.22 for comparison purposes.

Table 4.5 shows the notation used to simplify discussion of the volatilization experiments. This notation is intended to ease identification of the exact conditions used in any experiment without fully expressing these conditions. It will be used in the graphical presentation of the results as well as in the discussion of the results. 
Table 4.5 Notation for Volatilization Experiments

\begin{tabular}{ccccc}
\hline \hline Soil Type & $\begin{array}{c}\text { Gasoline } \% \\
\text { (by weight) }\end{array}$ & $\begin{array}{c}\text { Water } \% \\
\text { (by weight) }\end{array}$ & $\begin{array}{c}\text { Temperature } \\
\text { Conditions }\end{array}$ & Notation \\
\hline ESL & 17.5 & 3.5 (air-dry) & Cold & ESL17.5G-AD-C \\
ESL & 13 & 8 & Cold & ESL13G-8W-C \\
DLS & 14.5 & 0.5 (air-dry) & Cold & DLS14.5G-AD-C \\
DLS & 10 & 5 & Cold & DLS10G-5W-C \\
WCL & 14 & 5 (air-dry) & Room & WCL14G-AD-R \\
WCL & 5 & 5 (air-dry) & Room & WCL5G-AD-R \\
WCL & 5 & 20 & Room & WCL5G-20W-R \\
WCL & 5 & 30 & Room & WCL5G-30W-R \\
WCL & 5 & 5 (air-dry) & Frozen & WCL5G-AD-F \\
WCL & 5 & 20 & Frozen & WCL5G-20W-F \\
WCL & 5 & 30 & Frozen & WCL5G-30W-F \\
\hline \hline
\end{tabular}




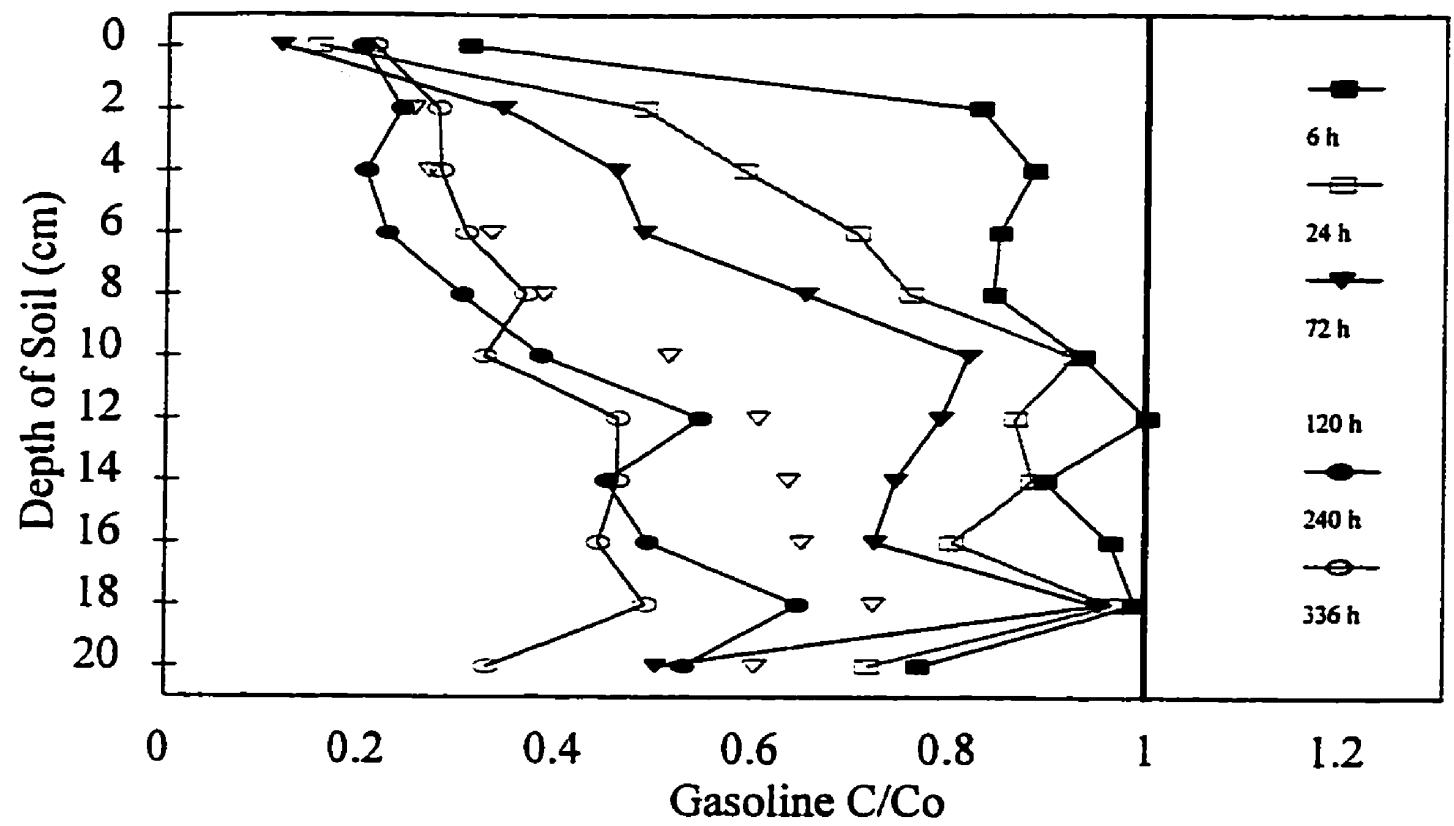

Figure 4.2: Total Gasoline C/Co in WCL-5G-AD-R

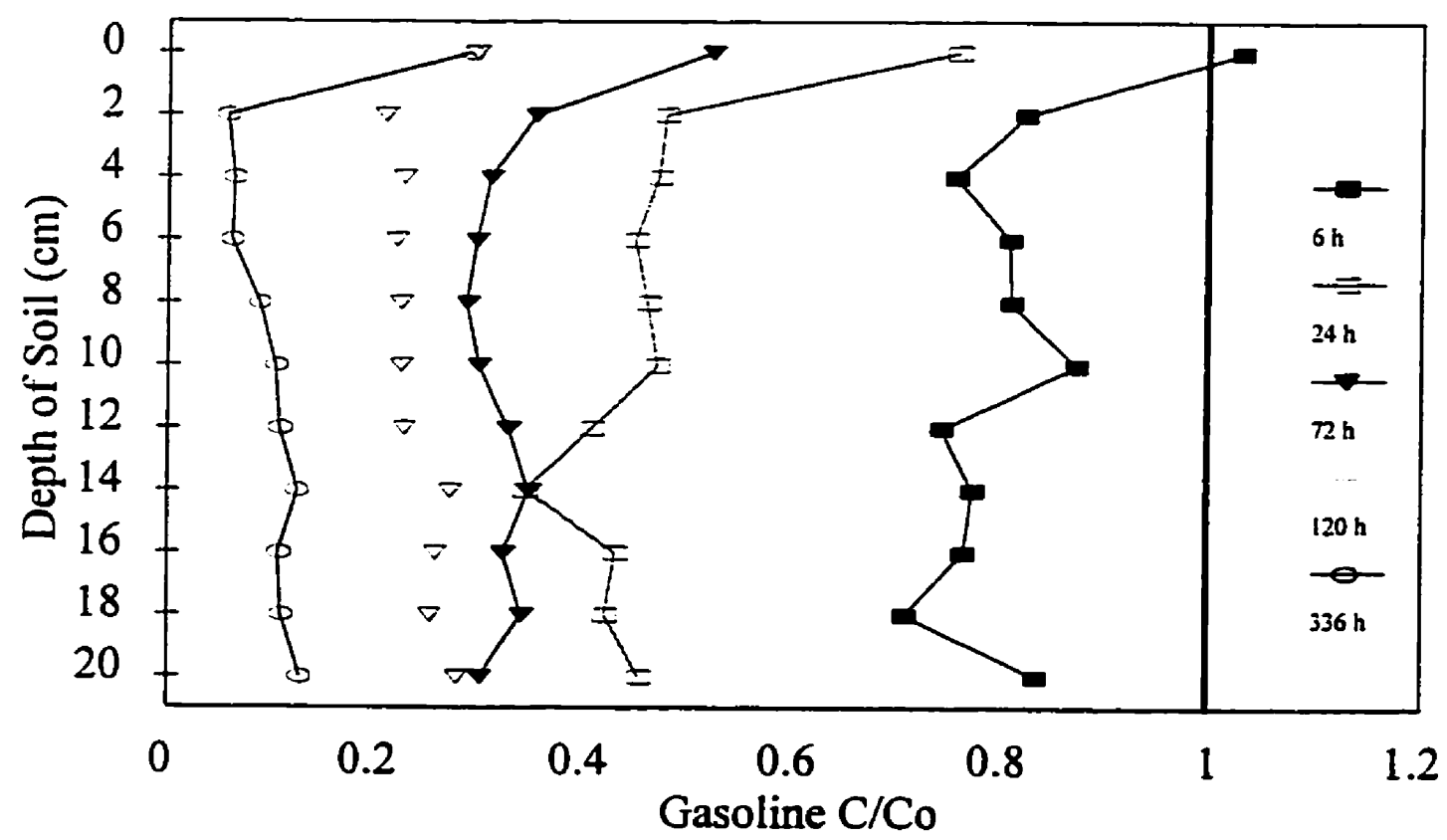

Figure 4.3: Total Gasoline C/Co in WCL-14G-AD-R 


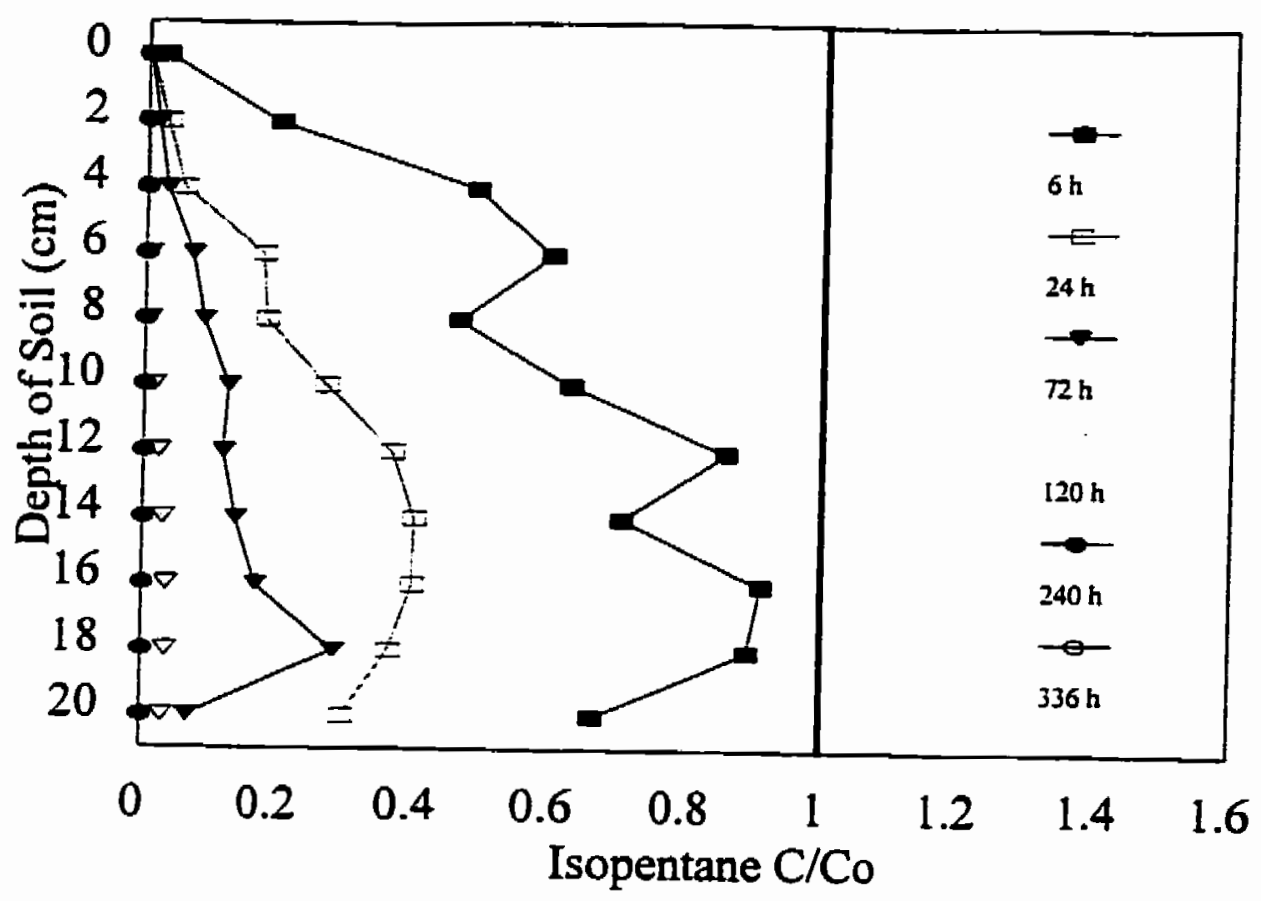

Figure 4.4: Isopentane C/Co in WCL-5G-AD-R

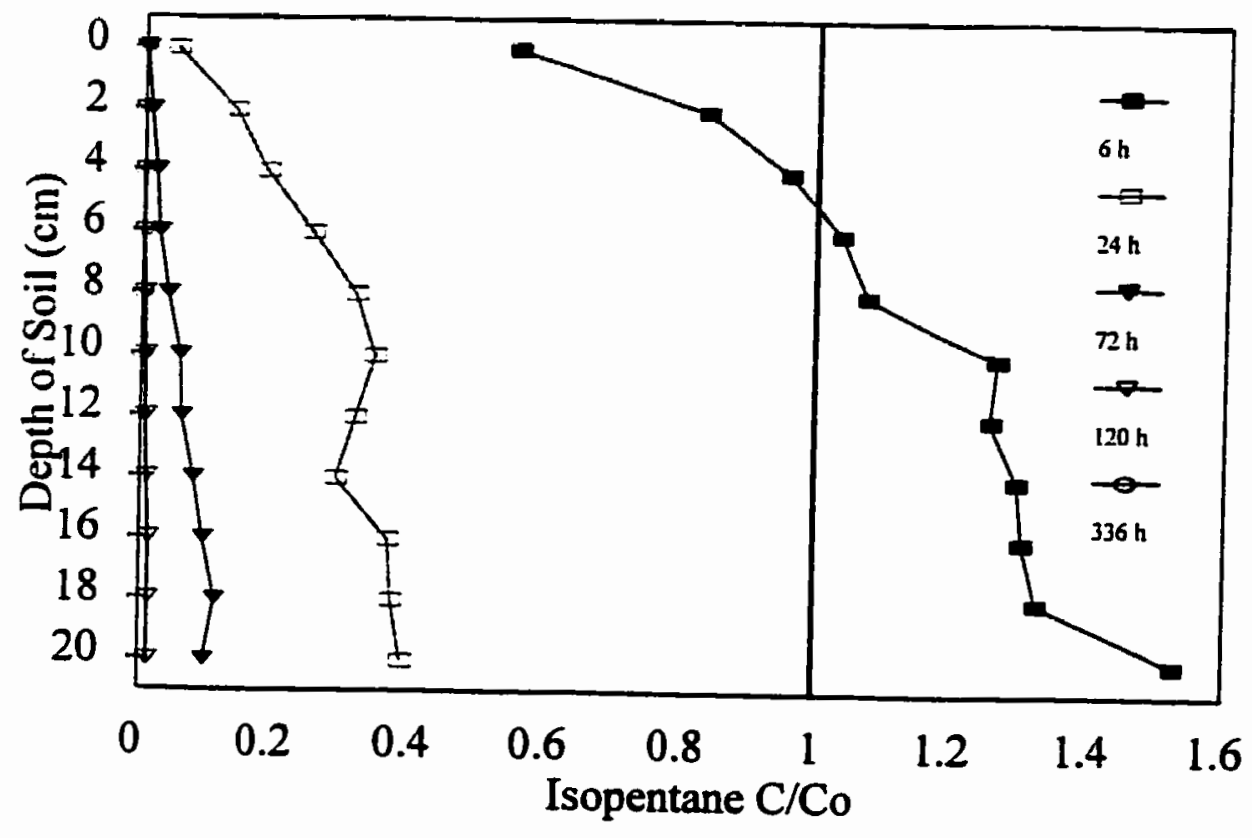

Figure 4.5: Isopentane C/Co in WCL-14G-AD-R 


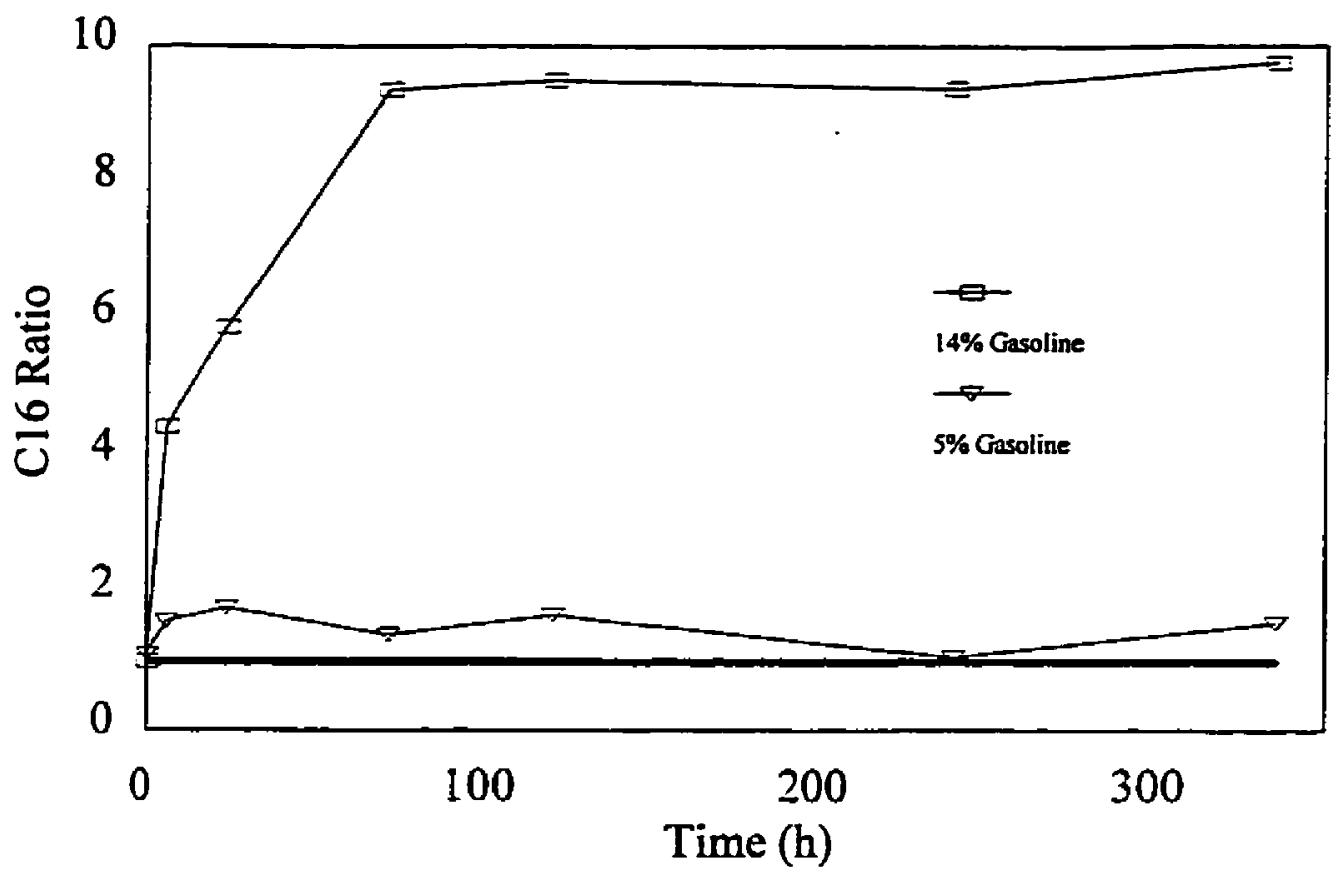

Figure 4.6: Cl6 Ratio for Air-Dry WCL (Room)

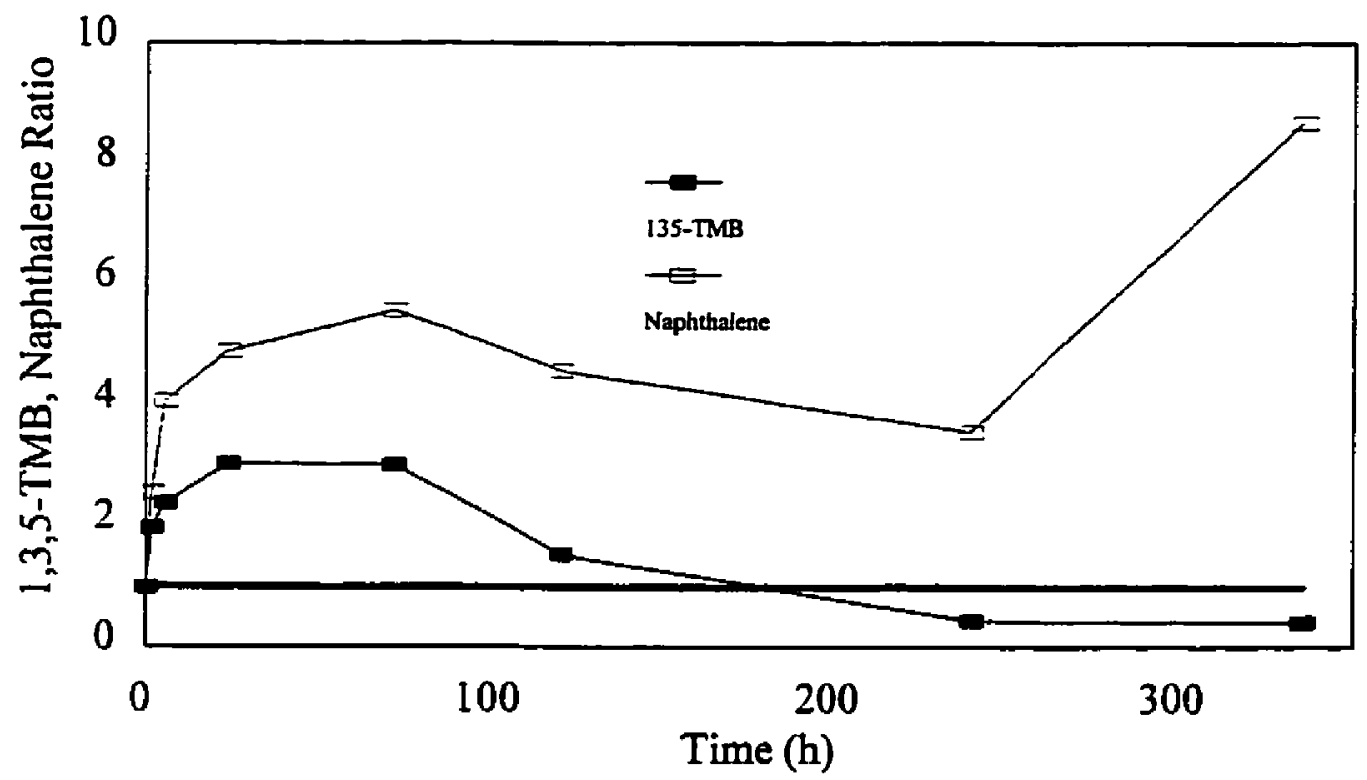

Figure 4.7: 1,3,5-Trimethylbenzene and Naphthalene Ratios in WCL-14G-AD-R 


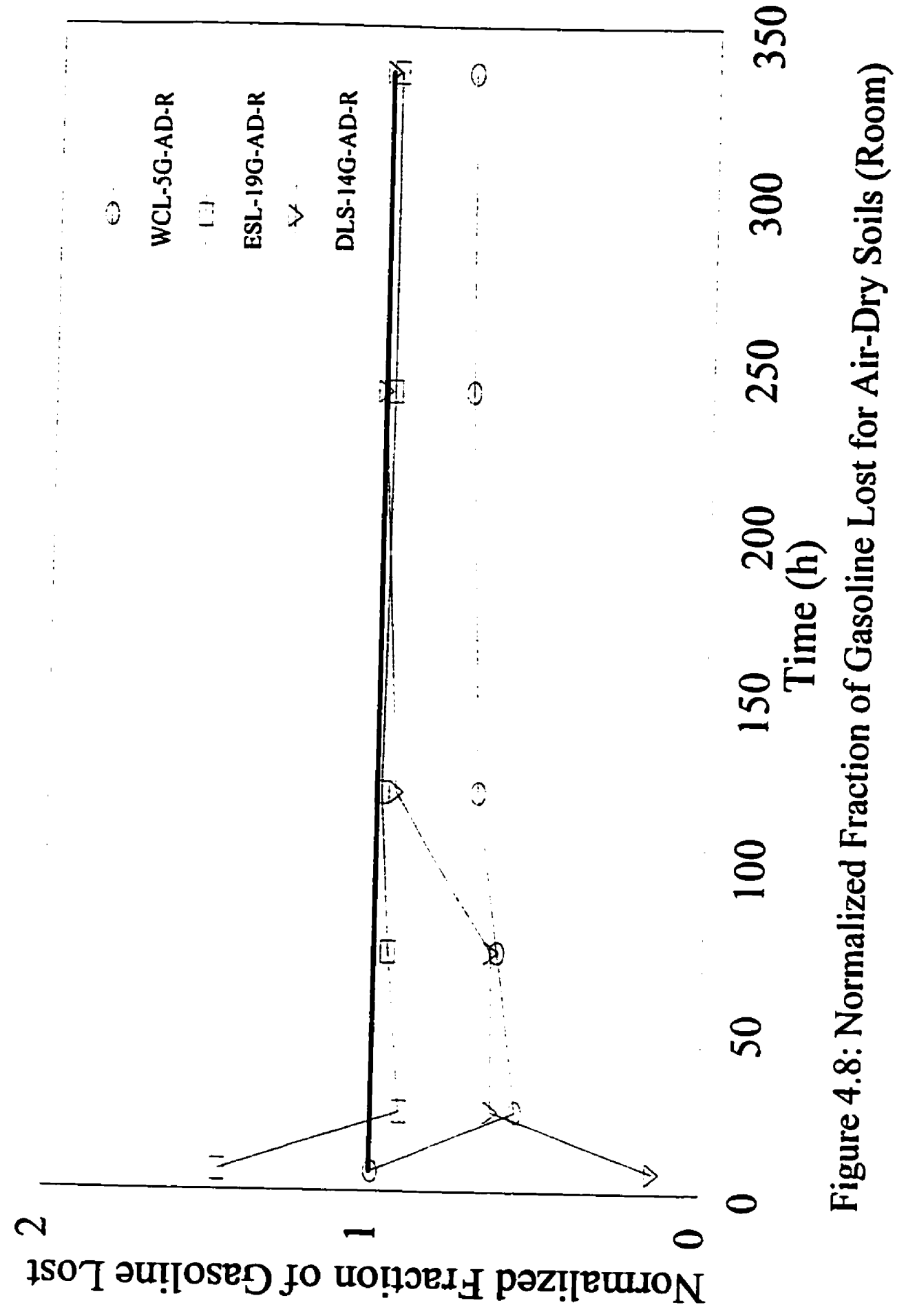




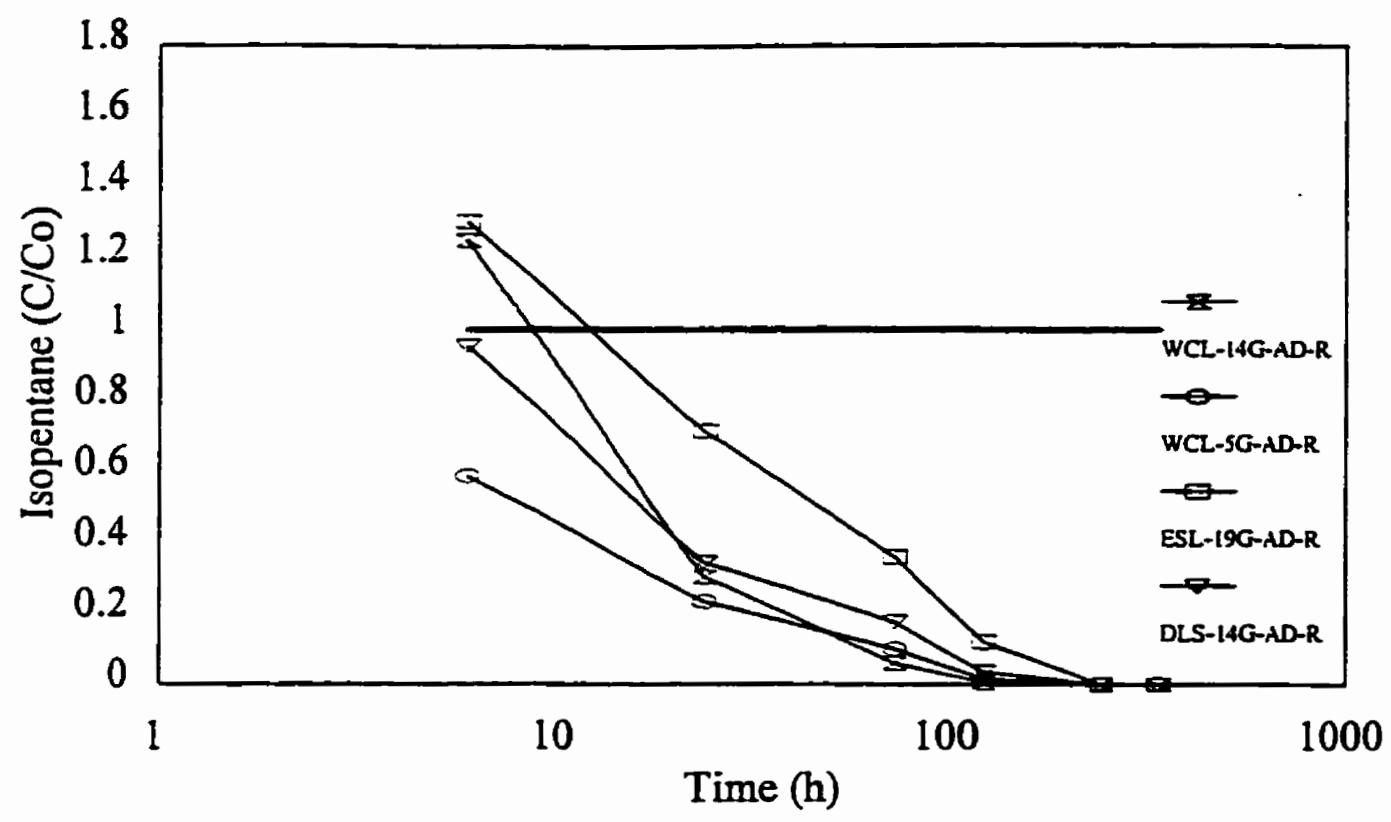

Figure 4.9a: Isopentane C/Co for Air-Dry Soils (Room)

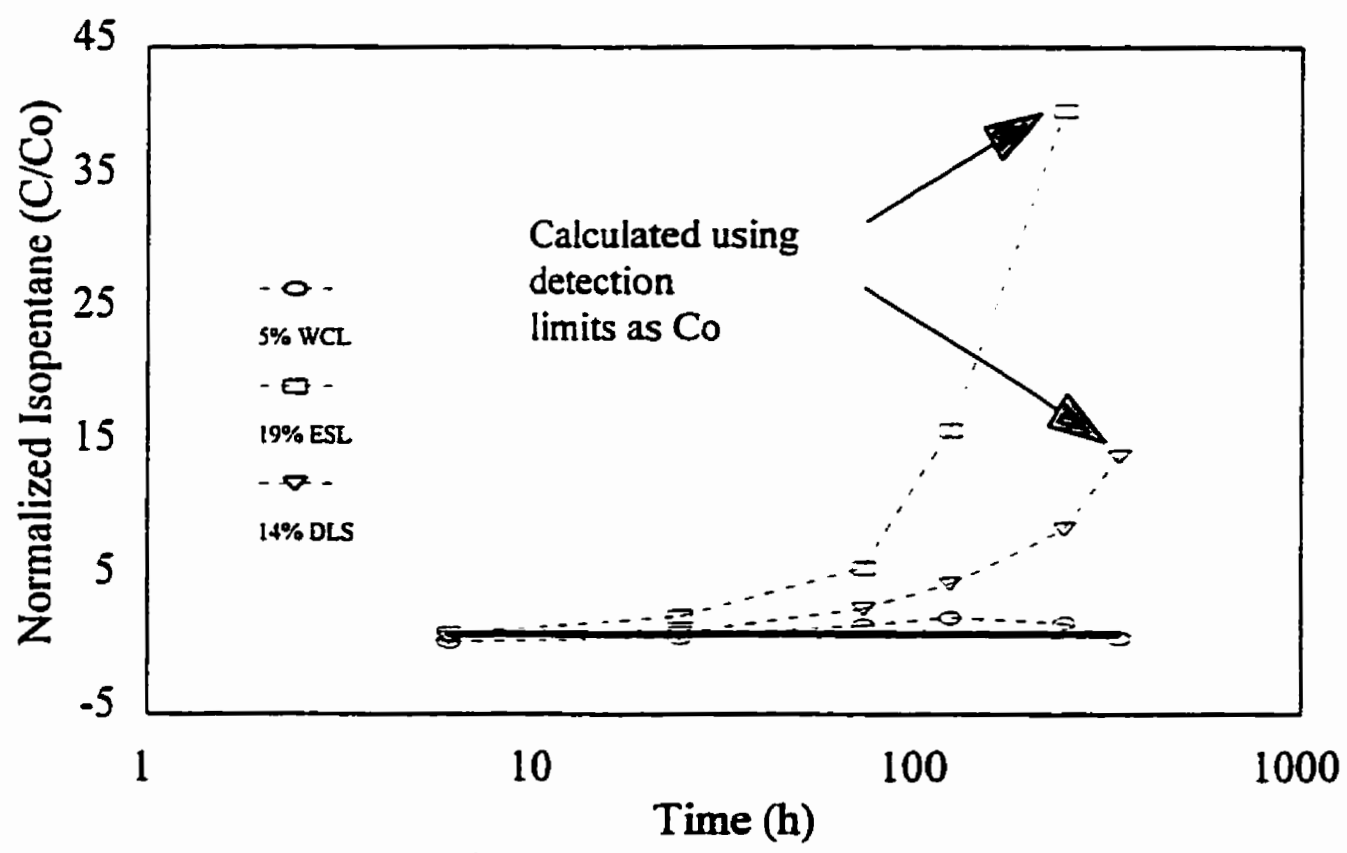

Figure 4.9b: Normalized Isopentane C/Co for Air-Dry Soils (Room) 


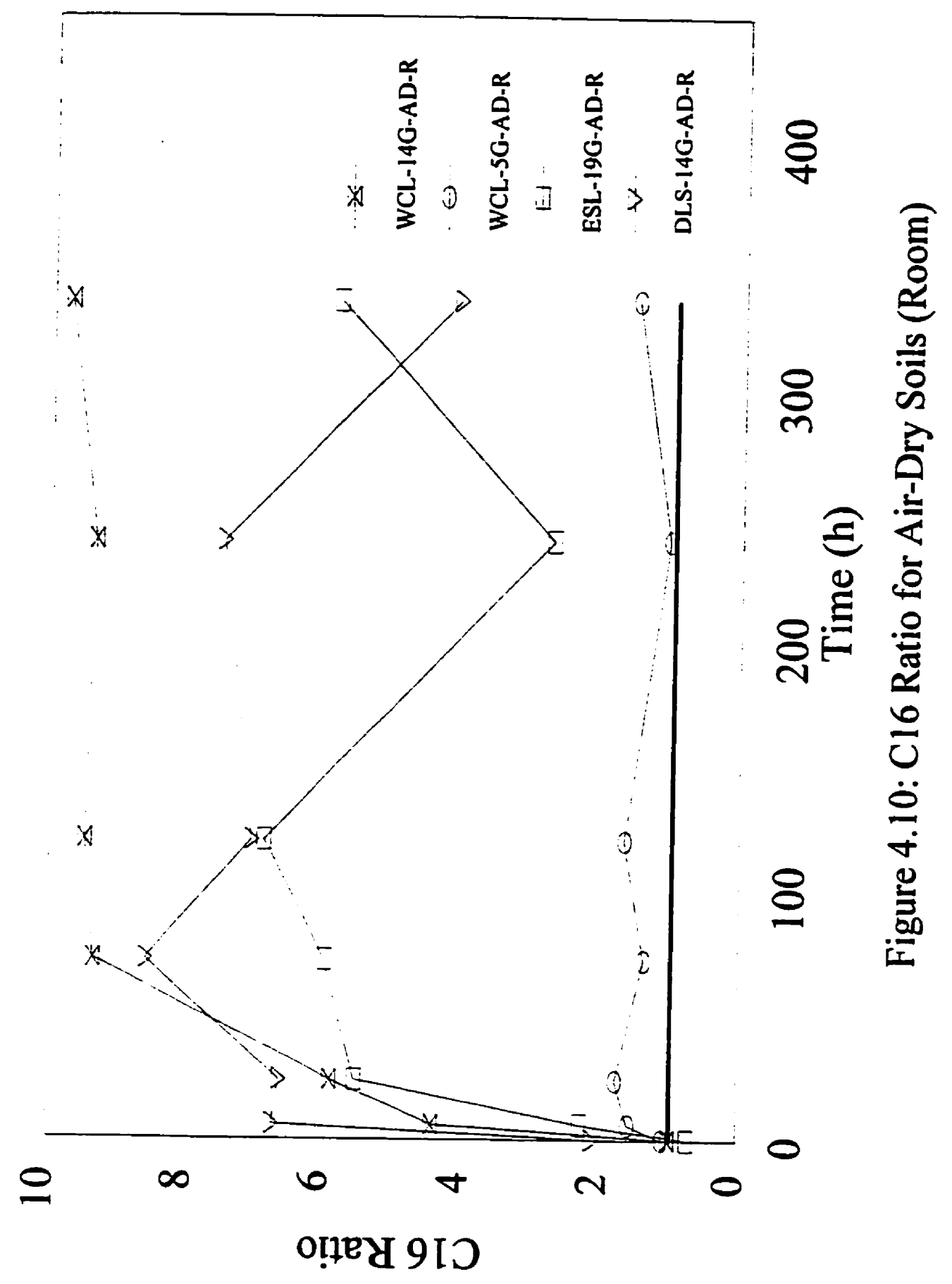




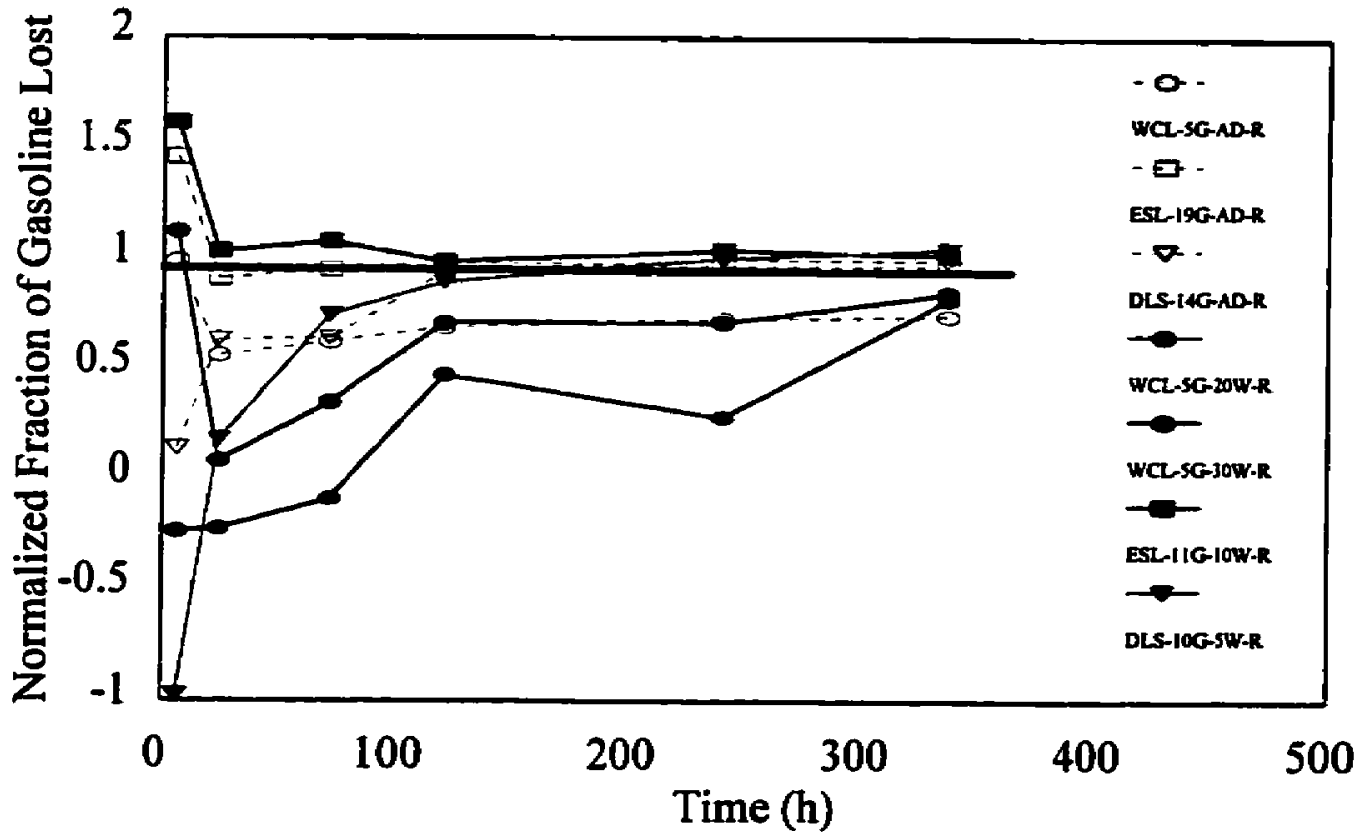

Figure 4.I la: Normalized Fraction of Gasoline Lost for Air-Dry and Wet Soils (Room)

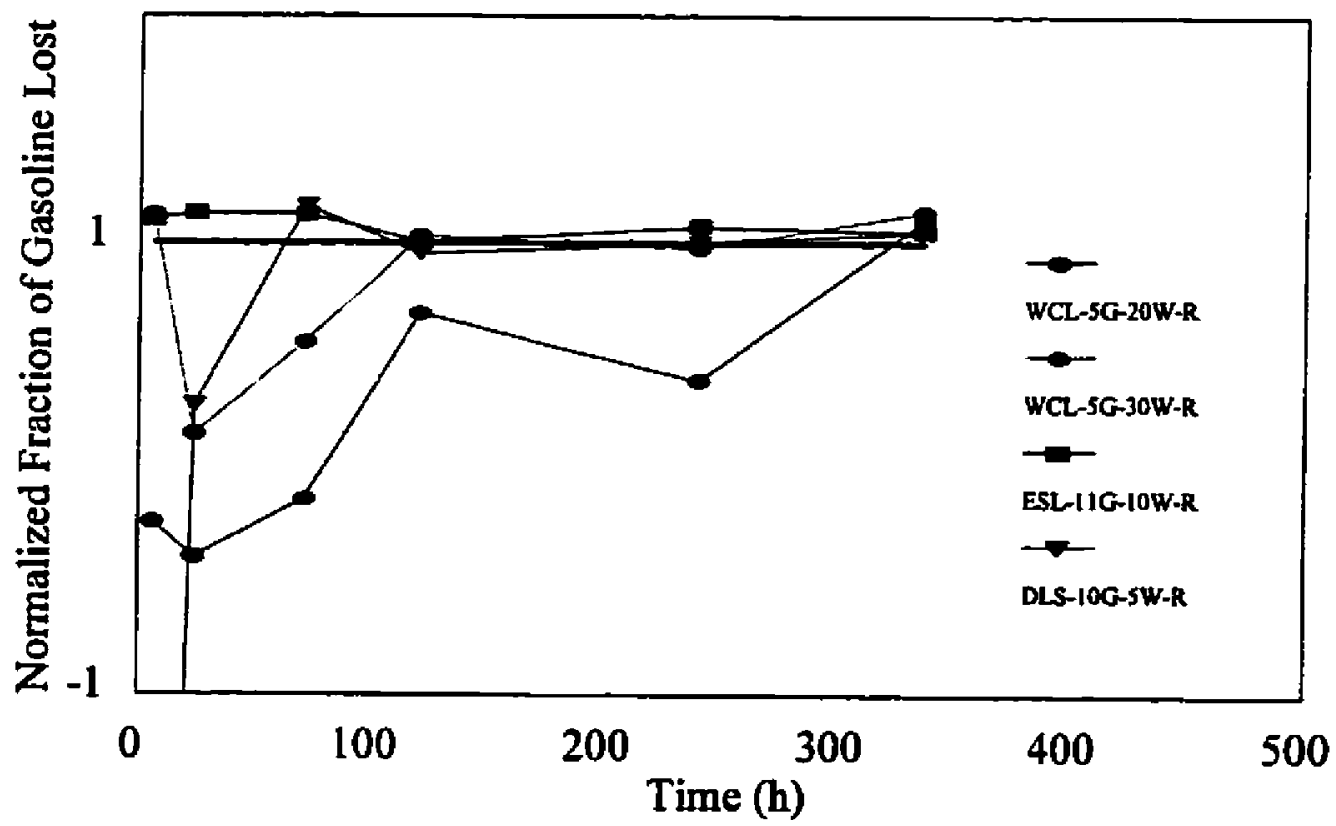

Figure 4.1 l b: Normalized C/Co for Wet Soils (Room) 


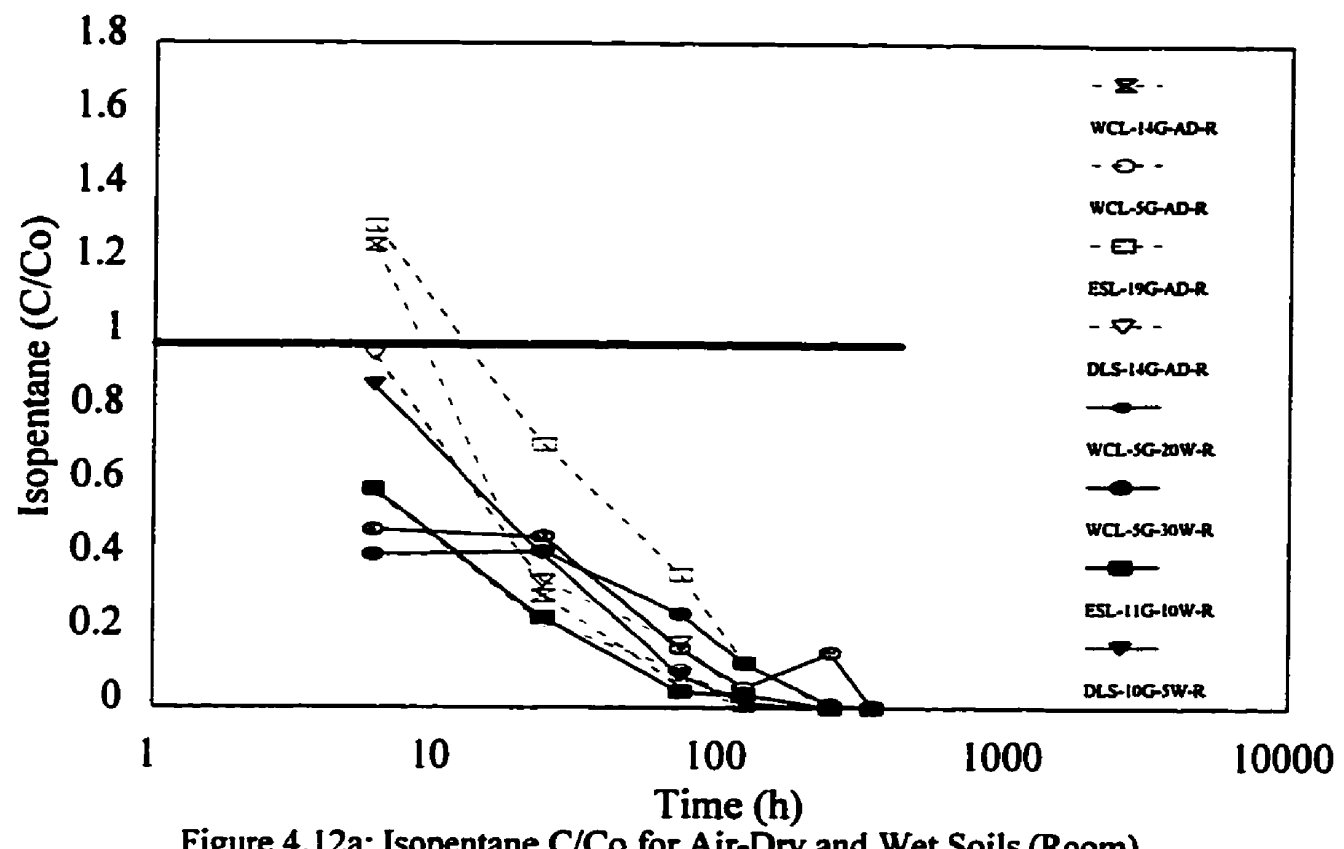

Figure 4.12a: Isopentane C/Co for Air-Dry and Wet Soils (Room)

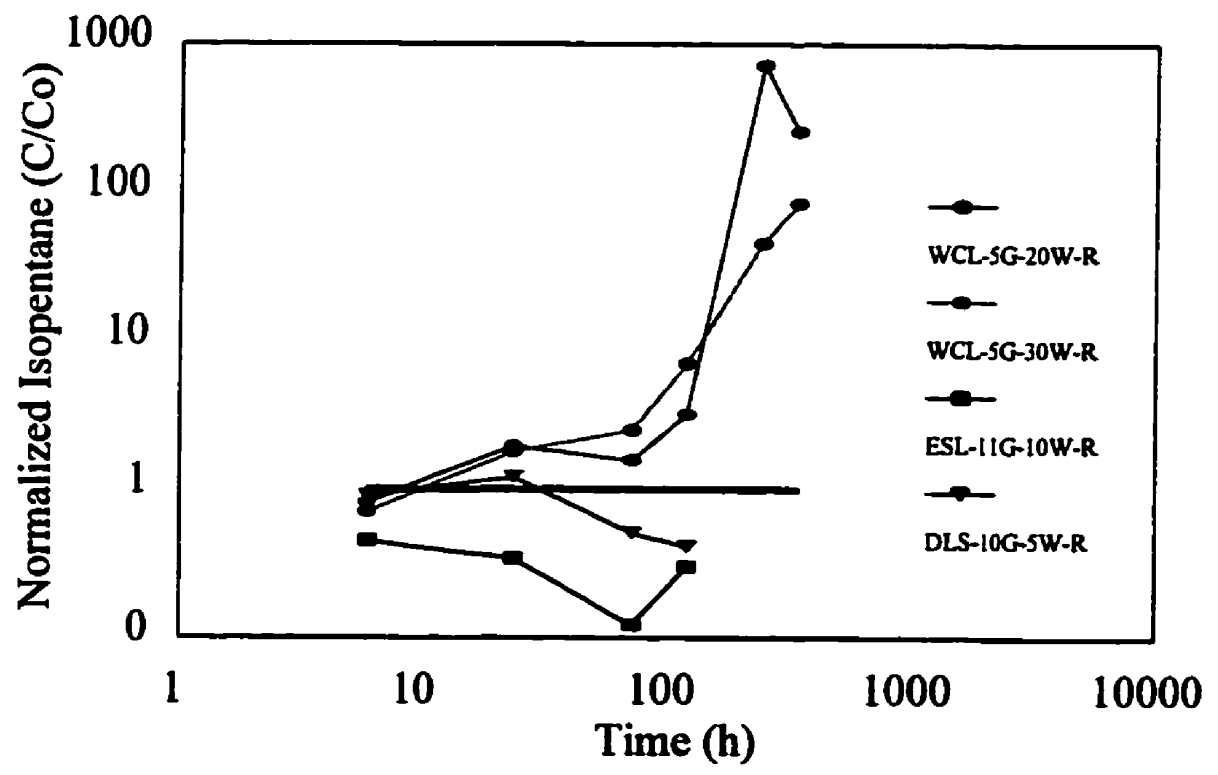

Figure 4.12b: Normalized Isopentane C/Co for Wet Soils (Room) 


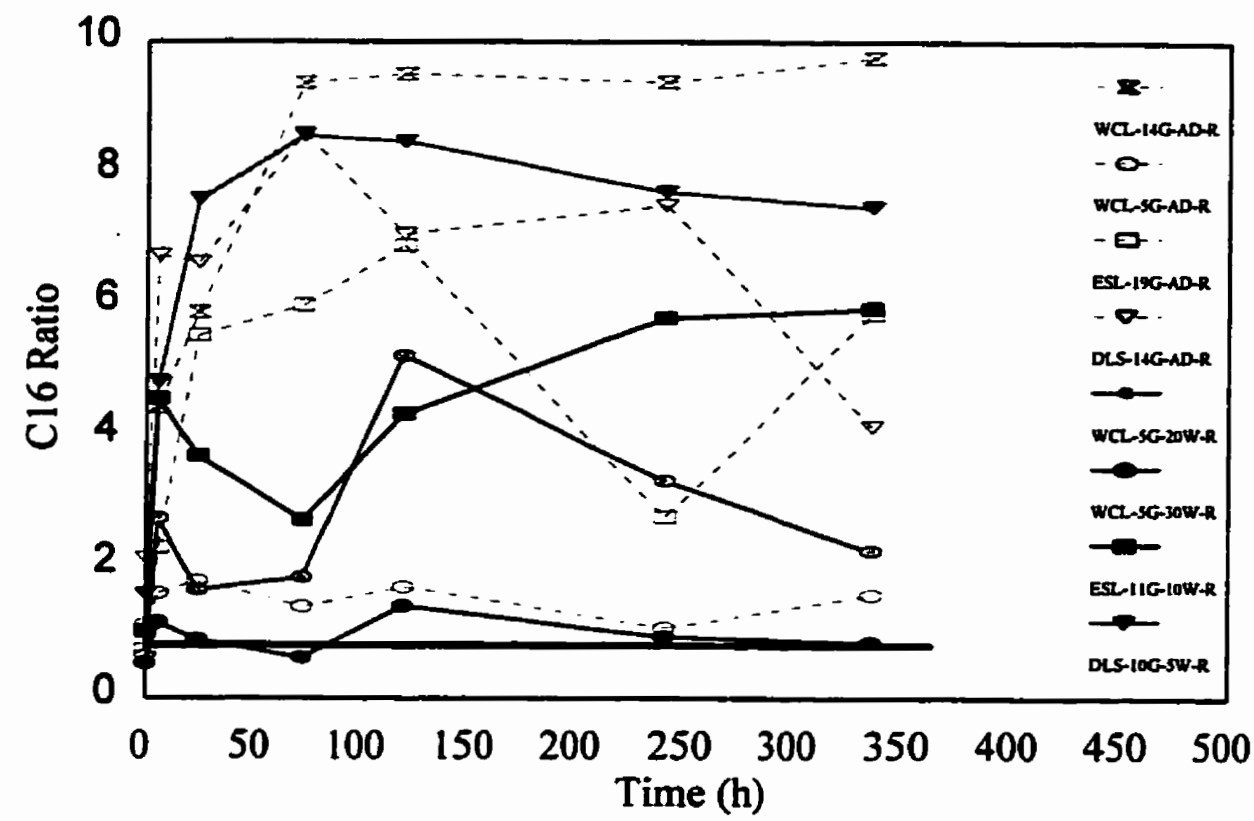

Figure 4.13a: C16 Ratio for Air-Dry and Wet Soils (Room)

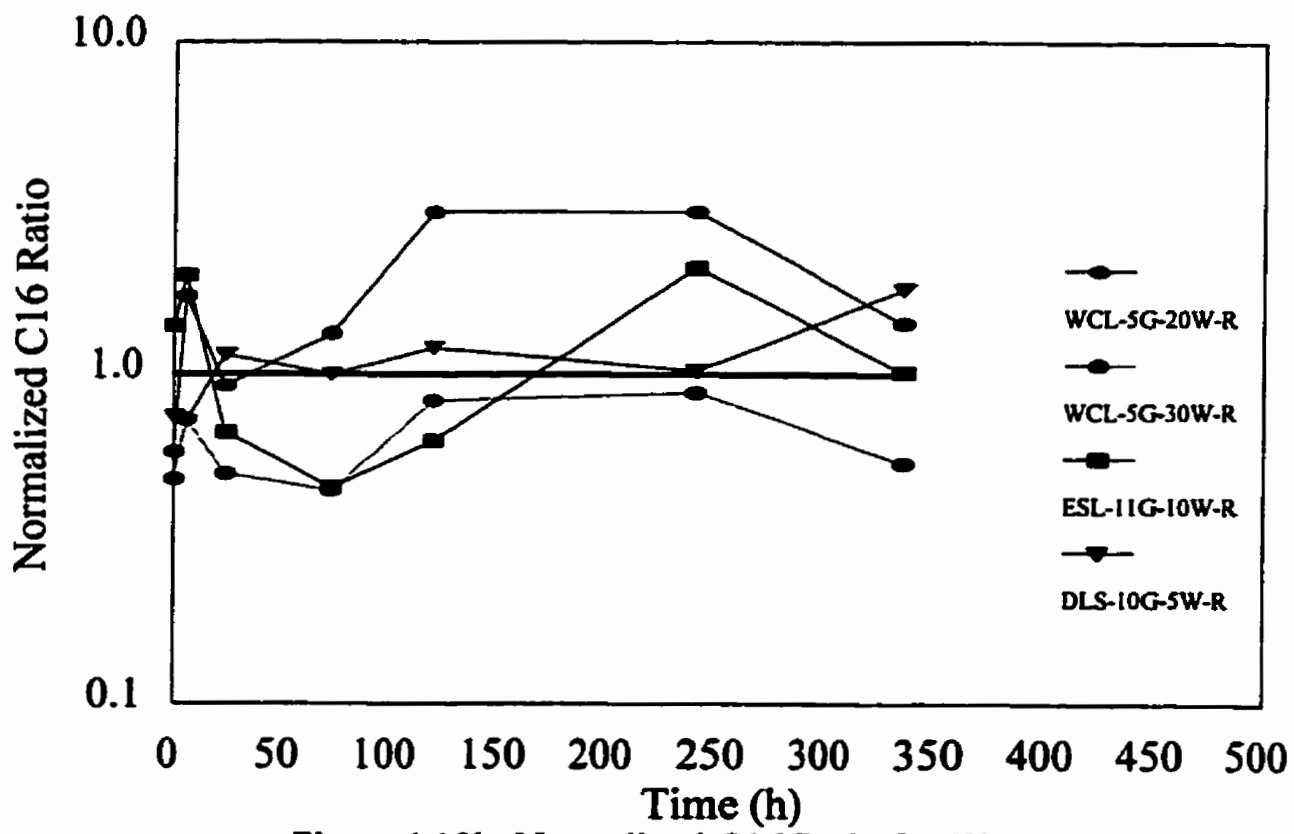

Figure 4.13b: Normalized C16 Ratio for Wet Soils (Room) 


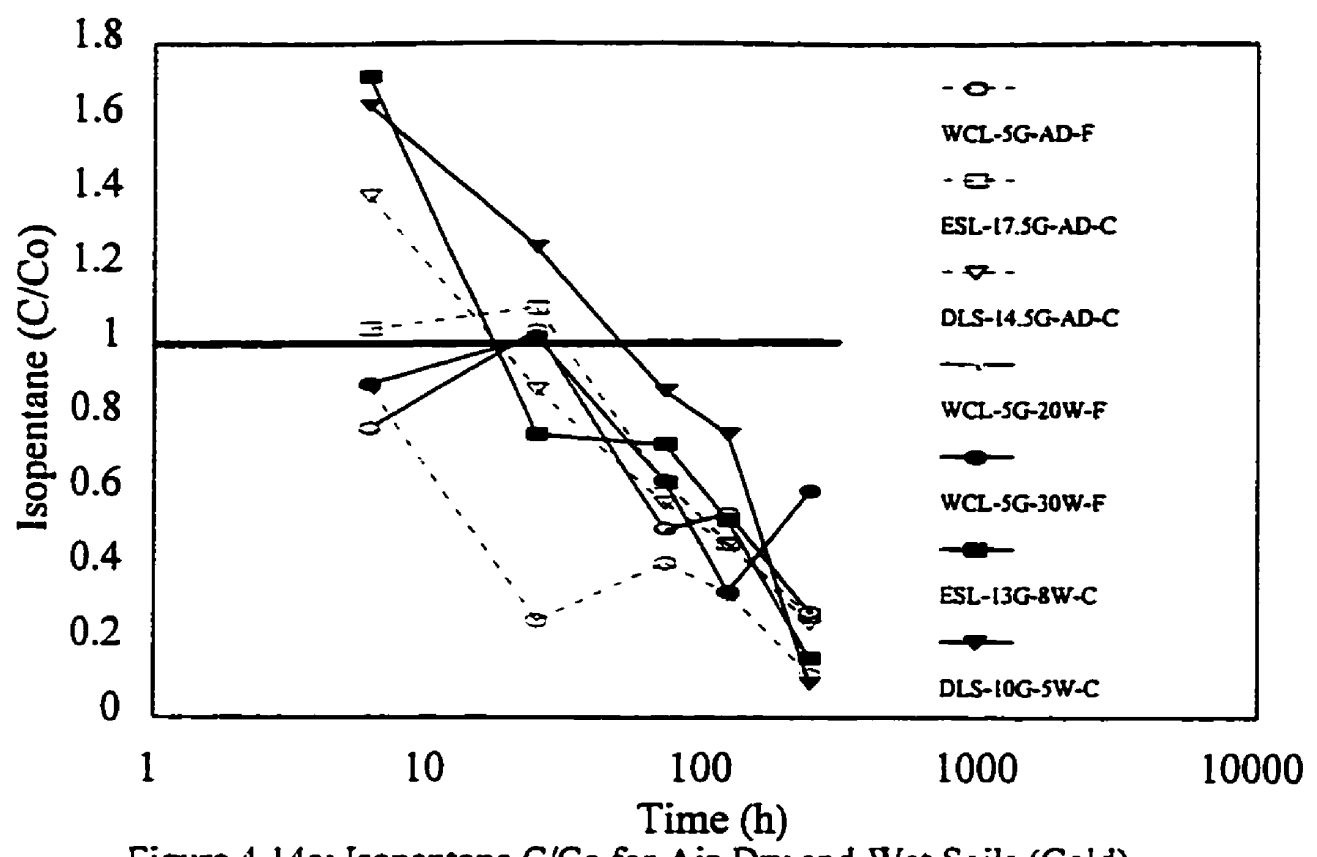

Figure 4.14a: Isopentane C/Co for Air-Dry and Wet Soils (Cold)

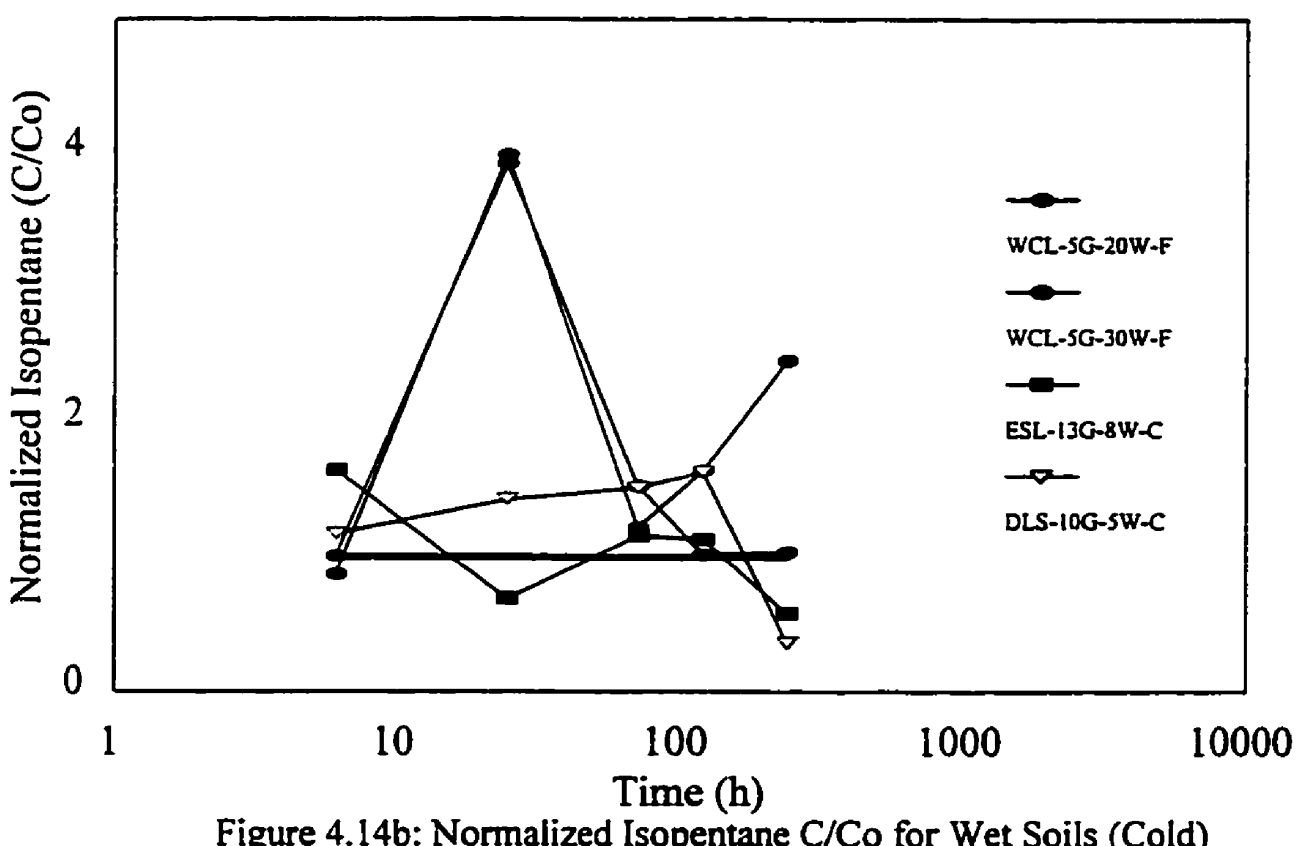

Figure 4.14b: Normalized Isopentane C/Co for Wet Soils (Cold) 


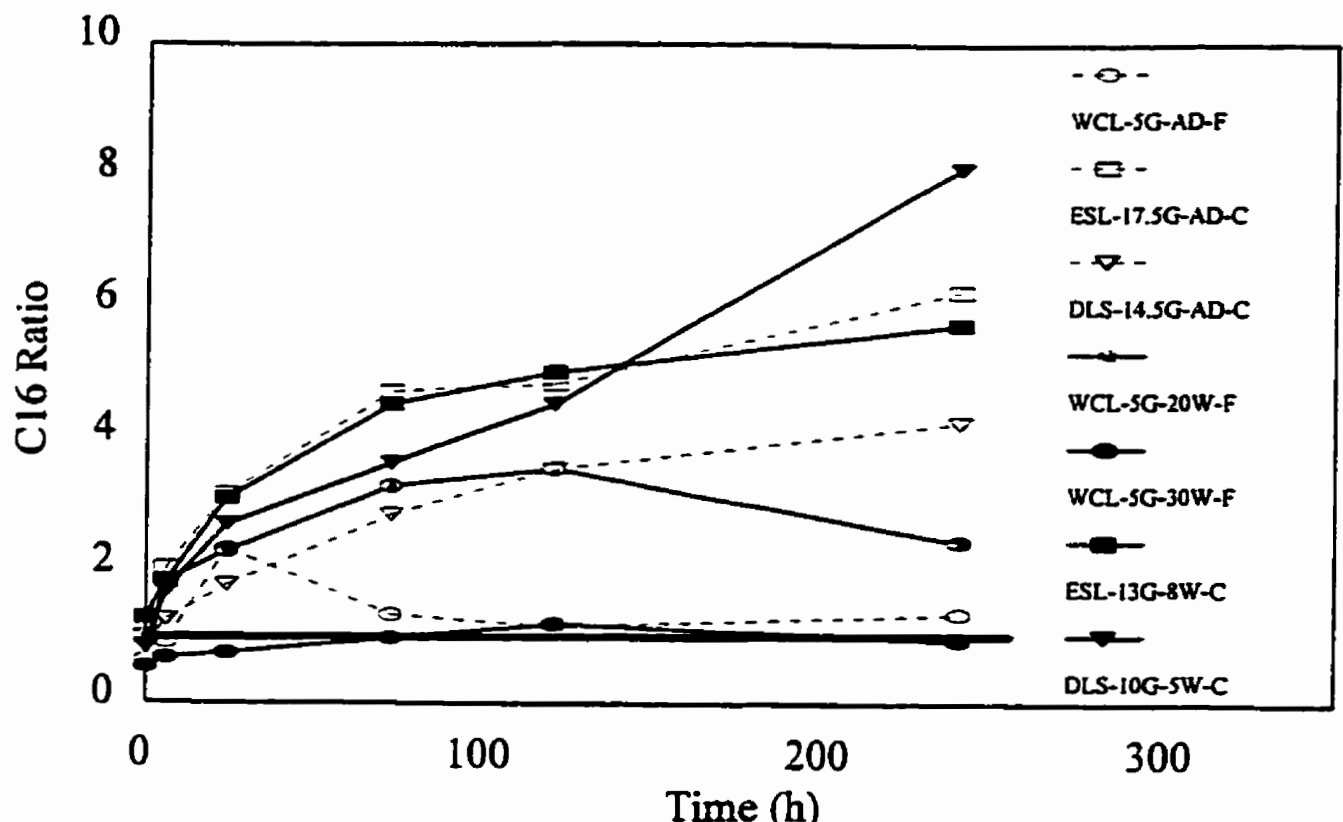

Figure 4.15a: C16 Ratio for Air-Dry and Wet Soils (Cold)

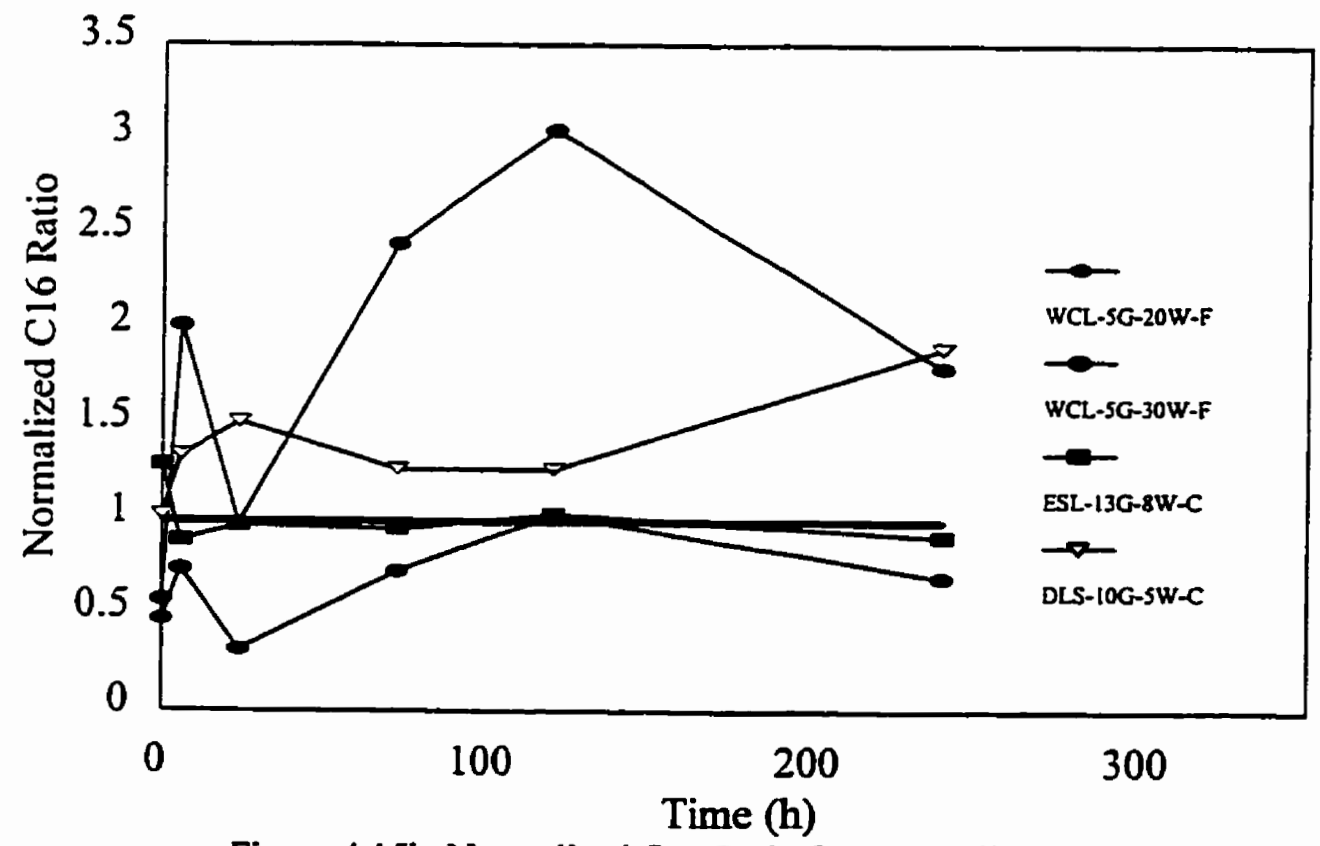

Figure 4.15b: Normalized C16 Ratio for Wet Soils (Cold) 


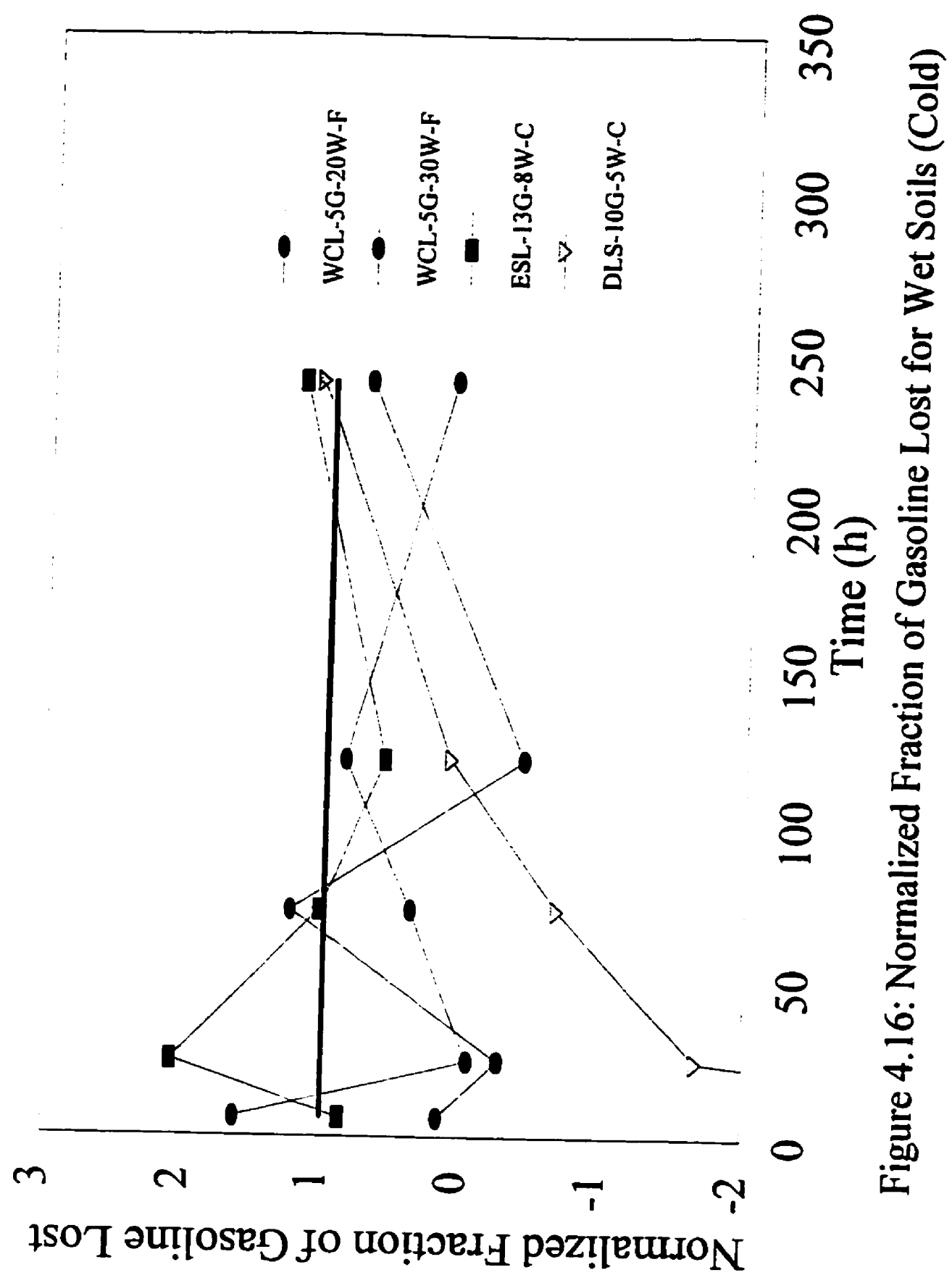




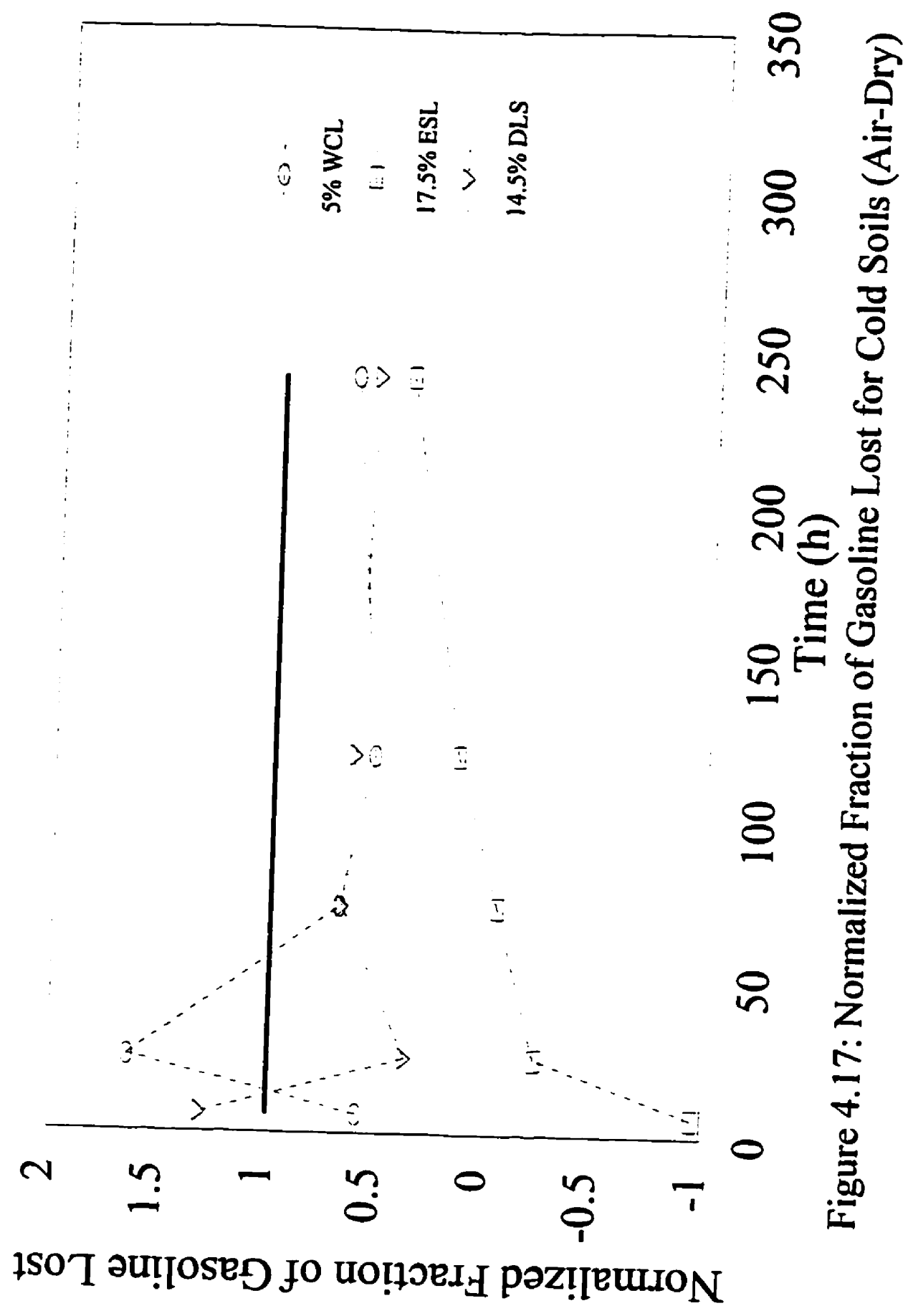




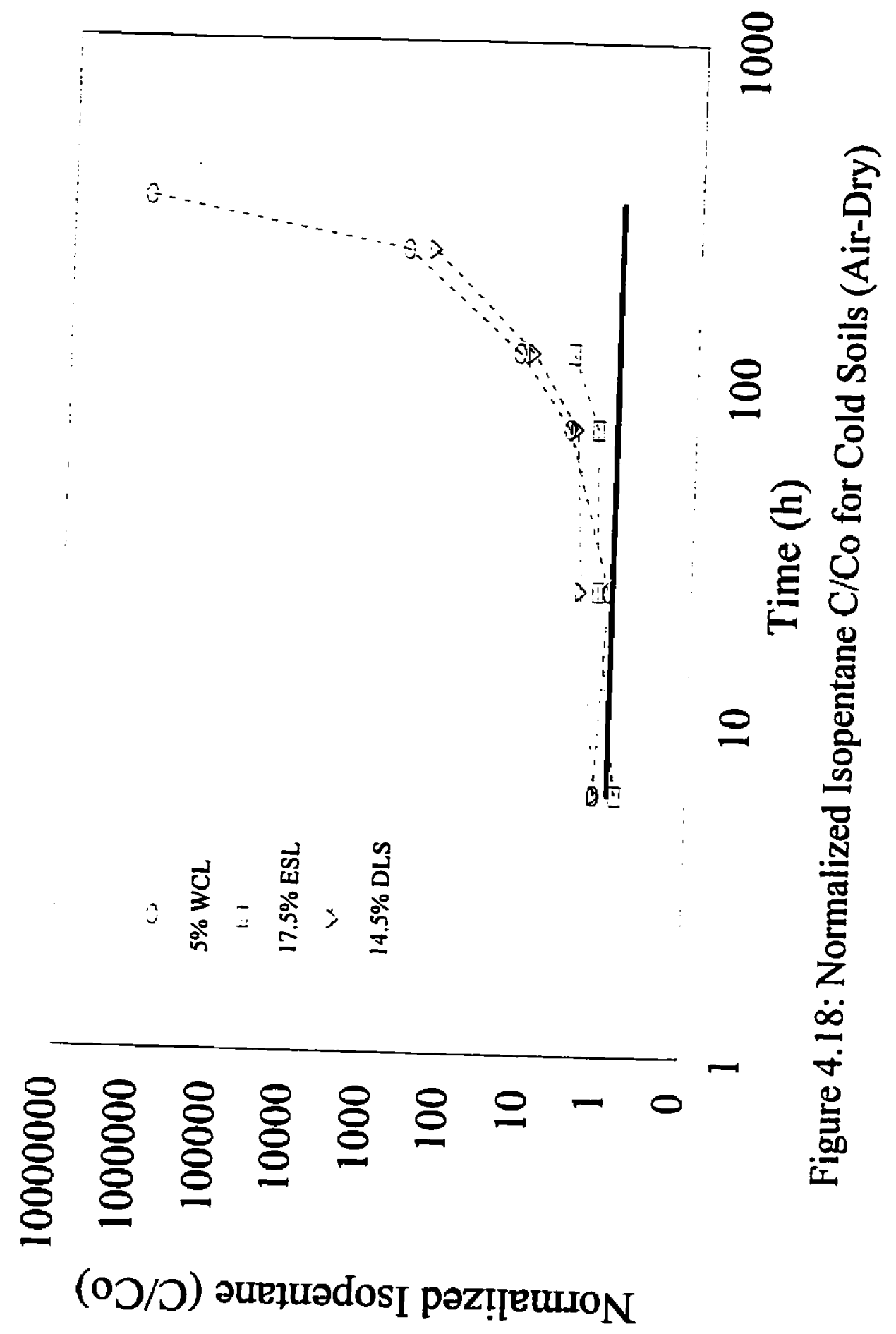




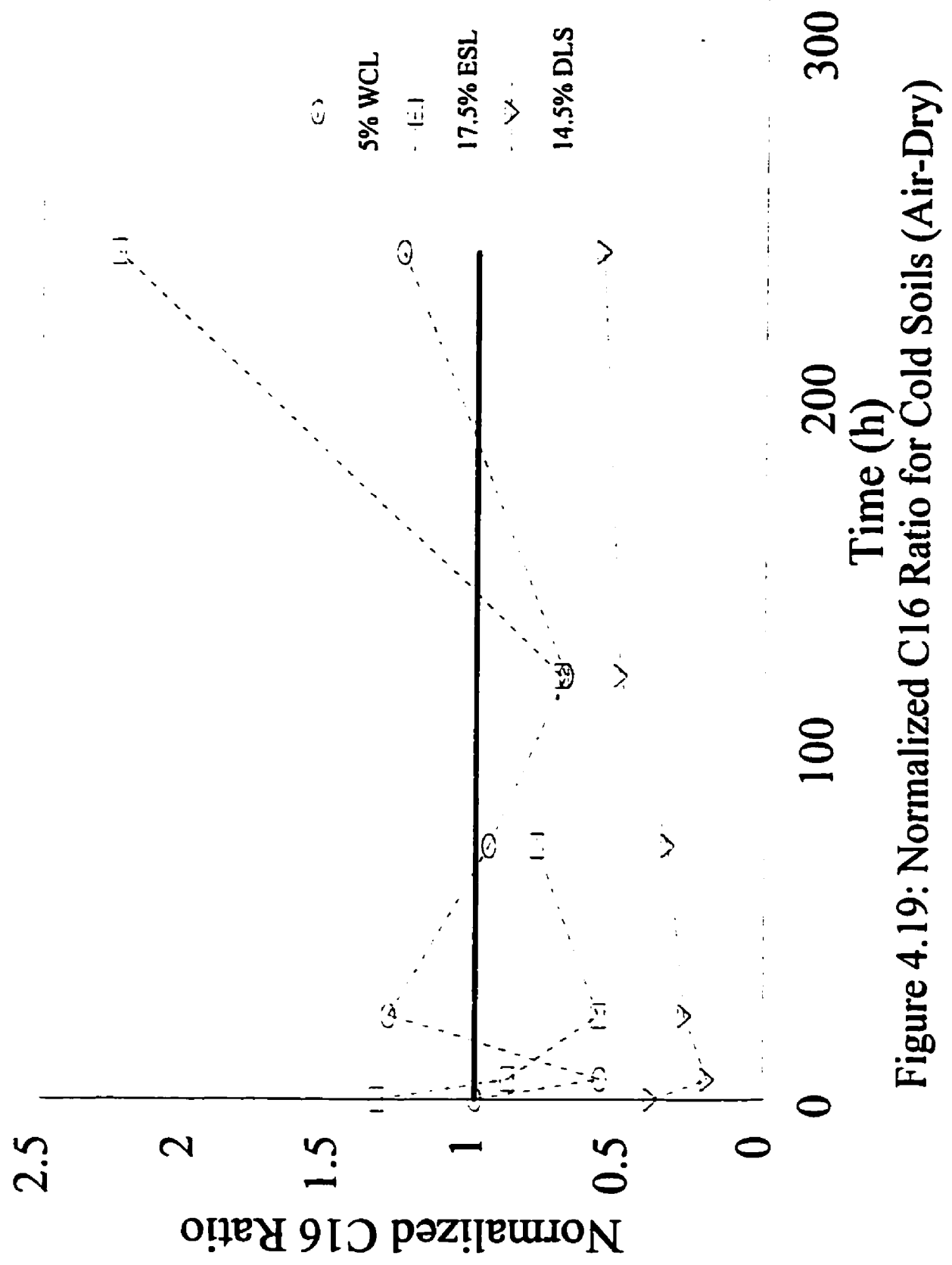




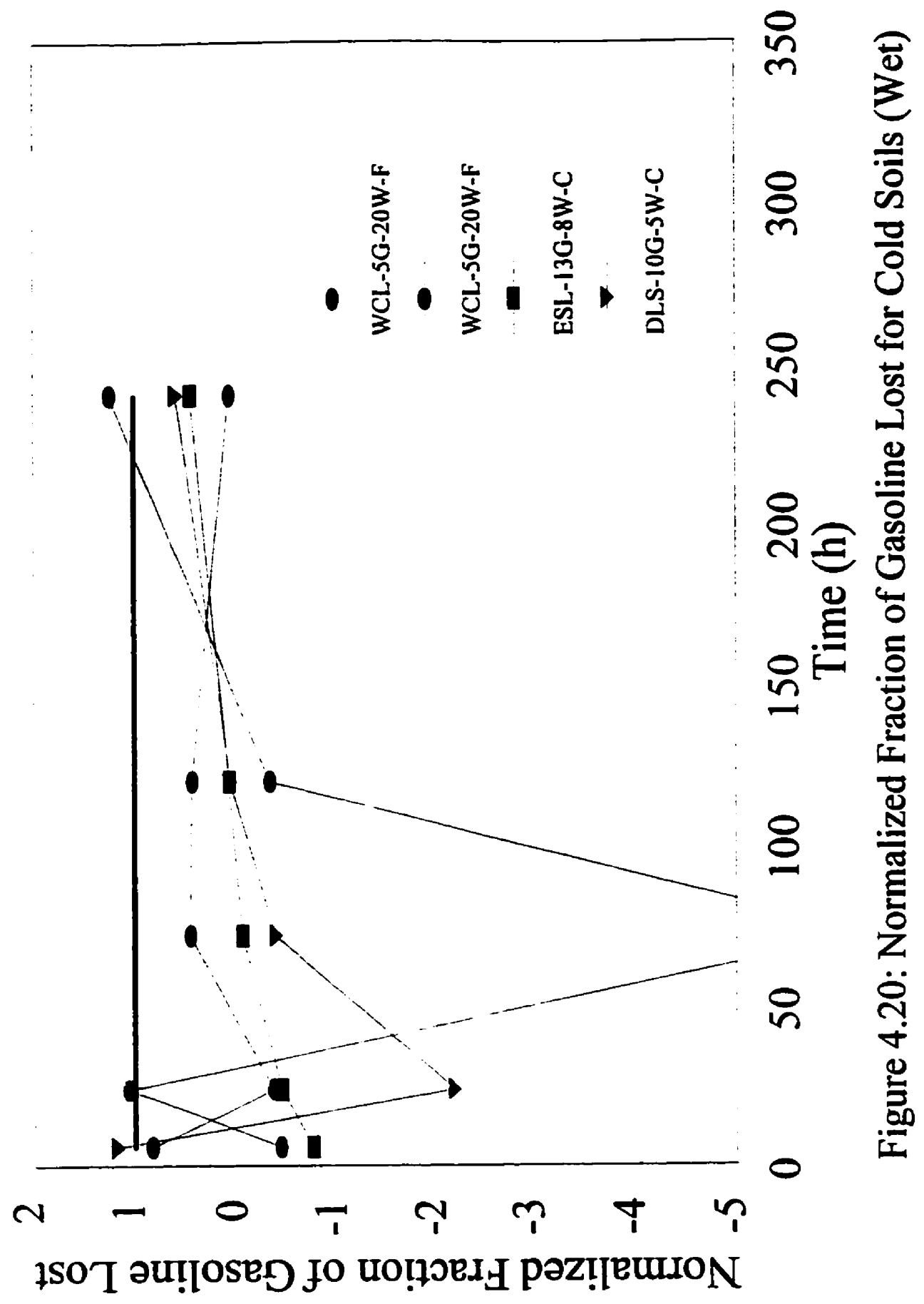




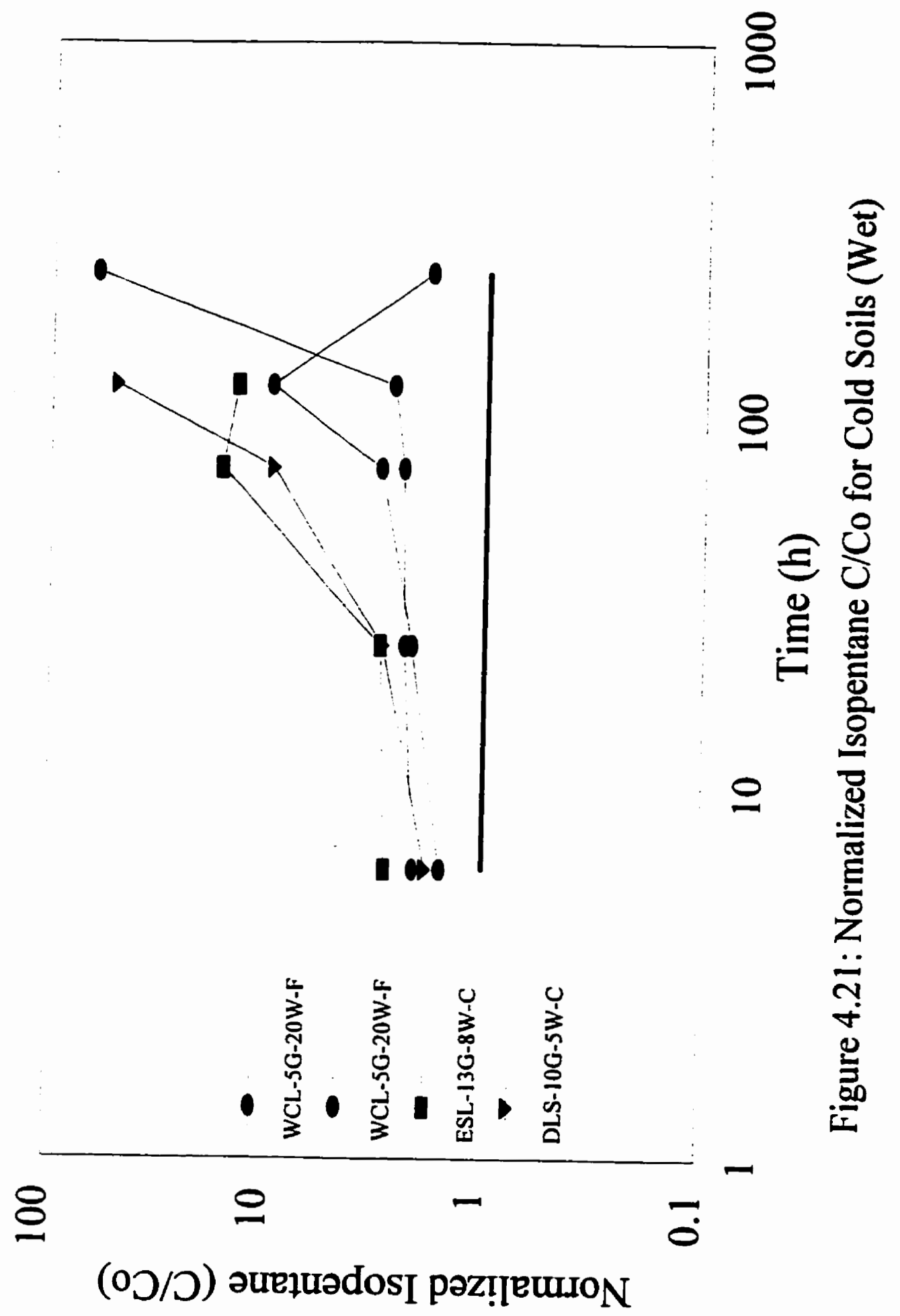




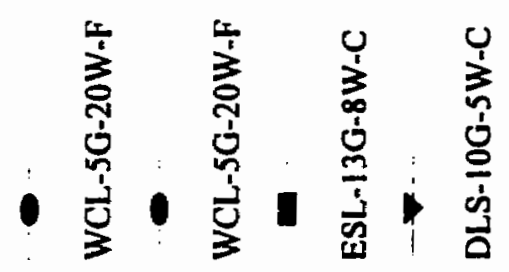

$$
8
$$

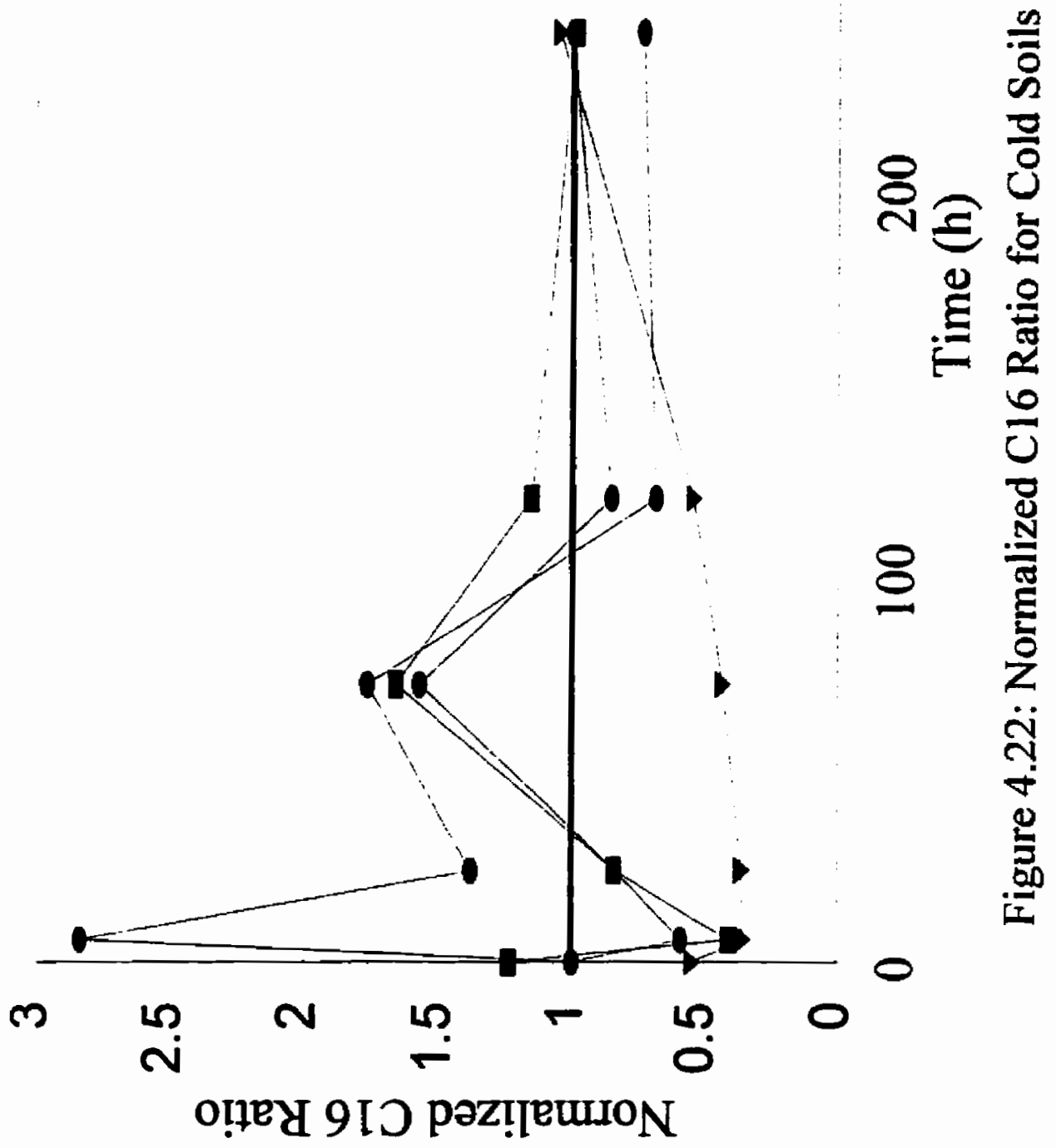




\subsection{Wicking Experiments}

Table 4.6 presents results from wicking experiments. Wicking experiments were conducted using the same materials and methods as used for the volatilization experiments. Their purpose was to isolate trends in hexadecane behaviour at different gasoline-water combinations. The hexadecane ratio (C16 Ratio) was calculated as the hexadecane concentration at the top of each column divided by the average hexadecane concentration in the column after 10 days of evaporation at the given gasoline-water conditions.

Table 4.6 10-Day C16 Ratio for Windsor Clay Loam

\begin{tabular}{cccc}
\hline Soil/Conditions & $\begin{array}{c}\text { Gasoline \% } \\
\text { (by weight) }\end{array}$ & $\begin{array}{c}\text { Water \% } \\
\text { (by weight) }\end{array}$ & $\begin{array}{c}\text { 10-Day C16 } \\
\text { Ratio }\end{array}$ \\
\hline WCL (Room) & 14 & 5 (air-dry) & 9.4 \\
WCL (Room) & 5 & 5 (air-dry) & 1.1 \\
WCL (Room) & 5 & 20 & 3.3 \\
WCL (Room) & 5 & 30 & 0.95 \\
WCL (Room)* & 5 & 15 & 2.0 \\
WCL (Room)* & 5 & 12.5 & 1.4 \\
WCL (Room)* & 5 & 25 & 0.5 \\
WCL (Room)* & 8.6 & 0 & 1.5 \\
\hline \hline * determined from wicking experiments & &
\end{tabular}

\subsection{Windsor Clay Loam Air Permeability Experiments}

The air permeability of Windsor Clay Loam at room temperature and frozen conditions is presented in Table 4.7. Permeability tests were run five times at each temperature condition. The average air permeability is presented. All data and calculations 
related to the permeability experiments are presented in Appendix $H$.

Table 4.7 Air Permeability of Windsor Clay Loam

\begin{tabular}{cccc}
\hline \hline Soil Condition & Soil Temperature & $\begin{array}{c}\text { Air } \\
\text { Permeability } \\
(\mathbf{m} / \mathbf{s})\end{array}$ & $\begin{array}{c}\text { Standard } \\
\text { Deviation }\end{array}$ \\
\hline $\begin{array}{c}\text { Room } \\
\text { Temperature } \\
\text { Frozen }\end{array}$ & $19^{\circ} \mathrm{C}$ & $1.33 \times 10^{-3}$ & $2.58 \times 10^{-5}$ \\
\hline \hline
\end{tabular}

\subsection{Frozen Gasoline Experiments}

Results of experiments conducted to determine the frozen fraction of petroleum mixtures is presented in Table 4.8. Six experiments were conducted on each mixture, with average $\%$ frozen as a function of the initial mass presented for each. Calculations and raw data used are shown in Appendix I.

Table 4.8 Petroleum Mixture Solidification

\begin{tabular}{ccc}
\hline Mixture & $\%$ (of Initial & Range (\%) \\
& Mass) Solidified & \\
\hline Gasoline (real) & 15 & $11-16$ \\
\hline \hline
\end{tabular}




\section{CHAPTER 5 DISCUSSION}

In this chapter, experimental methods and results will be discussed. Experimental procedures will be discussed in terms of column packing and extraction methods, overall handling losses, and the methods used to create cold and frozen weather environments. Results of the volatilization experiments will be discussed with respect to the effects of soil type, water content, temperature and immiscible phase capillary rise. Wicking experiments and permeability experiments will be used to assist in the explanation of the observed volatilization trends.

\subsection{Experimental Procedures}

In this section, experimental procedures for all volatilization experiments will be discussed. Column packing methods, extraction methods, and extraction efficiencies varied as a function of soil type and water content. The adequacy of the cold-weather environment for the cold and subzero experiments will also be discussed.

\subsubsection{Effect of Column Packing Procedures}

Experimental procedures for column packing varied between Delhi Loamy Sand and Elora Silt Loam, and Windsor Clay Loam. In particular, mixing of water with the soils for the wet experiments was a more complex process when using Windsor Clay Loam.

The 4-lift procedure used for the cold Delhi Loamy Sand and Elora Silt Loam experiments, described in Section 3.5.1, was adequate to mix these soils with water. The effectiveness of the mixing was determined by visual inspection of the shaking jars. Shaking of the Delhi Loamy Sand and Elora Silt Loam with water did not promote severe aggregation, and allowed the even distribution of water throughout the soil. Even though 
aggregates do occur naturally in soils, their presence in laboratory experiments leads to inconsistent mixing of soil with water.

The percent recovery values in Table 4.1 indicate the average gasoline concentrations in the air-dry and wet Delhi Loamy Sand and Elora Silt Loam zero-hour columns. These zero-hour columns describe initial conditions for each of the experiments, taking into account the contributions of handling losses and losses during extraction. Overall, the recovery of gasoline was relatively low from the zero-hour columns, ranging from a maximum of $70 \%$ for DLS-14.5G-AD-C to a minimum of $52 \%$ for DLS-10G-5W-C.

For the same experiments, percent recovery values were generally higher after 6 hours of volatilization, even though evaporative losses occurred during this interval. As a fraction of the percent recovery in the zero-hour columns, percent recoveries after 6 hours of volatilization were $6 \%$ lower for DLS-14.5G-AD-C, $23 \%$ higher for DLS-10G-5W-C, 27\% higher for ESL-19G-AD-C, and 29\% higher for ESL-13G-8W-C. These numbers indicate that procedures used to construct and take down the zero-hour columns need to be improved.

The 4-lift method was later modified for use with the Windsor Clay Loam by prechilling the gasoline to $-20^{\circ} \mathrm{C}$ and reducing the time to prepare the columns to an average of 5 minutes from 10 minutes. Table 4.1 indicates that percent recoveries from the air-dry Windsor Clay Loam zero-hour columns using the modified 4-lift method (14\% gasoline) were $86 \%$. Presumably, using the same precautions for the Elora Silt Loam and Delhi Loamy Sand cold-weather zero-hour columns would have improved the percent recovery values. 
Even though percent recoveries were relatively poor for the Elora Silt Loam and Delhi Loamy Sand zero-hour columns, they did improve after 6 hours of volatilization, indicating that the zero-hour columns, and not the column packing method itself, were flawed. As a result, the 4-lift method of column packing was considered adequate for the Loamy Sand and Silt Loam experiments.

Column packing of the Windsor Clay Loam soil was attempted using the same 4-lift method. The method was adequate at air-dry conditions. However, when introducing water to the soil, mixing became more difficult. At $10 \%$ water content, mixing of soil with water in the shaking jars was uneven. The water promoted the formation of large aggregates and numerous regions of dry soil. This aggregation in the Windsor Clay Loam was not seen to such an extent in the Loamy Sand or Silt Loam at similar water contents, and was attributed to the higher clay content of the Windsor Clay Loam. Raising the water content to $20 \%$ lead to larger aggregates and pockets of dry soil. The resulting soil-water mixture was not able to mix evenly with synthetic gasoline. The large aggregates were relatively impervious to gasoline, which primarily wetted the dry soil areas. New mixing methods for the Windsor Clay Loam with water were consequently investigated.

The first attempt at a new method involved increasing the mixing energy. A common household blender was used to mix the Clay Loam with water. At $10 \%$ water content, mixing in the blender bowl was relatively even but nevertheless encouraged the formation of small aggregates. This mixture was added to a shaking jar and mixed with $5 \%$ gasoline (by dry weight of soil). The larger pores formed by the aggregates were unable to hold the desired $5 \%$ gasoline when shaken in the jar. The altered pore size distribution 
resulting from aggregation resulted in ponding of gasoline at the bottom of the columns.

At $20 \%$ water content, the blender was unable to mix the water and the clay; instead, large clumps were formed that were relatively impervious to gasoline. Additionally, large masses of soil remained essentially air-dry. It was decided that increasing mechanical mixing was an ineffective method of mixing water with the Clay Loam.

The final mixing method tested, and the one subsequently used for the Windsor Clay Loam experiments, minimized the use of mechanical energy. Instead, mixing was done in the column. The number of soil lifts was increased to 48 , as slices had to be sufficiently thin as to evenly distribute water through them. Approximately $13 \mathrm{~g}$ of dry soil were used for each slice. Once placed in the column, each slice was doused with water, which was allowed to passively infiltrate through the soil. The slices were subsequently spiked with gasoline in a similar manner. Wetting of all soil slices was done carefully, so that the fluid would be distributed evenly across the entire soil area. To minimize evaporative losses of gasoline, the next soil slice was added, as quickly as possible, within a few seconds.

Visual observation of the resulting column profile demonstrated that aggregation was negligible, and that the water and gasoline seemed to have been evenly distributed in the soil at $20 \%$ and $30 \%$ water contents. It should be noted, however, that the 48 -lift method of column construction was less effective at water contents lower than $20 \%$, as it became difficult to wet the entire soil area. For the Windsor Clay Loam experiments, this was not a restriction, as clay soils in the field typically exist at high water contents.

Examination of the zero-hour columns showed that percent recovery of gasoline from the wet Clay Loam columns was extremely low, with minimum recovery of $16 \%$ at the 
higher water content. Improvements in extraction efficiencies (discussed in Section 5.1.2) lead to percent recoveries of $60 \%$ at $20 \%$ water content and $72 \%$ at $30 \%$ water content. Though these numbers are low compared to the Delhi Loamy Sand and Elora Silt Loam, they were the best achievable for the wet Clay Loam.

The 48-lift method required an average of 35 minutes for column construction, whereas the 4-lift method for the Delhi Loamy Sand and Elora Silt Loam experiments required only 10. However, the 48-lift method was favoured for the Clay Loam experiments because of the lack of aggregation and the even mixing with water.

As column setup procedures for all the volatilization experiments were not the same, an experiment was run to compare the methods at the same gasoline-water conditions. A $14 \%$ gasoline air-dry experiment was run for a full range of time durations using Windsor Clay Loam and the 4-lift method of column construction. The 14 day duration was compared with a $14 \%$ gasoline air-dry Clay Loam column constructed using the 48 -lift method. Results showed that the 48-lift column retained $28 \%$ more gasoline than the 4-lift column. The difference was attributed to the lower room temperature (average of $4.5^{\circ} \mathrm{C}$ lower) during the duration of the former experiment.

\subsubsection{Effect of Extraction Methods}

The ability to extract the synthetic gasoline from each of the soils using dichloromethane as the soivent did not result in the ideal $100 \%$ recovery. Less than ideal extraction efficiencies are the result of poor contact between the solvent and gasoline in the soil pores, possibly caused by the presence of water in the pores. In particular, extraction efficiencies were good for air-dry soils and poor for wet soils. Table 4.2 shows the 
extraction efficiencies for all the soil-water combinations using vial tests. Vial tests were used to assess extraction efficiencies because they offered a controlled setting where evaporative losses of gasoline could be minimized.

For the Delhi Loamy Sand and Elora Silt Loam, extraction efficiencies were high even after adding water, with a minimum of $81 \%$ for ESL-13G-8W-C. Addition of water to the soil reduced the extraction efficiencies by $13 \%$ for the Delhi Loamy Sand and $18 \%$ for the Elora Silt Loam. Water in the pores has the effect of either restricting contact between gasoline and solvent, or of creating aggregates during the shaking period that essentially confine the gasoline within the relatively impervious soil masses. Efficiencies for the air-dry experiments did not drop beneath $99 \%$ for either Delhi Loamy Sand or Elora Silt Loam.

Extraction efficiencies were also high for Windsor Clay Loam at air-dry conditions, reaching 99\%. For the wet Windsor Clay Loam experiments, a 30\% water content reduced the extraction efficiency by $30 \%$. Visual observations indicated that the wet Clay Loam formed sizeable clumps during the shaking period in dichloromethane, thus reducing the contact area between the gasoline in the pores and the solvent.

In order to increase the extraction efficiency from wet Windsor Clay Loam, a drying agent was added to the soil during the extraction process. Sodium sulfate was added to the grab sample in the $15 \mathrm{~mL}$ borosilicate vial at a ratio of approximately $3: 1$ (g sodium sulfate: g dry soil sample) in order to absorb water. Mechanical mixing of the soil sample was undertaken until it was sufficiently discretized. Solvent was added immediately upon completion of the mixing. 
Use of sodium sulfate as a drying agent resulted in a $16 \%$ increase in the extraction efficiency at $30 \%$ water content. Evaporative losses during the mechanical mixing process are inevitable, but were obviously minor compared to the improved extraction. Sodium sulfate was thus used for all wet Windsor Clay Loam experiments, and is effective in increasing the extraction efficiency from wet soils of high clay content.

The results in Table 4.2 demonstrate that extraction efficiencies from wet soil experiments are less than ideal. Further work should be done to improve the overall effectiveness of solvent extractions from wet soils, possibly by investigating the use of other drying agents. An alternative to improving the extraction is to monitor soil-gasoline levels by analysing vapour concentrations rather than soil concentrations. Potentially, a combination of both soil and vapour measurements would help to establish a reliable assessment of gasoline loss from wet soils. More work is needed in this context.

\subsubsection{Overall Losses}

The volatile nature of gasoline will result in losses during setup and take down of the volatilization experiments. Handling losses will occur during the mixing of soil and gasoline and during packing of the columns. Other losses will occur as a result of varying extraction efficiencies. Zero-hour columns were run for each experiment in order to assess the handling losses during column packing and takedown and the losses associated with extraction efficiencies. Zero-hour columns additionally provide reasonable estimates of the initial conditions for each experiment.

For the Delhi Loamy Sand and Elora Silt Loam experiments, results of the zero-hour columns, as shown in Table 4.1, demonstrate that overall losses were considerable. Given 
the relatively good extraction efficiencies for these soils even at wet conditions, the low percent recoveries can be attributed to handling losses. In particular, the time between shaking of gasoline with the soil-water mixture in the shaking jars and actual packing of the column was high, averaging approximately 3 minutes. This leads to evaporation into the headspace of the shaking jars. Either the use of smaller jars or cooling of the gasoline to lower temperatures prior to use would help to correct this problem.

Zero-hour columns run for air-dry Windsor Clay Loam showed lower overall losses, with recoveries of about $85 \%$. For the $5 \%$ gasoline experiment, use of the 48 -lift method resulted in limited exposure of the synthetic gasoline to the atmosphere, with a new slice being deposited on the order of a few seconds. In the 4-lift method, the gasoline-water-soil mixture could be sitting for up to 5 minutes. As a result, recovery from WCL-5G-AD-R experiments was good. For WCL-14-AD-R, the 4-lift method was employed with some modifications, as previously mentioned. First, the synthetic gasoline was prechilled to $-20^{\circ} \mathrm{C}$ before use and the average time of column packing was reduced to 5 minutes. These precautions resulted in good recoveries. Use of similar precautions for the Delhi Loamy Sand and Elora Silt Loam experiments would have improved results from those zero-hour columns.

Table 4.1 shows that for the $20 \%$ and $30 \%$ water content Clay Loam experiments, percent recovery was extremely low. Results of the extraction efficiency vial tests implicate the poor extraction as being the reason for the high losses. Use of sodium sulfate as a drying agent decreased the losses by $6 \%$ at the $20 \%$ water content and by $44 \%$ at the $30 \%$ water content. 
Further attempts were made to decrease the overall losses in the wet Windsor Clay Loam experiments. Rather than destructively sampling the zero-hour columns immediately upon packing, the columns were tightly capped with aluminum and placed in a refrigerator at $4^{\circ} \mathrm{C}$ for 3 hours. This procedure was used to allow the water and gasoline to evenly distribute through the soil. Results of zero-hour columns run using this method are shown in Table 4.1 . At $20 \%$ water content, the percent recovery increased by $24 \%$ over the case of no distribution period; at $30 \%$ water content, percent recovery increased by $12 \%$. As a result, it appears that the 48-lift method of column packing introduces some variability in gasoline distribution during the construction phase. A reasonable time period allows the fluids to more evenly distribute themselves through the soil, and leads to greater recovery of gasoline. The above method was used for all wet Clay Loam zero-hour columns.

\subsubsection{Checks on Analytical Methods}

To check the effectiveness of the extraction methods, gravimetric measurements were conducted on air-dry Windsor Clay Loam columns at room temperature and frozen conditions. Data was also collected for the wet experiments, but was deemed meaningless because it would not distinguish between losses of water and synthetic gasoline. Results of the comparisons are provided in Table 4.3. All comparisons were made after 336 hours of volatilization.

For the room temperature experiments, agreement between gravimetric measurements and Gas Chromatograph data is good, with a maximum variation of $6 \%$. At frozen conditions, gravimetric measurements indicate $19 \%$ less loss of gasoline when compared to the Gas Chromatograph data after 336 hours of volatilization. Comparisons 
between gravimetric analysis and Gas Chromatograph data after 5 days of volatilization at frozen conditions demonstrated a $20 \%$ lower apparent loss of gasoline using the gravimetric measurements. The lack of agreement at cold conditions can be attributed to error in the gravimetric measurements. In the frozen weather environment, columns are packed in ice. Inevitably, this leads to accumulation of ice on the column. Though attempts were made to clear the ice coating, they were obviously not completely effective.

Given the good agreement between gravimetric and Gas Chromatograph data at room temperatures, the extraction procedures were deemed acceptable for the air-dry soils. Though it is recognized that extraction efficiencies will drop when conducting wet soil experiments, the overall procedures were considered acceptable.

\subsubsection{Cold and Frozen Weather Environment}

Two temperature conditions were defined for the cold weather experiments: cold conditions and frozen conditions. Cold conditions, used for the Delhi Loamy Sand and Elora Silt Loam experiments, were those characterized by typically subzero temperatures. Frozen conditions, used for a set of Windsor Clay Loam experiments, were characterized by consistently subzero temperatures. Figure 4.1 shows the typical cooling response time for columns placed in the cold environment used for the Delhi Loamy Sand and Elora Silt Loam experiments. The average time to reach subzero temperatures for all soils and conditions tested was approximately $l$ hour, with a maximum freezing time of approximately 1.5 hours. In general, the ventilated box apparatus used in the coldweather experiments was sufficient to maintain cold conditions. Though temperatures did exceed $0^{\circ} \mathrm{C}$ within the box and columns as the outside temperature increased, there was a 
substantial lag time involved before the box's interior became warmer. Table 4.4 shows that temperatures within the box were generally subzero. In total, 102 out of 120 hours showed average temperatures below $0^{\circ} \mathrm{C}$, and no hourly average temperature exceeded $4^{\circ} \mathrm{C}$.

Modification of the box in order to create consistently freezing conditions for the frozen Clay Loam experiments was successful. Use of insulation on the box's interior, as well as ice packing around the columns, created subzero conditions for the duration of the frozen Windsor Clay Loam experiments. Temperatures within the columns did not exceed an average of $-0.5^{\circ} \mathrm{C}$ for any hour. Frozen conditions could not have been maintained without the use of dry ice approximately once a day during warm spells to refreeze the ice packing. The gravel base under the box was also adequate at providing drainage of the melt water.

\subsection{Volatilization Experiments}

Results of the volatilization experiments are presented in this section. The four primary parameters of interest are soil type, soil water content, temperature and immiscible phase movement of gasoline. In order to simplify the discussion of results, two sections have been created: Effect of Water Content and Effect of Temperature. Within the first section, gasoline behaviour in individual soils and a comparison of gasoline behaviour across soil type will be presented at air-dry and wet conditions. These comparisons will also be completed for soils at cold or frozen conditions. Comparisons of volatilization behaviour between room temperature and cold conditions will be completed in the second section at air-dry and wet conditions. The effect of immiscible phase gasoline movement will be discussed within the sections where it is relevant. 
Again, it should be noted that all data for room temperature experiments involving Delhi Loamy Sand and Elora Silt Loam (four experiments in total) were obtained by Rogaz and Hussain (1994) using the same experimental methods and synthetic gasoline blend.

\subsubsection{Effect of Water Content}

In this section, the effect of water content on volatilization behaviour for each individual soil and a comparison of behaviour between soils is presented. Trends are independently discussed for room temperature and cold soils. A number of general trends were observed in all experiments, particularly with respect to immiscible phase gasoline movement. These trends are fully explained in the section on air-dry experiments at room temperature, and will be mentioned in less detail in other sections where they are relevant.

\subsubsection{Room Temperature Air-Dry Experiments}

Four experiments will be discussed in this section: Delhi Loamy Sand, Elora Silt Loam and Windsor Clay Loam ( $14 \%$ gasoline and $5 \%$ gasoline) at air-dry conditions. A list of the conditions under which the experiments were run is presented in Table 3.7.

Figure 4.2 presents a plot of gasoline concentrations versus depth of soil and time for WCL-5G-AD-R. All concentrations are divided by the concentrations in the zero-hour columns. Normalization was done with the zero-hour columns rather than the added gasoline amounts because the zero-hour columns better represented initial conditions, taking into account the effect of overall losses.

Clearly, gasoline concentrations decrease with time. After 14 days of volatilization, the average column gasoline concentration was $35 \%$ of the initial concentration. Decreasing gasoline concentrations with time are to be expected based on the volatile nature of gasoline. 
Gasoline concentrations also decrease with proximity to the top of the column. After 14 days, the concentration at the top of the column was $61 \%$ of the average gasoline concentration in the column; the concentration at the bottom slice of the column was approximately equal to the average concentration. Lower surface gasoline concentrations imply that vapour-phase diffusion of gasoline at lower depths in the soil is impeded by the soil mass. Gasoline at the surface is able to evaporate without being impeded by such a resistance, and surface concentrations are consequently lower. A $25 \mathrm{~cm}$ soil depth thus presents a resistance to diffusion of gasoline vapours in the $5 \%$ gasoline air-dry Windsor Clay Loam.

Figure 4.3 shows a similar plot for WCL-14G-AD-R. Again, gasoline concentrations decrease with time. After 14 days of volatilization, column concentrations were $11 \%$ of the initial gasoline concentration. This represents a $24 \%$ greater fraction of initial gasoline lost as compared to WCL-5G-AD-R. Given the larger amount of gasoline in the pores in the $14 \%$ case, and the correspondingly reduced pore space, this behaviour would seem to be the opposite of what is expected. Additionally, Figure 4.3 shows that gasoline is clearly accumulating at the top of the columns, at concentrations in excess of the average concentrations in the column. For the 14 day data point, the surface gasoline concentration is 2.3 times greater than the average concentration in the column. This is in contrast to the $5 \%$ gasoline experiment, where surface concentrations were consistently lower than average column concentrations. After 14 days of volatilization, surface concentrations were $61 \%$ of the average column gasoline concentration for the $5 \%$ gasoline experiment.

To identify the reasons for these trends, individual component behaviour was 
investigated. Two synthetic gasoline components of particular interest were isopentane and hexadecane. Isopentane, with one of the highest vapour pressures in gasoline, will act in a basically diffusive manner ie., its transport will occur primarily in the vapour phase as a result of diffusion. Hexadecane, a non-volatile component, will display purely convective behaviour ie., movement will occur only in the liquid or immiscible phase.

Figures 4.4 and 4.5 show the concentrations of isopentane in $5 \%$ and $14 \%$ Windsor Clay Loam, respectively, as a function of time and depth. The isopentane concentrations were divided against concentrations calculated from the respective zero-hour columns for each experiment.

Isopentane concentrations in both air-dry Windsor Clay Loam experiments decrease with time and proximity to the top of the column. Isopentane loss in both experiments appears to be similar, though there is some evidence that initially, the $14 \%$ gasoline experiment is retaining isopentane to a greater extent. After 24 hours, the average isopentane concentration in the $5 \%$ gasoline soil is $23 \%$ of the initial average isopentane concentration; after the same time duration, the average isopentane concentration in the $14 \%$ gasoline soil is $30 \%$ of the original concentration. Given the reasonably good agreement between the experiments, an implication is that the extra gasoline present in the $14 \%$ experiment is not sufficient to restrict vapour-phase diffusion. As time proceeds, isopentane trends show a convergence. After 14 days of volatilization, isopentane concentrations in the $5 \%$ experiment are $0.002 \%$ of the initial concentration; in the $14 \%$ experiment, $\mathrm{C} / \mathrm{Co}$ is $0.003 \%$. In a purely diffusive process, total gasoline concentrations as a fraction of the initial gasoline added should thus be equivalent after longer durations of volatilization. 
Presumably, a mechanism other than vapour diffusion is responsible for lower total gasoline concentrations in the $14 \%$ gasoline Windsor Clay Loam.

An explanation can be found in the behaviour of the non-volatile tracer hexadecane. Figure 4.6 illustrates the concentration of hexadecane in the topmost slice of the column versus the average column hexadecane concentration against time (Cl6 ratio). Clearly, in the $14 \%$ gasoline case, hexadecane is accumulating at the top of the column, to a level 9.7 times the average hexadecane concentration in the column after 14 days of volatilization. There is some evidence of hexadecane accumulation in the 5\% gasoline case, with a Cl6 ratio of 1.5 after 14 days.

As hexadecane is non-volatile, it can only move in the column in the immiscible or dissolved phases; that is, it will not accumulate at the surface by evaporation from below. Since the experiments were conducted at air-dry conditions, it is unlikely that convective transport of hexadecane in water as a result of water evaporation is occurring. As a result, capillary rise of the bulk immiscible solution must be occurring, with movement of bulk fluid from regions of high concentration (bottom of the column) to regions of low concentration (top of the column). This driving force is created at the beginning of the experiments by faster evaporation of the synthetic gasoline from the top regions of the column as compared to lower regions. As hexadecane reaches the top of the column, its negligible volatility ensures that it does not evaporate; as a result, it accumulates at the top. Accumulation through wicking of hexadecane, and potentially other low-volatility components at the top of the columns, can thus explain the higher surface concentrations seen in the $14 \%$ gasoline columns; that is, the majority of the gasoline at the top slice must 
be composed of relatively non-volatile gasoline components.

As time progresses, the total gasoline concentrations at the top of the columns in the $14 \%$ gasoline experiments are consistently higher than the average gasoline concentration in the columns. This can be seen in Figure 4.3. The ratio of surface gasoline to average column gasoline concentrations increases from 0.95 after 6 hours to 2.3 after 14 days. Continually higher relative surface gasoline concentrations, however, contradict the conditions necessary for capillary rise of the fluid to occur. The driving force for upwards rise of the immiscible fluid is created by lower concentrations at the top of the column. Higher concentrations at the top of the column imply that the driving force should be downwards, and that this wicking effect should not continue with time.

An explanation for the continued wicking that was observed lies in the physical properties of the synthetic gasoline components. As bulk fluid is wicked upwards to the surface of the columns, more volatile components evaporate while components with lower vapour pressures, such as hexadecane, are retained. Evaporation of the more volatile components allows hexadecane to reach and exceed its solubility in the resulting solution, and hexadecane thus falls out of solution. Because its melting point is approximately equal to room temperature (see Table 3.6), the hexadecane which has dropped out of solution solidifies. As solidification of this component occurs, a mixture of liquid and solid chemical will exist at the soil surface. If the surface gasoline is primarily composed of solidified hexadecane, then the driving force necessary for wicking in the liquid phase is maintained even as the total surface gasoline concentration increases.

Potentially, other low volatility components are also solidifying. Figure 4.7 shows 
a plot of ratios similar to the $\mathrm{Cl} 6$ ratio for naphthalene and 1,3,5-trimethylbenzene, the next two least volatile components of the synthetic gasoline. Both of these components are present in real gasoline blends. Figure 4.7 demonstrates that after 14 days of volatilization, naphthalene is concentrated at the surface of the column at 8.6 times the average naphthalene concentration in the column. The similar ratio for $1,3,5$-trimethylbenzene is 0.4 . Thus, accumulation of naphthalene at the soil's surface is occurring, but not 1,3,5trimethylbenzene. This behaviour can be explained by the higher vapour pressure of $1,3,5$ trimethylbenzene as compared to that of naphthalene (data shown in Table 3.6), where the vapour pressure of naphthalene is two orders of magnitude smaller. Therefore, naphthalene, once it reaches the top of the column, will be less susceptible to volatilization. Conversely, 1,3,5-trimethylbenzene evaporates upon reaching the top of the column. Naphthalene, however, accumulates and falls out of the bulk solution. Given that the melting point of naphthalene is $107^{\circ} \mathrm{C}$, it is very likely that it would solidify at room temperature once it has fallen out of solution. Though not as non-volatile as hexadecane, naphthalene appears to display behaviour that makes it useful in tracking immiscible phase movement of gasoline. Further discussion on the solidification of gasoline components is given Section 5.2.2.1.

Figure 4.7 also indicates that up until 72 hours, the concentration of $1,3,5-$ trimethylbenzene at the top of the column is greater than the average column concentration. After 72 hours, this concentration of 1,3,5-trimethylbenzene at the surface begins to decrease. This indicates that wicking is bringing this component to the surface sufficiently fast during the first 72 hours of volatilization such that there is a limitation in vapour diffusion to the atmosphere. Examination of Figure 4.6 shows that the $\mathrm{C} 16$ ratio is 
essentially constant after 72 hours in the $14 \%$ gasoline experiment, implying that wicking is no longer occurring beyond this point. As wicking of the bulk solution ends, concentration of 1,3,5-trimethylbenzene at the top of the column also stops, and levels decrease with time as it evaporates. This behaviour was also seen for $m$-xylene, but not for any of the other components. Presumably, wicking rates in the first 72 hours are sufficiently fast that for chemicals with vapour pressures on the order of 1,3,5-trimethylbenzene and m-xylene, some amount of accumulation at the top will occur. As wicking ends, the chemical is no longer replenished, and surface levels drop when compared to the rest of the column.

Examination of hexadecane and naphthalene concentrations at the top of WCL-14G-AD-R after 14 days of volatilization indicate that they account for $94 \%$ of the total surface gasoline content. At these high concentrations, it is almost certain that they are removed from the bulk solution and are present in a solid phase at the soil surface. Wicking of the bulk solution to the top of the column in the $14 \%$ gasoline experiment thus provides an alternate means of gasoline reaching the surface of the soil. This explains the increased rate of gasoline loss from the $14 \%$ experiment over the $5 \%$ experiment, which demonstrated little or no wicking. As a result, conditions which favour a combination of diffusive and convective processes will promote greater volatilization than those which favour a purely diffusive process.

The contributions of wicking to volatilization are also more significant than are the restrictions in effective porosity imposed by having a greater amount of liquid in the pores. Further, immiscible phase movement explains the 'flatter' concentration profile seen in Figure 4.3. Wicking promotes the accumulation of non-volatiles at the top of the column, 
creating a lower overall gasoline concentration gradient between the bottom of the column and the top.

Based on Figure 4.6, it is apparent that wicking was not a factor in the $5 \%$ gasoline experiment. Gasoline did not accumulate at the top of the column. A possible explanation for the difference between the two air-dry experiments is that in the $5 \%$ gasoline experiment, the amount of gasoline added is sufficiently low that it only occupies the smaller soil pores. These smaller pores are poorly connected and offer little chemical conductivity; as a result, wicking does not occur. Work using cryo-scanning electron microscopy by Hayden and Voice (1993) described such a picture of immiscible chemicals in the soil. At low NAPL saturations ( $\sim 1 \%$ by volume), iodine was retained in soil as isolated lenses on the soil particles. Iodine existed as continuous films at intermediate and high saturations. Possibly, at $5 \%$ gasoline in the Windsor Clay Loam, the fluid exists as discontinuous films on soil particles. Because of the poor chemical conductivity between the gasoline in the pores, little or no wicking occurs.

The additional gasoline present in the $14 \%$ experiment case must then fill a fraction of pores that are sufficiently connected. Figure 4.6 shows that wicking in WCL-14G-AD-R has essentially stopped after 72 hours ie., non-volatiles are no longer being accumulated at the soil surface. The average gasoline content in the soil after 72 hours of volatilization is 4.0\%. At this point, connectivity between the pores has been lost, and immiscible phase movement of gasoline is restricted in the same manner as seen for WCL-5G-AD-R.

Figure 4.8 shows the normalized fraction of gasoline lost for the air-dry room temperature experiments. For each of the experiments, $1-\mathrm{C} / \mathrm{Co}$ is calculated at any time, and 
then normalized against the fraction of gasoline lost (1-C/Co) for WCL-14G-AD-R Results indicate that the 19\% Elora Silt Loam and the 14\% Delhi Loamy Sand exhibit approximately the same fractions of gasoline lost as the $14 \%$ Windsor Clay Loam, particularly after 50 hours. However, the 5\% Windsor Clay Loam shows much lower volatilization losses. After 14 days, evaporative losses from the $5 \%$ experiment are $63 \%$ of those seen in the $14 \%$ Clay Loam experiment. A convergence in the data points for the high gasoline content soils indicates that gasoline volatilization from air-dry soils demonstrate a similar behaviour. The difference seen in the $5 \%$ gasoline case has already been shown to be the result of the absence of wicking; thus, it would follow that wicking is possibly occurring in the Delhi Loamy Sand and Elora Silt Loam experiments. Examination of isopentane and hexadecane will isolate these trends.

Figure $4.9 \mathrm{a}$ presents the soil isopentane concentrations divided by the initial isopentane concentrations versus time for the room temperature air-dry soils. The lowest initial gasoline amount ( $5 \%$ Windsor Clay Loam) loses the most isopentane for a given time at the beginning of the experiment. The other experiments demonstrate greater retention of isopentane at the beginning of the experiments, possibly as a result of increased liquid in the pores and the resulting smaller effective porosity. Figure $4.9 \mathrm{~b}$ shows the isopentane ratio normalized against WCL-14-AD-R for each of the air-dry experiments. After 336 hours of volatilization, isopentane ratios for the WCL-14-AD-R and the WCL-5-AD-R experiments are essentially equal, suggesting that the extra gasoline in the former case does not impede vapour-phase diffusion of isopentane after longer periods of time. It is also clear that ESL19-AD- $R$ and DLS-14-AD- $R$ retain isopentane to a greater extent than WCL-14-AD- $R$ after 
longer periods of time. It should be noted that the final two points for the Silt and Sand experiments, as noted on Figure 4.9b, were calculated using minimum Gas Chromatograph detection limits to represent the isopentane concentration for the two soils. This was done because concentrations had dropped sufficiently that they were not detectable by the Gas Chromatograph, and the minimum detection limits represented the best estimate of the actual isopentane concentrations.

An explanation for these trends can be found by comparing the added amounts of gasoline to the porosity. A ratio that can be used to compare the effects of gasoline amount and overall pore volume is the liquid-filled porosity, which is defined as the volume of liquid in the pores divided by the overall pore volume. This data is presented in Table 5.1. Comparing the liquid-filled porosity for each experiment shows that the $5 \%$ gasoline has a liquid-filled porosity half of the $14 \%$ gasoline experiment, and 2.8 times less than the Delhi Loamy Sand and Elora Silt Loam experiments. The lower liquid-filled porosity of the $5 \%$ Clay Loam experiment can thus explain the faster loss of isopentane; that is, the lower relative amount of gasoline in the pores better accommodates the diffusion of isopentane vapours through the soil. 


\begin{tabular}{cc}
\hline \hline Experiment & Liquid-Filled Porosity \\
\hline WCL-14G-AD-R & 0.53 \\
WCL-5G-AD-R & 0.26 \\
ESL-19G-AD-R & 0.72 \\
DLS-14G-AD-R & 0.72 \\
WCL-5G-20W-R & 0.6 \\
WCL-5G-30W-R & 0.81 \\
ESL-1 1G-10W-R & 0.64 \\
DLS-10G-5W-R & 0.64 \\
\hline \hline
\end{tabular}

The ESL-19-AD-R and the DLS-14-AD-R show significantly higher retention of isopentane compared to WCL-14-AD-R, as seen in Figure 4.9b. Again, the liquid-filled porosities can be used to explain this. Table 5.1 shows that the liquid-filled porosity for the former experiments is $36 \%$ higher than that for the WCL experiment. A conclusion is that the extra added amount of gasoline is restricting the diffusion of isopentane in the Sand and Silt. A comparison can also be made between the Sand and Silt experiments, which were conducted at the same liquid-filled porosities. The Elora Silt Loam experiment is clearly retaining isopentane to a greater extent than is the Delhi Loamy Sand. Since the liquid-filled porosities are identical, then a difference in the diffusive behaviour of isopentane between the Sand and Silt can be attriblited to the average pore size of each soil. The Silt, with smaller average pores, restricts the movement of a diffusive component such as isopentane to a greater extent than does the Sand, which has larger average pores. 
Figure 4.10 illustrates the hexadecane ratio in the room temperature air-dry soils. Figure 4.10 demonstrates that the behaviour of the non-volatile tracer in the air-dry Delhi Loamy Sand and Elora Silt Loam experiments is similar to that observed in WCL-14G-AD$R$ and is consistently higher than that seen in WCL-5-AD- $R$ Wicking stops after approximately 72 hours of volatilization, as connectivity between gasoline in the pores is lost. After 72 hours, the average gasoline concentration in the Delhi Loamy Sand experiment is $5.2 \%$, and $8.7 \%$ in the Elora Silt Loam experiment, indicating that gasoline levels have dropped sufficiently such that the gasoline in the pores is no longer well connected.

\subsubsection{Room Temperature Wet Experiments}

This section will be separated into two parts. First, a comparison will be made between wet soil experiments, which include WCL-5G-20W-R, WCL-5G-30W-R, ESL11G-10W-R, and DLS-10G-5W-R; discussion will proceed in terms of total gasoline, isopentane and hexadecane trends. The second section involves a comparison between these wet soil experiments and the air-dry experiments for the corresponding soil types, also completed in terms of total gasoline, isopentane and hexadecane trends.

Figure 4.1la shows the normalized fractions of gasoline lost for the wet room temperature experiments. Normalization was done against WCL-14G-AD-R. Use of this normalizing factor for the wet experiments was arbitrary, as it was the relative differences between the experiments which were of interest. The normalization process simply involved calculating $1-\mathrm{C} / \mathrm{Co}$ for a time point, and dividing by the corresponding $1-\mathrm{C} / \mathrm{Co}$ value for WCL-14G-AD-R. As a result, data points residing above one on the $y$-axis represent a faster 
fractional loss of gasoline as compared to WCL-I4G-AD-R.

Clearly, Figure 4.11a demonstrates that ESL-1IG-10W-R and DLS-10G-5W-R exhibit approximately the same fractional loss of gasoline as WCL-14G-AD-R. This agreement is strongest after 120 hours of volatilization. Additionally, the wet Sand and Silt experiments show greater fractional loss of gasoline when compared to WCL-5G-20W-R and WCL-5G-30W-R. Investigation of liquid-filled porosities, shown in Table 5.1, for each of the wet experiments will determine if the amount of liquid in the pores is sufficiently different between experiments that vapour-phase diffusion is impeded as a result. WCL-5G20W-R and WCL-5G-30W-R have, respectively, liquid-filled porosities 0.94 and 1.3 times that of the ESL-11G-10W-R and DLS-10G-5W-R experiments (which have the same liquidfilled porosities). These numbers indicate that in a strictly diffusive process, gasoline should be evaporated from the $20 \%$ water content Windsor Clay Loam at the fastest rate, and from the $30 \%$ water content Clay Loam at the slowest rate. Investigation of isopentane, which will behave in a purely diffusive behaviour, will help to examine this trend.

Figure 4.12a illustrates isopentane $\mathrm{C} / \mathrm{Co}$ (not normalized) for the air-dry and wet soils. In general, the diffusive behaviour of isopentane for room temperature wet soil experiments is similar across soil type. After 240 hours of volatilization, isopentane concentrations approach negligible values for all experiments. It should be noted that the high value registered for WCL-5G-20W-R at 240 hours is the result of experimental error, given the low isopentane concentrations at 120 and 336 hours. With the diffusive behaviour of gasoline in the wet soils approximately the same, then another factor must explain the higher rate of total gasoline loss in the wet Delhi Loamy Sand and Elora Silt Loam 
experiments.

Hexadecane trends for all room temperature soils are shown in Figure 4.13a. Clearly, the wet Delhi Loamy Sand and Elora Silt Loam experiments show evidence of wicking. For the Sandy Loam, concentrations in the top slice of hexadecane after 336 hours of volatilization are 7.5 times the average concentration in the column; for the Silt Loam, concentrations are 6 times greater. This indicates that wicking will occur in these soils even at appreciable water contents. In the two wet Windsor Clay Loam experiments, wicking is considerably slower, as seen in Figure 4.13a. Slower wicking in these experiments can help to explain the higher overall loss of gasoline from the wet Sand and Silt experiments.

Based on the data collected, a number of possible explanations exist to explain why the Elora Silt Loam and Delhi Loamy Sand wet experiments showed wicking while the Windsor Clay Loam wet experiments showed only minimal wicking. A possible explanation is as follows. Figure 4.13a indicates that WCL-5G-20W-R shows top slice concentrations 2.3 times the average concentration in the column. For the $30 \%$ water content Windsor Clay Loam, the wicking effect is negligible, with surface concentrations essentially equal to the average column hexadecane concentrations. Possibly, at $20 \%$ water content, water is present in sufficient quantities that it occupies the smallest soil pores and a fraction of the larger pores. Gasoline is found in larger pores, given that it will not displace water from the soil matrix. As a result, gasoline and some water exists in the larger soil pores. Presumably, adding a high enough water content to the soil will force gasoline to the largest pores, which offer the weakest capillary forces; as a result, wicking is retarded. Further, the low initial gasoline amount (5\%) as compared to the wet Delhi Loamy Sand and Elora Silt Loam 
experiments likely has an effect on overall wicking. A lower gasoline content will have the effect of isolating gasoline in the pores, making it more difficult to maintain the continuous gasoline films needed for wicking to occur.

Increasing the water content to $30 \%$ in Windsor Clay Loam will have the effect of forcing gasoline to the largest soil pores which possess the weakest capillary forces. Correspondingly, wicking drops to even lower levels. To distinguish these results from the wet Delhi Loamy Sand and Elora Silt Loam experiments, it should again be noted that the wet Clay Loam experiments were conducted at lower gasoline and higher water contents. For example, an $8 \%$ water content Silt Loam allows wicking to occur as the smaller pores are filled with water. A $20 \%$ water content Clay Loam fills up a higher number of smaller pores with water, and forces gasoline to the pores with the weakest capillary forces. This, however, can also be coupled with the initial gasoline amounts, as higher initial gasoline amounts appear to aid the wicking process. As a result, there are optimal gasoline-water contents which favour wicking, and they are affected by the pore size distribution of the soil. Because of the differences in soil type and initial gasoline and water amounts, conclusive statements about wicking behaviour cannot be made. In order to better understand the process, additional wicking experiments involving Windsor Clay Loam at various gasolinewater contents were undertaken.

The wicking experiments involved running Windsor Clay Loam volatilization experiments for 10 days at room temperatures using various gasoline-water initial conditions. Changing gasoline and water contents helped to determine whether the gasoline content or the total liquid content controlled the wicking process. 10-Day C16 wicking 
ratios are presented in Table 4.6, along with 10-day C16 ratios for the other Windsor Clay Loam volatilization experiments. The liquid and gasoline-filled porosities were then plotted against these $\mathrm{C} 16$ values in Figure 5.1 for the Windsor Clay Loam series of experiments, and in Figure 5.2 for the Delhi Loamy Sand and Elora Silt Loam series of experiments. It is recognized that the $\mathrm{Cl} 6$ ratios are actually the dependent values, but for ease of explanation, they were used as the $\mathrm{x}$-axis values. As a result, there are two data points for any one 10-day C16 Ratio, corresponding to the liquid and gasoline-filled porosities for one experiment. The difference between the liquid and gasoline-filled porosity represents the water-filled porosity. 


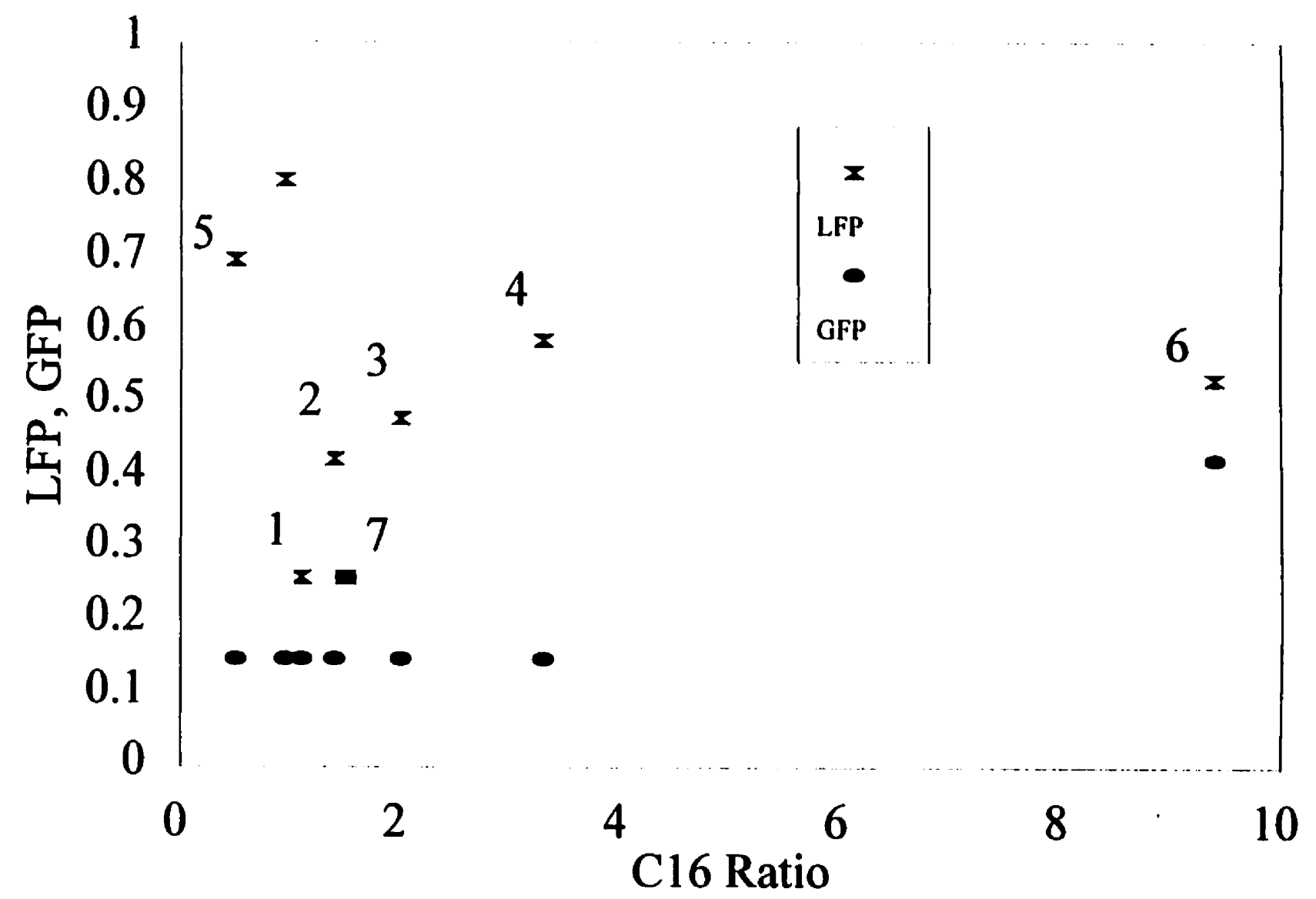

Figure 5.1: Liquid and Gasoline-Filled Porosity Versus C16 Ratio for WCL 


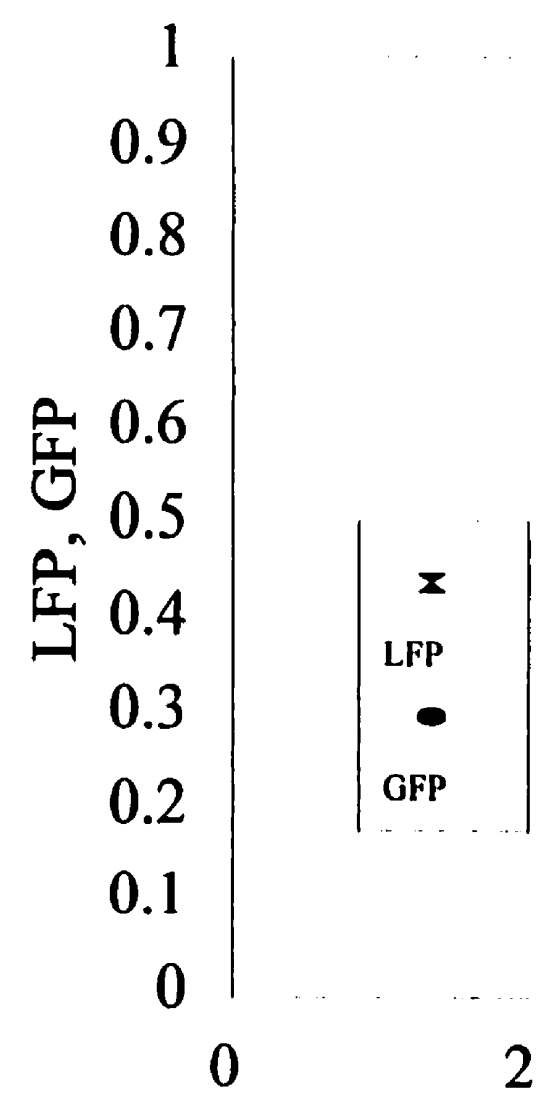

ESL

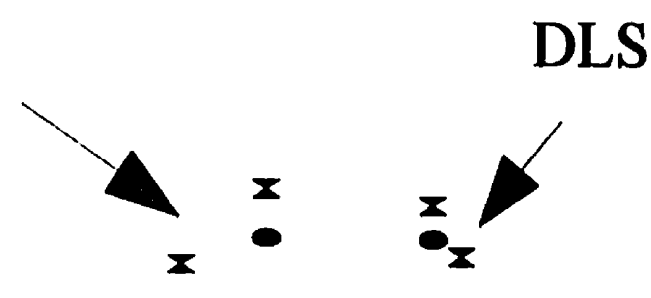

4

C16 Ratio

Figure 5.2: Liquid and Gasoline-Filled Porosity Versus C16 Ratio for DLS and 
Figure 5.1 illustrates two primary points relating to wicking behaviour. Points $1,2,3$ and 4 demonstrate that an increase in water content for the same gasoline content increases wicking. Point 4 represents a water content of $20 \%$. However, increasing the water content to $25 \%$ (Point 5) and higher reduces the $\mathrm{Cl} 6$ ratio. An implication is that below $20 \%$ water, for a constant gasoline content, increasing the total liquid content in the soil helps the wicking process. Beyond this point, water forces gasoline to pores with sufficiently weak capillary forces that wicking begins to be retarded. Thus, it appears that wicking is a nonlinear function of water content.

A second trend is apparent in Figure 5.1. Point 6 shows a high-gasoline content, low water-content experiment (WCL-14G-AD-R) 10-day C16 ratio. Clearly, increasing the gasoline content to $14 \%$ increases wicking, suggesting that the gasoline content also plays an important part in immiscible phase movement. As comparison, Point 7 shows a relatively higher initial gasoline content (8.6\%) at oven-dry (no water) conditions. The 10-day $\mathrm{Cl} 6$ ratio, however, is not much different from that shown in Point 1 (WCL-5G-AD-R). These two experiments have the same liquid-filled porosity, but Point 7 has a higher gasoline-filled porosity. Nevertheless, despite the higher gasoline content at Point 7 , wicking is not much different. This suggests that higher gasoline contents will enhance wicking only if the overall liquid-filled porosity is sufficient. Figure 5.2 reinforces this point. The Elora Silt Loam and Delhi Loamy Sand experiments were conducted at relatively high gasoline and water contents, and show significant wicking in all cases. Thus, it appears that the initial gasoline content most strongly determines the degree to which wicking occurs; however, at low gasoline contents, there is evidence that increasing the total liquid content will also 
serve to enhance wicking to a certain point. Further work needs to be done, however, to isolate the effect of gasoline content and water content on wicking behaviour across different soil types, in terms of initial gasoline content and the non-linear dependance of wicking on water content.

Comparisons can also be made between the room temperature wet experiments and the room temperature air-dry experiments performed on the same soil types; these comparisons will isolate the effect of water content on these soils. Figure 4.11b shows the normalized fraction of gasoline lost for the wet room temperature experiments. Fractions of gasoline lost were determined by calculating $1-\mathrm{C} / \mathrm{Co}$ for each time point and then dividing by $1-\mathrm{C} / \mathrm{Co}$ for the normalizing experiment at the same time point. For WCL-5G-20W-R and WCL-5G-30W-R, the normalizing experiment was WCL-5G-AD-R; for ESL-1 1G-10W-R, the normalizing factor was ESL-19G-AD-R; and for DLS-10G-5W-R, the normalizing factor was DLS-14G-AD-R For these graphs, data points above one represent fractions of gasoline lost for a given time point that are faster than those seen for the air-dry experiment using the same soil; conversely, data points below one on the y-axis indicate that water in the soil is reducing gasoline loss on a fractional basis compared to the corresponding air-dry experiments.

As seen in Figure 4.11b, the wet Sand and Silt experiments show fractional loss of gasoline at wet conditions that is similar to the fractional gasoline loss in the corresponding air-dry experiments. In particular, there is good agreement beyond 120 hours of volatilization. Additionally, it is clear that the wet Windsor Clay Loam experiments show retention of gasoline when compared to WCL-5-AD-R. Again, isopentane and hexadecane 
trends will help to explain these observations.

Figure $4.12 \mathrm{~b}$ shows the normalized isopentane $\mathrm{C} / \mathrm{Co}$ relationships for the wet soils. Again, the wet soils were normalized against the corresponding $\mathrm{C} / \mathrm{Co}$ values for air-dry experiments at room temperature. For this graph, data points above one on the $y$-axis indicate that isopentane is being retained by the wet experiment compared to the corresponding air-dry experiment. Figure $4.12 \mathrm{~b}$ shows that ESL-1 1G-10W-R and DLS10G-5W-R are losing isopentane to a greater degree than are the same soils at air-dry conditions. Full resolution for these experiments after 120 hours was not possible, as isopentane concentrations for the air-dry and wet experiments dropped below Gas Chromatograph detection limits. It is conceivable that retention of isopentane for the wet Sand and Silt experiments becomes evident at the later time points, as is seen for the wet Clay Loam experiments; however, in the absence of further data, a conclusion is not possible. There are potential reasons for the greater loss of isopentane from wet Sand and Silt at the earlier time points. First, the bulk of the liquid added in the wet experiments is gasoline, which will evaporate at a significantly faster rate than water. This will open up additional pore space at a faster rate than, for instance, in a soil with a high water-low gasoline content. Second, the pore sizes of the Delhi Loamy Sand and Elora Silt Loam may be sufficiently large that the added levels of water do not impede vapour diffusion of the synthetic gasoline. Based on the completed experiments, it is not possible to isolate which mechanism is more important; in all likelihood, a combination of factors is important.

The wet Windsor Clay Loam experiments shown in Figure 4.12b emphasize that water can impede diffusive behaviour in soil. Clearly, adding water contents of $20 \%$ and 
$30 \%$ to the Clay Loam greatly favours the retention of isopentane as compared to the air-dry $5 \%$ gasoline case. For both wet experiments, $\mathrm{C} / \mathrm{Co}$ for isopentane are almost two orders of magnitude higher for the wet experiments as compared to WCL-5G-AD-R after 336 hours of volatilization. Figure $4.12 \mathrm{~b}$ shows that this behaviour becomes more pronounced with time; this suggests that the rate of isopentane loss is faster from the air-dry than the wet Windsor Clay Loam. Slower loss of isopentane with water in the soil indicates a restriction in soil-air diffusion or a restriction in transfer of isopentane to the soil-air. Based on the data, it is not possible to distinguish between the two mechanisms; however, a combination of the two is likely responsible for the slower rate of isopentane loss seen for WCL-5G20W-R and WCL-5G-30W-R as compared to air-dry conditions.

Elements of wicking behaviour as a function of water content have already been discussed earlier in this section. Figure 4.13a demonstrates $\mathrm{Cl} 6$ ratio versus time for all room temperature wet and air-dry experiments. Figure $4.13 \mathrm{~b}$ normalizes the wet $\mathrm{C} 16$ ratios against the ratios for the corresponding air-dry experiments.

Figure 4.13b indicates that ESL-1 1G-10W-R and DLS-10G-5W-R show wicking behaviour that is similar to that seen in the corresponding air-dry experiments. The initial gasoline content has already been implicated as being important to immiscible phase wicking of the bulk gasoline solution. For the wet Sand and Silt experiments, even though the gasoline content has been decreased compared to the air-dry experiments, there is still sufficient gasoline that connectivity is maintained throughout the soil. Additionally, the water contents have not reached sufficiently high levels where they can affect immiscible phase movement. Further, WCL-5G-20W-R shows some amount of wicking over the air- 
dry case, whereas WCL-5G-30W-R shows behaviour similar to WCL-5G-AD-R. Again, the implication is that some amount of water in the pores will help the wicking process, but that too much water inhibits it.

\subsubsection{Cold and Frozen Air-Dry Experiments}

A number of observations for the cold and frozen experiments are similar to those seen at room temperature conditions. This will be outlined but not discussed again in depth. Where different behaviour was encountered, detailed explanation is given.

It must also be noted that cold experiments were not conducted at identical conditions. For the frozen Windsor Clay Loam experiments, temperatures were consistently maintained below $0^{\circ} \mathrm{C}$. Experiments were not initiated until the soil temperatures had dropped to subzero temperatures. The Delhi Loamy Sand and Elora Silt Loam were completed at cold conditions which typically involved subzero temperatures. Additionally, these experiments were initiated while the soil was still at room temperature. The average cooling response time was approximately one hour, during which time volatilization would have occurred at an accelerated pace. Results between the cold-weather sets of data are thus not strictly comparable. However, the overall length of the experiments, approaching 240 hours, should moderate this difference to some degree. Discussion will thus assume that cold-weather relative to frozen conditions were approximately equal.

Figure 4.14a illustrates isopentane $\mathrm{C} / \mathrm{Co}$ behaviour for all the cold experiments. WCL-5G-AD-F demonstrates the fastest rate of isopentane loss for the cold air-dry experiments, which is similar to the trend seen at room temperature for the air-dry soils. After 240 hours of volatilization, isopentane concentrations as a fraction of initial isopentane 
concentrations in the 5\% Clay Loam are 2.2 times lower than in DLS-14.5G-AD-C and 2.4 times lower than in ESL-17.5G-AD-C. Diffusive behaviour is thus clearly occurring to a greater degree in the $5 \%$ gasoline Clay Loam experiment. This can be explained by the lower liquid-filled porosity, and the correspondingly greater pore space available for vapourphase diffusion of isopentane.

Figure 4.15a illustrates the behaviour of hexadecane with time. Clearly, the cold airdry Loamy Sand and Silt Loam experiments show evidence of wicking. After 240 hours of volatilization, the concentration of hexadecane at the top of the column is 6.2 times greater than the average hexadecane concentration in the column for the Loamy Sand, and 4.2 times greater for the Silt Loam. Immiscible phase movement of the bulk gasoline solution is therefore aiding the movement of chemical to the surface of the soil, where it is more available for evaporation. This trend was not observed for the air-dry $5 \%$ gasoline experiment. As with the room temperature experiments, an explanation for this is that gasoline at such low concentrations exists as isolated soil-particle films which offer poor chemical conductivity. In the Loamy Sand and Silt Loam experiments, enough gasoline is added that there is connection between the gasoline-filled pores.

The trends seen in Figure $4.15 \mathrm{a}$ also demonstrate that wicking is continually increasing with time. In the room temperature experiments on air-dry soils, $\mathrm{C} 16$ ratios reached maximum values after 72 hours of volatilization. For the high gasoline content airdry cold-weather experiments, $\mathrm{Cl} 6$ ratios after 240 hours exceeded those after 72 hours by $49 \%$ for the Delhi Loamy Sand and by $32 \%$ for the Elora Silt Loam. This indicates that connectivity between gasoline in the pores is being maintained beyond 72 hours at cold 
conditions. Further examination of the data indicates that $\mathrm{C} 16$ ratios for 336 hours are essentially the same as those seen at 240 hours. This indicates that wicking has ended after 240 hours of volatilization. Increased wicking with time suggests that gasoline contents, up until 240 hours of volatilization, have not reached sufficiently low levels that gasoline in the pores is poorly-connected. As a result, the capillary rise of bulk solution continues. After 240 hours of volatilization, the average gasoline concentration in the Delhi Loamy Sand is $5.8 \%$, and is $8 \%$ in the Elora Silt Loam. These numbers compare well with the room temperature experiments, where wicking ended as gasoline contents dropped to $5.2 \%$ in the Delhi Loamy Sand and to $8.7 \%$ in the Elora Silt Loam.

\subsubsection{Cold and Frozen Wet Experiments}

Cold wet experiments were run simultaneously to the cold air-dry experiments. Of note in these experiments is that subzero temperatures will promote the freezing of water that has been added to the soil. Figure 4.16 illustrates the normalized fraction of gasoline lost for the cold temperature wet soils. Normalization of WCL-5G-20W-F and WCL-5G30W-F was done against WCL-5G-AD-F; normalization of ESL-13G-8W-C was done against ESL-17.5G-AD-C; and normalization of DLS-10G-5W-C was done against DLS14.5G-AD-C. For this plot, data points beneath the one line on the $y$-axis indicate lower fractions of gasoline lost at wet conditions than at air-dry conditions.

Figure 4.16 shows that at cold temperature conditions, water content generally has the effect of decreasing the fractional loss of gasoline. Again, this implies either a restriction of gasoline transfer to the soil pores or a restriction in diffusion through the soil. Once again, isopentane and hexadecane trends will help to investigate mechanisms of importance. 
Figure $4.14 \mathrm{~b}$ shows the normalized isopentane $\mathrm{C} / \mathrm{Co}$ ratios. Normalization was done against the corresponding cold air-dry experiment. Figure $4.14 \mathrm{~b}$ indicates that wet conditions generally restrict isopentane loss as compared to air-dry conditions in the cold soils. Water is clearly interfering with movement of isopentane into soil-air or with migration of isopentane through the soil.

Differences in wet and air-dry wicking behaviour at cold conditions was similar to that seen at room temperatures. Figure $4.15 \mathrm{~b}$ shows the normalized $\mathrm{C} 16$ ratios for the wet cold soils. Normalization was done against the corresponding cold air-dry experiments. Figure $4.15 \mathrm{~b}$ demonstrates that WCL-5G-20W-F shows considerably more wicking than WCL-5G-AD-F; this was the same as the behaviour seen at room temperatures. WCL-5G30W-F shows little difference in wicking from WCL-5G-AD-F, and ESL-1 1G-10W-C and DLS-10G-5W-C show similar wicking behaviour to the corresponding air-dry experiments; this behaviour was also seen at room temperatures.

As with the air-dry cold experiments, accumulation of gasoline at the top of the soil continues well beyond 72 hours for the Delhi Loamy Sand and Elora Silt Loam experiments. For the same reasons as outlined for the cold air-dry experiments, the implication is that the gasoline content in the soil has not dropped sufficiently as to lose connectivity between the gasoline-filled pores. It has already been demonstrated that in air-dry conditions, wicking stops when the average column gasoline concentrations reach $5.8 \%$ and $8 \%$ for the cold Delhi Loamy Sand and Elora Silt Loam, respectively. For the wet experiments, which were conducted at lower initial gasoline amounts, the column concentrations after 240 hours were 2.7\% for the Delhi Loamy Sand and 5\% for the Elora Silt Loam. 


\subsubsection{Effect of Temperature}

In this section, the effect of temperature will be discussed in terms of air-dry and wet experiments. Comparisons will be made between all soil types used, and wicking trends will be discussed.

\subsubsection{Air-Dry Cold or Frozen Versus Room Temperature Experiments}

Figure 4.17 presents the normalized fraction of gasoline lost for the air-dry cold and room temperature experiments. For each cold air-dry experiment, 1-C/Co was calculated and divided by the same ratio for the corresponding room temperature experiment. As a result, data points below the one line on the $y$-axis indicate lower fractions of gasoline lost compared to the corresponding room temperature experiment.

Figure 4.17 demonstrates that the fraction of gasoline lost in air-dry soils is higher at room temperature than at cold conditions. A combination of convective and diffusive processes have been shown to be responsible for volatilization behaviour, and presumably both processes are affected by changing temperatures. Investigation of individual component behaviour will help to explain lower gasoline losses from cold soils.

Figure 4.18 shows the normalized isopentane $\mathrm{C} / \mathrm{Co}$ ratios for cold air-dry soils against the corresponding room temperature air-dry soils. Clearly, isopentane is being retained to a larger degree in cold soils than in room temperature soils. For a component which will demonstrate purely diffusive behaviour such as isopentane, greater retention in cold weather suggests that two potential mechanisms are being affected. First, the decreased vapour pressure of the synthetic gasoline will restrict its evaporation into the soil-air. Vapour pressure is a non-linear function of temperature. A $20^{\circ} \mathrm{C}$ drop in temperature, for 
example, will significantly decrease the rate of gasoline evaporation into the soil-air. Second, subzero temperatures will have the effect of freezing water; consequently, water will expand and decrease the air permeability of the soil. Subzero temperatures thus have the effect of retarding vaporization of gasoline into the soil-air and creating greater resistance to vapour-phase diffusion. For the air-dry experiments, the effect of freezing and expanding of water will be negligible, and higher fractions of isopentane lost at room temperature temperatures must be the result of increased vapour pressure.

Figure 4.19 shows the normalized $\mathrm{Cl} 6$ ratios for cold air-dry soils against the corresponding room temperature air-dry soils. Wicking clearly occurs in cold and room temperature soils at air-dry conditions. In general, the accumulation of gasoline at the top of the columns is greater at room temperature than at cold conditions.

One exception to greater wicking at room temperature is provided by the air-dry $5 \%$ gasoline Windsor Clay Loam set of experiments. It has already been established that wicking does not occur in these experiments because there is insufficient gasoline in the pores to create the required continuous gasoline films. At cold and room temperature conditions, the $5 \%$ Clay Loam experiments demonstrate a similar inability to wick the gasoline. Immiscible phase movement is thus not a factor in these experiments at either cold or room temperatures. Given that air-dry Clay Loam was used, freezing and expansion of water at subzero conditions also cannot be responsible for a decrease in vapour-phase diffusion. As a result, greater fraction of gasoline lost at room temperature can be attributed solely to the difference in vapour pressures.

An explanation for higher wicking at room temperature in the high-gasoline content 
soils can also be found by examining the vapour pressure effect on volatilization. As previously described, accumulation of gasoline components at the top of the room temperature columns has essentially ended after 72 hours of volatilization. The cold-weather soils, as previously described, show reduced wicking after 240 hours, as gasoline levels drop to sufficiently low levels that wicking can no longer continue. Slower wicking in cold temperatures can be attributed to a vapour pressure effect. In the cold experiments, lower vapour pressures result in a lower fraction of gasoline being lost for any time point. As a result, the overall gasoline concentration gradient is reduced in the column, and wicking is slower.

Lower wicking in cold soils indicates that immiscible phase gasoline movement is another mechanism contributing to volatilization which will be retarded by cold temperatures. The effect of slower wicking acts in combination with the decreased vapour pressure to lower the fractions of gasoline lost from air-dry soils at high gasoline contents.

A further implication of wicking in lower temperature soils was examined in terms of the chemical constituents of gasoline. For the synthetic gasoline mixture used, components susceptible to solidification at the top of the columns have already been shown to be hexadecane and naphthalene. No other synthetic gasoline components were found to accumulate at the top of the columns at cold or room temperature conditions, and none of the synthetic gasoline components possessed melting points which suggested that they would solidify even at cold conditions.

A real gasoline mixture contains many more individual components, some of which may have similar properties to hexadecane and naphthalene. In particular, these properties 
are low vapour pressure and high melting point.

Freezing tests on real fuel mixtures were performed in beakers chilled to approximately $-2^{\circ} \mathrm{C}$ and placed in a fumehood. Real gasoline was added to the beakers. Volatile components were allowed to evaporate freely into the fumehood for 3 hours. This allowed less volatile components to reach their solubility in the increasingly weathered solution, and to eventually drop out of solution. Results of these tests are summarized in

Table 4.8. After 3 hours of evaporation, the gasoline had lost 57 to $66 \%$ of its initial mass, and a significant portion of the remaining gasoline had solidified. Approximately $15 \%$ of the original gasoline mixture was found to be solidified after 3 hours of evaporation. The frozen fractions were not analysed, but would assumedly be comprised of high melting point components with low vapour pressures. This solidification behaviour has implications to real gasolines spills in cold soils, which will demonstrate freezing of these high molecular weight compounds as volatiles are lost.

The results of these tests indicate that the accumulation of high molecular weight components as seen for the column experiments is possible for real gasoline mixtures.

\subsubsection{Wet Cold or Frozen and Room Temperature Experiments}

Figure 4.20 illustrates the normalized fraction of gasoline lost in the wet cold temperature experiments. Normalization for each of the cold experiments was done against the corresponding room temperature wet experiment.

As with the air-dry soils, the fraction of gasoline lost decreases with decreasing temperature. The effect of cold weather on two mechanisms has already been used to explain the different volatilization behaviour. Cold weather conditions result in lower 
overall vapour pressures, and restrictions in gasoline transfer into the soil-air. Reduced vapour pressures also decrease the liquid gradient necessary for wicking to occur, slowing the movement of the immiscible phase to the top of the column as a result.

A further factor in cold-weather wet experiments was described by Van Loon (1991). As the temperature of a soil drops to subzero temperatures, water freezes and expands, decreasing the air permeability of the soil. Individual component behaviour will be examined to determine the effect of this mechanism as well as the contributions of immiscible phase movement.

Figure 4.21 shows the normalized $\mathrm{C} / \mathrm{Co}$ ratios. Isopentane is clearly being retained in the cold experiments. For a component that will demonstrate purely diffusive behaviour such as isopentane, these differences can be explained by changes in the evaporation of chemical into soil-air, and the transport of the chemical through the soil structure. It has already been established that a decrease in vapour pressure reduces the evaporation of gasoline into the soil-air. This behaviour is also presumably affecting the loss of isopentane in the cold wet soils. Experiments were conducted to ascertain the effect of freezing conditions on air permeability through a wetted soil. The permeability experiments were conducted on Windsor Clay Loam at $30 \%$ water content at room temperature and $-5^{\circ} \mathrm{C}$. Table 4.7 indicates that the air permeability of the Windsor Clay Loam soil decreases by an average of $29 \%$ as the Clay Loam is cooled from $20^{\circ} \mathrm{C}$ to $-5^{\circ} \mathrm{C}$. This indicates that in addition to restricted evaporation of gasoline into the soil pores and slower wicking, a decrease in air permeability of wetted soils at cold temperatures also will help to increase the retention of volatiles. 
Normalized C16 ratios for the cold wet soils are presented in Figure 4.22. Normalization was done against the corresponding room temperature wet soils. There appears to be some noise in the data, and it is unclear if cold temperatures reduce wicking for the wet soils. As a result, a conclusion on hexadecane behaviour in cold wet soils compared to room temperature wet soils is not viable.

\subsection{Comparisons with Literature Values}

In this section, comparisons will be made between experimental values of volatilization found in the literature and those determined for this thesis. Comparisons are not made for all the data sets, as volatilization studies at some conditions were not found in the literature. For example, no comparison can be made with volatilization studies conducted on cold soils.

Galin et al. (1990a) found that of the spiked kerosene fuel, $36 \%$ had been lost from a silty loam, $65 \%$ from a dune sand, and $71 \%$ from a loamy sand after 14 days. All soils used in the experiment were at air-dry conditions. Experiments were conducted using columns sufficiently long $(20 \mathrm{~cm})$ as to impose a resistance on vapour phase diffusion. For comparison, fractions of gasoline lost for air-dry room temperature soils presented in this thesis were $88 \%$ for a Loamy Sand, $86 \%$ for a Silt Loam, and $88 \%$ for a Clay Loam (at $14 \%$ gasoline). These numbers compare well to the kerosene values, as lower rates of loss are expected for kerosene, given that it is composed of heavier compounds with lower vapour pressures. As a result, gasoline should be lost at a faster rate from soil than should kerosene. It is also evident that kerosene volatilization was a much greater function of soil type than was shown by the synthetic gasoline used for this thesis. Similar fractions of gasoline lost 
for the three air-dry soil experiments were attributed to the wicking mechanism. Possibly, this wicking did not occur in the kerosene experiments, and the soil properties were thus the greatest factor in volatilization.

Jarsjo et al. (1994) also performed kerosene experiments, but did so at two different temperatures on air-dry soils. After 14 days at $27^{\circ} \mathrm{C}$, cumulative loss of kerosene was $98 \%$ from sand, $92 \%$ from sandy loam and $82 \%$ from peat; at $5^{\circ} \mathrm{C}$, losses were $92 \%$ from sand, $77 \%$ from sandy loam, and 55\% from peat. Galin et al. (1990b) conducted similar experiments and arrived at almost identical results. Given the lower vapour pressure of kerosene, losses should be lower than those seen for gasoline, which they are clearly not. The high losses demonstrated here are likely a result of the experimental methods used in the kerosene experiments. Small $(40 \mathrm{~g})$ amounts of soil were added to Petri dishes, and then sprayed with kerosene. Given the significantly higher evaporative surface-soil depth ratio for a Petri dish over a column, faster volatilization is to be expected. In contrast, a column study introduces a considerable resistance because of the depth of soil through which vapours are forced to migrate. The difference in the experimental configurations is sufficient to offset the difference in vapour pressures between kerosene and gasoline.

Donaldson et al. (1992) conducted outdoor experiments using a synthetic gasoline blend in loamy sand at various water contents. The authors found that after 14 days in summer conditions, $80 \%$ of the initial gasoline mass was lost from a $0-2 \mathrm{~cm}$ depth in the soil, and that $21 \%$ was lost from $9 \mathrm{~cm}$ and below in an air-dry soil. An implication of higher losses from the soil surface is that the experiments are demonstrating an essentially diffusive process. In comparison, the experiments in this thesis show a similar behaviour with the $5 \%$ 
gasoline Clay Loam, in which no immiscible phase movement of the bulk solution was observed. The authors in the study used a $0.5 \%$ initial gasoline concentration for their experiments; this would be well below the concentrations necessary for wicking to occur. The authors also showed $55 \%$ greater loss of gasoline at wet soil conditions. This thesis shows that after 14 days, losses were $5 \%$ higher in a wet Loamy Sand and $5 \%$ higher in a wet Silt Loam as compared to air-dry conditions. It is likely that losses were greater in the wet experiments by Donaldson et al. (1992) because the soil was allowed to dry between applications of water, and the soil was mixed periodically.

Also using a synthetic gasoline blend, Arthurs et al. (1994) showed that times to reach $40 \%$ of the initial gasoline concentration were 6 hours from an Ottawa Sand, 160 hours from a Delhi Loamy Sand, and 240 hours from an Elora Silt Loam. These numbers represent slower losses of gasoline compared to the Loamy Sand and Silt Loam experiments determined in this thesis, possibly as a result of differences in the experimental apparatus. Arthurs et al.(1995) also demonstrated immiscible phase movement of the bulk solution, even though the experimental apparatus was significantly different from the columns used in this thesis.

Active venting experiments have also been conducted on organic chemicals in the soil. Fine and Yaron (1993) showed that fractions of kerosene lost in venting experiments were $40 \%$ from a high clay Nahal $\mathrm{Oz}$ soil, and $90 \%$ from a high-sand content sand after 17 days. In the former case, losses are lower than for any soils used in this thesis; presumably, venting is less successful in a low permeability soil. The sand, which exhibits a greater permeability, shows fractions of kerosene lost very similar to passive volatilization rates of 
gasoline in this thesis. This would seem reasonable, as the lower vapour pressure of kerosene is enhanced by the venting. Hickey and Paek (1996) conducted venting experiments on naphthalene, and found that $30 \%$ of the initial amount had been lost after 14 days. Under passive conditions used in this thesis, naphthalene was essentially non-volatile. Ho and Udell (1992) conducted venting experiments on higher vapour pressure components. They found that at air flow rates of $8.3 \mathrm{~L} / \mathrm{min}, 98 \%$ of the original toluene mass was lost from soil after 1400 minutes. In the experiments presented in this thesis, passive volatilization of even the most volatile component of the synthetic gasoline, isopentane, did not exhibit such fast removal from soil. Again, higher fractions of chemical loss are expected in a venting system, as air flow enhances losses.

\subsection{Engineering Significance}

Passive volatilization rates and behaviour of gasoline in soil can have a number of applications. It has been well established that spills occur from UST's and from surface sources. Once a spill has dispersed itself in the soil, volatilization becomes important. Rates of gasoline volatilization will be needed to assess impacts on, for example, air quality in buildings. This is important from both a long-term health aspect and from short-term explosion hazards resulting from excessive air concentrations. Volatilization rates can also be important in determining groundwater contamination, as gasoline vapours have been implicated in contaminating drinking water. Understanding volatilization in different soils and at different water contents will be important because of the variability in these parameters seen in natural soils.

Passive volatilization also has potential application as a remediation technique. 
Conceivably, this technique can be used in- or ex-situ. Both systems would involve maintaining conditions that would most favour evaporation of the contaminants ie., some amount of water in the soil will be helpful, but excessive amounts will impede the evaporative process. Where necessary, the soil surface can be enclosed so that vapours can be collected and subsequently treated.

Passive volatilization can also have application to remedial systems such as soil vapour extraction. In particular, natural soils contain clay lenses which are problematic for SVE systems. It is recognized that vapour transport through such clay lenses is impeded because of their low air permeability. A passive process in the clay lense results, and is important to understanding limitations on SVE systems.

Cold-weather conditions are particularly important to countries that enjoy Canadiantype climates. For a significant portion of the year, the surface soil is frozen. This will have implications on gasoline migration. Immiscible phase movement and solidification of gasoline components is important because these processes can lead to highly-concentrated regions of contaminated soil. While immiscible phase movement is most predominant at room temperature, solidification will presumably occur to a greater extent in cold temperatures.

Further, movement of chemical in the immiscible phase is generally overlooked when formulating predictive models for organic chemical migration in the soil. Results of this thesis indicate that wicking is an important process, and that it should not be ignored. 


\section{Chapter 6 Conclusions}

Based on the results of this research, the following conclusions can be made:

1. Higher initial gasoline content soils can show greater volatilization than lower gasoline content soils. Immiscible phase movement of gasoline in high initial gasoline content soils enhances volatilization of gasoline components; soils existing at conditions which do not favour this wicking show lower volatilization. For Windsor Clay Loam, a $14 \%$ initial gasoline content demonstrated wicking, while a 5\% initial gasoline content did so to a minimal level.

2. Because of wicking, surface gasoline concentrations can be higher than average gasoline concentrations. For a $14 \%$ gasoline Windsor Clay Loam, soil surface concentrations can reach levels twice the average gasoline concentration in the column. Predominantly, the surface gasoline is composed of non-volatile components which have solidified; this allows wicking to continue with time. Real gasoline mixtures can also exhibit solidification of low molecular weight compounds, particularly under cold conditions.

3. Wicking will stop when gasoline concentrations reach sufficiently low levels that the gasoline becomes poorly connected within the soil pores. At room temperatures, this occurred after 72 hours as gasoline concentrations reached $4 \%$ in Windsor Clay Loam, $5.2 \%$ in Delhi Loamy Sand and $8.7 \%$ in Elora Silt Loam. 
4. Adding water to soil will decrease volatilization; however, it will also affect immiscible phase movement. In a 5\% gasoline Windsor Clay Loam, increasing the water content up to $20 \%$ from air-dry conditions enhances wicking of gasoline. Beyond $25 \%$ water content, wicking will be inhibited.

5. Cold or frozen conditions reduce volatilization from soils. In particular, cold conditions maintain sufficient gasoline concentrations in the soil that wicking continues for 240 hours. Wicking at cold conditions is slower than at room temperatures.

6. Laboratory preparation of high clay content soils with water is best accomplished through a passive mixing process. Mechanical mixing promotes the formation of severe aggregates, especially at high water contents. 


\section{Chapter 7 Recommendations}

Based on the experimental results, the following recommendations can be made:

1. Immiscible phase movement of gasoline in soils needs to be further evaluated. In particular, the non-linear reliance of wicking on soil-water content should be investigated. Wicking as a function of the initial gasoline content of the soil should also be quantified across a range of soil types.

2. The solidification behaviour of gasoline, as a result of wicking, at the soil surface needs to be addressed. Specifically, the potential for real gasoline mixtures in field conditions to wick and subsequently solidify at the soil-atmosphere interface should be investigated.

3. The importance of wicking to models dealing with contaminant behaviour in the soil environment should be reevaluated.

4. Improvements to the experimental methodology could be made by taking measurements of the vapour-phase concentrations in addition to the soil concentrations. This would help to offset poor extraction efficiencies from wet clay soils. 


\section{Chapter 8 References}

Abriola, L.M. and Pinder, G.F. 1985. A Multiphase Approach to the Modelling of Porous Media Contamination by Organic Compounds. I. Equation Development. Water Resources Research, 21(1): 11-18.

Acher, A.J., Boderie, P. and Yaron, P. 1989. Soil Pollution by Petroleum Products, I. Multiphase Migration of Kerosene Components in Soil Columns. Journal of Contaminant Hydrology, 4: 333-345.

Arthurs, P., Stiver, W.H. and Zytner, R.G. 1995. Passive Volatilization of Gasoline from Soil. Journal of Soil Contamination, 4:123-135.

Baehr, A.L. and Corapcioglu, M.Y. 1987. A Compositional Multiphase Model for Groundwater Contamination by Petroleum Products, 2, Numerical Solution. Water Resources Research, 23(1): 201-213.

Barbee, G.C. and Brown, K.W. 1986. Movement of Xylene Through Unsaturated Soils Following Simulated Spills. Water Air and Soil Pollution, 29: 321-333.

Batterman, S., Kulshrestha, A. and Cheng, H. 1995. Hydrocarbon Vapor Transport in Low Moisture Soils. Environmental Science and Technology, 29(1): 171-180.

Bowles, J.E. 1992. Engineering Properties of Soils and their Measurement, 4th Edition. McGraw-Hill, Inc, New York, USA.

Burkhard, N. and Guth, J.A. 1981. Rate of Volatilization of Pesticides from Soil Surfaces; Comparison of Calculated Results with Those Determined in a Laboratory Model System. Pesticide Science, 12: 37-44.

Charbeneau, R.J. and Weaver, J.W. 1992. Modeling Contaminant Transport Through Subsurface Systems. Journal of Hazardous Materials, 32: 293-311.

Craig, R.F. 1992. Soil Mechanics, 4th Edition. Van Nostrand Reinhold (UK) Co. Ltd., Wokingham, Berkshire, England.

Donaldson, S.G., Miller, G.C. and Miller, W.W. 1992. Remediaton of GasolineContaminated Soil by Passive Volatilization. Journal of Environmental Quality, 21: 94-102.

English, C.W. and Loehr, R.C. 1991. Degradation of Organic Vapors in Unsaturated Soils. Journal of Hazardous Materials, 28: 55-63. 
Environment Canada Atlantic Region. 1997. State of the Environment in the Atlantic Region. http://atlenv.bed.ns.doe.ca/soe/chl-22.html.

Falta, R.W., Javandel, I., and Pruess, K. 1989. Density-Driven Flow of Gas in the Unsaturated Zone Due to Evaporation of Volatile Organic Compounds. Water Resources Research, 25(10): 2159-2169.

Fine, P. and Yaron, B. 1993. Outdoor Experiments on Enhanced Volatilization by Venting of Kerosene Component from Soil. Journal of Contaminant Hydrology, 12: 355-374.

Frind, E.O. 1982. Simulation of Long-Term Transient Density-Dependent Transport in Groundwater. Adv. Water Resources, 5:73-86.

Galin, T., Gerstl, Z. and Yaron, B. 1990a. Soil Pollution by Petroleum Products, III. Kerosene Stability in Soil Columns as Affected by Volatilization. Journal of Contaminant Hydrology, 5: 375-385.

Galin, T., McDowell, C. and Yaron, B. 1990b. The Effect of Volatilization on the Mass Flow of a Non-Aqueous Pollutant Liquid Mixture in an Inert Porous Medium: Experiments with Kerosene. Journal of Soil Science, 41: 631-641.

Goss, K. 1993. Effects of Temperature and Relative Humidity on the Sorption of Organic Vapors on Clay Minerals. Environmental Science and Technology, 27: 2127-2132.

Grass, B., Wenclawiak, B.W. and Rudel, H. 1994. Influence of Air Velocity, Air Temperature, and Air Humidity on the Volatilisation of Trifluralin from Soil. Chemosphere, 28(3): 491-499.

Grifoll, J. and Cohen, Y. 1994. Chemical Volatilization from the Soil Matrix: Transport Through the Air and Water Phases. Journal of Hazardous Materials, 37: 445-457.

Hamilton, B. 1996. Gasoline Frequently Asked Questions. Oxford University Libraries. http://micro.lib.ox.ac.uk/internet/news/faq/archive/autos.gasoline-faq.

Harper, B., Stiver, W.H. and Zytner, R.G. 1997. The Effects of Water and Free Liquid Content on SVE Contaminant Mass Transfer in Fine Grain Media. Proceedings of the Air and Waste Management Association's 90th Annual Meeting \& Exhibition, Toronto, June 813.

Hayden, N.J. and Voice, T.C. 1993. Microscopic Observation of a NAPL in a Three-FluidPhase Soil System. Journal of Contaminant Hydrology. 12: 217-226. 
Hayden, N. J., Voice, T.C. and Annable, M.D. 1992. Change in Gasoline Constituent Mass Transfer During Soil Venting. Journal of Environmental Engineering, 120(6): 1598-1614.

Hickey, W.J. and Paek, J. 1996. Ventilation Effects on Mineralization and Volatilization of Naphthalene in a Gasoline-Contaminated Subsurface Soil. Chemosphere, 32(8): 16551667.

Ho, C.K. and Udell, K.S. 1992. An Experimental Investigation of Air Venting of Volatile Liquid Hydrocarbon Mixtures from Homogeneous and Hetergeneous Porous Media. Journal of Contaminant Hydrology, 11:291-316.

Imperial Oil. 1994. Personal Communication with Dr. Larry Lawlor, Products and Chemical Division, May.

Jarsjo, J., Destouni, G. and Yaron, B. 1994. Retention and Volatilisation of Kerosene: Laboratory Experiments on Glacial and Post-Glacial Soils. Journal of Contaminant Hydrology, 17: 167-185.

Johnson, R.L. and Perott, M. 1990. Gasoline Vapor Transport Through a High-WaterContent Soil. Journal of Contaminant Hydrology, 8: 317-334.

Jury, W.A. 1986. Volatilization from Soil. Proceedings of the NWWA/API Conference on Petroleum Hydrocarbons and Organic Chemicals in Ground Water-Prevention, Detection and Restoration, November.

Jury, W.A., Spencer, W.F. and Farmer, W.J. 1983. Behavior Assessment Model for Trace Organics in Soil: I. Model Description. Journal of Environmental Quality, 12(4): 558-564.

Jury, W.A., Farmer, W.J. and Spencer, W.F. 1984. Behavior Assessment Model for Trace Organics in Soil: III. Application of Screening Model. Journal of Environmental Quality, 13(4): 573-580.

Jury, W.A., Russo, D. and Streile, G. 1990. Evaluation of Volatilization by Organic Chemicals Residing Below the Soil Surface. Water Resources Research, 26(1): 13-20.

Karimi, A.A., Farmer, W.J. and Cliath, M.M. 1987. Vapor-Phase Diffusion of Benzene in Soil. Journal of Environmental Quality, 16(1): 38-44.

Kirk-Othmer. 1990. Encyclopedia of Chemical Technology, 3rd Edition. John Wiley \& Sons, New York, USA.

Kostecki, P.T. and Calabrese, E.J. 1989. Petroleum Contaminated Soils Volume 2. Lewis Publishers, Michigan, USA. 
Marine Environmental Priorities Project. 1995. State of the Maine Marine Environment. http://www.state.me.us/dep/summary.htm\#grnd.

Mercer, J.W. and Cohen, R.M. 1990. Review of Immiscible Fluids in the Subsurface: Properties, Models and Characterization and Remediation. Journal of Contaminant Hydrology, 6: 107-163.

Morrison, R.T. and Boyd, R.N. 1983. Organic Chemistry, 4th Edition. Allyn and Bacon, Inc., Boston, USA.

Ong, S.K., Culver, T.B. and Lion, L.W. 1992. Effects of Soil Moisture and PhysicalChemical Properties of Organic Pollutants on Vapor-Phase Transport in the Vadose Zone. Journal of Contaminant Hydrology, 11: 273-290.

Petersen, A.B. 1996. Concepts of Petroleum Fractional Distillation for the Environmental Consultant. http://www.vitalnet.com/andywww/academic/distillation.

Prunty, L. 1992. Thermally Driven Water and Octane Redistribution in Unsaturated, Closed Soil Cells. Soil Science Society of America Journal, 56: 707-714.

Rogaz, A. and Hussain, L. 1994. Summer Co-op Work-Term Report, School of Engineering, University of Guelph, September.

Rutherford, D.W. and Chiou, C.T. 1992. Effect of Water Saturation in Soil Organic Matter on the Partition of Organic Compounds. Environmental Science and Technology, 26(5): 965-968.

Silka, L.R. 1988. Modeling the Transport of Volatile Organics in Variably Saturated Media. Groundwater Monitoring Review, 8(2): 115-123.

Shell Canada. 1995. Information Provided on Home Page. http://wwwshellcan.com/cmarket/gasoline.htm.

Sheppard, M.I. and Dzik, E.J. 1987. Soil Contamination by Irrigation and Capillary Rise of Groundwater. Journal of Soil and Water Conservation, May-June: 200-204.

Sheppard, M.I., Thibault, D.H. and Mitchell, J.H. 1987. Element Leaching and Capillary Rise in Sandy Soil Cores: Experimental Results. Journal of Environmental Quality, 16(3): 273-284.

Shonnard, D.R. and Bell, R.L. 1993. Benzene Emissions from a Contaminated Air-Dry Soil with Fluctuations of Soil Temperature or Relative Humidity. Environmental Science and Technology, 27: 2909-2913. 
Sleep, B.E. and Sykes, J.F. 1989. Modeling the Transport of Volatile Organics in Variably Saturated Media. Water Resources Research, 25(1): 81-92.

Smith, M., Stiver, W.H., and Zytner, R.G. 1994. The Effect of Varying Water Content on Passive Volatilization of Gasoline from Soil. Proceedings of the 49th Annual Purdue Industrial Waste Conference, West Lafayette, IN., May 9-II.

Spencer, W.F. and Cliath, M.M. 1973. Pesticide Volatilization as Related to Water Loss from Soil. Journal of Environmental Quality, 2:284-289.

Spencer, W.F., Farmer, W.J. and Jury, W.A. 1982. Behavior of Organic Chemicals at Soil, Air, Water Interfaces as Related to Predicting the Transport and Volatilization of Organic Pollutants. Environmental Toxicology and Chemistry, 1: 17-26.

Spencer, W.F., Cliath, M.M. and Jury, W.A. 1988. Volatilization of Organic Chemicals from Soil as Related to their Henry's Law Constants. Journal of Environmental Quality, 17(3): 504-510.

Swallow, J.A. and Gschwend, P.M. 1983. Volatilization of Organic Compounds from Unconfined Aquifers, Proceedings of the 3rd National Symposium on Aquifer Restoration and Groundwater Monitoring.

USEPA. 1996. Information Provided on Home Page, Office of Underground Storage Tanks. http://www.epa.gov/OUST.

Van Loon, W. 1991. Heat and Mass Transfer in Frozen Porous Media. Agricultural University Wageningen, the Netherlands.

Voudrias, E.A. and Li, C 1992. Effect of Organic Carbon on the Uptake of Benzene Vapor by Soil. Environmental Technology, 14: 189-194.

Voudrias, E.A. and Li, C. 1993. Benzene Vapor Transport in Unsaturated Soil: Adequacy of the Diffusion Equation. Journal of Hazardous Materials, 34: 295-311.

Vreeken, C., Eyk, J.V. and Loxham, M. 1990. Remedial Actions at Operating Petrochemical Sites. Geotechnique, 42(1): 23-31.

Yaron, B., Sutherland, P. and Galin, T. 1989. Soil Pollution by Petroleum Products, II. Adsorption-Desorption of Kerosene Vapors on Soils. Journal of Contaminant Hydrology, 4: 347-358.

Zaidel, J. and Russo, D. 1994. Diffusive Transport of Organic Vapours in the Unsaturated Zone with Kinetically-Controlled Volatilization and Dissolution: Analytical Model and 
Analysis. Journal of Contaminant Hydrology, 17: 145-165.

Zwolinski, B.J. and Withoit, R.C. 1971. Handbook of Vapor Pressures and Heats of Vaporization of Hydrocarbons and Related Compounds, API44-TRC Publications in Science and Engineering, College Station, Texas.

Zytner, R.G., Biswas, N. and Bewtra, J.K. 1989. PCE Volatilized from Stagnant Water and Soil. Journal of Environmental Engineering, 115(6): 1199-1212.

Zytner, R.G. 1994. Sorption of Benzene, Toluene, Ethylbenzene and Xylenes to Various Media. Journal of Hazardous Materials, 38: 113-126. 
Appendix A

Temperature Program for Datalogger 


\section{Datalogging Temperature Program}

Following is the temperature logging program for the CR10 and CR10X dataloggers. The program allows for input by five Type $T$ thermocouples. Temperatures are noted every minute, and the hourly average of the minute data is recorded by the datalogger's internal memory and by a floppy disk in the attached computer. Two reference temperature are also included, one internally in the datalogger and one from an attached thermistor.

\section{\}$; \mathrm{CR} 10$}

;B:TEJ.DLD

;\$

;:Ref. Temp:cr10-temp:temp\#1 :temp\#2 :temp\#3

;:temp\#4 :temp\#5 :

;:therm. V

;\$

MODE 1

SCAN RATE 60

1:P5

I:1

$2: 22$

$3: 1$

4:3

5:2000

$6: 11$

7:800

8:0

2:P55

1:1

2:11

$3: 1$

4:-53.46

5:90.807

6:-83.257

7:52.283

8:-16.723

9:2.211

3:P17

1:2

4:P14

1:5

2:23

$3: 2$

4:1 


5:1
$6: 3-$
$7: 1$
$8: 0.0000$
$5: P 92$
$1: 0$
$2: 60$
$3: 10$
$6: P 77$
$1: 1110$
$7:$ P71
$1: 7$
$2: 1$
MODE 2
SCAN RATE 0.0000
MODE 3
MODE 10
$1: 28$
$2: 64$
3:0.0000
MODE 12
1:0000
$2: 0000$
$3: 0000$
\$2⿺


Appendix B

Extraction Efficiency Data and Sample.Calculations 
Extraction Efficiency Data and Sample Calculati

\begin{tabular}{|l|cccccc|}
\hline Soil Type & $\begin{array}{c}\text { Mass of } \\
\text { Soil (g) }\end{array}$ & $\begin{array}{c}\text { Mass of } \\
\text { Water (g) }\end{array}$ & $\begin{array}{c}\text { Mass of } \\
\text { Gasoline (g) }\end{array}$ & $\begin{array}{c}\text { Gasoline } \\
\text { onc (g gas } \\
\text { g dry soil) }\end{array}$ & $\begin{array}{c}\text { Extracted } \\
\text { onc (g gas } \\
\text { g dry soil) }\end{array}$ & \\
\hline DLS (Air-Dry & 5.25 & 0.00 & 0.77 & 0.1467 & 0.1455 & 99 \\
DLS (Air-Dry & 6.75 & 0.00 & 0.98 & 0.1455 & 0.1446 & 99 \\
DLS (Air-Dry & 9.87 & 0.00 & 1.41 & 0.1425 & 0.1414 & 99 \\
DLS (Wet) & 7.34 & 0.34 & 0.87 & 0.1190 & 0.1027 & 86 \\
DLS (Wet) & 9.65 & 0.45 & 1.09 & 0.1133 & 0.0984 & 87 \\
DLS (Wet) & 6.2 & 0.25 & 0.77 & 0.1234 & 0.1061 & 86 \\
ESL (Air-Dry & 5.98 & 0.00 & 1.06 & 0.1772 & 0.1761 & 99 \\
ESL (Air-Dry & 10.75 & 0.00 & 1.87 & 0.1743 & 0.1734 & 99 \\
ESL (Air-Dry & 8.86 & 0.00 & 1.56 & 0.1757 & 0.1750 & 100 \\
ESL (Wet) & 7.61 & 0.42 & 1.01 & 0.1325 & 0.1079 & 81 \\
ESL (Wet) & 7.29 & 0.39 & 0.96 & 0.1317 & 0.1059 & 80 \\
ESL (Wet) & 5.88 & 0.34 & 0.78 & 0.1327 & 0.1094 & 82 \\
WCL (Air-Dr & 12.3 & 0.00 & 0.63 & 0.0510 & 0.0501 & 98 \\
WCL (Air-Dr & 11.89 & 0.00 & 0.62 & 0.0526 & 0.0515 & 98 \\
WCL (Air-Dr & 10.22 & 0.00 & 0.53 & 0.0514 & 0.0507 & 99 \\
WCL (Wet) & 7.74 & 0.19 & 0.41 & 0.0532 & 0.0359 & 68 \\
WCL (Wet) & 6.2 & 0.16 & 0.33 & 0.0526 & 0.0358 & 68 \\
WCL (Wet) & 7.54 & 0.17 & 0.45 & 0.0591 & 0.0401 & 68 \\
WCL (Wet+ & 7.21 & 0.19 & 0.37 & 0.0513 & 0.0435 & 85 \\
WCL (Wet+ & 9.46 & 0.24 & 0.44 & 0.0468 & 0.0393 & 84 \\
WCL (Wet+ & 3.65 & 0.10 & 0.18 & 0.0481 & 0.0404 & 84 \\
\hline
\end{tabular}

eg. DLS Wet Test \#1

$\begin{array}{llr}\text { Gas Conc. (g gasoline/g dry } & = & 0.87 \mathrm{~g} / 7.34 \mathrm{~g} \\ & = & 0.119\end{array}$

$\%$ Extracted $=\quad 0.102710 .1190 * 100$

$=86$

Note: extracted concentrations derived from GC data; for calculations relating to GC data, see Appendix D 
Appendix C

Soil Gasoline Concentration Sample Calculations 


\section{Soil Concentration Sample Calculations}

eg. WCL air-dry $5 \%$ gasoline, 3 day time duration, slice 8

Component Calibration

Note: calibration is performed individually for all components; the calibration procedure is shown here for hexadecane only

\begin{tabular}{|l|cr|}
\hline & $\begin{array}{c}\text { Hexadecane } \\
\text { Conc (g C16/ } \\
\mathrm{g} \mathrm{dry} \mathrm{soil)*100}\end{array}$ & GC Response \\
\hline Point 1 & 1.0332 & 62172200 \\
Point 2 & 0.009586 & 642713 \\
Point 3 & 0.000197 & 3748 \\
\hline
\end{tabular}

Constant

Regression Output:

Std Err of $Y$ Est

28846.212637

52477.85288

$R$ Squared

0.9999989202

No. of Observations

Degrees of Freedom

3

$X$ Coefficient(s)

Std Err of Coef.

60149695.248

62503.667855

Repeat calibration for other chemicals

Stock Solution

Stock Solution

\begin{tabular}{|c|c|c|c|}
\hline Component & GC Response & $\begin{array}{l}\text { Conc. in } \\
\text { Stock }\end{array}$ & $\begin{array}{c}\text { Mass \% in } \\
\text { Stock }\end{array}$ \\
\hline Isopentane & 39809500 & 0.8469134442 & 21.205198492 \\
\hline MTBE & 3422972 & 0.0850295298 & 2.1289874054 \\
\hline Hexane & 36332600 & 0.7369651026 & 18.452288587 \\
\hline MCP & 18172000 & 0.3136831282 & 7.8540647116 \\
\hline Isooctane & 26746900 & 0.4641794117 & 11.622222586 \\
\hline Toluene & 47659100 & 0.7298345483 & 18.273752256 \\
\hline m-Xylene & 32353200 & 0.4787810378 & 11.987821199 \\
\hline 135-TMB & 14747700 & 0.2223204112 & 5.5665056221 \\
\hline Naphthalene & 4008909 & 0.0573849727 & 1.4368171211 \\
\hline Hexadecane & 3538685 & 0.0588038 & 1.4723420198 \\
\hline & & 9938953863 & \\
\hline
\end{tabular}


eg. hexadecan

GC Response $=$

Conc in Stock $=$ 3538685

(GC Response-Constant)/St 0.058803 g Ci6lg stock

Mass $\%$ in Sto $=$

C16 Conc. in Stock/Sum (Conc. in Stock)*1 1.47

Slice 8 (5\% Gasoline WCL, 3Day)

Note: stice mass and mass of dry soil are determined by the amount of soil and gasoline added to the column during column constructi

\begin{tabular}{|c|c|c|c|c|c|c|c|}
\hline $\begin{array}{l}\text { Mass Sample } \\
\text { Mass Solvent } \\
\text { Mass Soil (q) }\end{array}$ & $\begin{array}{r}4.0148 \\
13.1879 \\
3.93\end{array}$ & $\begin{array}{l}\text { Mass Diy Soil } \\
\text { Slice Mass (g }\end{array}$ & & $\begin{array}{r}56.16 \\
58.968\end{array}$ & & & \\
\hline Chernical & GC Response & Mass \% & $\begin{array}{l}\text { Vial Conc. } \\
\text { (g comp/g } \\
\text { solt+gas) }\end{array}$ & $\begin{array}{l}\text { Soil Conc. } \\
\text { (g complg } \\
\text { soil) }\end{array}$ & $\begin{array}{l}\text { Mass of } \\
\text { Comp in } \\
\text { Slice (q) }\end{array}$ & $\begin{array}{c}\text { Initial } \\
\text { Mass \% }\end{array}$ & $\begin{array}{l}\text { Initial Ma } \\
\text { Comp in } \\
\text { Slice (g) }\end{array}$ \\
\hline Isopentane & 479430 & 0.010199467 & 0.000335034 & 0.000342379 & 0.01922801 & 1.009771368 & 0.59544 \\
\hline $\begin{array}{l}\text { MTBE } \\
\text { Hexane }\end{array}$ & & $\begin{array}{l}0.020157206 \\
0.060339126\end{array}$ & & 0.000676643 & 0.038000316 & 0.101380353 & $\begin{array}{r}0.05978 \\
0.51814\end{array}$ \\
\hline MCP & 697 & 0.028259445 & 0.000928272 & 0.000948622 & 0.05327463 & 0.37400308 & 0.22054 \\
\hline Isooctane & 4862508 & 0.084385456 & 0.002771944 & 0.002832712 & 0.159085143 & 0.553 & 0.32635 \\
\hline Toluene & 1185330 & 0.181517230 & 0.005962516 & 0.006093230 & 0.342195845 & 0.870178689 & 0.51312 \\
\hline $\begin{array}{l}\text { m-Xylene } \\
\text { 135-TMB }\end{array}$ & $\begin{array}{r}1040980 \\
4905543\end{array}$ & $\begin{array}{l}0.154050135 \\
0.073950572\end{array}$ & $\begin{array}{l}0.005060271 \\
0.002429147\end{array}$ & $\begin{array}{l}0.005171206 \\
0.002482400\end{array}$ & $\begin{array}{l}0.290414943 \\
0.139411629\end{array}$ & $\begin{array}{l}0.570848635 \\
0.265071699\end{array}$ & $\begin{array}{l}0.33661 \\
0.15630\end{array}$ \\
\hline Naphthalene & & & 12494 & & 0.036873524 & 0.068419863 & 0.04034 \\
\hline Hexadecar & 191217 & & 000078563 & 0.000693439 & 0.038943547 & 0.070111468 & 0.04134 \\
\hline
\end{tabular}

eg. isopentane

GC Response =

Mass\%

$=$

Vial Conc. =

Mass Soil =

$=$

Soil Conc. =

Mass $\mathrm{C}_{16}$ in Slice

Initial Mass $\%=$

$=$

Initial Mass of C16 in Slice
1243127

(GC Response-Constant)/Slop 0.0207

(Mass\%" Mass Solvent)/Mass of Sample/100 $0.000679 \mathrm{~g}$ C16/g sample

Mass Sample-Sum(Vial Conc)"Mass Sample 3.93 g sample-g gasoline

(Mass\% * Mass Solvent)/Mass of Soil $0.000693 \mathrm{~g} \mathrm{C} 16 / \mathrm{g}$ dry soi

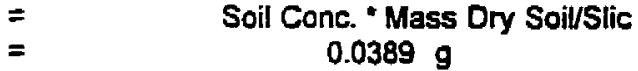

Initial Gasoline\% (wet basis)"Mass\% in Stock/100 $4.76 \% * 1.47 \% / 100$ 0.0701

$\begin{array}{cc}= & \text { Initial Mass\%"Total Slice Mass } / 100 \\ = & 0.0701^{* 58.96 / 100} \\ = & 0.0413 \mathrm{~g}\end{array}$


Appendix D

Graph Sample Calculations 


\section{Sample Calculations for Normalized Fractions of Gasoline Lost Graphs}

eg. 336 hour data point for air-dry Windsor Clay Loam (room temperature) at $5 \%$ gasoline

Total gasoline in WCL $5 \%$ gasoline -336 hours:

Total gasoline in WCL $5 \%$ gasoline -0 hours:

Fraction of gasoline lost
$10.43 \mathrm{~g}$

$30.79 \mathrm{~g}$

$1-10.43 / 30.79$

$=$

0.66

Total gasoline in WCL 14\% gasoline -336 hours:

Total gasoline in WCL $14 \%$ gasoline -0 hours:

Fraction of gasoline lost

$9.57 \mathrm{~g}$

$82.69 \mathrm{~g}$

$1-9.57 / 82.69$

0.88

Normalized fraction of gasoline lost (nomalized against $14 \%$ gasoline figure)

$=$

$0.66 / 0.88$

$=$

Repeat for other times

\section{Sample Calculations for Isopentane C/Co Graph}

eg. 24 hour data point for air-dry Windsor Clay Loam (room temperature) at $5 \%$ gasoline

WCL $5 \%$ isopentane concentration at 24 hours:

$0.00133 \mathrm{~g}$ isop/g dry soi

WCL $5 \%$ isopentane concentration at 0 hours:

$0.00568 \mathrm{~g}$ isop/g dry soi

Isopentane C/C

$=\quad 0.00133 / 0.00568$

$=\quad 0.234$

Repeat for other times

Sample Calculations for C16 Ratio Graphs

eg. 240 hour data point for air-dry Windsor Clay Loam (room temperature) at $5 \%$ gasoline

for 240 hours:

WCL $5 \%$ hexadecane concentration at top column slice:

WCL $5 \%$ average hexadecane concentration in column:

$0.000644 \mathrm{~g}$ hexad/g dry soil

C16 Ratio

$=$

$0.000597 / 0.000644$

$=\quad 1.0776699029$

Repeat for other times 
Appendix E

Cold Temperature Delhi Loamy Sand and Elora Silt Loam Volatilization Data 
Delhi Loamy Sand: 14.5\% Gasoline, 0.5\% Water (Air Dry)

\begin{tabular}{|c|c|c|c|c|c|c|c|c|c|c|c|}
\hline & & & & & & & & & & & \\
\hline Themical & $20 \mathrm{~cm}$ & $18 \mathrm{~cm}$ & $16 \mathrm{~cm}$ & $14 \mathrm{~cm}$ & $12 \mathrm{~cm}$ & $10 \mathrm{~cm}$ & $8 \mathrm{~cm}$ & $6 \mathrm{~cm}$ & $4 \mathrm{~cm}$ & $2 \mathrm{~cm}$ & $\mathrm{~cm}$ \\
\hline & 0.01901 & 0,01329 & 0.016443 & 0.015243 & 0.014556 & 0.01411 & 0.012975 & 0.011958 & 0.01184 & 0.008131 & 0,010304 \\
\hline & 101306 & 000752 & 000855 & 0.002182 & 100848 & 0.000822 & 0.000755 & 0.000748 & 0,000721 & 0.001065 & \\
\hline & & & & & & & & & & 0.009625 & \\
\hline & 0.009376 & 005162 & 0,005898 & 0.007115 & 0.006072 & 0.006008 & 0.005707 & 0.005517 & 0.005474 & 0.003394 & \\
\hline & 0.02512 & 013292 & 0.01476 & 0.016739 & 0.015221 & 0.015238 & 0.014482 & 0.014086 & 0.014002 & 0.007889 & 0.01219 \\
\hline & 0.039567 & .020606 & 231 & 0.025597 & 0.0231 & 0.023098 & 0.022047 & 0.021649 & 0.021303 & 0.012092 & 8604 \\
\hline & 0.026688 & .014004 & 0.015191 & 0.017127 & 0.015319 & 0.01551 & 0.014943 & 0.014585 & 0.014671 & 0.008234 & 0.01 \\
\hline & 0,015116 & 008057 & 0.008727 & 0.009771 & 0.008675 & 0.008846 & 0,008574 & 008353 & 0.008445 & 0.004752 & 0.00 \\
\hline & 3064 & 002716 & & 0.003282 & 2889 & & 0.002855 & & 0.00 & 601 & 476 \\
\hline exadecane & 0.002628 & 01434 & .001521 & 0.001704 & 1483 & 001522 & 0.001456 & 1.001 & 0.001409 & 0,000829 & 0.00126 \\
\hline
\end{tabular}

Delhi Loamy Sand: 14.5\% Gasoline, 0.5\% Water (Air Dry)

\begin{tabular}{|c|c|c|c|c|c|c|c|c|c|c|c|}
\hline Chemical & $20 \mathrm{~cm}$ & $18 \mathrm{~cm}$ & $16 \mathrm{~cm}$ & $14 \mathrm{~cm}$ & $12 \mathrm{~cm}$ & $10 \mathrm{~cm}$ & $8 \mathrm{~cm}$ & $6 \mathrm{~cm}$ & $4 \mathrm{~cm}$ & $2 \mathrm{~cm}$ & $0 \mathrm{~cm}$ \\
\hline Isopentane & $\overline{0.029309}$ & 0.024421 & 0.022812 & 0.020496 & 0.01719 & 0.019591 & 0.012988 & 0.013492 & 0.008262 & 0.011384 & 0.005633 \\
\hline MTBE & 0.005011 & 0.000529 & 0.004574 & 0.00594 & 0.005183 & 0.000431 & 0.004237 & 0.000338 & 0,005444 & 0.0041 & 0.003695 \\
\hline Hexane & 0.025338 & 0.014981 & 0.02138 & 0.020448 & 0.018269 & 0.012167 & 0.015366 & 0,009294 & 0,015085 & 0.01476 & 0,012347 \\
\hline Methylcyclopentane & 0.008491 & 0.005847 & 0.00714 & 0.006645 & 0.005979 & 0,004315 & 0.00513 & 0,003766 & 0,004868 & 0.004919 & 0.004236 \\
\hline Isooctane & 0,017327 & 0.014457 & 0.01461 & 0.012176 & 0.011418 & 0.011917 & 0.009989 & 0,009528 & 0.009094 & 0.010147 & 0,011717 \\
\hline Toluene & 0.02744 & 0.023044 & 0.023324 & 0.0193 & 0.018288 & 0.019033 & 0.016159 & 0.015458 & 0.014994 & 0.017096 & 0.023383 \\
\hline m-Xylene & 0.018927 & 0.016209 & 0.016284 & 0.013797 & 0.013128 & 0.013425 & 0.011488 & 0.011031 & 0.011266 & 0.013033 & 0.021223 \\
\hline 135-trimethylbenze & 0.010208 & 0.008856 & 0.008841 & 0.007638 & 0.007262 & 0.007337 & 0.006313 & 0.006054 & 0.006351 & 0.007351 & 0.012526 \\
\hline Naphthalene & 0.004299 & 0.003756 & 0.003747 & 0.00326 & 0.003103 & 0.003114 & 0.002699 & 0.00259 & 0.002754 & 0.003157 & 0.005406 \\
\hline Hexadecane & 0.002201 & 0.001918 & 0.001913 & 0.001669 & 0.001584 & 0.001589 & 0.001368 & 0.001306 & 0.001413 & 0.001607 & 0.002768 \\
\hline
\end{tabular}


Delhi Loamy Sand: $14.5 \%$ Gasoline, $0.5 \%$ Water (Air Dry)

\begin{tabular}{|c|c|c|c|c|c|c|c|c|c|c|c|}
\hline \multirow{2}{*}{$\begin{array}{l}\text { Duration: } 2 \text { h } \\
\text { Chemical }\end{array}$} & \multirow[b]{2}{*}{$20 \mathrm{~cm}$} & \multirow[b]{2}{*}{$18 \mathrm{~cm}$} & \multirow[b]{2}{*}{$16 \mathrm{~cm}$} & \multicolumn{7}{|c|}{ (omponcent (oncentration (e component/g dry soil) } & \multirow[b]{2}{*}{$10 \mathrm{~cm}$} \\
\hline & & & & $14 \mathrm{~cm}$ & $12 \mathrm{~cm}$ & $10 \mathrm{~cm}$ & $8 \mathrm{~cm}$ & $6 \mathrm{~cm}$ & $4 \mathrm{~cm}$ & $2 \mathrm{~cm}$ & \\
\hline Isopentane & 0.027735 & 0.020775 & 0.02096 & 0.016947 & 0.014707 & 0.01017 & 0.012477 & 0.010839 & 0.004926 & 0,004911 & 0.004503 \\
\hline MTBE & 0.005217 & 0.000601 & 0.000583 & 0.000484 & 0.006506 & 0.000492 & 0.000388 & 0.005459 & 0.004529 & 0.00495 & 0.005205 \\
\hline Hexane & 0.027372 & 0.014764 & 0.014486 & 0.012094 & 0.018871 & 0,011348 & 0,009568 & 0,015843 & 0.012941 & 0.013058 & 0.013292 \\
\hline Methylcyclopentane & 0.009324 & 0.005904 & 0.005812 & 0,005071 & 0.006164 & 0.004629 & 0.003411 & 0,005108 & 0.00432 & 0.004312 & 0.00439 \\
\hline Isooctane & 0.019853 & 0.015061 & 0.014683 & 0,012518 & 0.01149 & 0.012284 & 0.009757 & 0.009367 & 0.010535 & 0.010156 & 0.010579 \\
\hline Toluene & 0.032653 & 0.024848 & 0.023875 & 0.02083 & 0.019009 & 0.020911 & 0,016172 & 0.015499 & 0.019859 & 0.018602 & 0.019213 \\
\hline$m$-Xylene & 0.02255 & 0.017717 & 0.017044 & 0.015036 & 0.013992 & 0.015107 & 0.011848 & 0.011426 & 0.017061 & 0.015539 & 0.015863 \\
\hline 135-trimethylbenze & 0.012674 & 0.010186 & 0.009793 & 0,00873 & 0.008208 & 0.008737 & 0.006928 & 0.006718 & 0.010503 & 0.009462 & 0.009576 \\
\hline Naphthalene & 0.003696 & 0.003011 & 0.002894 & 0.002597 & 0.002459 & 0.002601 & 0,00208 & 0.002024 & 0.003188 & 0,00286 & 0.002888 \\
\hline Hexadecane & 0.002004 & 0.001639 & 0.001579 & 0.001418 & 0.001339 & 0,001415 & 0.001129 & 0.001096 & 0.001753 & 0.001586 & 0.001585 \\
\hline
\end{tabular}

ลั

Delhi Loamy Sand: $14.5 \%$ Gasoline, 0.5\% Water (Air Dry)

\begin{tabular}{|c|c|c|c|c|c|c|c|c|c|c|c|}
\hline Duration: $6 \mathrm{~h}$ & & & & & III & (1) & 101018 & 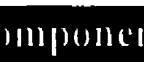 & I/n dry & s(iil) & \\
\hline Chemical & $20 \mathrm{~cm}$ & $18 \mathrm{~cm}$ & $16 \mathrm{~cm}$ & $14 \mathrm{~cm}$ & $12 \mathrm{~cm}$ & $10 \mathrm{~cm}$ & $8 \mathrm{~cm}$ & $6 \mathrm{~cm}$ & $4 \mathrm{~cm}$ & $2 \mathrm{~cm}$ & $0 \mathrm{~cm}$ \\
\hline Isopentane & 0.034853 & 0.026062 & 0.025016 & 0.02346 & 0.021311 & 0.019568 & 0.01751 & 0.015015 & 0.012713 & 0.006558 & 0.0038 \\
\hline MTBE & 0.005536 & 0.000606 & 0.005589 & 0.000558 & 0.000468 & 0.000455 & 0.000356 & 0.000328 & 0.000355 & 0.004089 & 0.000186 \\
\hline Hexane & 0.028005 & 0.015292 & 0.021468 & 0.01406 & 0.012084 & 0.011308 & 0.0096 & 0.008554 & 0.009168 & 0.013558 & 0.005738 \\
\hline Methylcyclopentane & 0.009542 & 0.005971 & 0.007135 & 0.004956 & 0.004784 & 0.004138 & 0.004074 & 0.003611 & 0.003335 & 0.004538 & 0.002274 \\
\hline Isooctane & 0.018095 & 0.013776 & 0.012747 & 0.012614 & 0.010934 & 0.010622 & 0,009101 & 0.008186 & 0,008506 & 0.009885 & 0.009179 \\
\hline Toluene & 0.031351 & 0.023986 & 0.02196 & 0.021921 & 0.01889 & 0.018499 & 0.015443 & 0.014076 & 0.014795 & 0.018461 & 0.019098 \\
\hline m-Xylene & 0.020379 & 0.015769 & 0.01457 & 0.014368 & 0.012489 & 0.012407 & 0.010411 & 0.00951 & 0.009903 & 0,013538 & 0.015699 \\
\hline 135-trimethylbenze & 0.014208 & 0.011087 & 0.010303 & 0.010077 & 0.008816 & 0.008824 & 0.007456 & 0.00682 & 0.007039 & 0.009877 & 0.011898 \\
\hline Naphthalene & 0.003346 & 0.002642 & 0.002468 & 0.002401 & 0.002112 & 0,002123 & 0.001802 & 0.001656 & 0.001701 & 0.002383 & 0.002897 \\
\hline Hexadecane & 0.001975 & 0.001553 & 0.001453 & 0.001411 & 0,001239 & 0.001245 & 0,001064 & 0.000972 & 0.000994 & 0,001407 & 0.001717 \\
\hline
\end{tabular}



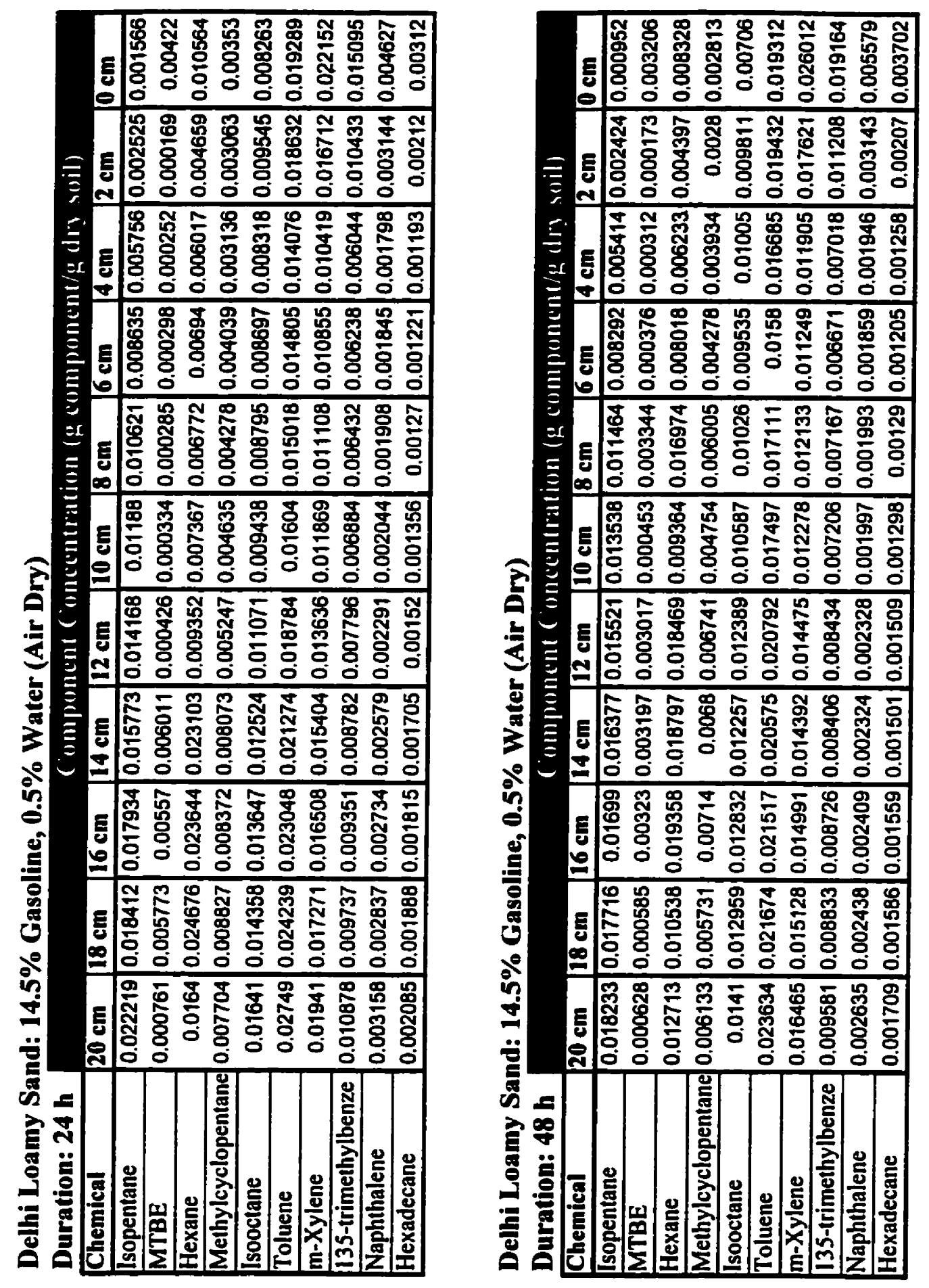
Delhi Loamy Sand: 14.5\% Gasoline, 0.5\% Water (Air Dry)

\begin{tabular}{|c|c|c|c|c|c|c|c|c|c|c|c|}
\hline \multirow{2}{*}{$\begin{array}{l}\text { Duration: } 72 \mathrm{~h} \\
\text { Chemical }\end{array}$} & & & \multicolumn{9}{|c|}{ (omponent Concentration (g component/g dry soil) } \\
\hline & $20 \mathrm{~cm}$ & $18 \mathrm{~cm}$ & $116 \mathrm{~cm}$ & $14 \mathrm{~cm}$ & $12 \mathrm{~cm}$ & $10 \mathrm{~cm}$ & $8 \mathrm{~cm}$ & $6 \mathrm{~cm}$ & $4 \mathrm{~cm}$ & $2 \mathrm{~cm}$ & $0 \mathrm{~cm}$ \\
\hline Isopentane & 0.014289 & 0.013905 & 0.014132 & 0.011544 & 0.010456 & 0.007953 & 0.006002 & 0.003381 & 0.00214 & 0.000549 & 0.000338 \\
\hline MTBE & 0.004972 & 0.005023 & 0.000413 & 0.000349 & 0.000363 & 0.005909 & 0.000316 & 0.005616 & 0,000186 & 0,004429 & 4.45E-05 \\
\hline Hexane & 0.018812 & 0.018729 & 0.010911 & 0,009679 & 0.009545 & 0.016259 & 0.009587 & 0.016099 & 0.00694 & 0.007712 & 0.001842 \\
\hline Methylcyclopentane & 0.005638 & 0.005616 & 0.003717 & 0.003681 & 0.003765 & 0.004853 & 0.003847 & 0.004917 & 0,002942 & 0,002245 & 0.001089 \\
\hline sooctane & 0.010378 & 0.010169 & 0.010078 & 0.009026 & 0.00898 & 0.008222 & 0.009688 & 0.009727 & 0.010703 & 0.007866 & 0.006858 \\
\hline Toluene & 0.016176 & 0.015872 & 0.015739 & 0.014137 & 0.014142 & 0.012878 & 0.015186 & 0.015202 & 0.017064 & 0.017632 & 0.017109 \\
\hline $\mathbf{m}$-Xylene & 0.012045 & 0.011788 & 0.011826 & 0.010638 & 0.010717 & 0.00981 & 0.011493 & 0.011557 & 0,013251 & 0.023347 & 0.026936 \\
\hline 135-trimethylbenze & 0.006312 & 0,006176 & 0.00625 & 0.005618 & 0.005681 & 0.005215 & 0.006067 & 0.006099 & 0.006916 & 0.017707 & 0.022021 \\
\hline Naphthalene & 0.001958 & 0.001916 & 0.001947 & 0.001753 & 0.001776 & 0.001627 & 0,001883 & 0.00189 & 0.002121 & 0.006054 & 0,007865 \\
\hline Hexadecane & 0.001172 & 0,00115 & 0,001175 & 0.001064 & 0.001065 & 0.000968 & 0.00112 & 0,001119 & 0.001255 & 0.003801 & 0,004866 \\
\hline
\end{tabular}

$\bar{\ddagger}$

Delhi Loamy Sand: 14.5\% Gasoline, 0.5\% Water (Air Dry)

\begin{tabular}{|c|c|c|c|c|c|c|c|c|c|c|c|}
\hline Juration: $120 \mathrm{~h}$ & & & & (III) & III & centist & $\operatorname{lin}(20$ & $m p m n$ & $1 / g$ di? & (iil) & \\
\hline Chemical & $20 \mathrm{~cm}$ & $18 \mathrm{~cm}$ & $16 \mathrm{~cm}$ & $14 \mathrm{~cm}$ & $12 \mathrm{~cm}$ & $10 \mathrm{~cm}$ & $8 \mathrm{~cm}$ & $6 \mathrm{~cm}$ & $4 \mathrm{~cm}$ & $2 \mathrm{~cm}$ & $0 \mathrm{~cm}$ \\
\hline Isopentane & 0.011554 & 0.010091 & 0.01048 & 0.008761 & 0.007788 & 0.006231 & 0.005565 & 0,003579 & 0,002452 & 0,001019 & 0.000589 \\
\hline MTBE & 0.000279 & 0,00703 & 0.000272 & 0.000248 & 0.000236 & 0.000207 & 0.00021 & 0.006428 & 0.000115 & 5.13E-05 & 2.31E-05 \\
\hline Hexane & 0.0075 & 0.015481 & 0.007237 & 0.006953 & 0.006711 & 0.006154 & 0.006581 & 0.013471 & 0.003982 & 0.001737 & 0.000992 \\
\hline Methylcyclopentane & 0.003335 & 0.004694 & 0.002819 & 0.003165 & 0,003037 & 0.002917 & 0.003015 & 0.0041 & 0.002178 & 0,000901 & 0.000548 \\
\hline Isooctane & 0.007845 & 0.006895 & 0.007677 & 0,007418 & 0.007187 & 0,006998 & 0,007795 & 0.007484 & 0.008089 & 0.005905 & 0.004435 \\
\hline Toluene & 0.01342 & 0.011807 & 0.01318 & 0.012758 & 0.012368 & 0.01201 & 0.013279 & 0.012711 & 0.014539 & 0.014067 & 0.013187 \\
\hline m-Xylene & 0.009246 & 0.008242 & 0.009151 & 0.008819 & 0.00852 & 0.008317 & 0,009101 & 0.008838 & 0.010802 & 0.015932 & 0.020686 \\
\hline 135-trimethylbenze & 0.006008 & 0.005408 & 0.005988 & 0.00575 & 0.005548 & 0.005433 & 0,005916 & 0.005772 & 0.007004 & 0.015611 & 0.023381 \\
\hline Naphthalene & 0.002088 & 0.001892 & 0.002092 & 0.002005 & 0.001936 & 0.001898 & 0.002068 & 0.002018 & 0.002409 & 0.005853 & 0.012771 \\
\hline Hexadecane & 0.000932 & 0.000851 & 0.00094 & 0.0009 & 0.000867 & 0.000847 & 0,000934 & 0.000912 & 0.001086 & 0,003452 & 0.005604 \\
\hline
\end{tabular}



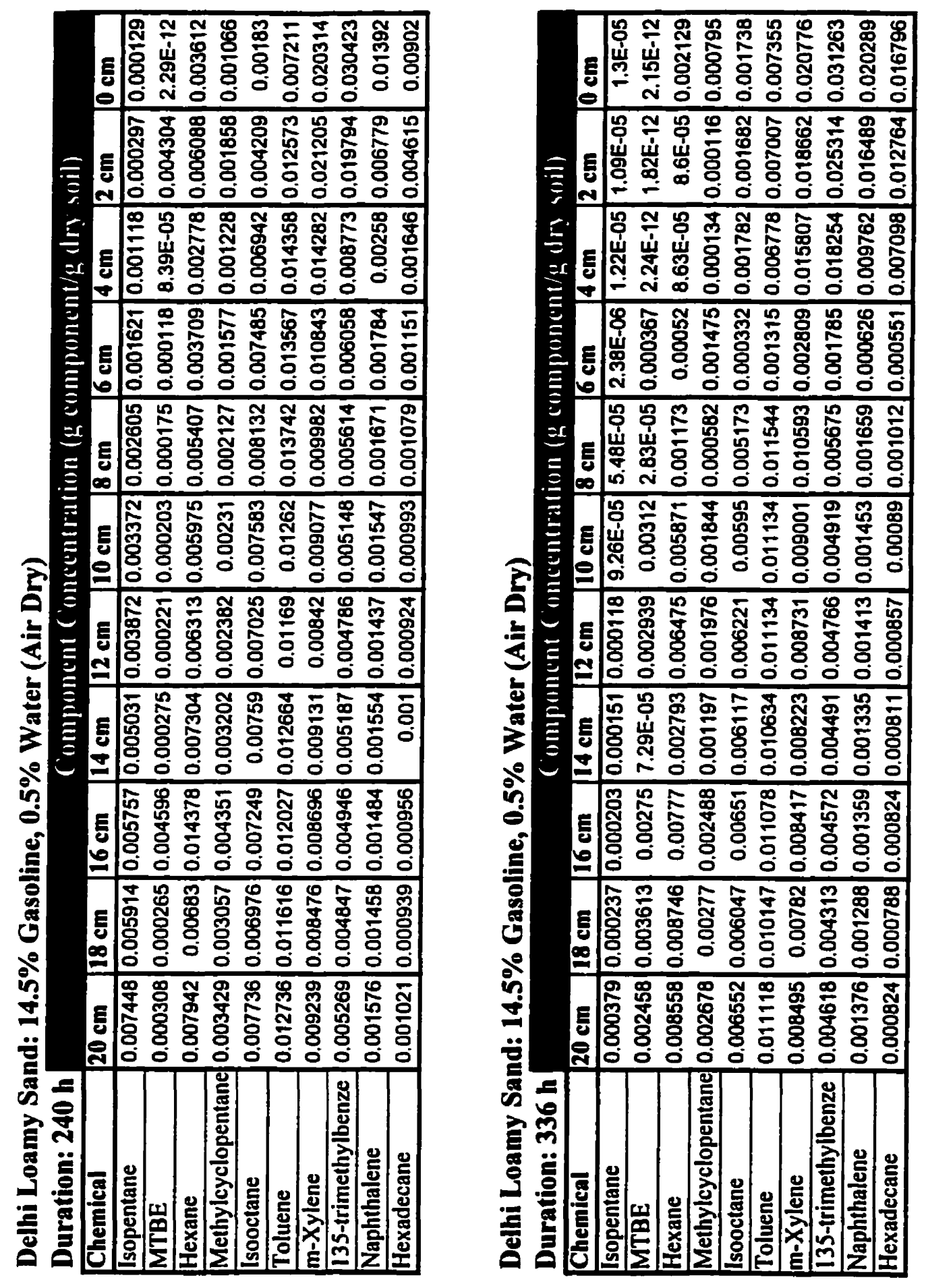

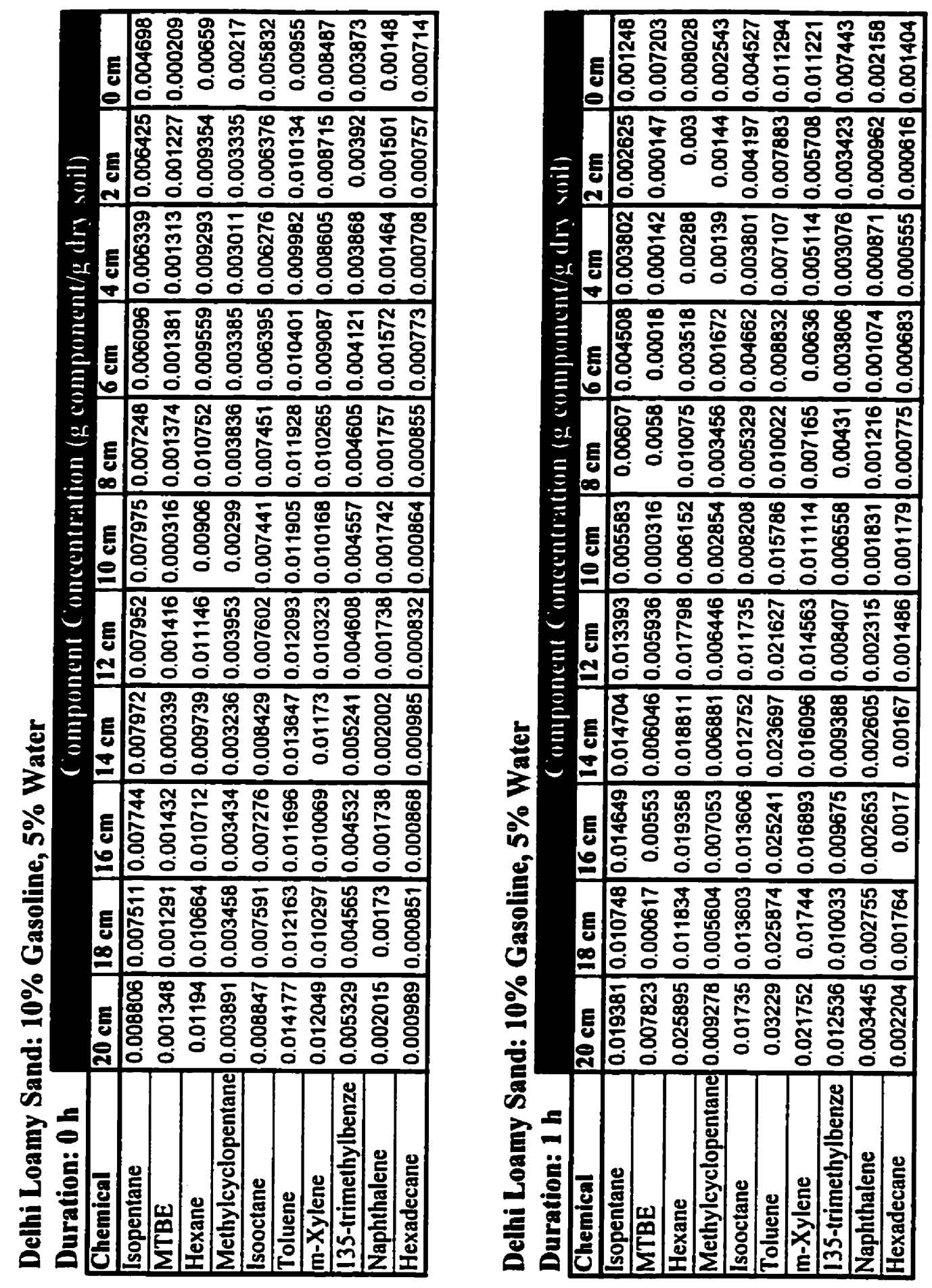

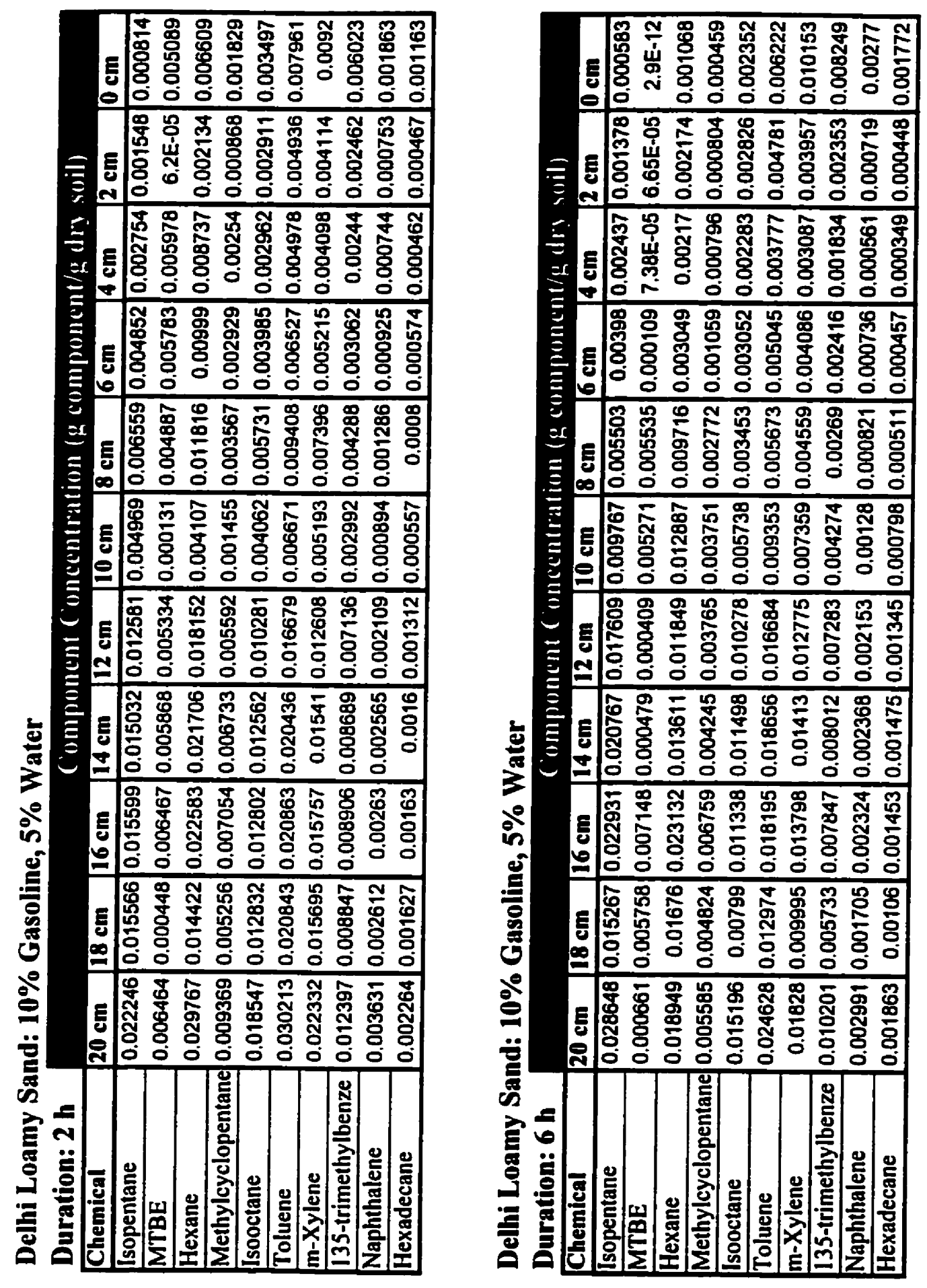

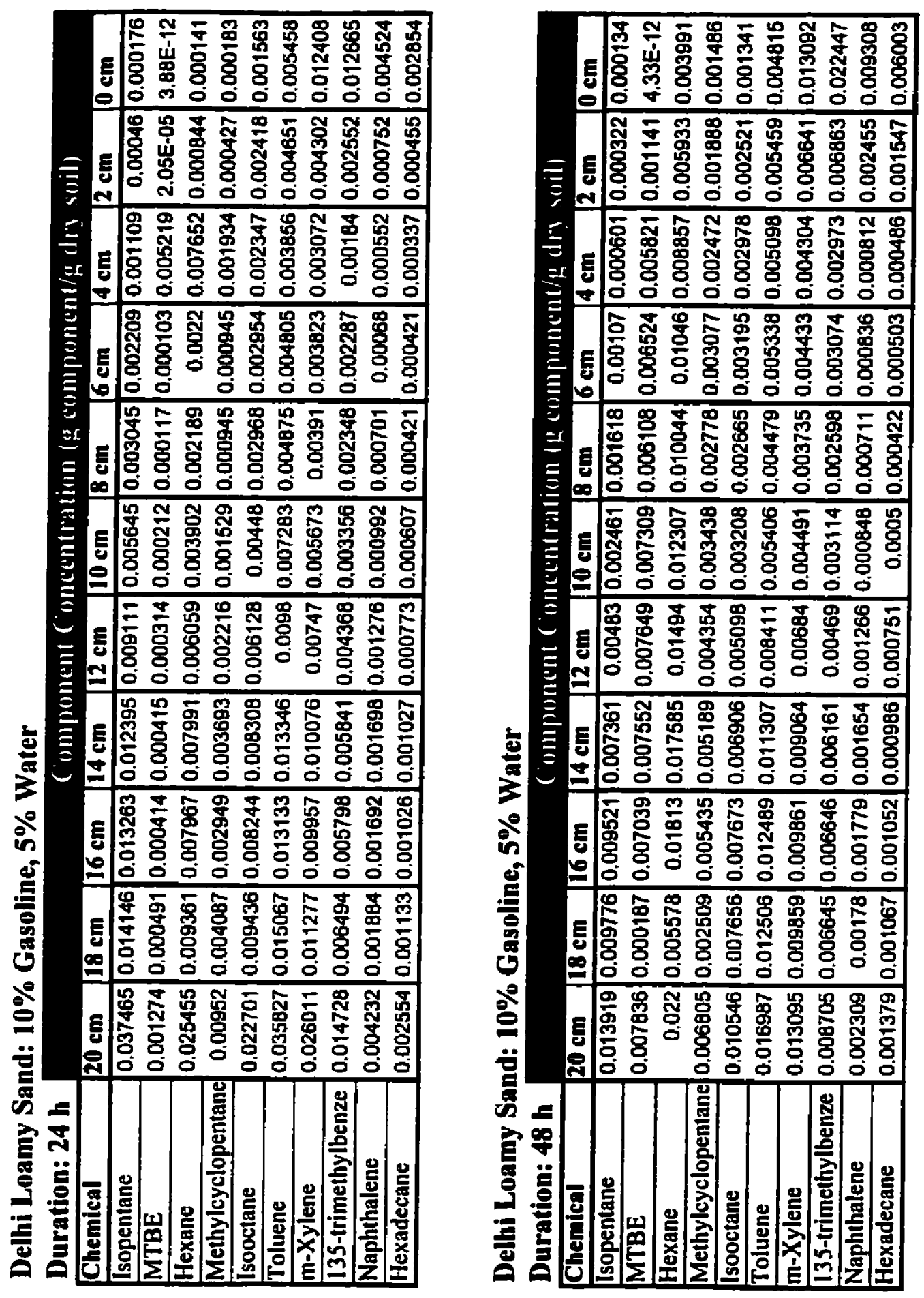

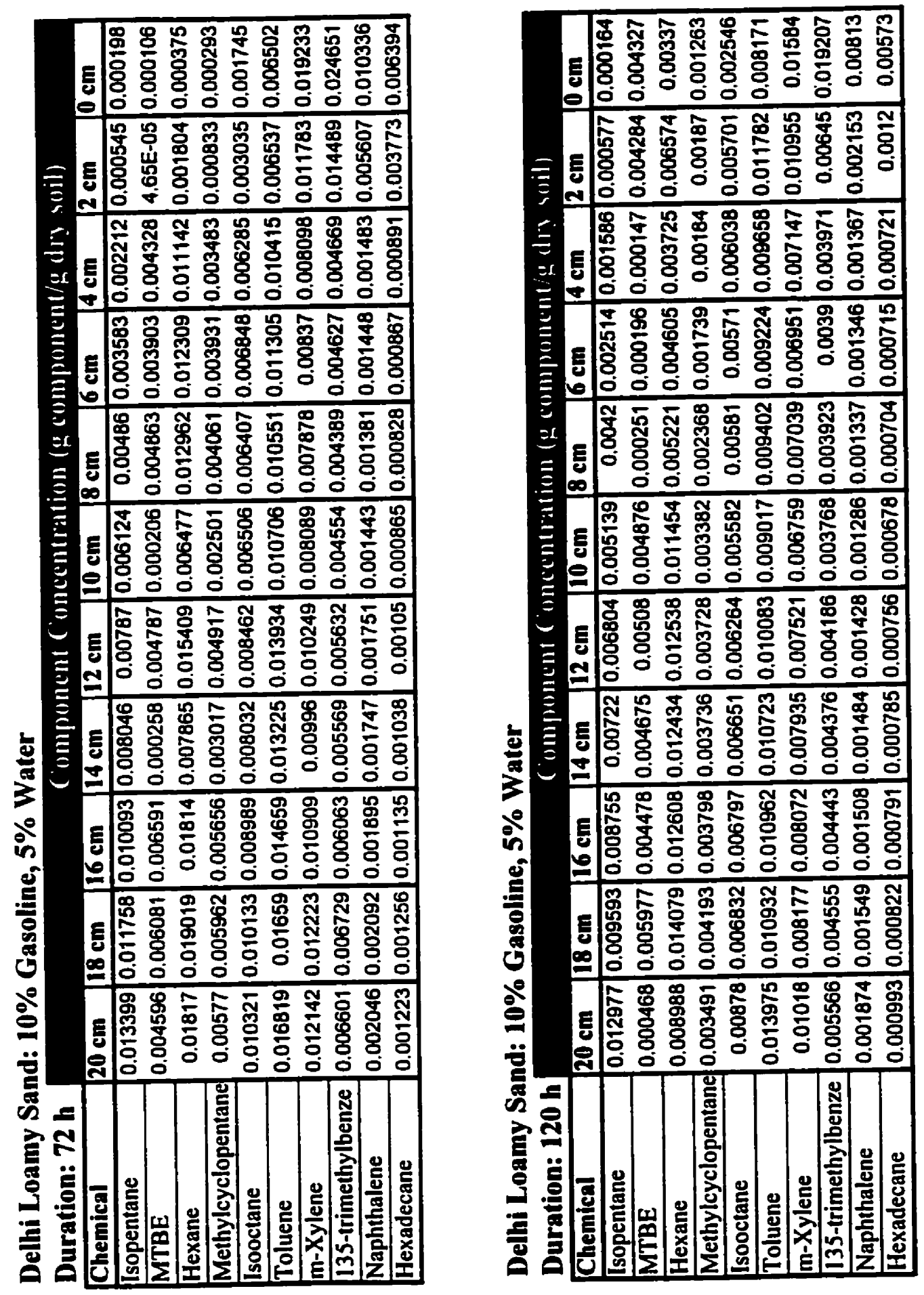

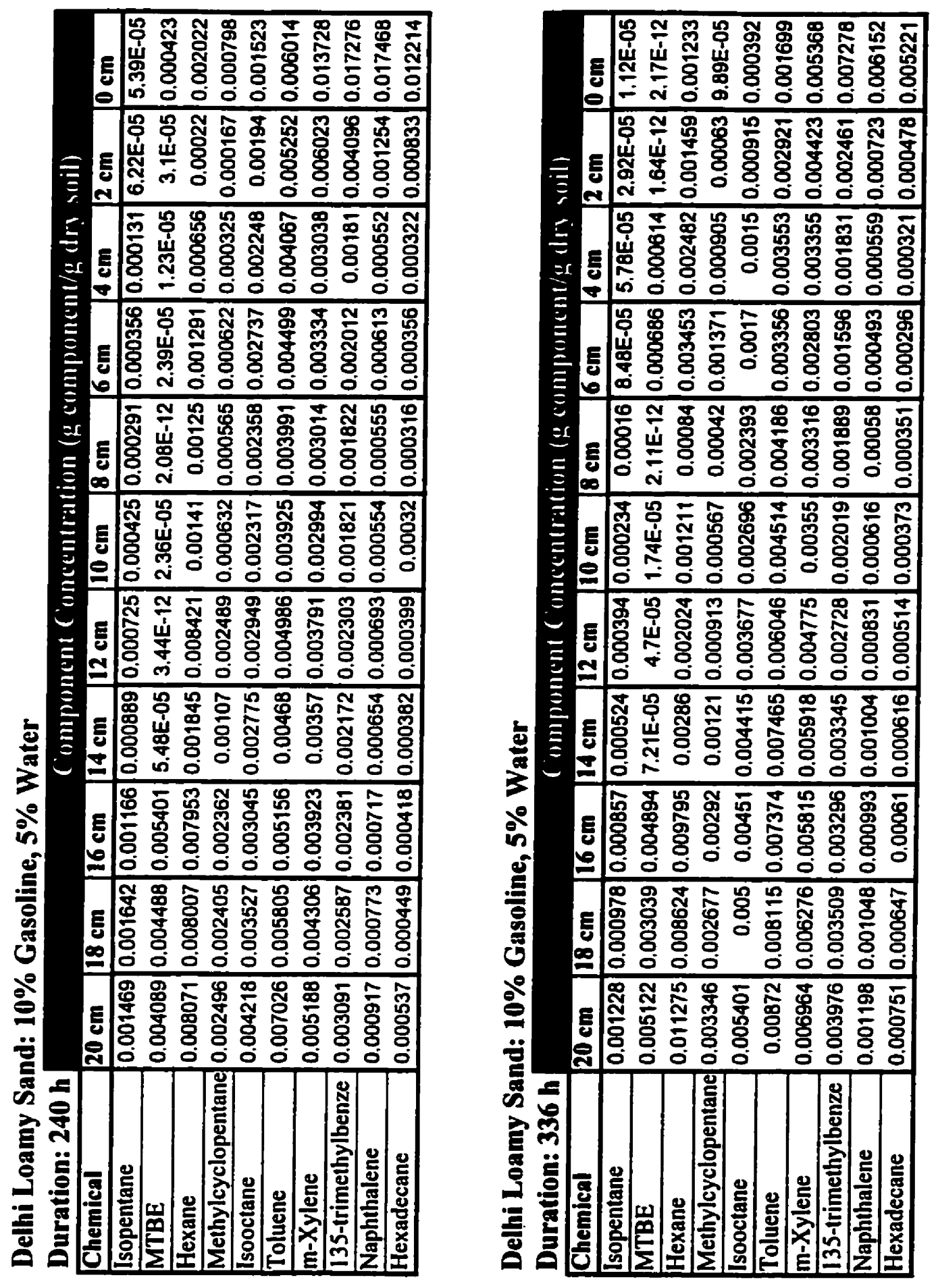


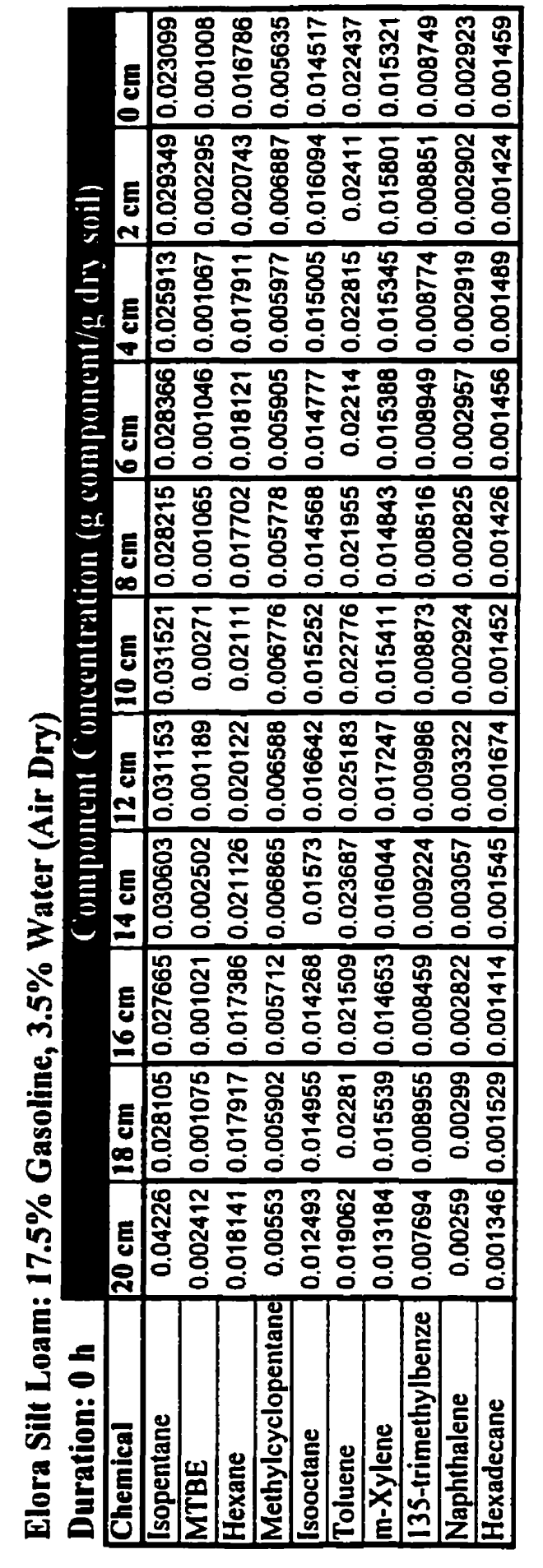

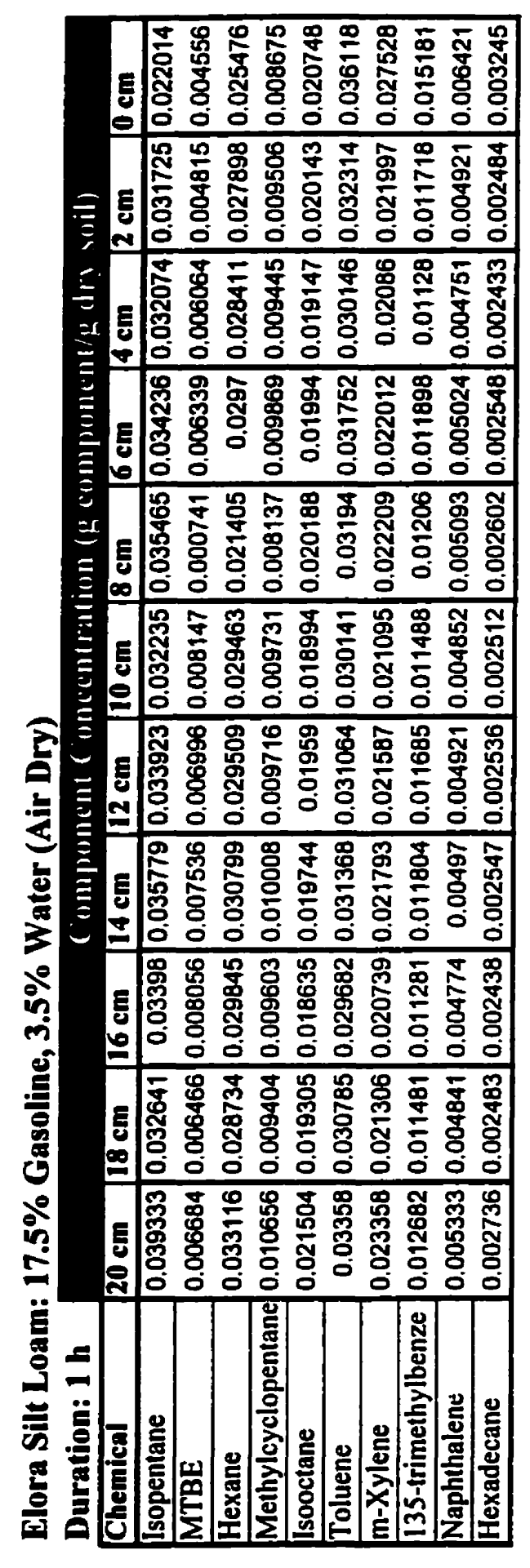


Elora Silt Loam: 17.5\% Gasoline, 3.5\% Water (Air Dry)

\begin{tabular}{|c|c|c|c|c|c|c|c|c|c|c|c|}
\hline \multirow{2}{*}{$\begin{array}{l}\text { Duration: } 2 \text { h } \\
\text { Chemical }\end{array}$} & \multirow[b]{2}{*}{$20 \mathrm{~cm}$} & \multirow[b]{2}{*}{$18 \mathrm{~cm}$} & \multicolumn{9}{|c|}{ (omponent (oncentration ( $\rho$ component/g des soil) } \\
\hline & & & $16 \mathrm{~cm}$ & $14 \mathrm{~cm}$ & $12 \mathrm{~cm}$ & $10 \mathrm{~cm}$ & $8 \mathrm{~cm}$ & $6 \mathrm{~cm}$ & $4 \mathrm{~cm}$ & $2 \mathrm{~cm}$ & $0 \mathrm{~cm}$ \\
\hline Isopentane & 0.043925 & 0.043023 & 0.039864 & 0.043992 & 0.037158 & 0.036489 & 0.039607 & 0.033417 & 0.030443 & 0.031439 & 0.017409 \\
\hline MTBE & 0.000847 & 0.008144 & 0.000816 & 0.007849 & 0.000796 & 0,006703 & 0.008497 & 0.00075 & 0.000755 & 0.000781 & 0,008691 \\
\hline Hexane & 0.021515 & 0.031983 & 0.02006 & 0.032218 & 0.019195 & 0.029368 & 0.032035 & 0.01849 & 0.018228 & 0.018714 & 0.027331 \\
\hline Methylcyclopentane & 0.006916 & 0.009188 & 0.006672 & 0.009361 & 0.006724 & 0.008886 & 0,009567 & 0.006027 & 0.006861 & 0.006197 & 0.008572 \\
\hline Isooctane & 0.016832 & 0.016987 & 0.016129 & 0.017548 & 0.016317 & 0.017461 & 0,017909 & 0.01694 & 0,016888 & 0.017035 & 0.019373 \\
\hline Toluene & 0.02709 & 0.027298 & 0.026283 & 0.028494 & 0.026595 & 0.028516 & 0,029053 & 0.027694 & 0.027648 & 0.027821 & 0.035376 \\
\hline m-Xylene & 0.019306 & 0.019628 & 0.01876 & 0.020408 & 0,019262 & 0.020209 & 0.02084 & 0.020151 & 0.019845 & 0.01987 & 0.029452 \\
\hline 135-trimethylbenze & 0.011092 & 0.011352 & 0.01081 & 0.011773 & 0.011195 & 0.011564 & 0.012053 & 0,01174 & 0.011465 & 0.011446 & 0.017697 \\
\hline Naphthalene & 0.003266 & 0.003355 & 0.003194 & 0,003472 & 0.003318 & 0.003402 & 0.003564 & 0,003481 & 0,003393 & 0.003382 & 0.005248 \\
\hline Hexadecane & 0.001778 & 0.00184 & 0.001738 & 0.001899 & 0.001821 & 0.001852 & 0.001957 & 0,001918 & 0,001846 & 0.001842 & 0.002891 \\
\hline
\end{tabular}

Elora Silt Loam: 17.5\% Gasoline, 3.5\% Water (Air Dry)

\begin{tabular}{|c|c|c|c|c|c|c|c|c|c|c|c|}
\hline Duration: $6 \mathrm{~h}$ & & & & & III & till & $\therefore$ & וmpmine & $11 / 2$ dr & suil) & \\
\hline Chemical & $20 \mathrm{~cm}$ & $18 \mathrm{~cm}$ & $16 \mathrm{~cm}$ & $14 \mathrm{~cm}$ & $12 \mathrm{~cm}$ & $10 \mathrm{~cm}$ & $8 \mathrm{~cm}$ & $6 \mathrm{~cm}$ & $4 \mathrm{~cm}$ & $2 \mathrm{~cm}$ & $0 \mathrm{~cm}$ \\
\hline Isopentane & 0.037549 & 0.033383 & 0.035469 & 0.038583 & 0,036592 & 0.037958 & 0.036872 & 0,034932 & 0.001549 & 0.032392 & 0.012895 \\
\hline MTBE & 0.006098 & 0.000738 & 0,000813 & 0.006239 & 0.006461 & 0.00651 & 0,006396 & 0.006398 & 0.000299 & 0,000748 & 0,000508 \\
\hline Hexane & 0.029004 & 0.01905 & 0.02065 & 0.030686 & 0.030617 & 0.031042 & 0.030655 & 0.029862 & 0.001109 & 0,019996 & 0.014729 \\
\hline Methylcyclopentane & 0.009751 & 0.007483 & 0.007919 & 0.010372 & 0.010348 & 0,01043 & 0.010339 & 0.010073 & 0.001368 & 0.0078 & 0.005616 \\
\hline Isooctane & 0.018471 & 0.017355 & 0.018404 & 0.019497 & 0.019683 & 0.019679 & 0.019426 & 0.018924 & 0.000956 & 0.018011 & 0.020886 \\
\hline Toluene & 0.031843 & 0.029998 & 0.032206 & 0.033829 & 0.034176 & 0.033948 & 0.033757 & 0.032721 & 0.001899 & 0.031026 & 0.045556 \\
\hline m-Xylene & 0.020744 & 0.019809 & 0.021066 & 0,022057 & 0.022394 & 0.022231 & 0.022035 & 0.021408 & 0.002466 & 0.020332 & 0.039832 \\
\hline 135-trimethylbenze & 0.014499 & 0.013968 & 0.014745 & 0.015413 & 0.015687 & 0.015607 & 0.015435 & 0.014993 & 0.002527 & 0.014288 & 0,030468 \\
\hline Naphthalene & 0.003439 & 0.00333 & 0.003503 & 0.00365 & 0.00372 & 0.003709 & 0.003666 & 0.00356 & 0.000798 & 0,003394 & 0,007348 \\
\hline Hexadecane & 0.002011 & 0.001958 & 0.002044 & 0,002136 & 0.002189 & 0.002186 & 0,002151 & 0.002085 & 0.000734 & 0.002008 & 0,004444 \\
\hline
\end{tabular}


Elora Silt Loam: 17.5\% Gasoline, 3.5\% Water (Air Dry)

\begin{tabular}{|c|c|c|c|c|c|c|c|c|c|c|c|}
\hline Duration: 24 h & & & & (i)m & III & CIIIT: & 10110 & 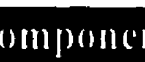 & $t / g d r y$ & (t)il) & \\
\hline Chemical & $20 \mathrm{~cm}$ & $18 \mathrm{~cm}$ & $16 \mathrm{~cm}$ & $14 \mathrm{~cm}$ & $12 \mathrm{~cm}$ & $10 \mathrm{~cm}$ & $8 \mathrm{~cm}$ & $6 \mathrm{~cm}$ & $4 \mathrm{~cm}$ & $2 \mathrm{~cm}$ & $0 \mathrm{~cm}$ \\
\hline Isopentane & 0.039218 & 0.038076 & 0.039748 & 0.040572 & 0.037412 & 0.036704 & 0,036071 & 0.032701 & 0.028552 & 0.022905 & 0.0051 \\
\hline MTBE & 0.000998 & 0.001022 & 0.006304 & 0.001056 & 0.001048 & 0.001037 & 0.000972 & 0.000965 & 0.000956 & 0.000908 & 0,005608 \\
\hline Hexane & 0.018599 & 0.020023 & 0.032271 & 0.01717 & 0.017727 & 0.020335 & 0.018872 & 0.019033 & 0,016507 & 0.019064 & 0.019489 \\
\hline Methylcyclopentane & 0.006839 & 0.007053 & 0.009542 & 0.007301 & 0.007285 & 0.007409 & 0.007427 & 0.007632 & 0.00754 & 0.007925 & 0,006259 \\
\hline Isooctane & 0.012606 & 0.013232 & 0.013185 & 0.013485 & 0.013763 & 0.014135 & 0.014066 & 0.014581 & 0.014721 & 0.016196 & 0,014607 \\
\hline Toluene & 0.020359 & 0.021494 & 0.021334 & 0.02184 & 0.022483 & 0.023327 & 0.022869 & 0,023841 & 0.024271 & 0.02648 & 0.03803 \\
\hline m-Xylene & 0.01466 & 0.015526 & 0.015419 & 0.015728 & 0.016168 & 0.01679 & 0.016446 & 0.017225 & 0.017496 & 0.018910 & 0.05067 \\
\hline 135-trimethylbenze & 0.008359 & 0.008864 & 0.008809 & 0.008985 & 0.0092 & 0.009546 & 0.009381 & 0.009833 & 0.009971 & 0.010692 & 0.035401 \\
\hline Naphthalene & 0.002434 & 0.002594 & 0.002572 & 0.002623 & 0,002685 & 0.002785 & 0,002738 & 0.002871 & 0.002911 & 0.0031 & 0.010871 \\
\hline Hexadecane & 0.001609 & 0.001724 & 0.001698 & 0,001733 & 0.001778 & 0.001845 & 0.001821 & 0.001909 & 0.001933 & 0.002057 & 0.00732 \\
\hline
\end{tabular}

Elora Silt Loam: 17.5\% Gasoline, 3.5\% Water (Air Dry)

\begin{tabular}{|c|c|c|c|c|c|c|c|c|c|c|c|}
\hline & & & & & & & & & & & \\
\hline Chemical & $20 \mathrm{~cm}$ & $18 \mathrm{~cm}$ & $16 \mathrm{~cm}$ & $14 \mathrm{~cm}$ & $12 \mathrm{~cm}$ & $10 \mathrm{~cm}$ & $8 \mathrm{~cm}$ & $6 \mathrm{~cm}$ & $4 \mathrm{~cm}$ & $2 \mathrm{~cm}$ & $0 \mathrm{~cm}$ \\
\hline Isopentane & 0,031662 & 0.033658 & 0.000583 & 0.031203 & 0.032033 & 0.032783 & $8,19 E-11$ & 0,026069 & 0.023208 & 0.015681 & 0.002706 \\
\hline MTBE & 0.000648 & 0.004878 & 0.000581 & 0.004956 & 0.005282 & 0.000681 & 0.000616 & 0.000646 & 0,000621 & 0.000533 & 0.000149 \\
\hline Hexane & 0.015529 & 0.030081 & 0.015398 & 0.02972 & 0.030075 & 0.015382 & 0.013695 & 0.014375 & 0.015994 & 0.014251 & 0.003448 \\
\hline Methylcyclopentane & 0.006042 & 0.008445 & 0.00575 & 0.008415 & 0.008523 & 0.006422 & 0.005952 & 0.006367 & 0,00643 & 0.005258 & 0.00162 \\
\hline Isooctane & 0.013225 & 0.013429 & 0.012559 & 0.013412 & 0.01344 & 0.014016 & 0.012967 & 0.013893 & 0.014372 & 0.015421 & 0.008284 \\
\hline Toluene & 0.021809 & 0.022309 & 0.020746 & 0,022347 & 0.022271 & 0.023251 & 0.021413 & 0.023016 & 0.023656 & 0.025716 & 0.029694 \\
\hline$m$-Xylene & 0.015419 & 0.015893 & 0.014677 & 0.015949 & 0.015887 & 0.01641 & 0.015109 & 0.016295 & 0.016666 & 0.019063 & 0,058243 \\
\hline 135-trimethylbenze & 2.85E-05 & 0.009418 & 2.74E-05 & 0,009446 & 0.009423 & 0.009662 & 0.008902 & 0.009602 & 0.009797 & 0.011301 & 0.050851 \\
\hline Naphthalene & 0.002499 & 0.002603 & 0.002384 & 0.002607 & 0.002605 & 0.002665 & 0.002455 & 0.002645 & 0.0027 & 0.003079 & 0.016106 \\
\hline Hexadecane & 0.001614 & 0.001679 & 0.001555 & 0.001686 & 0.001694 & 0.001737 & 0.001598 & 0.001726 & 0.001766 & 0.002036 & 0.01076 \\
\hline
\end{tabular}


Elora Silt Loam: 17.5\% Gasoline, 3.5\% Water (Air Dry)

\begin{tabular}{|c|c|c|c|c|c|c|c|c|c|c|c|}
\hline \multirow{2}{*}{$\begin{array}{l}\text { Duration: } 72 \text { h } \\
\text { Chemical }\end{array}$} & \multicolumn{11}{|c|}{ (omponent Concentration (g component/g dry soil) } \\
\hline & $20 \mathrm{~cm}$ & $18 \mathrm{~cm}$ & $16 \mathrm{~cm}$ & $14 \mathrm{~cm}$ & $12 \mathrm{~cm}$ & $10 \mathrm{~cm}$ & $8 \mathrm{~cm}$ & $6 \mathrm{~cm}$ & $4 \mathrm{~cm}$ & $2 \mathrm{~cm}$ & $0 \mathrm{~cm}$ \\
\hline Isopentane & 0.025065 & 0.024064 & 0.023272 & 0.020443 & 0.024316 & 0.020531 & 0,021237 & 0.017539 & 0,015137 & 0.010217 & 0.00299 \\
\hline MTBE & 0.006529 & 0.008768 & 0.005734 & 0.000497 & 0.000624 & 0.007884 & 0.000548 & 0.000503 & 0.000547 & 0.000432 & 0.000174 \\
\hline Hexane & 0,02685 & 0.028262 & 0,024736 & 0,013261 & 0.016552 & 0.024721 & 0.015037 & 0.014591 & 0,015509 & 0.014293 & 0.00584 \\
\hline Methylcyclopentane & 0.008575 & 0.008841 & 0.008053 & 0,004928 & 0.005893 & 0.007996 & 0.005602 & 0.006254 & 0.006356 & 0.006091 & 0.003028 \\
\hline Isooctane & 0.015977 & 0.015189 & 0.014992 & 0,013248 & 0.01539 & 0.014007 & 0.014764 & 0.014884 & 0.015922 & 0.016904 & 0.012761 \\
\hline Toluene & 0.024757 & 0.023431 & 0.023412 & 0.020563 & 0.023833 & 0.021701 & 0,022948 & 0.023204 & 0.024843 & 0.025971 & 0.026931 \\
\hline m-Xylene & 0.018219 & 0.017503 & 0.017024 & 0.015346 & 0.017457 & 0.016122 & 0,017081 & 0.017204 & 0.018139 & 0.019775 & 0.043974 \\
\hline 135-trimethylbenze & 0.009482 & 0,009242 & 0.008791 & 0.008085 & 0.009075 & 0.008464 & 0.008995 & 0.009014 & 0.009375 & 0.010279 & 0.044726 \\
\hline Naphthalene & 0.002932 & 0.002873 & 0.002715 & 0.002509 & 0.0028 & 0.002621 & 0.002789 & 0.002791 & 0.002888 & 0.003135 & 0.018868 \\
\hline Hexadecane & 0.001737 & 0.00172 & 0,001598 & 0.001489 & 0.00166 & 0.001557 & 0.001666 & 0,001662 & 0.00171 & 0,001871 & 0.012503 \\
\hline
\end{tabular}

Elora Silt Loam: 17.5\% Gasoline, 3.5\% Water (Air Dry)

Duration: $120 \mathrm{~h}$ ( omproncent (oncentration (g compentent/g dey soil)

\begin{tabular}{|c|c|c|c|c|c|c|c|c|c|c|c|}
\hline Chemical & $20 \mathrm{~cm}$ & $18 \mathrm{~cm}$ & $16 \mathrm{~cm}$ & $14 \mathrm{~cm}$ & $12 \mathrm{~cm}$ & $10 \mathrm{~cm}$ & $8 \mathrm{~cm}$ & $6 \mathrm{~cm}$ & $4 \mathrm{~cm}$ & $2 \mathrm{~cm}$ & $0 \mathrm{~cm}$ \\
\hline Isopentane & 0.01972 & 0.02031 & 0.019476 & 0.019443 & 0.017666 & 0,015949 & 0.01406 & 0.01068 & 0,008288 & 0,004942 & 0.00122 \\
\hline MTBE & 0.000446 & 0.005549 & 0.000429 & 0.006349 & 0.000452 & 0.006861 & 0.000431 & 0.000407 & 0,005737 & 0.005451 & 7.36E-05 \\
\hline Hexane & 0.011756 & 0.020415 & 0.012019 & 0.022337 & 0.012423 & 0.022614 & 0,012737 & 0.012568 & 0.020992 & 0.017281 & 0.002537 \\
\hline Methylcyclopentane & 0.004912 & 0.006437 & 0.004827 & 0.007063 & 0.005275 & 0.007109 & 0,004612 & 0.006927 & 0.006787 & 0,005628 & 0.001187 \\
\hline Isooctane & 0.011809 & 0.011386 & 0.011188 & 0.012403 & 0.012531 & 0.012368 & 0.012583 & 0.013388 & 0.015037 & 0.015662 & 0,008176 \\
\hline Toluene & 0.020054 & 0.019297 & 0.019102 & 0.021107 & 0.021456 & 0.021055 & 0.021436 & 0.022737 & 0,025435 & 0.028141 & 0.023012 \\
\hline m-Xylene & 0.013627 & 0.012961 & 0.012827 & 0.014248 & 0.014545 & 0.014261 & 0.014403 & 0.015262 & 0.017251 & 0.022078 & 0.037292 \\
\hline 135-trimethylbenze & 0.008769 & 0.008283 & 0.008198 & 0.009156 & 0.009353 & 0.009176 & 0.00921 & 0.009724 & 0.010894 & 0,01429 & 0,046681 \\
\hline Naphthalene & 0.003011 & 0.002849 & 0.002823 & 0.003142 & 0.003212 & 0.00315 & 0.003154 & 0.003318 & 0.003697 & 0.004723 & 0.020291 \\
\hline Hexadecane & 0.001337 & 0.001251 & 0.001241 & 0.001408 & 0.001434 & 0.001409 & 0.001409 & 0.001484 & 0.001654 & 0.002049 & 0.011519 \\
\hline
\end{tabular}



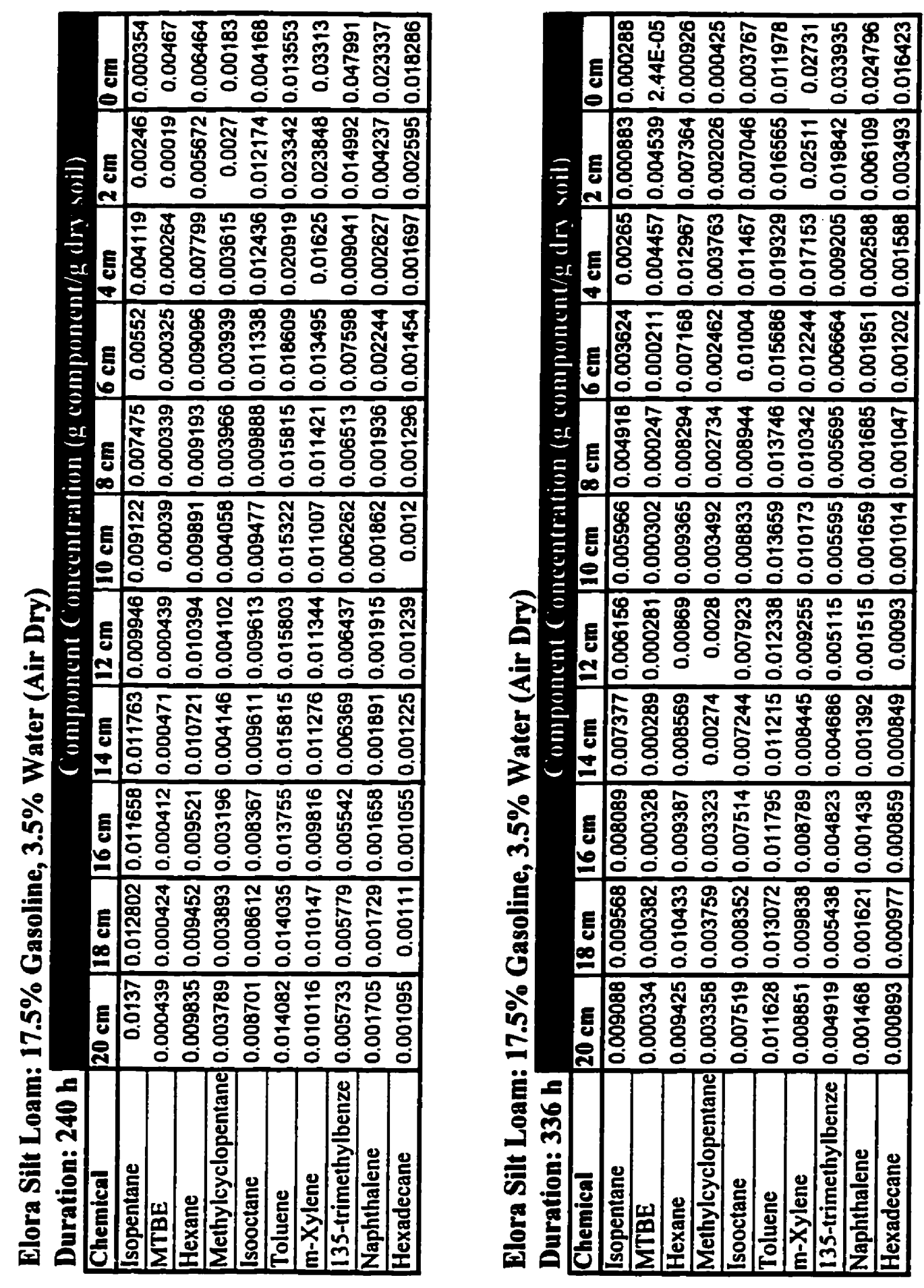
Elora Silt Loam: 13\% Gasoline, 8\% Water

\begin{tabular}{|c|c|c|c|c|c|c|c|c|c|c|c|}
\hline & & & & & & & & & & & \\
\hline Chemical & $20 \mathrm{~cm}$ & $18 \mathrm{~cm}$ & $16 \mathrm{~cm}$ & $14 \mathrm{~cm}$ & $12 \mathrm{~cm}$ & $10 \mathrm{~cm}$ & $8 \mathrm{~cm}$ & $6 \mathrm{~cm}$ & $4 \mathrm{~cm}$ & $2 \mathrm{~cm}$ & $0 \mathrm{~cm}$ \\
\hline & 029653 & 0.021372 & 0.018831 & 0.021254 & 022391 & .075395 & 0.023067 & 0.020563 & 0.002391 & 0.018191 & 0,012561 \\
\hline & 30047 & 0.00042 & .000407 & 0.001578 & 0.001655 & 0.000355 & 0.001429 & .000456 & 0.000833 & 0.000495 & 0.00041 \\
\hline & & 0.01 & & & 0.01562 & 009439 & & & & & \\
\hline & 004249 & 0.003876 & 0.003708 & 0.004562 & 0.005081 & 0.003125 & 0.004784 & .00414 & 0.003433 & 0.004326 & 00398 \\
\hline & .010798 & 0.010268 & 0.0094 & 0.010078 & 0.011671 & 0.008034 & 0.010887 & 0.010549 & 0.000538 & 0.010875 & \\
\hline & 017111 & 0.016627 & 015046 & 0.015983 & 0.018657 & 0.012912 & 0.017193 & 0.016921 & 0.000606 & 0.017446 & \\
\hline & & 0.014378 & 0.012855 & 0.013414 & 0.015608 & 0.010878 & 0.01426 & 0.014422 & 0.000744 & & \\
\hline & 006382 & 0.006412 & 0.005725 & 0.005913 & 0.00684 & 0.00479 & 0.006227 & 0.00642 & 0.001099 & 0.006461 & 0.00721 \\
\hline & 02411 & 0.002439 & 0.002159 & 0.002232 & 0.00259 & 0.001801 & 0.002349 & 0.00 & & 451 & \\
\hline exadecane & 001105 & 0.001156 & 0.001026 & 0.001074 & 0.001276 & 0.000865 & 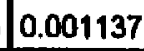 & 216 & 349 & 001 & \\
\hline
\end{tabular}

5

Elora Silt Loam: 13\% Gasoline, 8\% Water

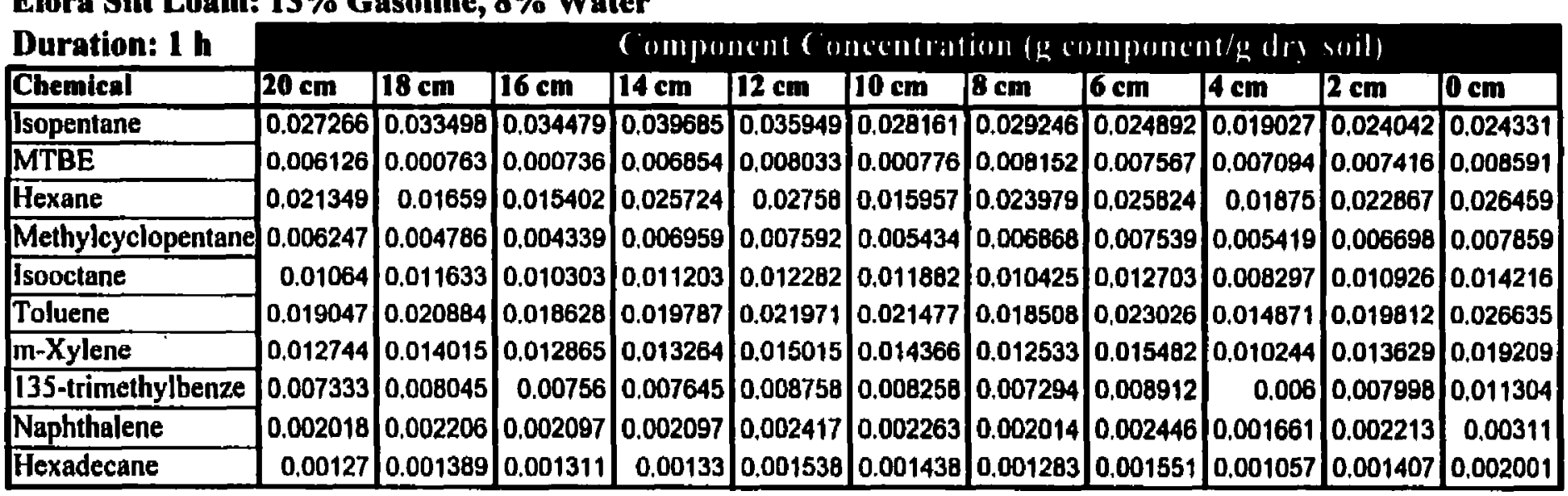



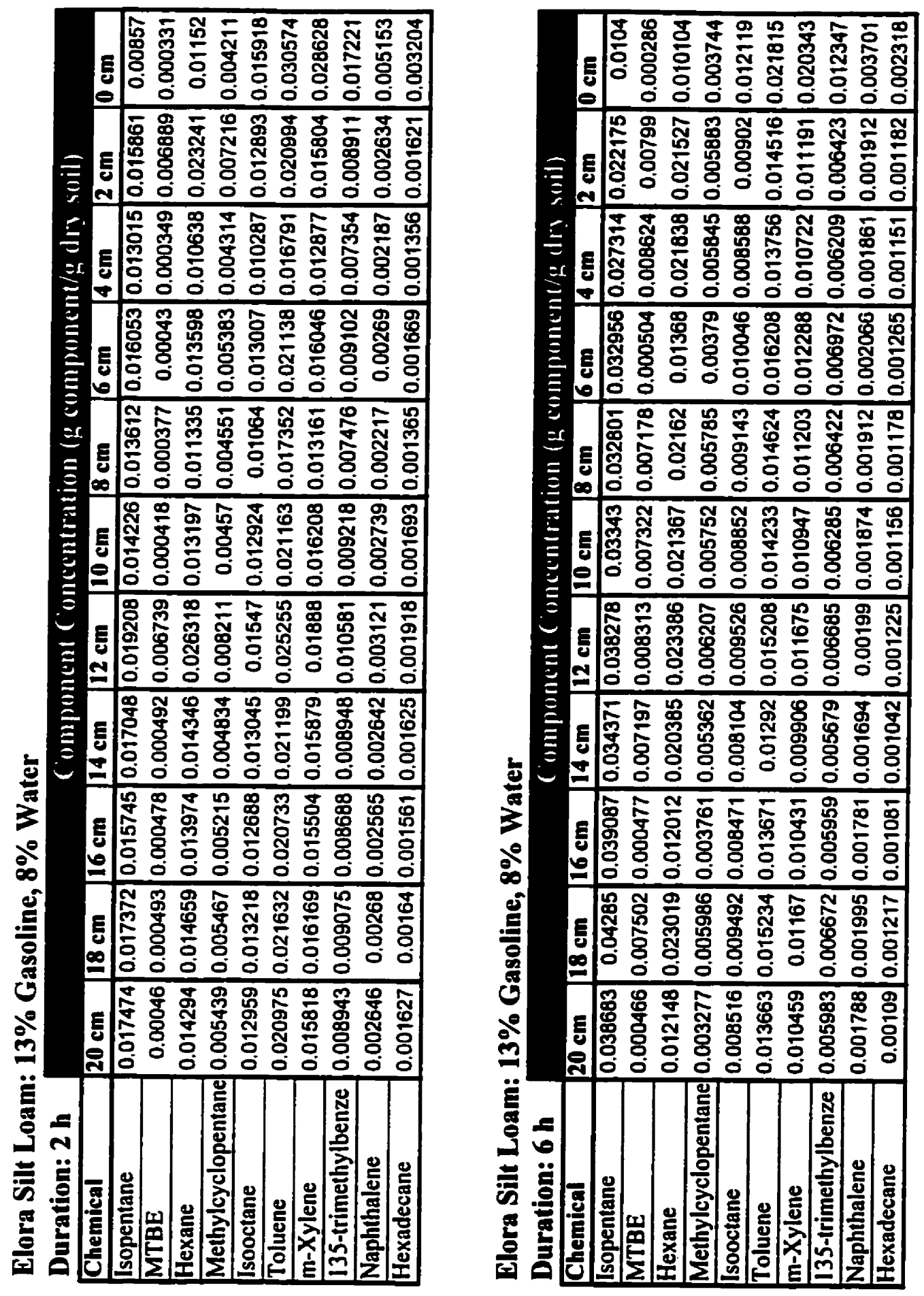
Elora Silt Loam: $13 \%$ Gasoline, $8 \%$ Water

\begin{tabular}{|c|c|c|c|c|c|c|c|c|c|c|c|}
\hline \multirow{2}{*}{$\begin{array}{l}\text { Duration: } 24 \mathrm{~h} \\
\text { Chemical }\end{array}$} & \multicolumn{11}{|c|}{ (omponent ('oncentration (g component/g dry soil) } \\
\hline & $\mathbf{b} \mathbf{c m}$ & $18 \mathrm{~cm}$ & $16 \mathrm{~cm}$ & $14 \mathrm{~cm}$ & $12 \mathrm{~cm}$ & $10 \mathrm{~cm}$ & $8 \mathrm{~cm}$ & $6 \mathrm{~cm}$ & $4 \mathrm{~cm}$ & $2 \mathrm{~cm}$ & $\mathbf{c m}$ \\
\hline Isopentane & 0.018406 & 0.018184 & 0.009641 & 0.017381 & 0,019748 & 0.01349 & 0.017535 & 0.018329 & 0.014524 & 0.006531 & 0.001672 \\
\hline MTBE & 0.006399 & 0.008037 & 0.000389 & 0.000559 & 0.007752 & 0.000449 & 0.009446 & 0.000677 & 0.000593 & 0.007285 & 0,00671 \\
\hline Hexane & 0.022452 & 0.024239 & 0.008159 & 0.010595 & 0.025527 & 0.008676 & 0.025223 & 0.012879 & 0.012156 & 0.020504 & 0.012355 \\
\hline Methylcyclopentane & 0.006631 & 0.007142 & 0.00295 & 0,003859 & 0.007556 & 0.003241 & 0.007234 & 0,004551 & 0.004987 & 0.006056 & 0,003636 \\
\hline Isooctane & 0.011242 & 0.011445 & 0.010216 & 0.010911 & 0.012893 & 0.009768 & 0.011013 & 0.012337 & 0.011661 & 0.012014 & 0.010397 \\
\hline Toluene & 0.017853 & 0.01823 & 0.018422 & 0.017371 & 0.0206 & 0.016451 & 0.017559 & 0.019537 & 0.018496 & 0.019437 & 0.029004 \\
\hline m-Xylene & 0.013092 & 0.013621 & 0.015998 & 0.012932 & 0.015296 & 0.013483 & 0,013106 & 0,014519 & 0.013676 & 0.015133 & 0.041608 \\
\hline 135-trimethylbenze & 0.007457 & 0.007848 & 0,009718 & 0.007437 & 0.008753 & 0.00811 & 0.007561 & 0.008356 & 0.007836 & 0.00865 & 0.029744 \\
\hline Naphthalene & 0.002152 & 0.002273 & 0.002879 & 0.002153 & 0.002526 & 0.002389 & 0.002192 & 0.002417 & 0.002272 & 0.002469 & 0.009243 \\
\hline Hexadecane & 0.001279 & 0.001365 & 0.001741 & 0.001301 & 0.00152 & 0.00145 & 0.001322 & 0.001455 & 0.001363 & 0.001479 & 0.005602 \\
\hline
\end{tabular}

Elora Silt Loam: 13\% Gasoline, 8\% Water

\begin{tabular}{|c|c|c|c|c|c|c|c|c|c|c|c|}
\hline Chemical & $20 \mathrm{~cm}$ & $18 \mathrm{~cm}$ & $16 \mathrm{~cm}$ & $14 \mathrm{~cm}$ & $12 \mathrm{~cm}$ & $10 \mathrm{~cm}$ & $8 \mathrm{~cm}$ & $6 \mathrm{~cm}$ & $4 \mathrm{~cm}$ & $2 \mathrm{~cm}$ & $0 \mathrm{~cm}$ \\
\hline Isopentane & 0.012742 & 0.013711 & 0.013039 & 0.013428 & 0.013818 & 0.01231 & 0.010312 & 0.010291 & 0.005897 & 0.004209 & 0.000974 \\
\hline MTBE & 0.007736 & 0.006164 & 0.000248 & 0.000274 & 0.000264 & 0.000293 & 0.005605 & 0.006297 & 0.004914 & 0.007192 & 5.15E-12 \\
\hline Hexane & 0.021228 & 0.019678 & 0.007449 & 0.007837 & 0.008085 & 0.007769 & 0.017732 & 0.020813 & 0.016499 & 0.019781 & 0.012003 \\
\hline Methylcyclopentane & 0.006352 & 0.006075 & 0.004066 & 0.003985 & 0.003464 & 0.004099 & 0.005394 & 0.006506 & 0.005173 & 0,006194 & 0,00342 \\
\hline Isooctane & 0.009458 & 0.009719 & 0.009178 & 0.00893 & 0.009913 & 0.008959 & 0.008239 & 0.01018 & 0.0091 & 0.01301 & 0.007435 \\
\hline Toluene & 0.01515 & 0.015614 & 0.014778 & 0.014325 & 0.01588 & 0.014309 & 0.013174 & 0.016194 & 0,014482 & 0,021335 & 0.01979 \\
\hline m-Xylene & 0.011736 & 0.011903 & 0.011399 & 0.010929 & 0.012181 & 0.010935 & 0.010106 & 0,012327 & 0.010985 & 0.018267 & 0.035082 \\
\hline 135-trimethylbenze & 0,007838 & 0.007868 & 0.007604 & 0.007247 & 0.008109 & 0.007259 & 0.006723 & 0,008161 & 0.007211 & 0,012149 & 0.0386 \\
\hline Naphthalene & 0.002089 & 0.002098 & 0.002025 & 0.001925 & 0.002158 & 0.001927 & 0.00179 & 0,002164 & 0.00191 & 0.003146 & 0.013121 \\
\hline Hexadecane & 0.001222 & 0.001226 & 0.001183 & 0.001122 & 0.001273 & 0.00113 & 0.001041 & 0.001272 & 0.001118 & 0.001828 & 0.008286 \\
\hline
\end{tabular}



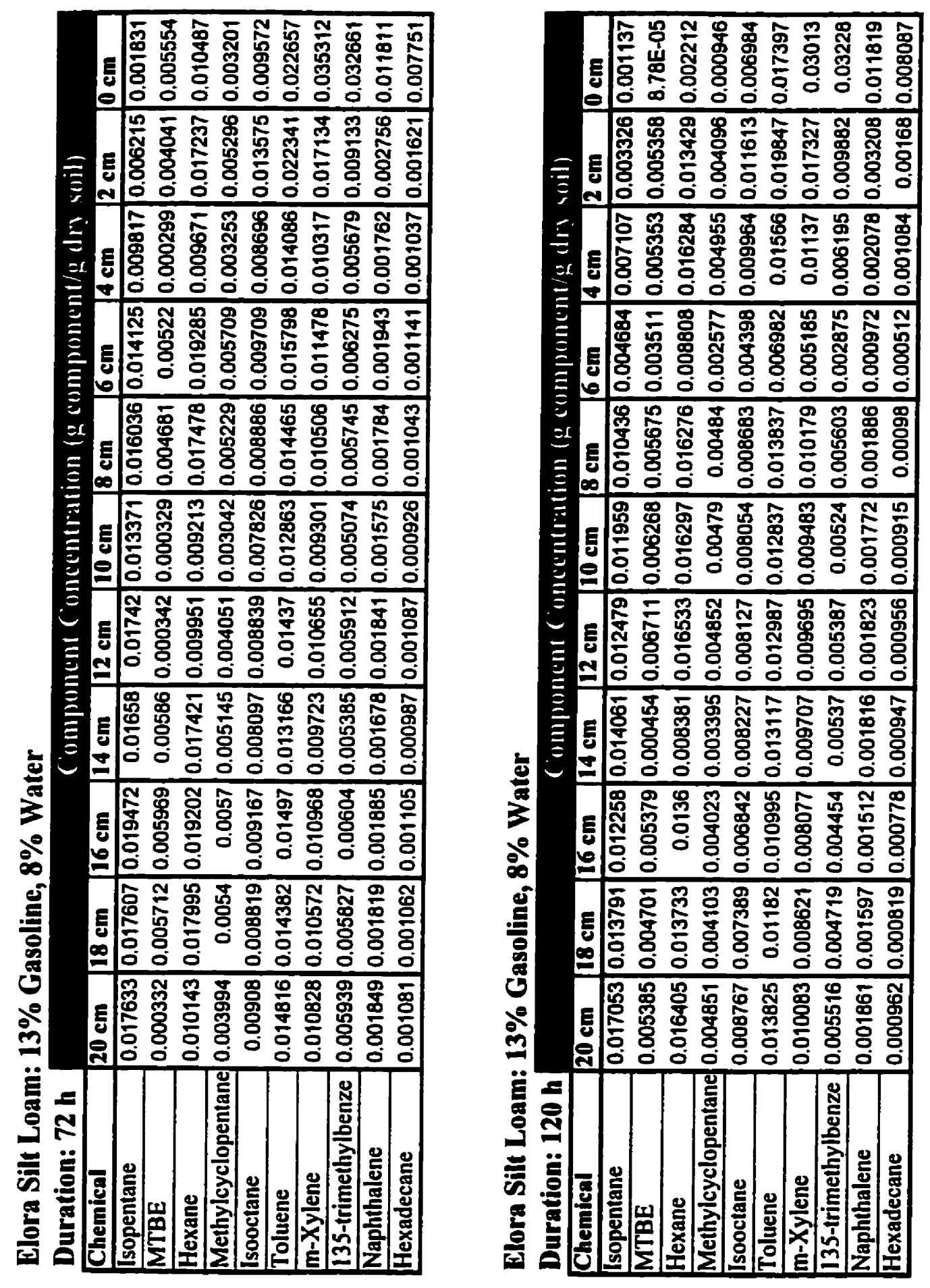

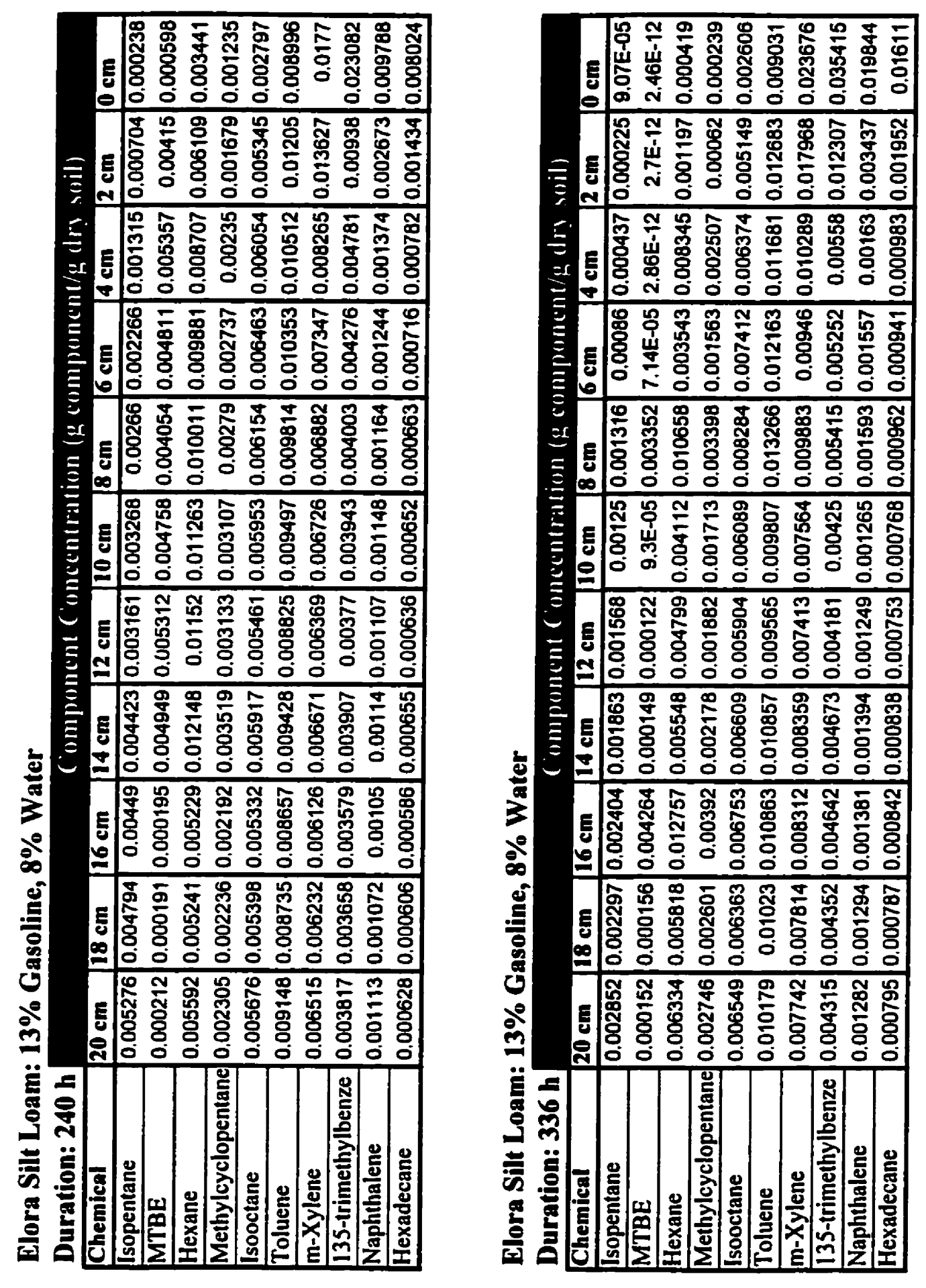
Appendix F

Room Temperature Windsor Clay Loam Volatilization Data 

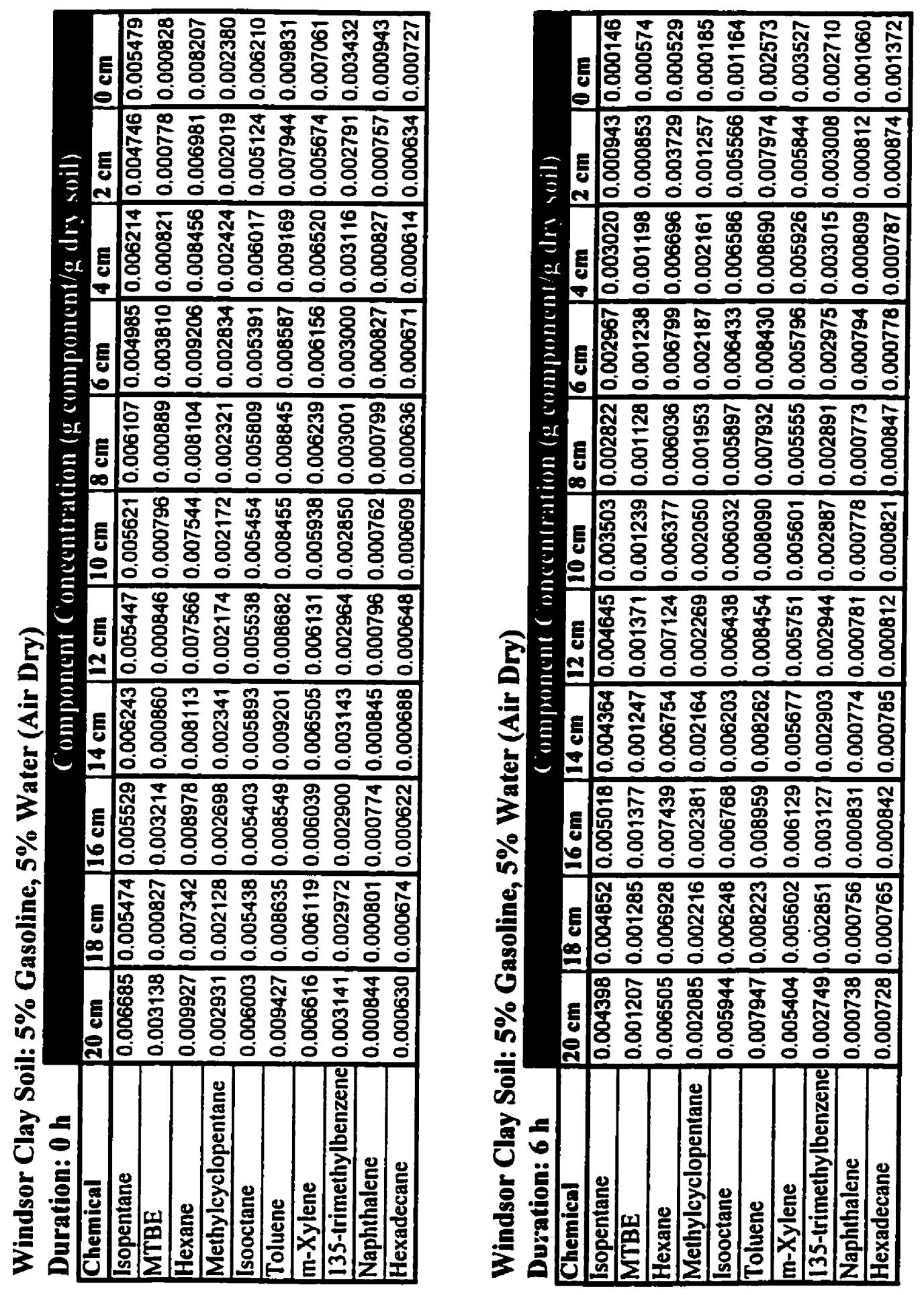

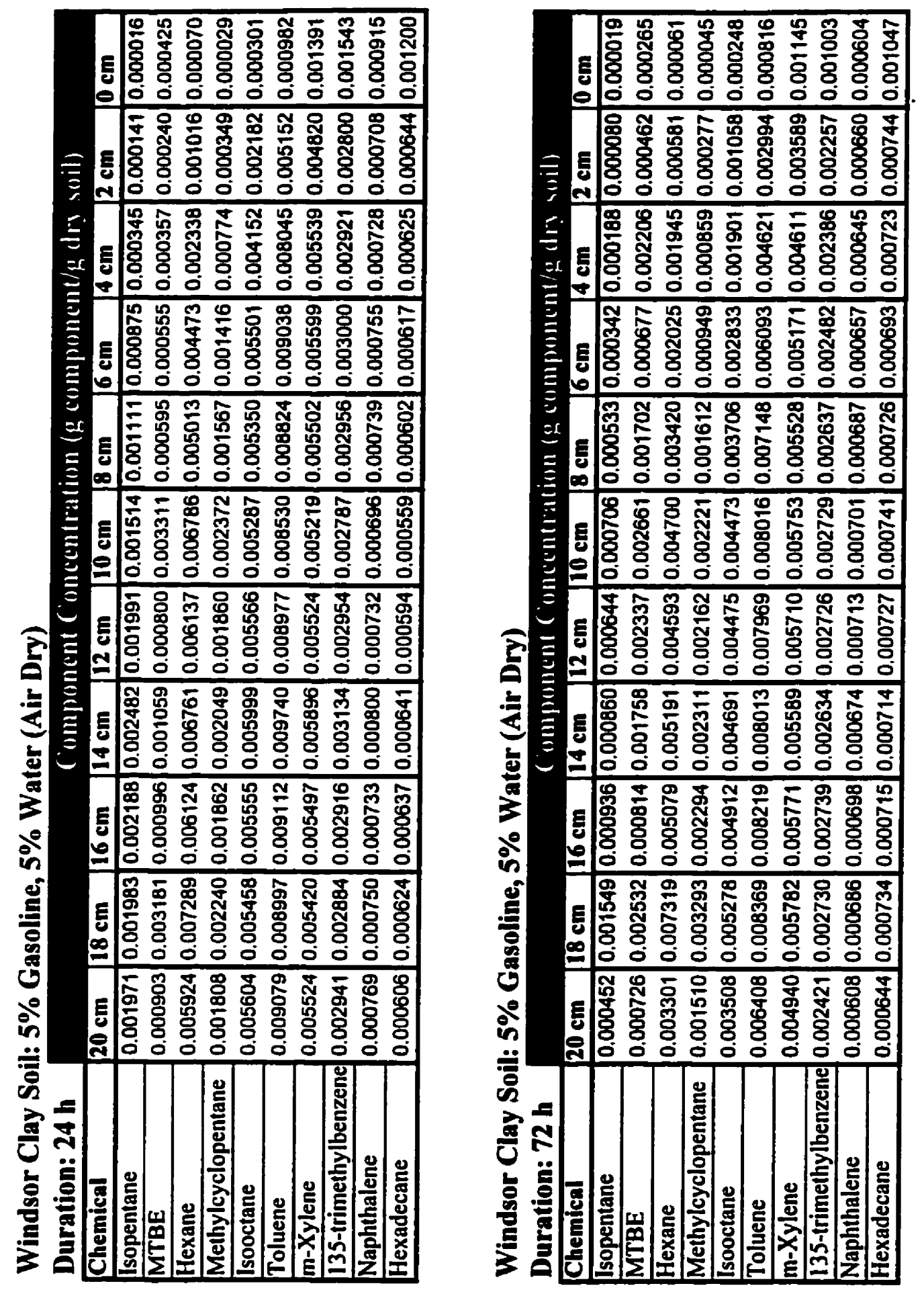

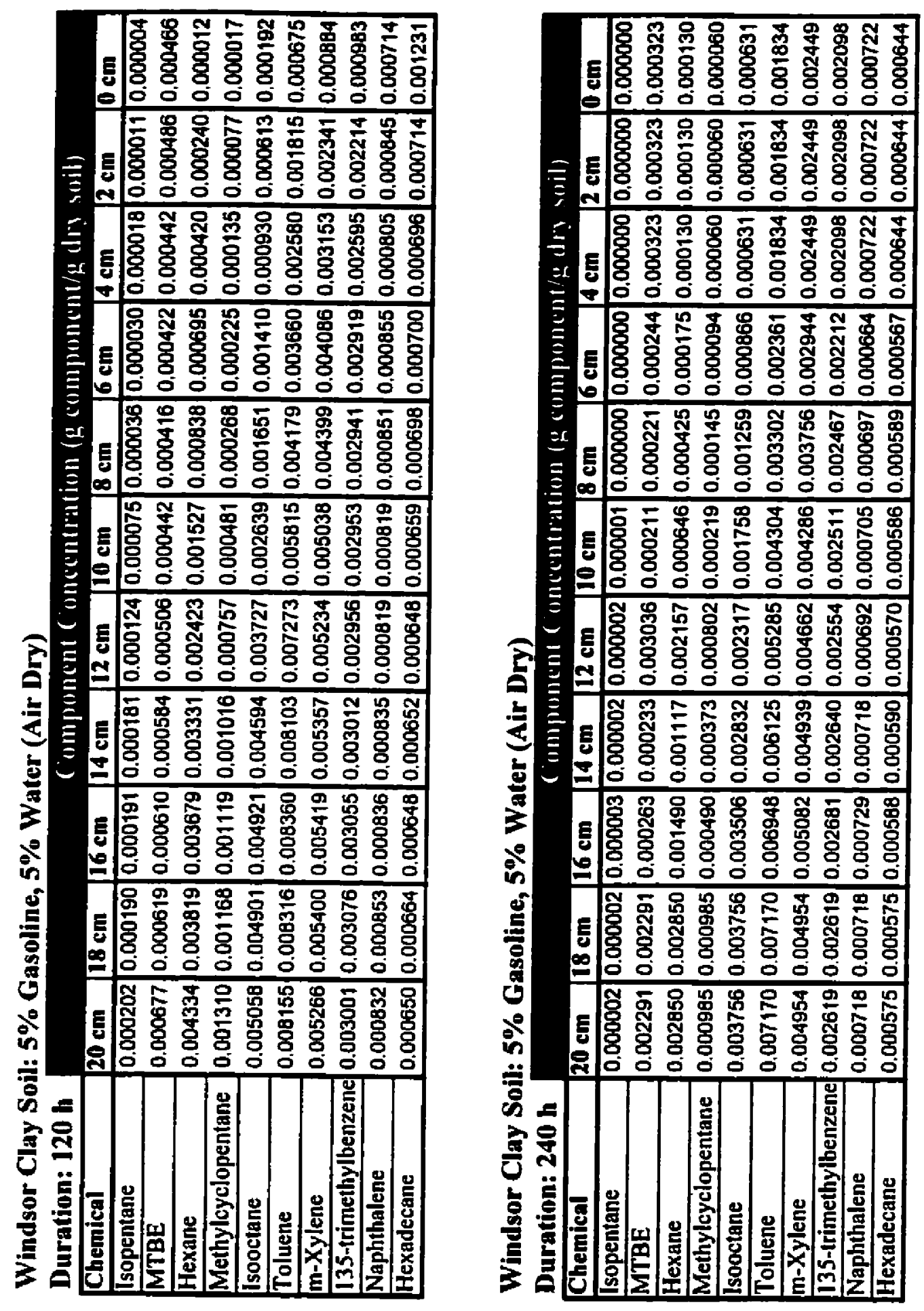
Windsor Clay Soil: 5\% Gasoline, 5\% Water (Air Dry)

\begin{tabular}{|c|c|c|c|c|c|c|c|c|c|c|c|}
\hline & & & & & & & & & & & \\
\hline Chemical & $20 \mathrm{~cm}$ & $18 \mathrm{~cm}$ & $16 \mathrm{~cm}$ & $14 \mathrm{~cm}$ & $12 \mathrm{~cm}$ & $10 \mathrm{~cm}$ & $8 \mathrm{~cm}$ & $6 \mathrm{~cm}$ & $4 \mathrm{~cm}$ & $2 \mathrm{~cm}$ & $0 \mathrm{~cm}$ \\
\hline Isopentane & 0.000001 & 0.000000 & 0.000000 & 0.000000 & 0.000000 & 0.000000 & 0,000000 & 0.000000 & 0.000000 & 0.000000 & 0.0000 \\
\hline MTBE & 0.000607 & 0.003551 & 0.003518 & 0.003727 & 0.003912 & 0.000543 & 0.004184 & 0.004435 & 0.004740 & 0.003839 & 0.005 \\
\hline Hexane & 0.000014 & 0.000492 & 0.000496 & 0.000520 & 0.000507 & 0,000000 & 0.000000 & $0.000000 \mid$ & 0,000000 & 0.000000 & 0.0000 \\
\hline Methylcyclopentane & 0.000028 & 0.000452 & 0.000316 & 0.000570 & 0.000314 & 0.000018 & 0.000329 & 0.000327 & 0.000102 & 0.000084 & 0.000 \\
\hline Isooctane & 0.001452 & 0,001461 & 0.001443 & 0.001311 & 0.001127 & 0.000922 & 0.000706 & 0.000525 & 0.000390 & 0.000310 & 0.0000 \\
\hline Toluene & 0.005450 & 0.005281 & 0.005257 & 0.004981 & 0.004355 & 0.003625 & 0.002946 & 0.002232 & 0.001666 & 0.001298 & 0.000418 \\
\hline m-Xylene & 0.004714 & 0.004631 & 0.004767 & 0.004852 & 0.004511 & 0.004044 & 0.003545 & 0.002835 & 0.002207 & 0.001759 & 0.0006 \\
\hline 135-trimethylbenzene & 0.002587 & 0.002514 & 0.002595 & 0.002725 & 0.002667 & $|0,002568|$ & 0.002488 & 0.002225 & 0.001919 & 0.001647 & 0,000655 \\
\hline Naphihalene & 0.000711 & 0.000689 & 0.000701 & 0.000749 & 0.000728 & 0.000715 & 0.000745 & $\mid 0.000717$ & 0.000717 & 0.000727 & 0.000474 \\
\hline Hexadecane & 0.000576 & 0.000559 & & & & & & & 0.00 & 0.0007 & 0.000 \\
\hline
\end{tabular}

ज 

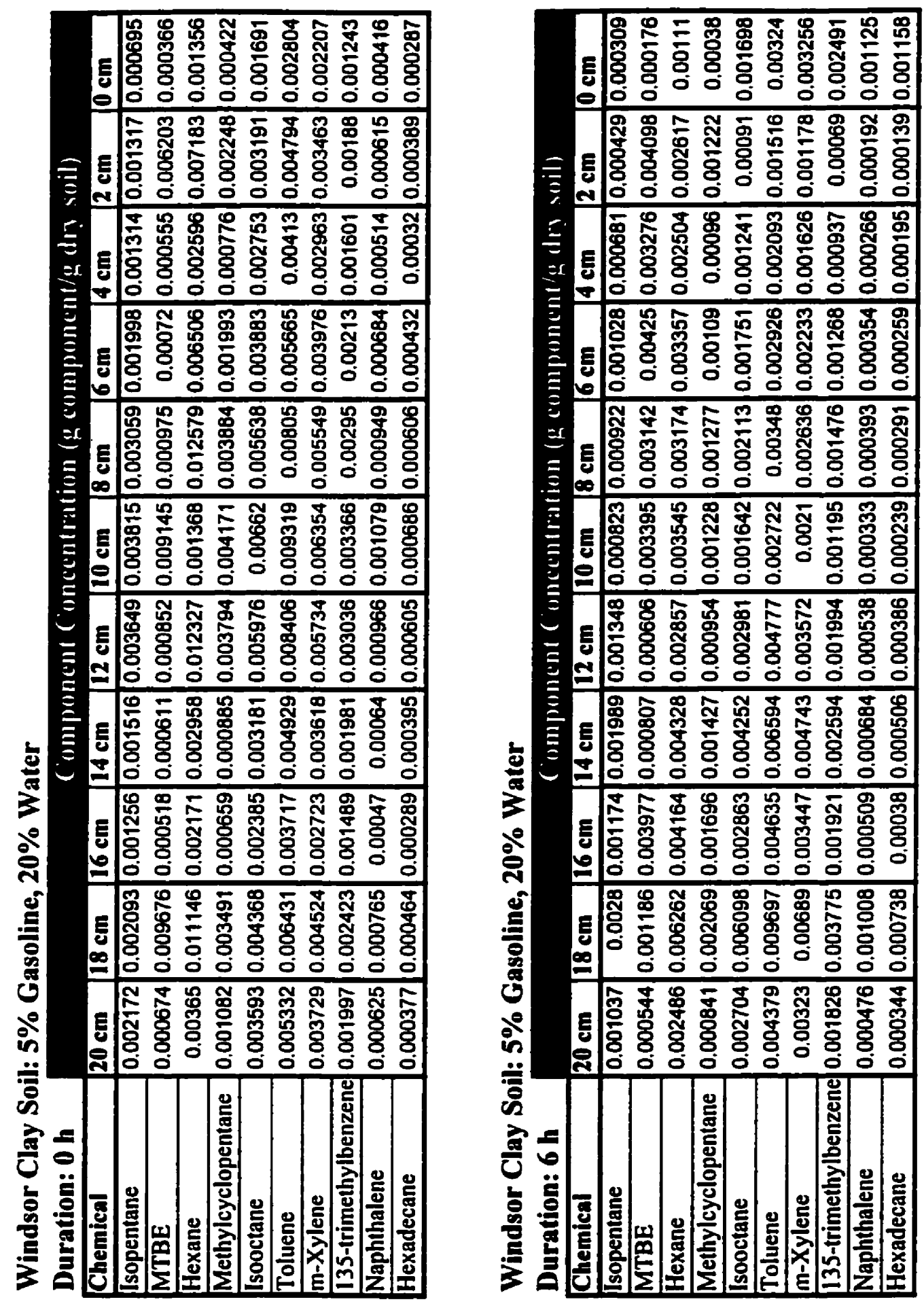

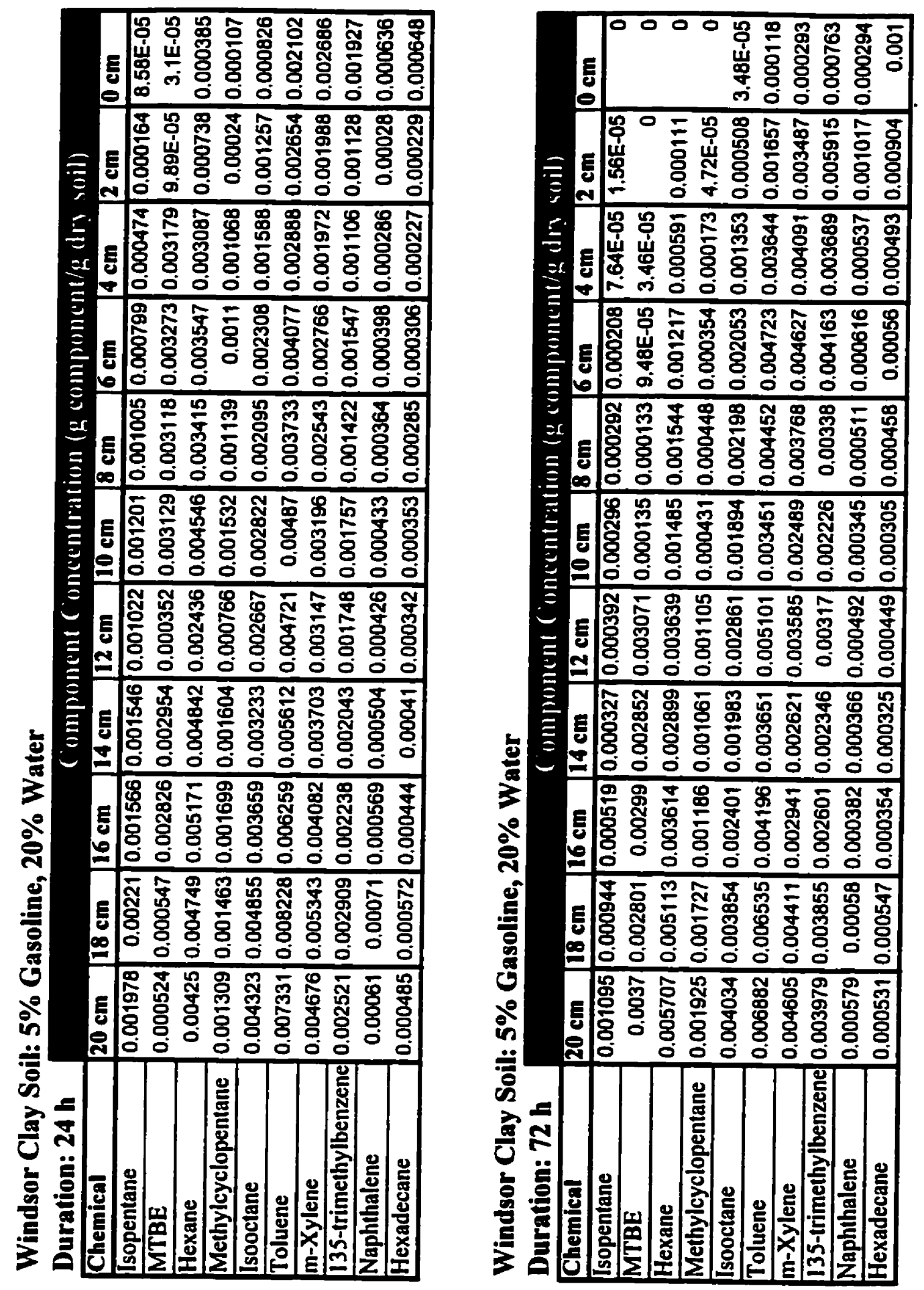
Windsor Clay Soil: $\mathbf{5 \%}$ Gasoline, $\mathbf{2 0 \%}$ Water

\begin{tabular}{|c|c|c|c|c|c|c|c|c|c|c|c|}
\hline Duration: $120 \mathrm{~h}$ & & & & ( & 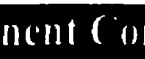 & 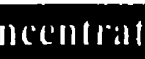 & I1)II (g & mpene & $1 / \operatorname{g~d}(1)$ & s(iil) & \\
\hline Chemical & $20 \mathrm{~cm}$ & $18 \mathrm{~cm}$ & $16 \mathrm{~cm}$ & $14 \mathrm{~cm}$ & $12 \mathrm{~cm}$ & $10 \mathrm{~cm}$ & $8 \mathrm{~cm}$ & $6 \mathrm{~cm}$ & $4 \mathrm{~cm}$ & $2 \mathrm{~cm}$ & $0 \mathrm{~cm}$ \\
\hline sopentane & 0.000347 & 0.000281 & 0.000189 & 0.000134 & 0.0002 & 9.78E-05 & 5,89E-05 & $6.18 \mathrm{E}-05$ & $3,08 \mathrm{E}-05$ & $2,44 E-05$ & \\
\hline MTBE & 0.000333 & 0.000293 & 0.000206 & 0.002963 & 0.003372 & 0.002822 & 0.002642 & 0.002836 & 0.002885 & 4.02E-05 & \\
\hline Hexane & 0.001691 & 0.001338 & 0.000927 & 0.002115 & 0.003053 & 0.001953 & 0.0017 & 0,001713 & 0.001014 & 0.000193 & \\
\hline Methylcyclopentane & 0.00068 & 0.000544 & 0.000383 & 0.000876 & 0.001426 & 0.000796 & 0,000537 & 0.000592 & 0.000599 & 0.000113 & 0 \\
\hline Isooctane & 0,001826 & 0.001485 & 0,001113 & 0,001242 & 0.002181 & 0.001191 & 0,001117 & 0.000978 & 0.000842 & 0.000795 & 3.04E-05 \\
\hline Toluene & 0.002904 & 0,002431 & 0,001922 & 0.002138 & 0.003513 & 0.002176 & 0.002291 & 0.002298 & 0.002209 & 0.002101 & 0.000118 \\
\hline m-Xylene & 0.002452 & 0.002086 & 0,001709 & 0.001856 & 0,002924 & 0.001966 & 0.002262 & 0.002619 & 0,003688 & 0.004648 & 0.000391 \\
\hline nethylbenzene & 0.001315 & 0.001137 & 0.000952 & 0.001009 & 0.001564 & 0.001089 & 0.001238 & 0.001435 & 0.00225 & 0.004305 & 0.000742 \\
\hline Naphthalene & 0.000341 & 0,000297 & 0.000252 & 0.000264 & 0.000407 & 0,000286 & 0.00033 & 0.000378 & 0.000542 & 0.001362 & 0.000842 \\
\hline Hexadecane & 0.000232 & 0.000196 & 0.000172 & 0.000178 & 0.000287 & 0.000193 & 0,000229 & 0.000255 & 0,000397 & 0,001015 & 0.002857 \\
\hline
\end{tabular}

Windsor Clay Soil: 5\% Gasoline, 20\% Water

\begin{tabular}{|c|c|c|c|c|c|c|c|c|c|c|c|}
\hline & & & & & & II & & & 1 & & \\
\hline Chemical & $20 \mathrm{~cm}$ & $18 \mathrm{~cm}$ & $16 \mathrm{~cm}$ & $14 \mathrm{~cm}$ & $12 \mathrm{~cm}$ & $10 \mathrm{~cm}$ & $8 \mathrm{~cm}$ & $6 \mathrm{~cm}$ & $4 \mathrm{~cm}$ & $2 \mathrm{~cm}$ & $0 \mathrm{~cm}$ \\
\hline Isopentane & $1.93 \mathrm{E}-05$ & 2.11E-05 & $1.86 \mathrm{E}-05$ & 9.02E-06 & 7.19E-06 & $5.18 E-06$ & $3.89 E-06$ & 3.17E-06 & $\begin{array}{c}\mathbf{0} \\
\end{array}$ & 0 & 0.003818 \\
\hline MTBE & 0.003788 & 0.002993 & 0.000161 & 0.003186 & 0.002281 & 0.003075 & $3.63 E-05$ & $1.78 \mathrm{E}-05$ & 0 & 0 & 0.004458 \\
\hline Hexane & 0.003382 & 0.002546 & 0.001163 & 0.002607 & 0.001736 & 0.001571 & 0.000195 & 0.000124 & 1.26E-05 & 0 & 0 \\
\hline Methylcyclopentane & 0.001384 & 0.001055 & 0.000358 & 0.00093 & 0.000597 & 0.00053 & 7.15E-05 & 4.7E-05 & 8.4E-06 & 0 & $\mathbf{0}$ \\
\hline Isooctane & 0.003736 & 0.002773 & 0.002676 & 0.001988 & 0,001324 & 0.00103 & 0.000785 & 0,000582 & 0.000197 & $1.22 E-05$ & 8.97E-06 \\
\hline Toluene & 0.005765 & 0.004625 & 0.004658 & 0.004127 & 0.003154 & 0.002656 & 0.002021 & 0,001347 & 0,000376 & 2.3E-05 & $3,99 \mathrm{E}-05$ \\
\hline m-Xylene & 0.004059 & 0.003297 & 0.003361 & 0.003373 & 0.003101 & 0.00336 & 0.003289 & 0.002664 & 0.000834 & 5.74E-05 & 7.44E-05 \\
\hline 135-trimethylbenzene & 0.002308 & 0.001875 & 0.001894 & 0.001908 & 0.001733 & 0.001991 & 0.002451 & 0,002972 & 0.001292 & 0.000102 & 0.000104 \\
\hline Naphthalene & 0.000631 & 0.000511 & 0.000514 & 0,00052 & 0.000472 & 0.000527 & 0.000636 & 0.000946 & 0.000897 & 0.000155 & 0.000134 \\
\hline Hexadecane & 0.000502 & 0.000382 & 0.000389 & 0.000406 & 0.000354 & 0.000405 & 0,000483 & 0.000674 & 0.000736 & 0,000391 & 0.002049 \\
\hline
\end{tabular}




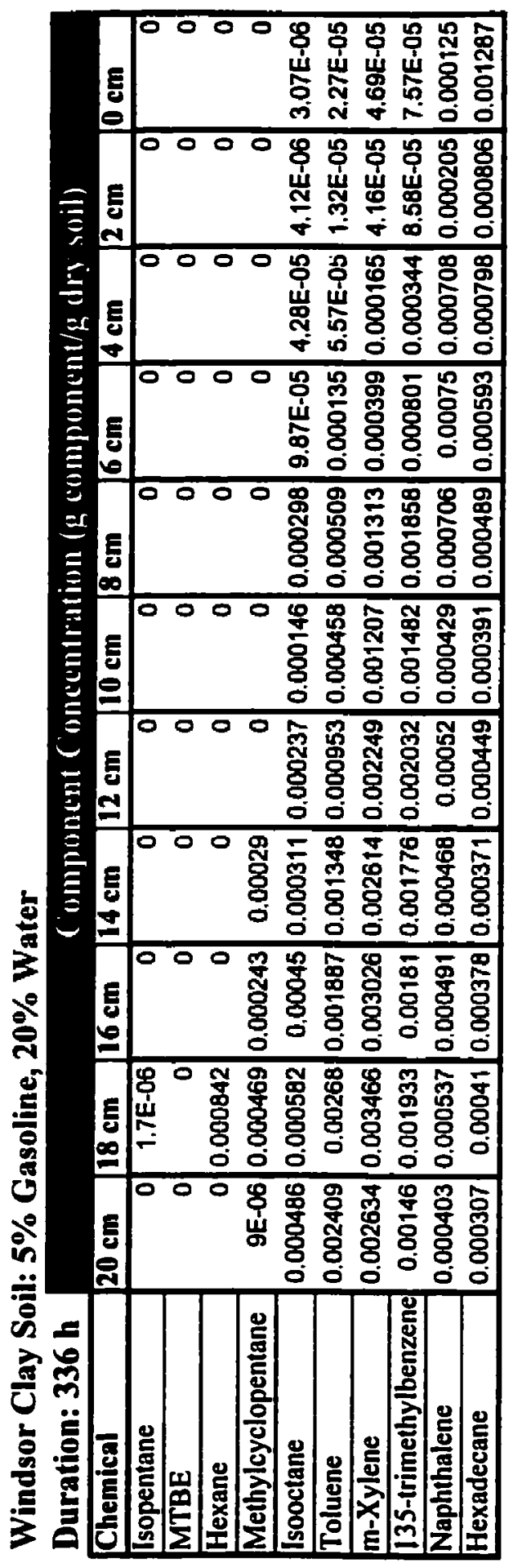



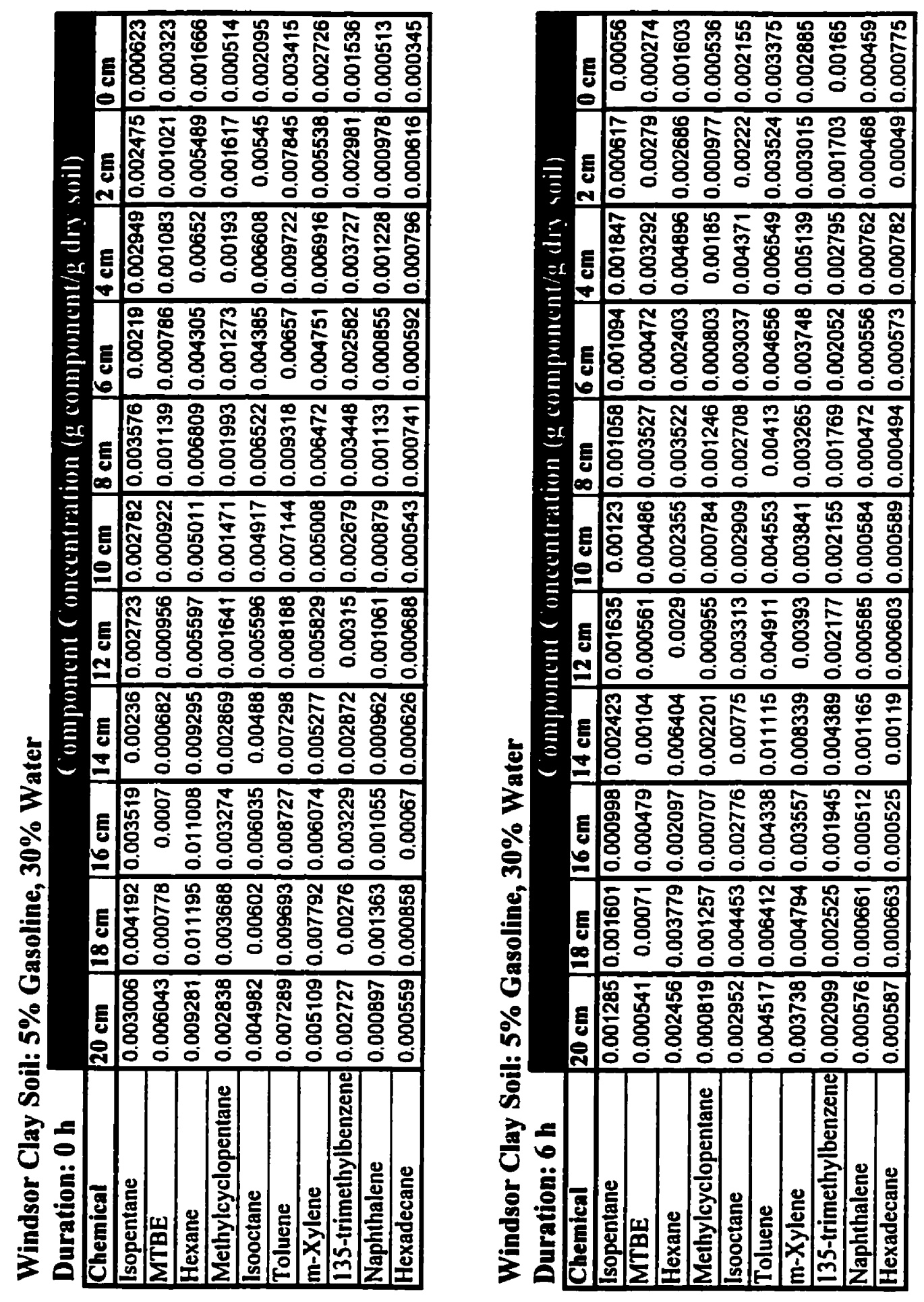

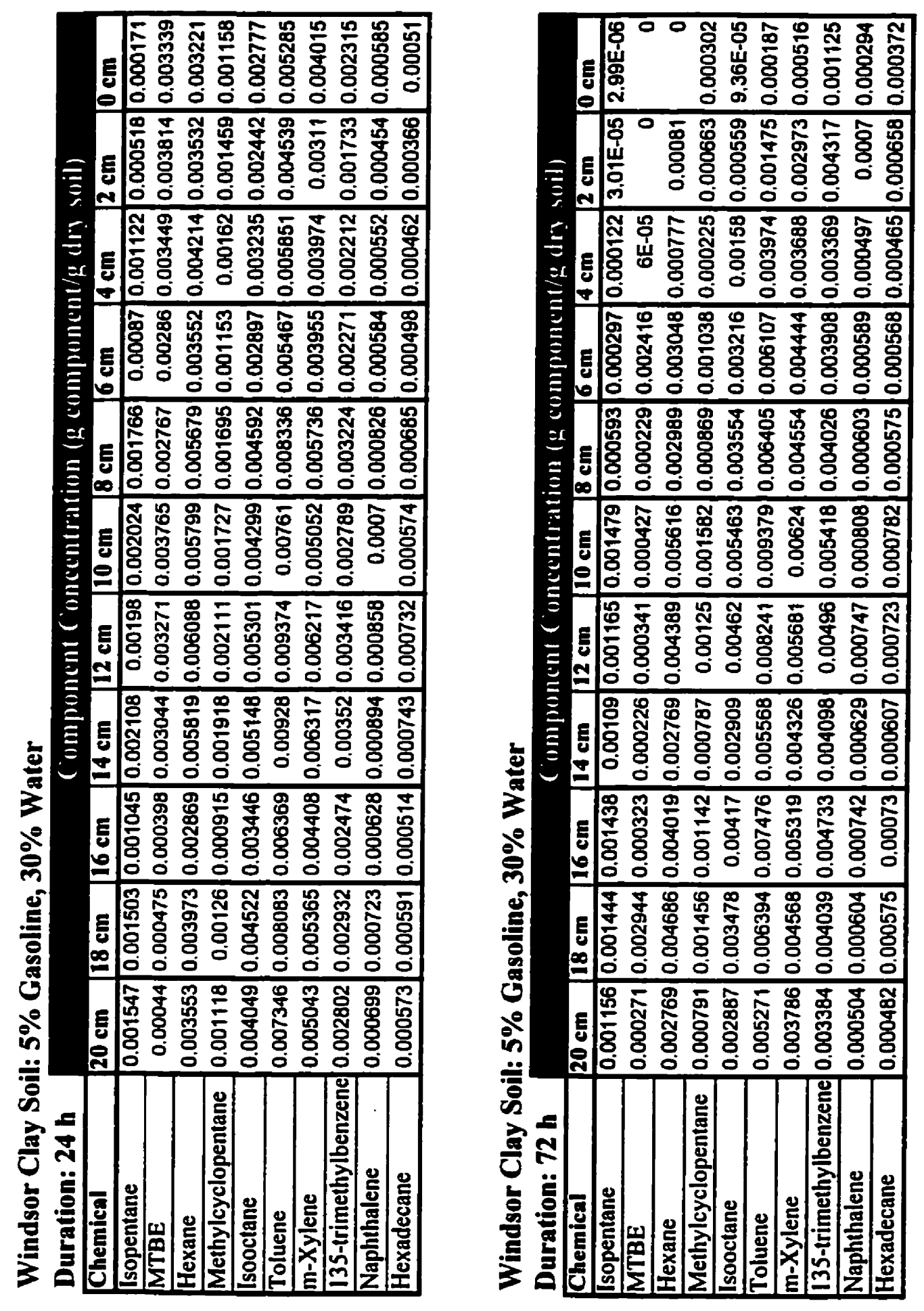

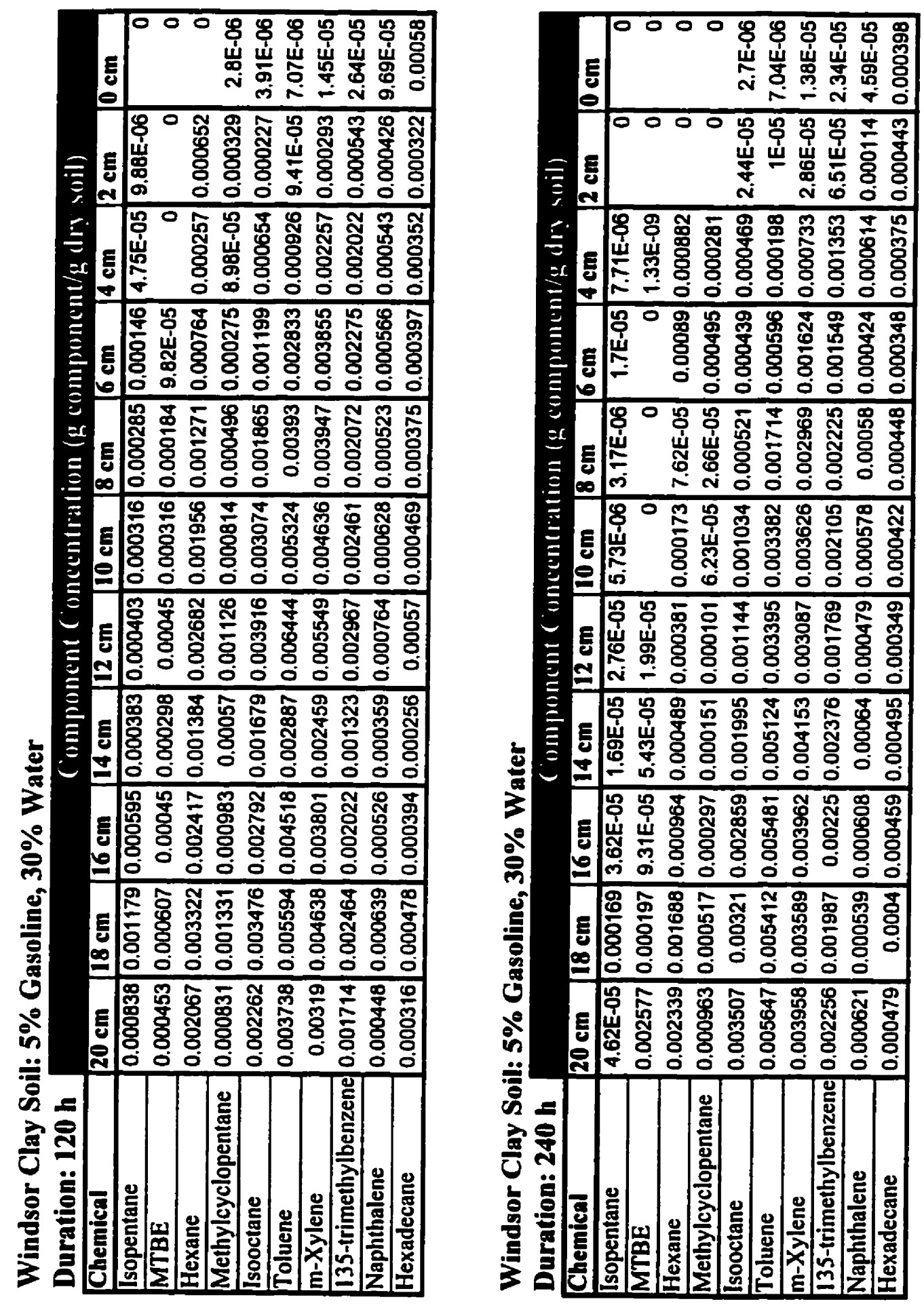
Windsor Clay Soil: 5\% Gasoline, 30\% Water

Duration: $336 \mathrm{~h}$ ('omponcent (oncentration (g compuncontg dry suil)

\begin{tabular}{|c|c|c|c|c|c|c|c|c|c|c|c|}
\hline Chemical & $20 \mathrm{~cm}$ & $18 \mathrm{~cm}$ & $16 \mathrm{~cm}$ & $14 \mathrm{~cm}$ & $12 \mathrm{~cm}$ & $10 \mathrm{~cm}$ & $8 \mathrm{~cm}$ & $6 \mathrm{~cm}$ & $4 \mathrm{~cm}$ & $2 \mathrm{~cm}$ & $0 \mathrm{~cm}$ \\
\hline Isopentane & 1.67E-05 & $1.2 \mathrm{E}-05$ & 1.17E-05 & 4.15E-06 & $9.06 \mathrm{E}-06$ & 6.73E-06 & o & 0 & 0 & 0 & 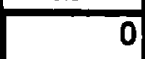 \\
\hline MTBE & 0.003454 & 0.003515 & 0 & & & & 0 & 0 & 0 & 0 & 0 \\
\hline Hexane & 0.002181 & 0.001865 & 0.000151 & 0.001011 & 0.000109 & 0.000178 & 0 & 0 & 0 & $\mathbf{0}$ & 0 \\
\hline Methylcyclopentane & 0.000856 & 0.000527 & 5.8E-05 & 0.000489 & 1.59E-05 & $1.52 E-05$ & 0 & 0.00051 & 0 & $\mathbf{0}$ & 0 \\
\hline Isooctane & 0.002121 & 0.001192 & 0.000529 & 0.00043 & 0.00042 & 0.000686 & 0.000185 & 0.000172 & $1.96 \mathrm{E}-05$ & 0 & 0 \\
\hline Toluene & 0.005333 & 0.003361 & 0.001132 & 0.000434 & 9.11E-05 & $5.27 \mathrm{E}-05$ & $1.06 E-05$ & $3,08 E-06$ & $1.56 E-06$ & 0 & 0 \\
\hline$m$-Xylene & 0.004568 & 0.00367 & 0.001701 & 0.000993 & 0.000377 & 0.000218 & $2,6 \mathrm{E}-05$ & 9.53E-06 & $2.51 E-06$ & 0 & 0 \\
\hline 135-trimethylbenzene & 0.002544 & 0,002303 & 0.001467 & 0,001519 & 0.000833 & 0,000858 & 0.000207 & 0.000126 & $1,36 E-05$ & $5.55 E-06$ & $3.27 E-06$ \\
\hline Naphthalene & 0.000684 & 0.000629 & 0.000485 & 0.000709 & 0.000603 & 0,000686 & 0.000371 & 0.000314 & 9.96E-05 & 4.59E-05 & $3.01 E-05$ \\
\hline Hexadecane & 0.000562 & 0.000557 & 0.000372 & 0,00068 & 0.000489 & 0.000464 & 0,000552 & 0.000351 & 0.000495 & 0.000609 & 0,000432 \\
\hline
\end{tabular}

$\vec{\infty}$ 

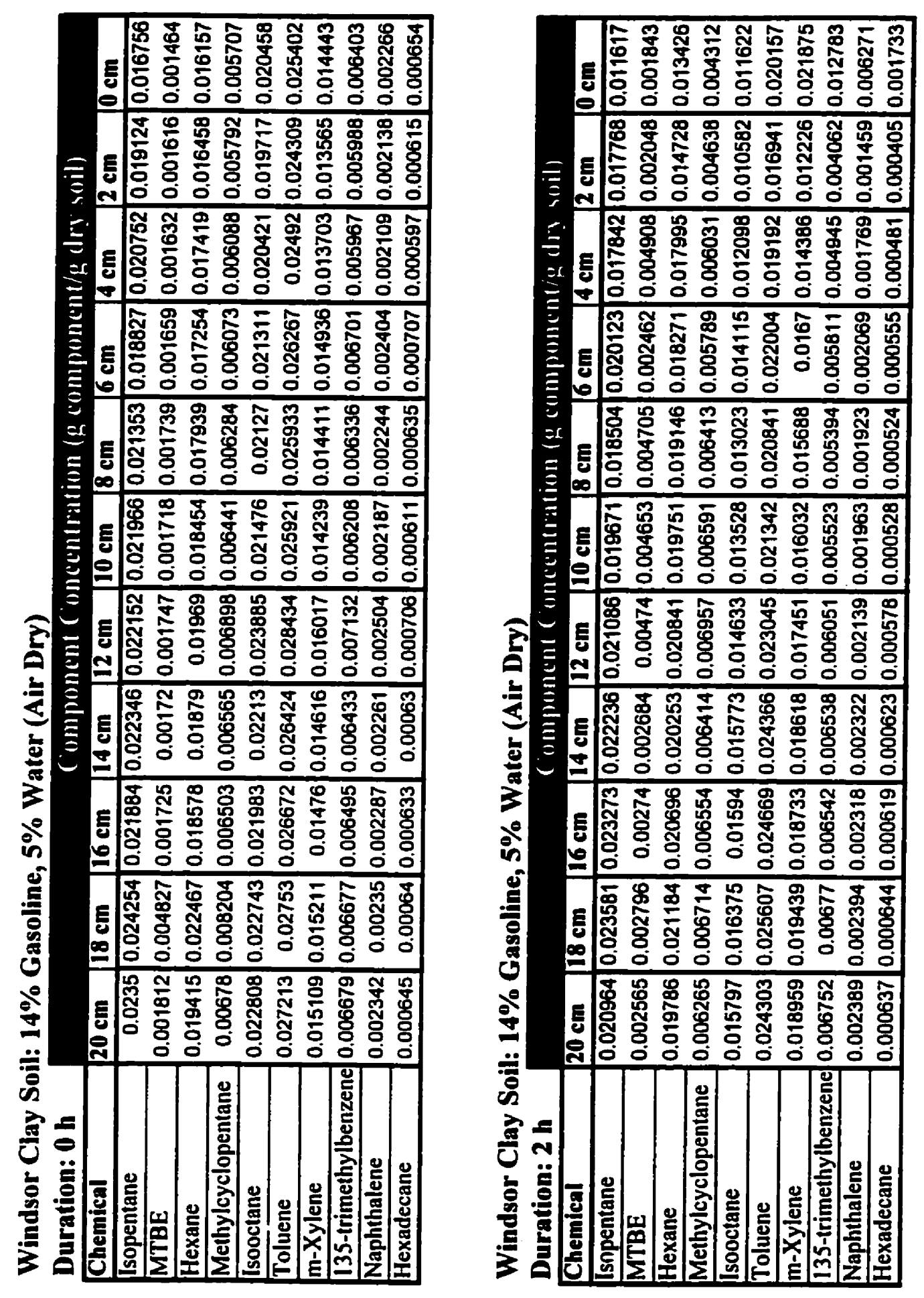

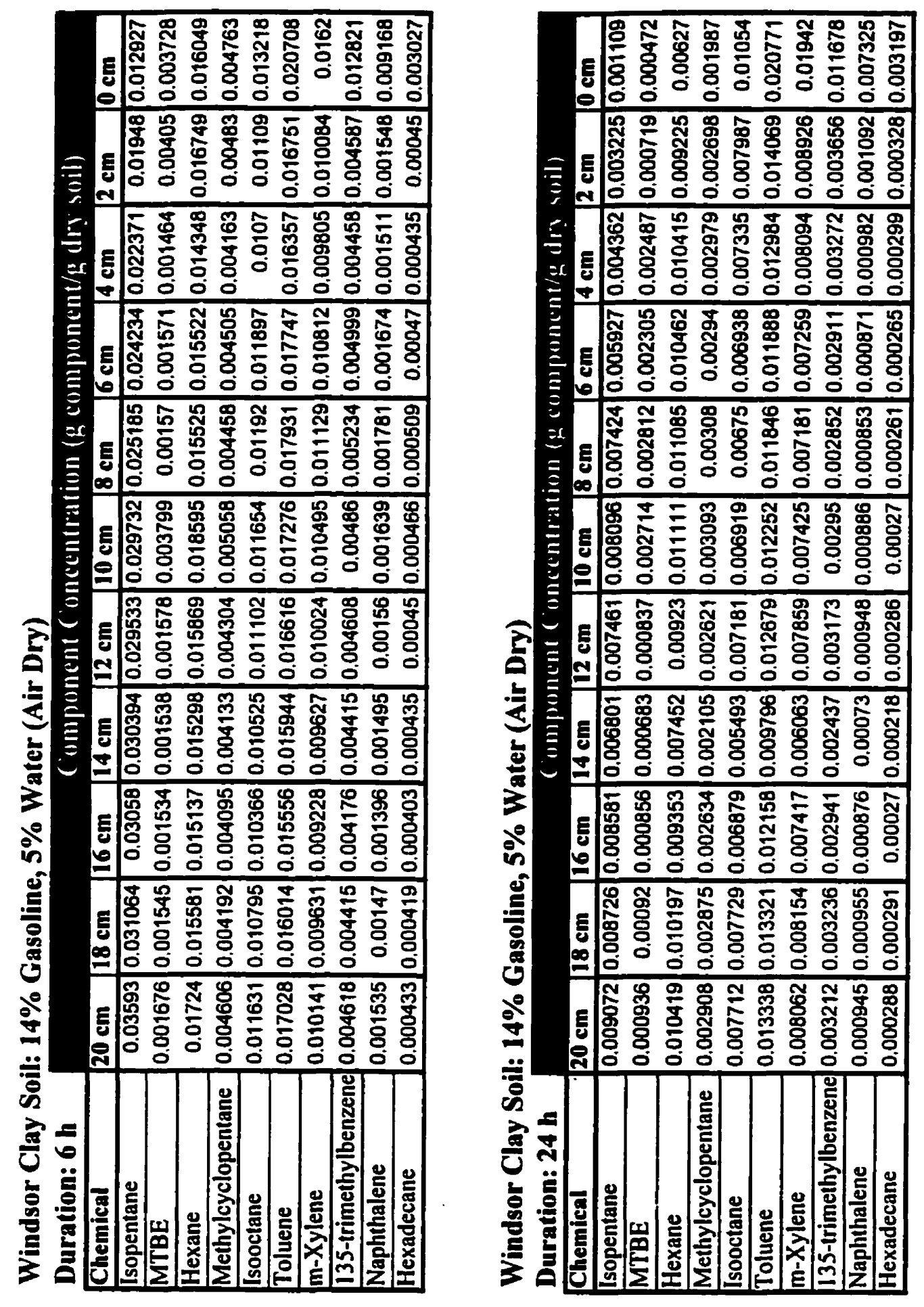

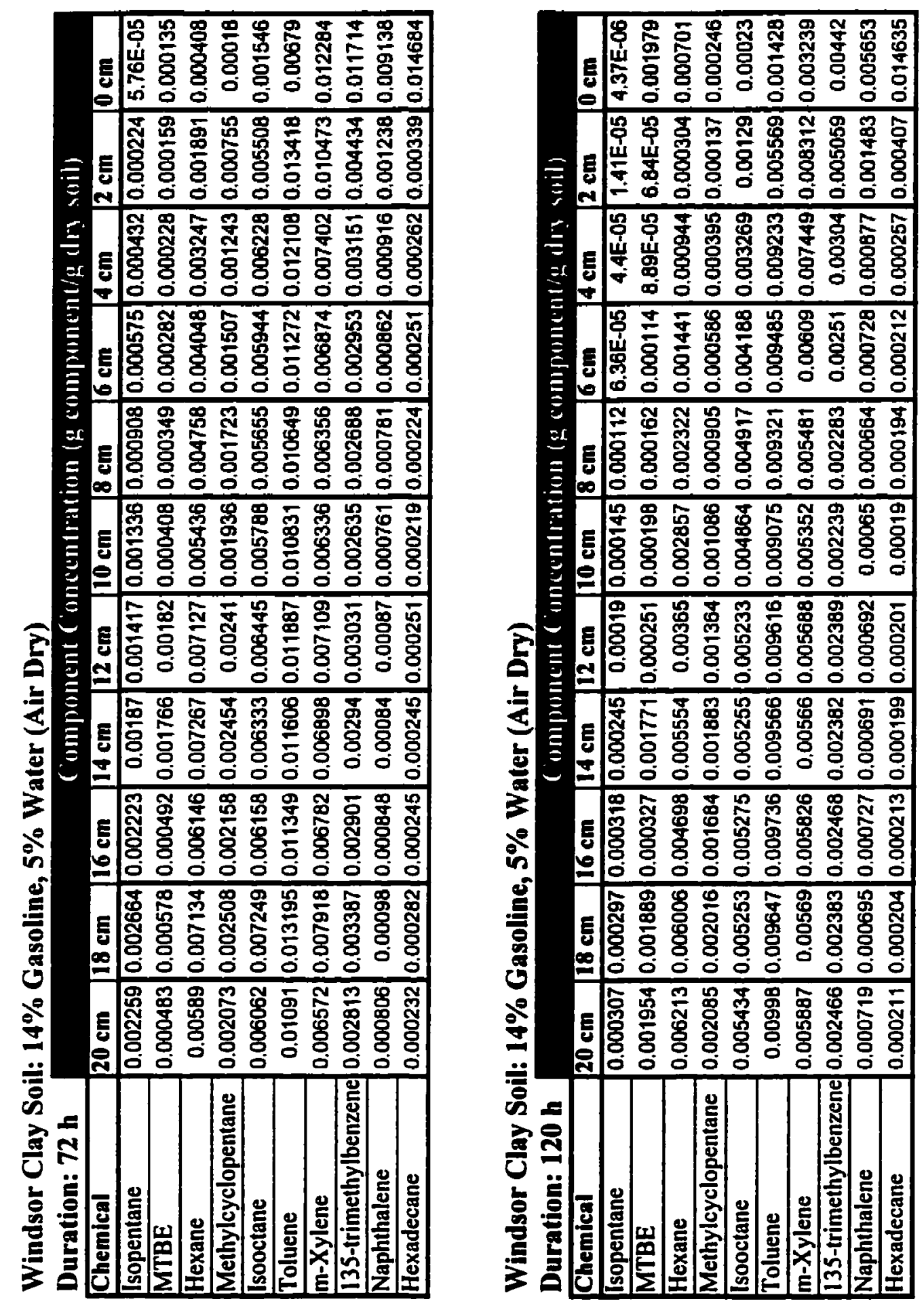
Windsor Clay Soil: 14\% Gasoline, 5\% Water (Air Dry)

\begin{tabular}{|c|c|c|c|c|c|c|c|c|c|c|c|}
\hline \multirow{2}{*}{$\begin{array}{l}\text { Duration: } 240 \mathrm{~h} \\
\text { Chemical }\end{array}$} & \multirow[b]{2}{*}{$20 \mathrm{~cm}$} & \multirow[b]{2}{*}{$18 \mathrm{~cm}$} & \multicolumn{9}{|c|}{ Component (ancentration (g eomponent/g dry soil) } \\
\hline & & & $16 \mathrm{~cm}$ & $14 \mathrm{~cm}$ & $12 \mathrm{~cm}$ & $10 \mathrm{~cm}$ & $8 \mathrm{~cm}$ & $6 \mathrm{~cm}$ & $4 \mathrm{~cm}$ & $2 \mathrm{~cm}$ & $0 \mathrm{~cm}$ \\
\hline Isopentane & 4.23E-06 & 3.73E-06 & 3.56E-06 & 2.44E-06 & $2.16 E-06$ & $2,04 E-06$ & $1.04 \mathrm{E}-06$ & 1.31E-06 & $1.98 E-06$ & $7,46 E-07$ & 9.33E-07 \\
\hline GTBE & 001209 & 0.001208 & $9.28 \mathrm{E}-05$ & 0,001424 & 0.001402 & 0.001393 & 0.001113 & 0.001287 & 0.00136 & 0.001507 & 0.002001 \\
\hline Texane & 0.002708 & 0.002404 & 0,001239 & 0,001909 & 0.001644 & 0.001409 & 0.00097 & 0.000825 & 0.000765 & 0.000458 & 0,000449 \\
\hline Methylcy & 0.000905 & 0.000795 & 0.000479 & 0.000617 & 0.000516 & 0.000433 & 0.000261 & 0,000239 & 0.000189 & 0.000174 & 0.000146 \\
\hline sooctane & 0.004363 & 0.003964 & 0.0036 & 0.002904 & 0.00241 & 0.001751 & 0.001098 & 0.000553 & 0,000287 & 0.000145 & 3.97E-05 \\
\hline Toluene & 0.00767 & 0.007467 & 0,007568 & 0.006883 & 0.006495 & 0.005578 & 0,004123 & 0.002401 & 0.001398 & 0.000834 & 0.000282 \\
\hline m-Xylene & 0.004716 & 0.004642 & 0.004928 & 0,004825 & 0.005154 & 0.005555 & 0.00527 & 0.003678 & 0.002621 & 0.001803 & 0,000573 \\
\hline 135-trimethylbenzene & 0.001879 & 0.001829 & 0.001935 & 0.001845 & 0.001989 & 0.002167 & 0.002332 & 0,002034 & 0,002068 & 0.002203 & 0.000852 \\
\hline Naphthalene & 0.00058 & 0.000566 & 0.000608 & 0.000558 & 0.000605 & 0.000648 & 0.000688 & 0.000635 & 0,000721 & 0.001665 & 0.0022 \\
\hline Hexadecane & 0.000176 & 0.000173 & 0.000193 & 0.000168 & 0.000183 & 0.000197 & & $0.000<00$ & 0.00025 & 0,000456 & 0,012 \\
\hline
\end{tabular}

Windsor Clay Soil: 14\% Gasoline, 5\% Water (Air Dry)

\begin{tabular}{|c|c|c|c|c|c|c|c|c|c|c|c|}
\hline & & & & & & & & & & & \\
\hline Chemical & $20 \mathrm{~cm}$ & $18 \mathrm{~cm}$ & $16 \mathrm{~cm}$ & $14 \mathrm{~cm}$ & $12 \mathrm{~cm}$ & $10 \mathrm{~cm}$ & $8 \mathrm{~cm}$ & $6 \mathrm{~cm}$ & $4 \mathrm{~cm}$ & $2 \mathrm{~cm}$ & $0 \mathrm{~cm}$ \\
\hline Isopentane & 5.59E-07 & 4.49E-07 & $7.49 E-07$ & 5.61E-07 & 6.03E-07 & $6.14 E-07$ & 6.11E-07 & $5.55 E-07$ & $\longdiv { 5 . 2 5 E - 0 7 }$ & $4,62 \mathrm{E}-07$ & 6.15E-07 \\
\hline MTBE & 0.001324 & $1.94 \mathrm{E}-05$ & $1.88 E-05$ & 0.001353 & 0.001757 & 0.001479 & 0.001421 & 0.001483 & 0.002 & 0,001683 & $2,05 E-05$ \\
\hline Hexane & 0.000963 & 0.000197 & 0.000169 & 0.000876 & 0.000776 & 0.000582 & 0.00055 & 0.000327 & 0,000331 & 0,000272 & 1.95E-07 \\
\hline Methylcyclopentane & 0,000296 & 0.000107 & 9.45E-05 & 0.000267 & 0.000293 & 0.000228 & 0.0002 & $5,39 E-05$ & 5.46E-05 & $3.02 E-05$ & 2.21E-05 \\
\hline Isooctane & 0.002152 & 0.002189 & 0.001764 & 0.001341 & 0.00099 & 0,000698 & 0.000433 & 0.000177 & 0.000129 & 8.53E-05 & $8,89 E-05$ \\
\hline Toluene & 0.005686 & 0.006024 & 0.005304 & 0,00483 & 0.003952 & 0.003121 & 0.002137 & 0.001003 & 0.000783 & 0.00057 & 0.000296 \\
\hline m-Xylene & 0.003789 & 0,004272 & 0.003931 & 0.004491 & 0.004287 & 0.00414 & 0.003438 & 0.001987 & 0.001662 & 0.001309 & 0.000358 \\
\hline 135-trimethylbenzene & 0.001525 & 0.001615 & 0.001414 & 0.001626 & 0.00159 & 0.00173 & 0.001813 & 0.00157 & 0,001564 & 0.001443 & 0.00062 \\
\hline Naphthalene & 0.000471 & 0.00048 & 0.000417 & 0.000474 & 0.00045 & 0.000492 & 0.000527 & 0.000547 & 0,000642 & 0,000744 & 0.019747 \\
\hline Hexadecane & 0.000102 & 0.000106 & 9.41E-05 & 0,000106 & 0,000102 & 0.000126 & 0.000145 & 0,000155 & 0.000217 & 0,000208 & 0,010779 \\
\hline
\end{tabular}


Appendix G

Frozen Temperature Windsor Clay Loam Volatilization Data 

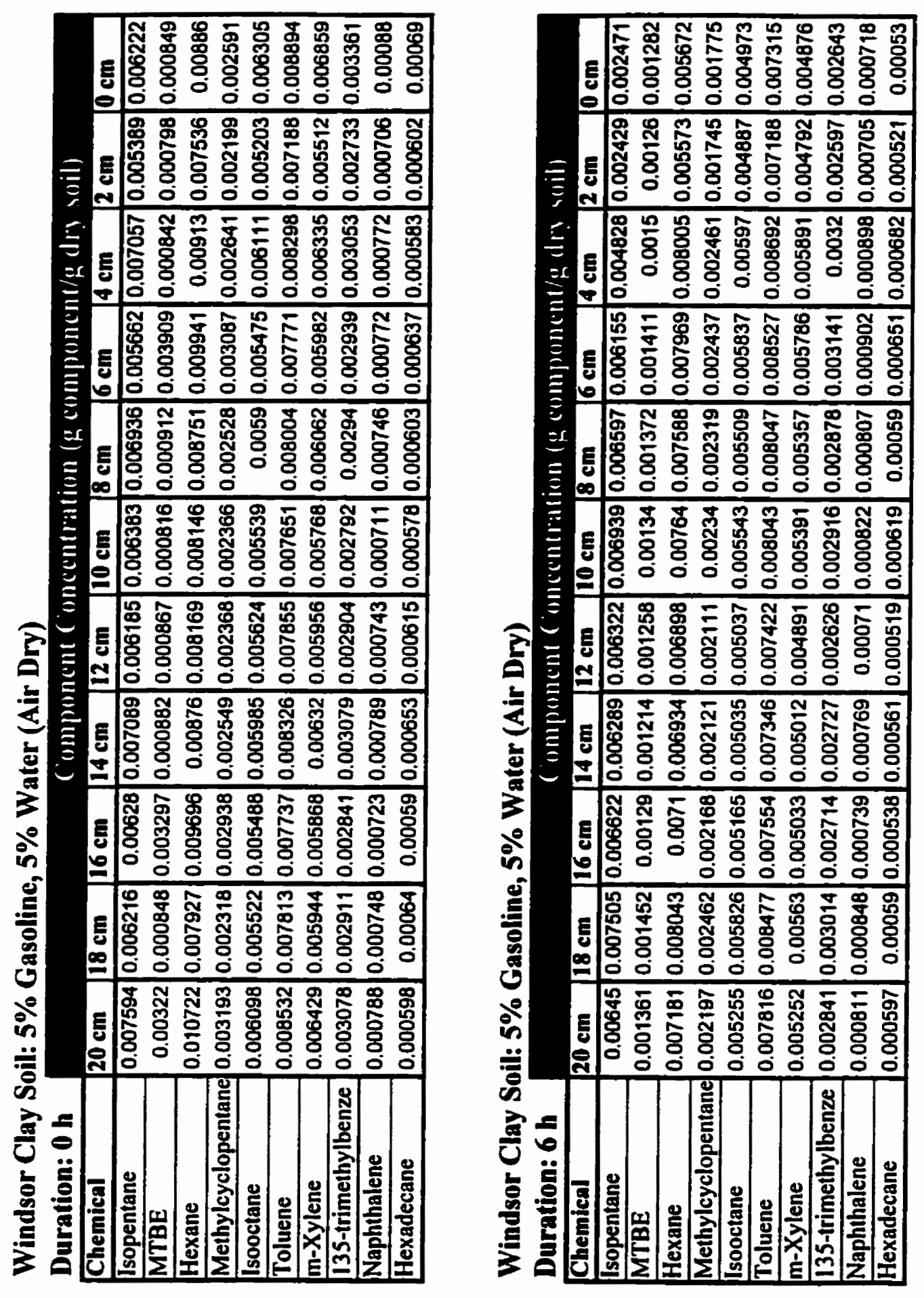
Windsor Clay Soil: 5\% Gasoline, 5\% Water (Air Dry)

\begin{tabular}{|c|c|c|c|c|c|c|c|c|c|c|c|}
\hline & & & & & & & & & $=101$ & & \\
\hline Chemical & $20 \mathrm{~cm}$ & $18 \mathrm{~cm}$ & $16 \mathrm{~cm}$ & $14 \mathrm{~cm}$ & $12 \mathrm{~cm}$ & $10 \mathrm{~cm}$ & $8 \mathrm{~cm}$ & $6 \mathrm{~cm}$ & $4 \mathrm{~cm}$ & $2 \mathrm{~cm}$ & $0 \mathrm{~cm}$ \\
\hline & 003176 & 0.003241 & 0,001677 & 0,00123 & 0.002129 & 0,002292 & 0.002366 & 0.00131 & 0.000537 & 0,000371 & $4.37 \mathrm{E}-05$ \\
\hline & 103516 & 71 & 30048 & 0.000392 & 0,000574 & 0.00068 & 0.000742 & 0.000459 & 0,000294 & 0.003104 & 0,002781 \\
\hline & 06931 & 05638 & .003458 & 0.002731 & 0.004118 & 0.004891 & 0.005321 & 0,003268 & 0.001982 & 0.004077 & 0,001433 \\
\hline ane & 0.002431 & 0.001743 & 0.001085 & 0.00086 & 0.001283 & 0,001531 & 0,001666 & 0.001021 & 0.000627 & 0.001158 & 0,00042 \\
\hline & 0.004305 & 004463 & 0.002964 & 0.00242 & 0.003378 & 0.004059 & 0.004477 & 0.002767 & 0,001834 & .002508 & 0,000723 \\
\hline & 0.006073 & 006377 & 0.004308 & 0.003531 & 0.004832 & 0.005843 & 0.006552 & 0.003991 & 0.002742 & 0.003691 & 1.001798 \\
\hline & 0.00458 & 0,004801 & 0.003346 & 0.002752 & 0,003693 & 0,004533 & 0.005054 & 0.003076 & 0.002178 & 0.002918 & 0.002773 \\
\hline & 0.002154 & 0,00225 & .001588 & 0.001305 & 0,001748 & 0.002164 & 0.002404 & 0.001457 & 0.00 & 0.00139 & 0.001897 \\
\hline & 00535 & .000562 & 000394 & 335 & 0.00045 & & & & & & \\
\hline lexadecane & 0.000366 & .000386 & & & 00 & & & & 1186 & 124 & 000 \\
\hline
\end{tabular}

Windsor Clay Soil: 5\% Gasoline, 5\% Water (Air Dry)

\begin{tabular}{|c|c|c|c|c|c|c|c|c|c|c|c|}
\hline uration: $72 \mathrm{~h}$ & & & & & 118 & 1111 & $t$ & & & & \\
\hline Chemical & $20 \mathrm{~cm}$ & $18 \mathrm{~cm}$ & $16 \mathrm{~cm}$ & $14 \mathrm{~cm}$ & $12 \mathrm{~cm}$ & $10 \mathrm{~cm}$ & $8 \mathrm{~cm}$ & $6 \mathrm{~cm}$ & $4 \mathrm{~cm}$ & $2 \mathrm{~cm}$ & \\
\hline Isopentane & 0,005082 & 0.004541 & 0.004404 & 0.003993 & 0.003724 & 0.002879 & 0.002127 & 0.001371 & 0,000727 & 0.000273 & $7,3 E-05$ \\
\hline MTBE & 0.00095 & 0.000813 & 0.000791 & 0.004306 & 0.003827 & 0,001188 & 0.001043 & 0.003605 & 0,000969 & 0.003935 & 0.000144 \\
\hline Hexane & 0.007563 & 0.007215 & 0.007338 & 0.009253 & 0.009906 & 0.007359 & 0.005966 & 0.006303 & 0.002638 & 0.003078 & 0.000157 \\
\hline Methylcyclopentane & 0.002255 & 0.002155 & 0.002191 & 0.003115 & 0.003065 & 0.002243 & 0.001843 & 0.002053 & 0.000841 & 0.000914 & $7.26 \mathrm{E}-05$ \\
\hline Isooctane & 0.00538 & $0.005 \uparrow 65$ & 0.005217 & 0.005608 & 0.005993 & 0.00599 & 0.005404 & 0,005061 & 0.003691 & 0,001744 & 0.000413 \\
\hline Toluene & 0,007286 & 0.007009 & 0.006998 & 0.007523 & 0.008114 & 0.008209 & 0,007427 & 0.007394 & 0,006376 & 0,003745 & 0.000934 \\
\hline m-Xylene & 0.005198 & 0.005041 & 0.00505 & 0.005364 & 0.005709 & 0.005777 & 0.005223 & 0,005302 & 0.005087 & 0.004441 & 0,001632 \\
\hline 135-trimethylbenze & 0,002604 & 0.002538 & 0,002546 & 0,00268 & 0.002853 & 0.002897 & 0.002621 & 0.002661 & 0.002542 & 0.00259 & 0,001678 \\
\hline Naphthalene & 0.000677 & 0.000657 & 0.000654 & 0.000659 & 0.000759 & 0,000771 & 0.00067 & 0.000723 & 0.000687 & 0.000717 & 0.000801 \\
\hline Hexadecane & 0.000487 & 0.000495 & 0.000497 & 0.000538 & 0,000593 & 0,000621 & 0.000586 & 0,000623 & 0.000619 & 0.000653 & 0,00079 \\
\hline
\end{tabular}


Windsor Clay Soil: 5\% Gasoline, 5\% Water (Air Dry)

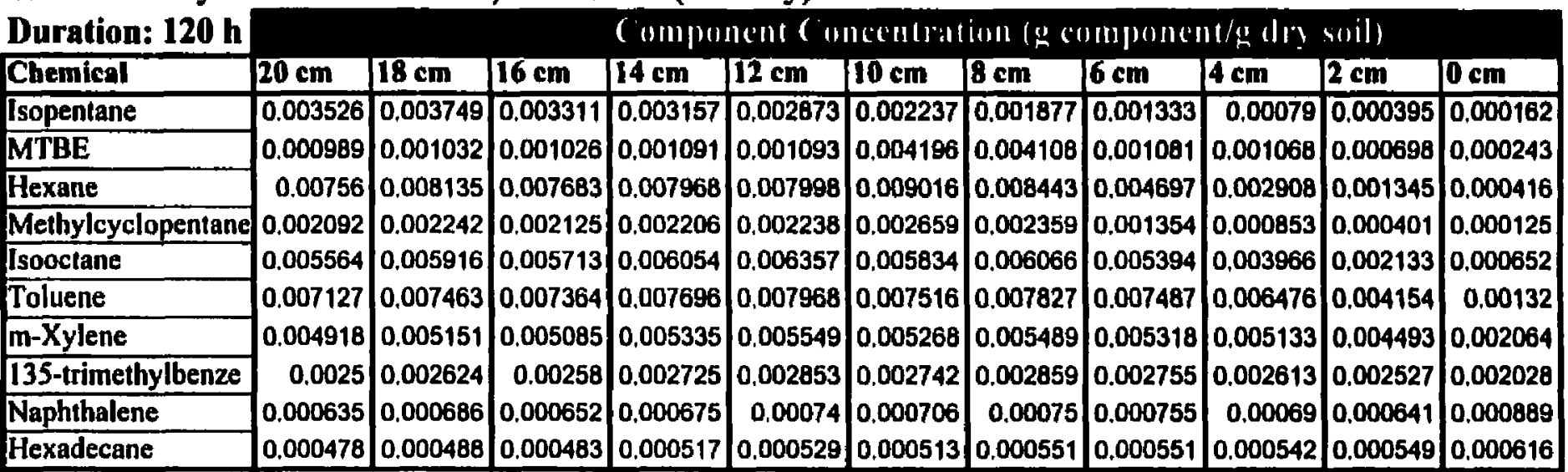

Windsor Clay Soil: 5\% Gasoline, 5\% Water (Air Dry)

\begin{tabular}{|c|c|c|c|c|c|c|c|c|c|c|c|}
\hline ar & & & & & & & & & & & \\
\hline Chemical & $20 \mathrm{~cm}$ & $18 \mathrm{~cm}$ & $16 \mathrm{~cm}$ & $14 \mathrm{~cm}$ & $12 \mathrm{~cm}$ & $10 \mathrm{~cm}$ & $8 \mathrm{~cm}$ & $6 \mathrm{~cm}$ & $4 \mathrm{~cm}$ & $2 \mathrm{~cm}$ & $\mathrm{~cm}$ \\
\hline Isopentane & 0.001315 & 0.001459 & 0.001286 & 0,001058 & 0.000903 & 0,000754 & 0,000609 & 0.000333 & 0.000236 & $9.37 E-05$ & 3.16E-05 \\
\hline MTBE & 0,001041 & 0,001022 & 0.000993 & 0.001048 & 0.001001 & 0,000995 & 0,001068 & 0,000928 & 0.002794 & 0.000388 & 0.002676 \\
\hline Hexane & 0.007071 & 0.007255 & 0.006896 & 0.006116 & 0.005356 & 0,004577 & 0.003934 & 0.00241 & 0.003126 & 0,000656 & 0.001426 \\
\hline Methylcyclopentane & 0.002141 & 0.002191 & 0.002097 & 0.001875 & 0.001666 & 0.001435 & 0.001244 & 0.000766 & 0.001027 & 0.000211 & 0.000315 \\
\hline Isooctane & 0.005528 & 0.005633 & 0.005693 & 0.005467 & 0,005333 & 0.00496 & 0.004779 & 0.003378 & 0.002481 & 0.001186 & 0.00026 \\
\hline Toluene & 0,007482 & 0.007431 & 0.007513 & 0,007323 & 0,007402 & 0.007081 & 0.007414 & 0.006032 & 0.004948 & 0,002682 & 0.000553 \\
\hline m-Xylene & 0.005374 & 0,005273 & 0.005334 & 0.005147 & 0.005269 & 0,005061 & 0.005492 & 0.005148 & 0.00495 & 0.003798 & 0.000993 \\
\hline 135-trimethylbenze & 0.002682 & 0.002637 & 0,002672 & 0.002558 & 0.002662 & 0,002544 & 0.00276 & 0.002616 & 0.002582 & 0,002669 & 0.00112 \\
\hline Naphthalene & 0,000703 & 0.000699 & 0.000712 & 0.000662 & 0,000726 & 0.000696 & 0,000761 & 0,000715 & 0.000729 & 0,000778 & 0.000639 \\
\hline Hexadecane & 0,000582 & 0.000555 & 0.000574 & 0.000526 & 0.000583 & 0.000557 & 0.000614 & 0.000617 & 0.000633 & 0.00069 & 0.000832 \\
\hline
\end{tabular}


Windsor Clay Soil: 5\% Gasoline, 20\% Water

\begin{tabular}{|c|c|c|c|c|c|c|c|c|c|c|c|}
\hline \multirow{2}{*}{$\begin{array}{l}\text { Duration: } 0 \text { h } \\
\text { Chemical }\end{array}$} & \multirow[b]{2}{*}{$20 \mathrm{~cm}$} & \multicolumn{10}{|c|}{ ('omponent (oncentration (g component/p des soil) } \\
\hline & & $18 \mathrm{~cm}$ & $16 \mathrm{~cm}$ & $14 \mathrm{~cm}$ & $12 \mathrm{~cm}$ & $10 \mathrm{~cm}$ & $8 \mathrm{~cm}$ & $6 \mathrm{~cm}$ & $4 \mathrm{~cm}$ & $2 \mathrm{~cm}$ & $0 \mathrm{~cm}$ \\
\hline Isopentane & 0.00172 & 0.002378 & 0.001425 & 0.00172 & $\longdiv { 0 . 0 0 4 1 4 4 }$ & 0.00433 & 0.003475 & 0.002268 & 0.001491 & 0.001495 & 0.000788 \\
\hline MTBE & 0.000626 & 0.009928 & 0.000531 & 0.000626 & 0.000874 & 0.009376 & 0.001 & 0,000738 & 0.000569 & 0,006362 & 0.000376 \\
\hline Hexane & 0.003192 & 0.012037 & 0.002343 & 0.003192 & 0.013311 & 0.001477 & 0.013584 & 0.007023 & 0.002802 & 0.007755 & 0.001463 \\
\hline Methylcyclopentane & 0.000964 & 0.003802 & 0.000717 & 0.000964 & 0.004133 & 0.004541 & 0.004231 & 0.00217 & 0.000844 & 0,002448 & 0.00046 \\
\hline Isooctane & 0,003229 & 0.004437 & 0.002421 & 0.003229 & 0.00607 & 0.00672 & 0.005727 & 0.003942 & 0.002794 & 0.003241 & 0.001716 \\
\hline Toluene & 0.004457 & 0.005821 & 0.003361 & 0.004457 & 0,007607 & 0.008429 & 0.007285 & 0.005124 & 0.003734 & 0.004337 & 0.002535 \\
\hline m-Xylene & 0.003512 & 0.004397 & 0.002644 & 0.003512 & 0.005571 & 0.00617 & 0.005392 & 0.003861 & 0.002877 & 0.003364 & 0.002143 \\
\hline 135-trimethylbenze & 0.001939 & 0.002374 & 0.001457 & 0.001939 & 0.002974 & 0.003296 & 0.00289 & 0,002085 & 0.001568 & 0.001841 & 0.001217 \\
\hline Naphthalene & 0.000597 & 0.000714 & 0.000439 & 0.000597 & 0,000902 & 0.001007 & 0.000886 & 0,000639 & 0,00048 & 0.000574 & 0.000389 \\
\hline Hexadecane & 0.000375 & 0.00044 & 0.000274 & 0.000375 & 0.000574 & 0.000651 & 0.000576 & 0.00041 & 0.000304 & 0.000369 & 0.000272 \\
\hline
\end{tabular}

Windsor Clay Soil: 5\% Gasoline, 20\% Water

\begin{tabular}{|c|c|c|c|c|c|c|c|c|c|c|c|}
\hline \multirow{2}{*}{ Duration: $6 \mathrm{~h}$} & \multicolumn{11}{|c|}{ (ampenent (oncentration (p compunent/g dr) soil) } \\
\hline & $20 \mathrm{~cm}$ & $18 \mathrm{~cm}$ & $16 \mathrm{~cm}$ & $14 \mathrm{~cm}$ & $12 \mathrm{~cm}$ & $10 \mathrm{~cm}$ & $8 \mathrm{~cm}$ & $6 \mathrm{~cm}$ & $4 \mathrm{~cm}$ & $2 \mathrm{~cm}$ & $0 \mathrm{~cm}$ \\
\hline sopentane & 0.003012 & 0.002118 & 0.001827 & 0.002605 & 0.002933 & 0.001709 & 0.001133 & 0.001337 & 0.001437 & 0.001418 & 0.0004 \\
\hline MTBE & 0.001007 & 0.000808 & 0,005236 & 0.000966 & 0.000921 & 0.000754 & 0.00528 & 0.005159 & 0.004906 & 0,005128 & 0.0004 \\
\hline Hexane & 0.005506 & 0.004249 & 0,006976 & 0.005234 & 0,005227 & 0.003948 & 0.005759 & 0.006121 & 0.006559 & 0.007097 & 0.0031 \\
\hline Methylcyclopentane & 0.00172 & 0.001335 & 0.001816 & 0.001648 & 0.001619 & 0.001254 & 0.001459 & 0.001594 & 0.001952 & 0,002127 & 0.0010 \\
\hline Isooctane & 0.004651 & 0.003779 & 0.003548 & 0.004568 & 0.004378 & 0.003752 & 0,002374 & 0.002795 & 0.003433 & 0.00393 & 0.00387 \\
\hline Toluene & 0.007006 & 0.005858 & 0.00553 & 0.00702 & 0,006515 & 0.005905 & 0.003734 & 0,004285 & 0.005394 & 0,006116 & 0,00 \\
\hline m-Xylene & 0.004691 & 0.00401 & 0,003846 & 0.004797 & 0.004465 & 0.004153 & 0.002616 & 0.002967 & 0.003802 & 0.00425 & 0.0046 \\
\hline 135-trimethylbenze & 0.002501 & 0.002153 & 0.002082 & 0.002593 & 0.002437 & 0.00227 & 0.001422 & 0.001612 & 0.002072 & 0.002311 & 0.0026 \\
\hline Naphthalene & 0.000633 & 0.000558 & 0.000556 & 0.000677 & 0.000642 & 0.000598 & 0.000378 & 0.000431 & 0,000557 & 0.000606 & 0.00101 \\
\hline Hexadecane & 0.000446 & 0.000393 & 0.000386 & 0.00048 & 0.000471 & 0.00043 & 0.000259 & 0.000299 & 0.000386 & 0.000437 & 0,0008 \\
\hline
\end{tabular}


Windsor Clay Soil: 5\% Gasoline, 20\% Water

\begin{tabular}{|c|c|c|c|c|c|c|c|c|c|c|c|}
\hline \multirow{2}{*}{$\begin{array}{l}\text { Duration: } 24 \text { h } \\
\text { Chemical }\end{array}$} & \multicolumn{11}{|c|}{ Componcent Concentration (g component/u dry solil) } \\
\hline & $20 \mathrm{~cm}$ & $18 \mathrm{~cm}$ & $16 \mathrm{~cm}$ & $14 \mathrm{~cm}$ & $12 \mathrm{~cm}$ & $10 \mathrm{~cm}$ & $8 \mathrm{~cm}$ & $6 \mathrm{~cm}$ & $4 \mathrm{~cm}$ & $2 \mathrm{~cm}$ & $0 \mathrm{~cm}$ \\
\hline Isopentane & 0.004567 & 0.004582 & 0.002871 & 0.002287 & 0.00301 & 0.003096 & 0.002788 & 0.001909 & 0.001039 & 0.00061 & 6.38E-05 \\
\hline MTBE & 0.000506 & 0.00109 & 0.000822 & 0.000728 & 0.000811 & 0.000918 & 0.000874 & 0.00067 & 0.000567 & 0.00051 & 0,000406 \\
\hline Hexane & 0.009966 & 0.00797 & 0,00592 & 0.005078 & 0.005821 & 0.006606 & 0,006269 & $0.004765 \mid$ & 0.003831 & 0.0067 & 0.002091 \\
\hline Methylcyclopentane & 0.003495 & 0.002464 & 0.001858 & 0.001598 & 0,001813 & 0.002068 & 0.001963 & 0.001489 & 0,001211 & 0.001903 & 0,000613 \\
\hline Isooctane & 0.00619 & 0.006309 & 0.005073 & 0.004499 & 0.004774 & 0.005483 & 0.005274 & 0.004034 & 0.003544 & 0.004122 & 0.001055 \\
\hline Toluene & 0.008732 & 0.009014 & 0.007375 & 0.006564 & 0.006831 & 0.007892 & 0.007719 & 0.005819 & 0.005299 & 0.006066 & 0.002623 \\
\hline m-Xylene & 0.006585 & 0.006787 & 0.005729 & 0.005117 & 0.005221 & 0.006123 & 0.005954 & 0,004484 & 0.00421 & 0.004796 & 0.004046 \\
\hline 135-trimethylbenze & 0.003097 & 0.003181 & 0.002719 & 0.002426 & 0.002471 & 0.002922 & 0.002832 & 0.002124 & 0.002019 & 0.002285 & 0.002767 \\
\hline Naphthalene & 0.00077 & 0.000795 & 0.000674 & 0.000622 & 0.000636 & 0.000744 & 0.000714 & 0.000542 & 0.000522 & 0.000573 & 0,001486 \\
\hline Hexadecane & 0.000526 & 0.000546 & 0,000474 & 0.000425 & 0.000442 & 0.000537 & 0.000511 & 0.000373 & 0.00036 & 0.00041 & 0,001211 \\
\hline
\end{tabular}

Windsor Clay Soil: 5\% Gasoline, 20\% Water

\begin{tabular}{|c|c|c|c|c|c|c|c|c|c|c|c|}
\hline Duration: 72 h & & & & ( & (') & cents & I0I) 19 & m & $\lg (\log$ & (riil) & \\
\hline Chemical & $20 \mathrm{~cm}$ & $18 \mathrm{~cm}$ & $16 \mathrm{~cm}$ & $14 \mathrm{~cm}$ & $12 \mathrm{~cm}$ & $10 \mathrm{~cm}$ & $8 \mathrm{~cm}$ & $6 \mathrm{~cm}$ & $4 \mathrm{~cm}$ & $2 \mathrm{~cm}$ & $0 \mathrm{~cm}$ \\
\hline Isopentane & 0.001475 & 0.002301 & 0.001792 & 0.002212 & 0.001488 & 0.000842 & 0.001141 & 0.001003 & 0.000465 & 0.000224 & 0.000129 \\
\hline MTBE & 0,000522 & 0.00069 & 0.003272 & 0.004073 & 0.000503 & 0.000343 & 0.000506 & 0.000472 & 0.000324 & 0.000227 & 0.000138 \\
\hline Hexane & 0.002906 & 0.004419 & 0.00461 & 0.006036 & 0.00312 & 0.001777 & 0.00323 & 0.00302 & 0.001866 & 0,001476 & 0.000999 \\
\hline Methylcyclopentane & 0.000854 & 0.001289 & 0.001417 & 0.002152 & 0.00091 & 0.000521 & 0.000952 & 0.000886 & 0.000559 & 0.000466 & 0.00032 \\
\hline Isooctane & 0.00259 & 0,003784 & 0.002843 & 0.003795 & 0.002723 & 0,001699 & 0.003066 & 0.002739 & 0.001899 & 0.00253 & 0.00199 \\
\hline Toluene & 0.003645 & 0.005169 & 0.003955 & 0.005169 & 0.003773 & 0.002476 & 0,004323 & 0.003793 & 0.002675 & 0.004099 & 0.003498 \\
\hline m-Xylene & 0.003347 & 0.004673 & 0.003647 & 0.004721 & 0.003477 & 0,00238 & 0.004078 & 0.003522 & 0,002509 & 0,004257 & 0.005219 \\
\hline 135-trimethylbenze & 0.001642 & 0.002283 & 0,001803 & 0.002328 & 0.001717 & 0.001192 & 0.002018 & 0.00174 & 0.00124 & 0.002085 & 0.003883 \\
\hline Naphthalene & 0.000357 & 0.000482 & 0.000386 & 0.000499 & 0.000372 & 0.000266 & 0.00044 & 0.000376 & 0.000269 & 0.000448 & 0.001385 \\
\hline Hexadecane & 0.000309 & 0,000442 & 0.000356 & 0.000465 & 0.000352 & 0,000242 & 0.000409 & 0,000359 & 0.000245 & $0,00042 B$ & 0.001537 \\
\hline
\end{tabular}


Windsor Clay Soil: 5\% Gasoline, $20 \%$ Water

\begin{tabular}{|c|c|c|c|c|c|c|c|c|c|c|c|}
\hline & & & & & & & & & & & \\
\hline hemical & $20 \mathrm{~cm}$ & $18 \mathrm{~cm}$ & $16 \mathrm{~cm}$ & $14 \mathrm{~cm}$ & $2 \mathrm{~cm}$ & $10 \mathrm{~cm}$ & $8 \mathrm{~cm}$ & $6 \mathrm{~cm}$ & $4 \mathrm{~cm}$ & $2 \mathrm{~cm}$ & $\mathbf{c m}$ \\
\hline je & .007505 & 0.000894 & 000972 & 000857 & 0,000684 & 0.000809 & 0.000626 & 0,000626 & 0.000739 & 0.000364 & $5.14 E-05$ \\
\hline & 101708 & 00376 & 0397 & 000627 & 0.000494 & .000631 & 0,000527 & 0.000527 & 0.000683 & 0.000437 & 4.55E-0 \\
\hline & 201 & 0.002324 & 0.005846 & 0.006189 & 0,006354 & 0.008032 & 0,00393 & 0.004197 & 0.006147 & 0.003803 & 0.000277 \\
\hline et & 0.003941 & 0.000671 & 0.00137 & .001552 & 0.001687 & 0.002148 & 0.001147 & 0.001224 & 0.001802 & 0.001162 & 0.00012 \\
\hline Doct & 0.010825 & {$[0.002317$} & 0.002976 & 0.0026 & 0.00301 & 0,003725 & 0.004117 & 0.004345 & .007211 & .006404 & 0.001051 \\
\hline olue & 0.01374 & 0.003301 & 0.004093 & 0.00369 & 0.004219 & 0,00514 & 0.005663 & 0.005817 & .009528 & 0.008989 & 0.0023 \\
\hline$-\mathbf{X}_{3}$ & 0.009651 & 0.002547 & 0.003092 & 0.002866 & 0.003241 & 0.003896 & 0.004308 & 0.004283 & 0.006976 & 0.006805 & 0.002947 \\
\hline & 0.004953 & 0,001354 & 0.001628 & 0.001532 & 0.001718 & 0.002064 & 0.002293 & 0.002241 & .00364 & 0.00352 & 0.001865 \\
\hline & & 0,000344 & & 388 & & & 0,000593 & & & & \\
\hline exadecane & 0,000831 & 0.00022 & 0.000264 & 0,00024 & 0.000279 & 0,000336 & 0.00038 & 0.000385 & 0.000622 & 0.000593 & 0.00 \\
\hline
\end{tabular}

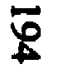

Windsor Clay Soil: 5\% Gasoline, 20\% Water

\begin{tabular}{|c|c|c|c|c|c|c|c|c|c|c|c|}
\hline Themical & $20 \mathrm{~cm}$ & $18 \mathrm{~cm}$ & $16 \mathrm{~cm}$ & $14 \mathrm{~cm}$ & $12 \mathrm{~cm}$ & $110 \mathrm{~cm}$ & $8 \mathrm{~cm}$ & $6 \mathrm{~cm}$ & $4 \mathrm{~cm}$ & $2 \mathrm{~cm}$ & $0 \mathrm{~cm}$ \\
\hline ie & 0.001564 & 0,000793 & 0.001057 & 0.001292 & 0.000689 & .000802 & 0.000457 & 0.000318 & 0.00023 & $9.57 \mathrm{E}-05$ & \\
\hline IDE & 000636 & 0,00042 & 0.000543 & 0.000639 & 0.000466 & 0.000516 & 0.004158 & 0,000334 & 0.000274 & 0,000146 & \\
\hline ext & 04553 & 0.002756 & 0.003846 & 0.004531 & 0.003081 & 0.00369 & 0,005652 & 0.002344 & 0.001929 & 0.000784 & $1,94 \mathrm{E}-05$ \\
\hline leth & 0.001399 & 0.00085 & 0.001192 & 0.001394 & 0,000958 & 0.00115 & 0.0016 & 0.000768 & 0.000641 & 0.000272 & 3:02E-05 \\
\hline $300 \mathrm{c}$ & 0.003894 & 0.002533 & 0.003525 & 0.003931 & 0.002916 & 0,003451 & 0,003191 & 0.003379 & 0.003352 & 0.00178 & .000298 \\
\hline olu & 0.005461 & 0.003672 & 0.005097 & 0.005658 & 0.004271 & 0.004917 & 0,004685 & 0.00516 & 0.005492 & 0.003948 & .000663 \\
\hline $1-X$ & 0.004091 & 0.002843 & 0.003907 & 0.004232 & 0.003258 & 0.003692 & 0.003601 & 0.004098 & 0.004476 & 0.00439 & 0.001666 \\
\hline$z e$ & 0.002077 & 0.001469 & 0.002009 & 0.002153 & 0.001671 & 0.001884 & 0,001853 & 0.002124 & 0.002292 & 0,002296 & 0.001818 \\
\hline & 0.000529 & 0.000391 & 0.000534 & 0.000556 & & 0.000501 & & 0.000561 & 0.000595 & 0.000589 & 0.001067 \\
\hline lexadecane & 0.000432 & 0.00030 & 0.000 & & 0000 & 0,000 & 100003 & 0000 & 0.000491 & 0.000474 & $0.0011 !$ \\
\hline
\end{tabular}



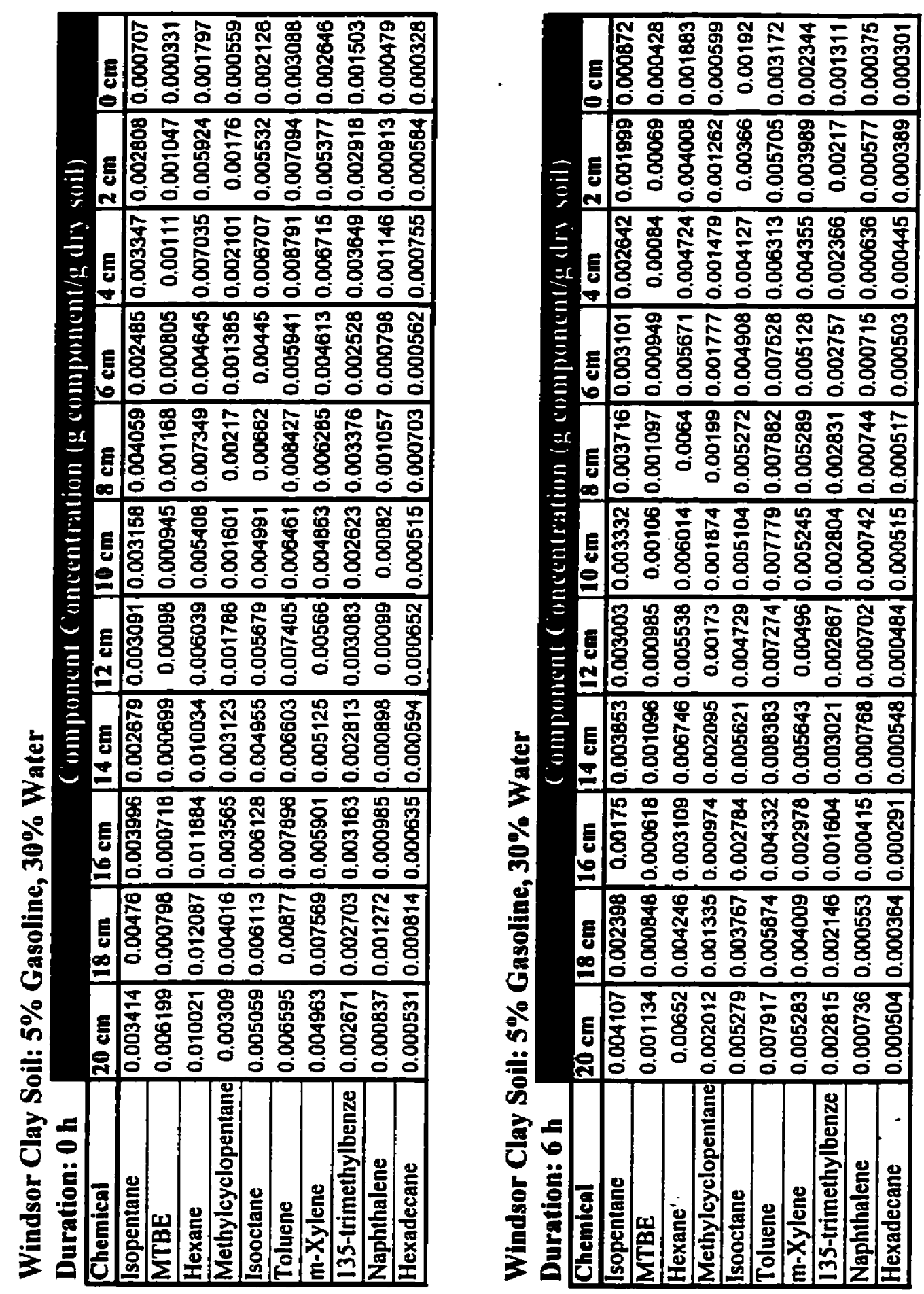

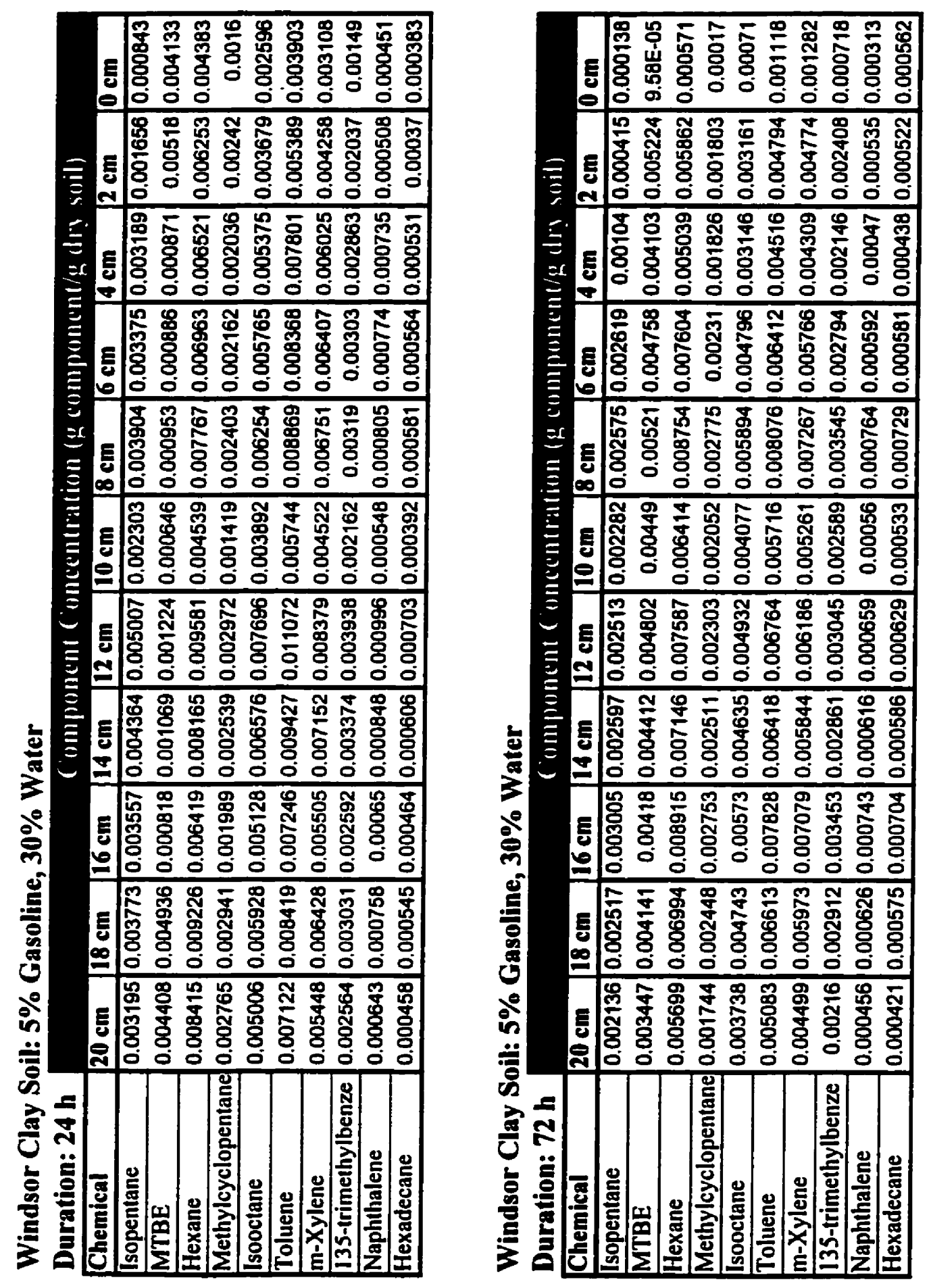

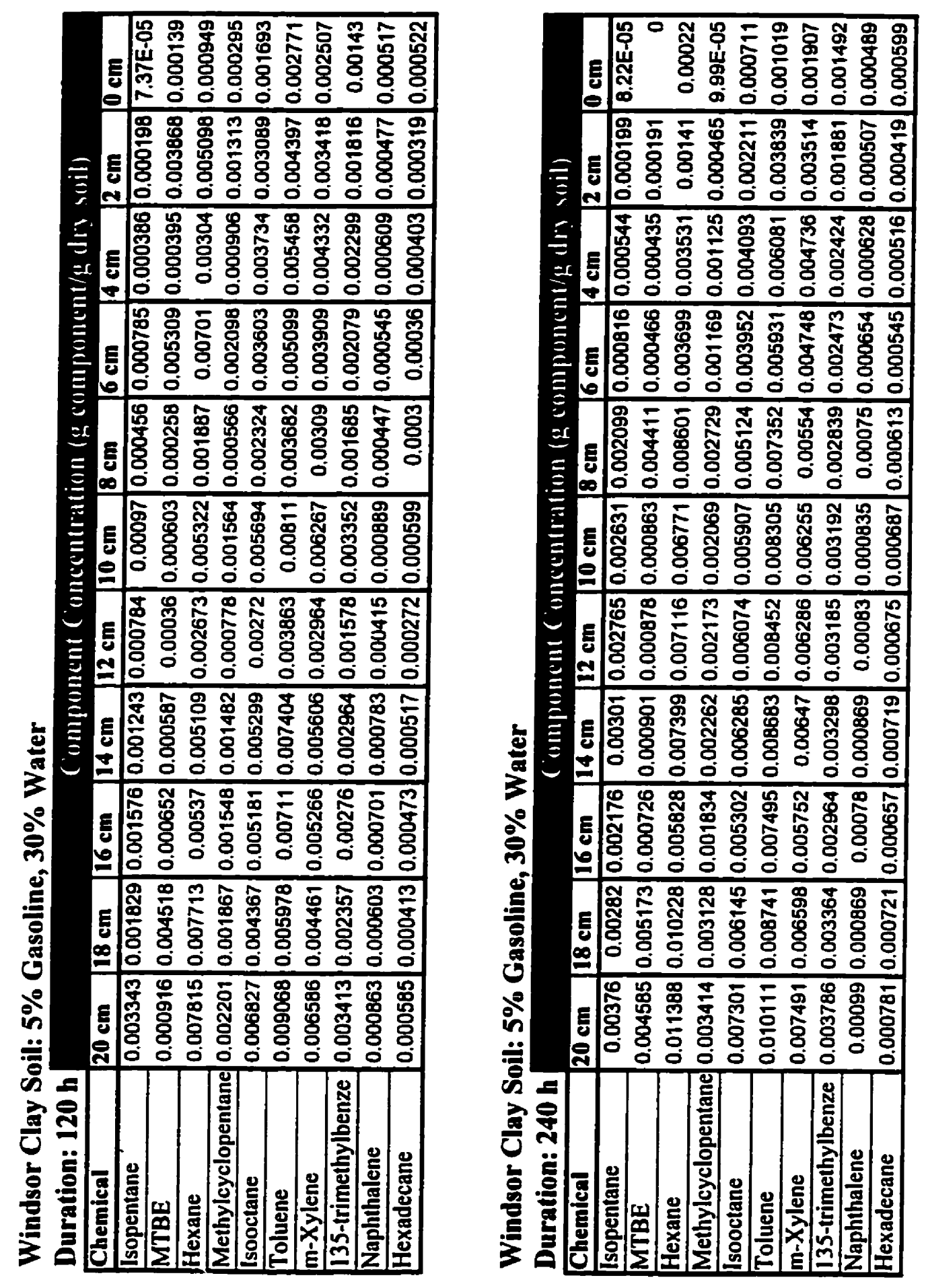


\section{Appendix H}

Windsor Clay Loam Air Permeability Data and Sample Calculations 
Wet WCL Air Permeability Data and Sample Calculations

Diameter of glass column:

Cross-sectional area of column A:

$6 \mathrm{~cm}$

Length of column $d x$.

$0.0028 \mathrm{~m} 2$

$0.2 \mathrm{~m}$

\begin{tabular}{|l|ccr|}
\hline \multirow{2}{*}{$\begin{array}{l}\text { Air Permeability } \\
\text { Test }\end{array}$} & $\begin{array}{c}\text { Air Fiow } \\
\text { Rate }\end{array}$ & $\begin{array}{c}\text { Head Loss } \\
\text { (cm of } \\
\text { water) }\end{array}$ & $\begin{array}{l}\text { Air } \\
\text { Permeability } \\
\text { (m/s) }\end{array}$ \\
\cline { 2 - 4 } & (Umin) & 8.8 & 0.0012861 \\
\hline $30 \%$ WC (warm & 80 & 8.5 & 0.0013315 \\
$30 \%$ WC (warm & 80 & 8.4 & 0.0013473 \\
$30 \%$ WC (warm & 80 & 8.5 & 0.0013315 \\
$30 \%$ WC (warm & 80 & 8.3 & 0.0013636 \\
$30 \%$ WC (warm & 80 & 10.1 & 0.0009805 \\
$30 \%$ WC (cold) & 70 & 9 & 0.0011003 \\
$30 \%$ WC (cold) & 70 & 9.6 & 0.0010316 \\
$30 \%$ WC (cold) & 70 & 9.2 & 0.0010764 \\
$30 \%$ WC (cold) & 70 & 10.2 & 0.0009709 \\
\hline $30 \%$ WC (cold) & 70 & & \\
\hline
\end{tabular}

Darcy's Law: $Q=k A(d h / d x)$

eg. $30 \%$ WC (warm) trial \# 1

Air Flow Rate $Q=$

$=\quad 0.0013 \mathrm{~m} 3 / \mathrm{s}$

Density of air (20oC)

$=$

$=$

Head loss ( $\mathrm{cm}$ of water)

Head loss (m of air) dh

$=$

$8.8 * 1000 / 1.2$

$=$

$=$

Air permeability $k$

73.33
$1.2 \mathrm{~kg} / \mathrm{m} 3$ $1000 \mathrm{~kg} / \mathrm{m} 3$

8.8

Repeat for other tests 
Appendix I

Gasoline Freezing Data and Sample Calculations 
Frozen Gasoline Data and Sample Calculations

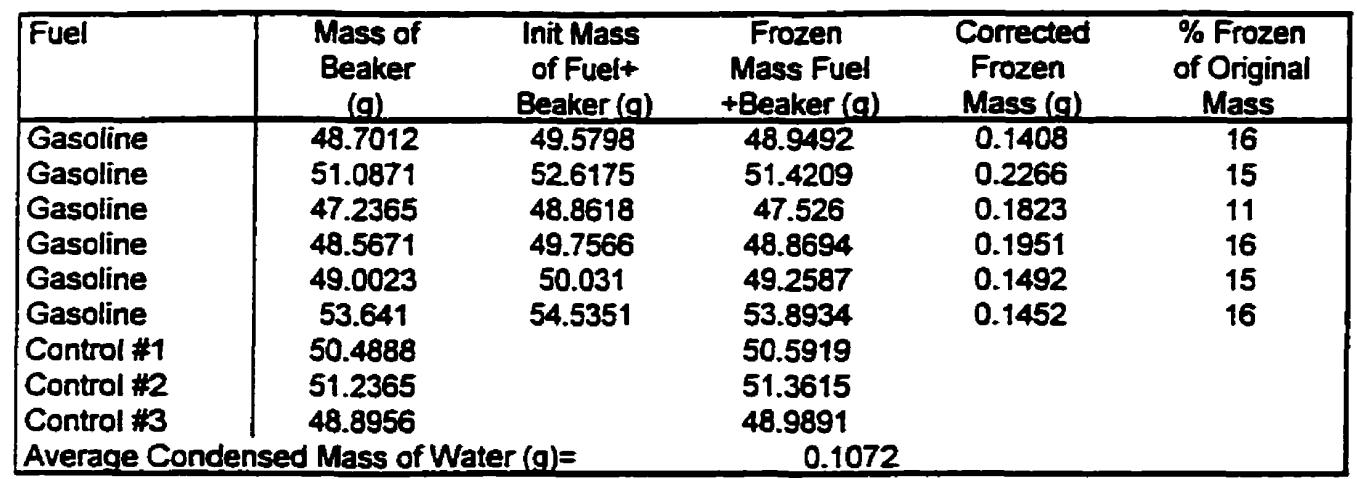

eg. Gasoline Test $\$ 1$

\begin{tabular}{|c|c|c|}
\hline Frozen Mass & $\begin{array}{c}8.9492-48.7012 \\
0.248\end{array}$ & $\begin{array}{l}\mathbf{g} \\
\mathbf{g}\end{array}$ \\
\hline Average Condensed Mass of Water & $\begin{array}{l}= \\
=\end{array}$ & $\begin{array}{l}\text { Average (Control Frozen Mass-Mass of Beaker } \\
0.1072 \mathrm{~g}\end{array}$ \\
\hline Corrected Frozen Mass of Gasoline & $\begin{array}{l}= \\
=\end{array}$ & $\begin{array}{l}\text { Frozen Mass-Average Condensed Water Mass } \\
0.1408 \mathrm{~g}\end{array}$ \\
\hline$\%$ (of Original Mass) Frozen & $\begin{array}{l}= \\
=\end{array}$ & $\begin{array}{c}0.1408 /(49.5798-48.7012)^{*} 100 \\
16\end{array}$ \\
\hline
\end{tabular}


